DOE/RL-93-03

Revision 0

UC-630, 721

\title{
Hanford Facility Dangerous rCFVEO Waste Permit Application, 200 Area Effluent Treatment Facility
}

Date Published

August 1993

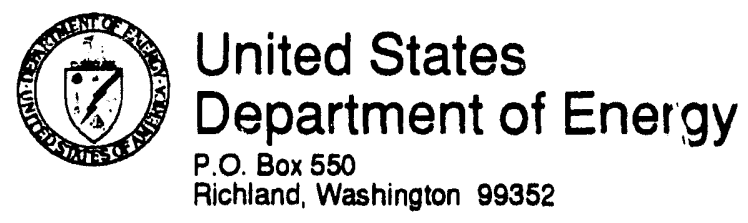


TRADEMARK DISCLAIMER

Reference herein to any specific commercial product, process, or service by trade name, trademark, manufacturer, or

otherwise, does not necessarily constitute or imply its

endorsement, recommendation, or favoring by the United

States Government or any agency thereof or its contractors or sibcontractors.

This report has been reproduced from the best available copy. Available in paper copy and microfiche.

Available to the U.S. Department of Energy

and its contractors from

Office of Scientific and Technical Information

P.O. Box 62

Oak Ridge, TN 37831

(615) $576-8401$

Available to the public from the U.S. Department of Commerce

National Tectinical Information Service

5285 Port Royal Road

Springfield, VA 22161

(703) 487.4650

Printed in the United States of America

DISCLM-5.CHP (8.91) 
DOE/RL-93-03, Rev. 0 $08 / 31 / 93$

\section{HANFORD FACILITY DANGEROUS WASTE PERMIT APPLICATION, 200 AREA EFFI.UENT TREATMENT FACILITY}

\section{FOREWORD}

The Hanford Site is owned by the U.S. Government and operated by the U.S. Department of Energy, Richland Operations Office. Dangerous waste and mixed waste (containing both radioactive and dangerous components) are produced and managed on the Hanford Facility. The dangerous waste is regulated in accordance with the Resource Conservation and Recovery Act of 1976 and the State of Washington Hazardous Waste Management Act of 1976 (as administered through the Washington State Department of Ecology Dangerous Waste Regulations, Washington Administrative Code 173-303). The radioactive component of mixed waste is interpreted by the U.S. Department of Energy to be regulated under the Atomic Energy Act of 1954; the nonradioactive dangerous component of mixed waste is interpreted to be regulated under the Resource Conservation and Recovery Act and Washington Administrative Code 173-303.

For purposes of the Resource Conservation and Recovery Act and the Washington State Department of Ecology Dangerous Waste Regulations, the Hanford Facility is considered to be a single facility. The single dangerous waste permit identification number issued to the Hanford Facility by the U.S. Environmental Protection Agency and the Washington State Department of Ecology is U.S. Environmental Protection Agency/State Identification Number WA7890008967. This identification number encompasses over 60 treatment, storage, and/or disposal units within the Hanford Site, hereinafter referred to as the Hanford Facility when cited in the context of the Resource Conservation and Recovery Act and the Washington State Department of Ecology Dangerous Waste Regulations.

Westinghouse Hanford Company is a major contractor to the U.S. Department of Energy, Richland Operations Office and serves as co-operator of the 200 Area Effluent Treatment Facility, the treatment and storage unit addressed in this permit application documentation.

Westinghouse Hanford Company is identified in the permit application as a 'co-operator' and signs in that capacity. Any identification of Westinghouse Hanford Company as an 'operator' elsewhere in this application is not meant to conflict with Westinghouse Hanford Company's designation as a co-operator but rather is based on Westinghouse Hanford Company's contractual status (i.e., as an operations and engineering contractor) for the U.S. Department of Energy.

The current Hanford Facility Dangerous Waste Permit Application is considered to be a single application organized into a General Information Portion (DOE/RL-91-28) and a treatment, storage, and/or disposal Unit-Specific Portion, which includes documentation for individual treatment, storage, and/or disposal units. Both portions consist of a Part A division and a Part $B$ division. The Part $B$ division consists of 15 chapters that address the content of the Part B checklists prepared by the Washington State Department 
DOE/RL-93-03, Rev. 0

of Ecology (Ecology 1987) and the U.S. Environmental Protection Agency

( 40 Code of Federal Regulations 270 ), with additional information requirements mandated by the Hazardous and Solid Waste Amendments of 1984 and revisions of Washington Administrative Code 173-303. For ease of reference, the Washington State Department of Ecology checklist section numbers, in brackets, follow the chapter headings and subheadings. Documentation contained in the General Information Portion (DOE/RL-91-28) is broader in nature and applies to all treatment, storage, and/or disposal units for which final status is sought.

In accordance with the preceding discussion, the 200 Area Effluent Treatment Facility Dangerous Waste Permit Application documentation consists of both Part $A$ and a Part $B$ permit application documentation. An explanation of the Part $A$ revisions associated with this treatment and storage unit, including the current revision, is provided at the beginning of the Part $A$ section.

Once the initial Hanford Facility Dangerous Waste Permit is issued, the following process will be used. As final, certified treatment, storage, and/or disposal unit-specific documents are developed, and completeness notifications are made by the U.S. Environmental Protection Agency and the Washington State Department of Ecology, additional unit-specific permit conditions will be incorporated into the Hanford Facility Dangerous Waste Permit through the permit modification process. All treatment, storage, and/or disposal units that are included in the Hanford Facility Dangerous Waste Permit Application will operate under interim status until final status conditions for these units are incorporated into the Hanford Facility Dangerous Waste Permit.

The Hanford Facility Dangerous Waste Permit Application, 200 Area Effluent Treatment Facility contains information current as of May 1, 1993. 


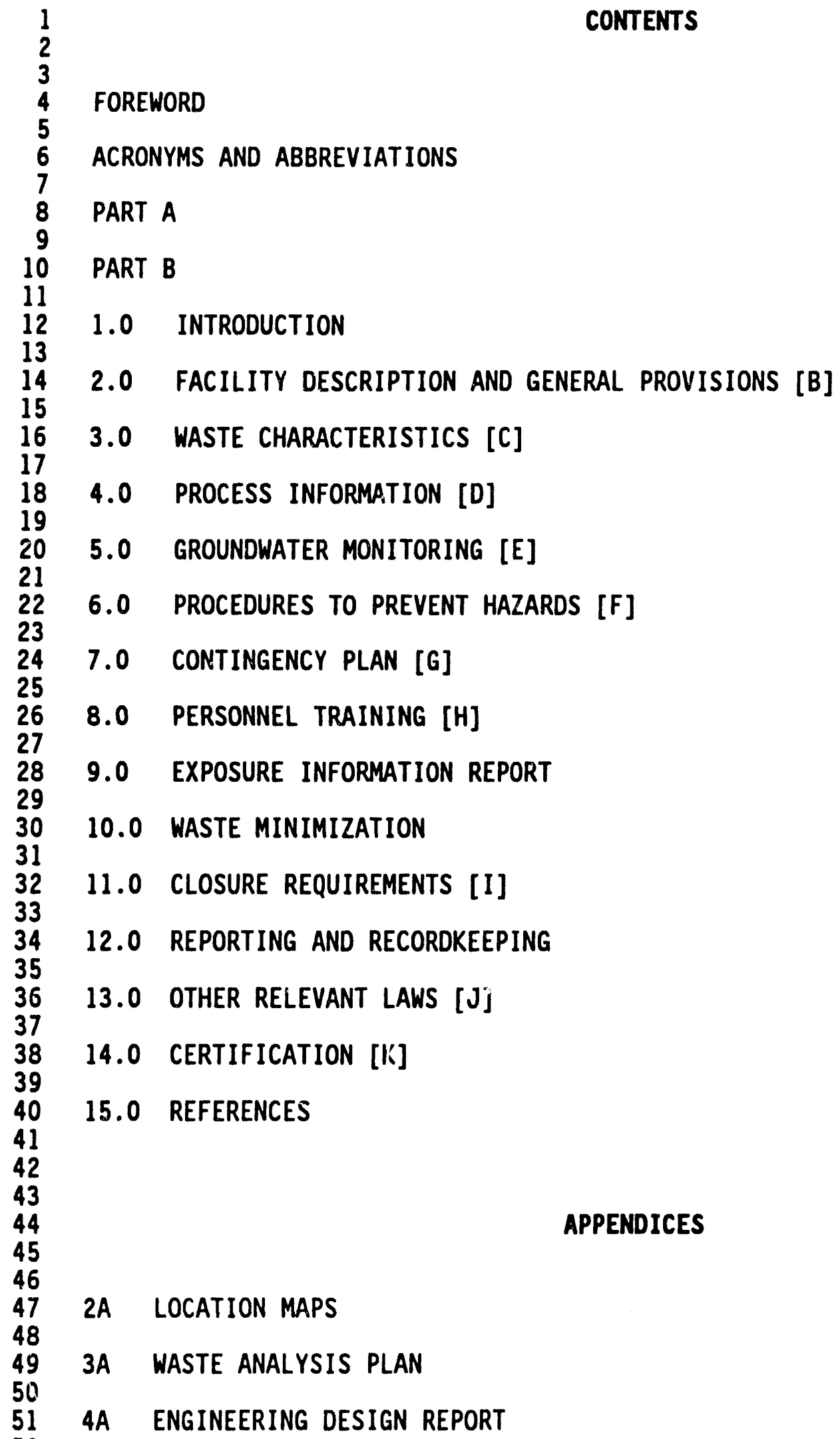

$472 A$ LOCATION MAPS

3A WASTE ANALYSIS PLAN

4A ENGINEERING DESIGN REPORT 


\section{APPENDICES (cont)}

4B CERTIFICATION OF NEW TANK SYSTEM INTEGR'TY

$4 C$ SEISMIC ANALYSIS

4D CORROSION ANALYSIS

7A BUILDING EMERGENCY PLAN 200 AREA EFFLUENT TREATMENT FACILITY

8A TRAINING COURSE DESCRIPTIONS

15

16 
ACI

API

ARI

ATP

CFR

DOE

DST

${ }^{\circ} \mathrm{C}$

EPA

ETF

FR

IX

KEH

LDR

ox

PNL

\section{ACRONYMS AND ABBREVIATIONS}

AISC

ALARA

ANS I

ASME

ASNT

ASTM

AWS

AWWA

DOE-RL

Ecology

HEPA

LERF

NACE

NFPA

PUREX

American Concrete Institute

as low as reasonably achievable

American National Standards Institute

American Petroleum Institute

Acceptance Test Procedure

American Welding Society

American Water Works Association

Code of Federal Regulations

U.S. Department of Energy double-shell tank

degrees Centigrade

degrees Fahrenheit

Washington State Department of Ecology

U.S. Environmental Protection Agency

200 Area Effluent Treatment Facility

Federal Register

high-efficiency particulate air

ion exchange

Kaiser Engineers Hanford Company

1 and disposal restriction

Liquid Effluent Retention Facility

National Fire Protection Association

oxidation

process condensate

process distillate discharge concentration

Pacific Northwest Laboratory

plutonium-uranium extraction

American Institute of Steel Construction

Air Conditioning and Refrigeration Institute

American Society of Mechanical Engineers

American Society for Nondestructive Testing

American Society for Testing and Materials

U.S. Department of Energy, Richland Operations Office

National Association of Corrosion Engineers

negative concentration logarithm of the hydrogen-ion 
DOE/RL-93-03, Rev. 0 $08 / 31 / 93$

$\begin{array}{ll}1 & \\ 2 & \\ 3 & \\ 4 & \text { RCRA } \\ 5 & \text { RO } \\ 6 & \\ 7 & \text { SALDS } \\ 8 & \\ 9 & \text { TCLP } \\ 10 & \text { Tri-Party Agreement } \\ 11 & \text { TSD } \\ 12 & \\ 13 & \text { UV } \\ 14 & \text { UV } / O X \\ 15 & \\ 16 & \text { WAC } \\ 17 & \text { WSDOT }\end{array}$

\section{ACRONYMS AND ABBREVIATIONS}

Resource Conservation and Recovery Act of 1976 reverse osmosis

State-Approved Land Disposal Site

toxicity characteristics leaching procedure

Hanford Federal Facility Agreement and Consent Orcier treatment, storage, and/or disposal

ultraviolet

ultraviolet oxidation

Washington Administrative Code

Washington State Department of Transportation 
DOE/RL-93-03, Rev. 0

$08 / 31 / 93$

\begin{abstract}
PART A
This section consists of a Form 1 (not revised) and a Form 3, Revision 1, that describes the 200 Area Effluent Treatment Facility in general terms. In Revision 1, the title of this treatment and storage unit has been changed from the "242-A Evaporator/PUREX Plant Condensate Treatment Facility" to the "200 Area Effluent Treatment Facility" to reflect the expansion of the intended function of this treatment and storage unit.

The 200 Area Effluent Treatment Facility Part A, Form 3, has been revised to add greater than 90-day tank and container storage. This revision adds three 670,000-gallon $(2,536,000-1$ iter) verification tanks for greater than 90-day storage because of possible delays in sampling the effluent before discharge to the soil column. The Part $A$ also is being revised to add greater than 90-day container storage because of possible delays in transferring the waste to either the Central Waste Complex or the 616 Nonradioactive Dangerous Waste Storage Facility. The container stiorage area is designed to store a maximum of 720 55-gallon (208-1iter) containers. In addition to adding tank and container storage to the 200 Area liffluent Treatment Facility, four dangerous waste codes were added for treaiment process code T01, six dangerous waste codes were added for tank storage process code $\mathrm{SO2}$, and 32 dangerous waste codes were added for container storage process code S01. These dangerous waste codes were added in compliance with Washington Administrative Code 173-303-805.
\end{abstract}




\section{DOE/RL-93-03, Rev. 0}

$08 / 31 / 93$

1
2
3
4
5

This page intentionally left blank. 


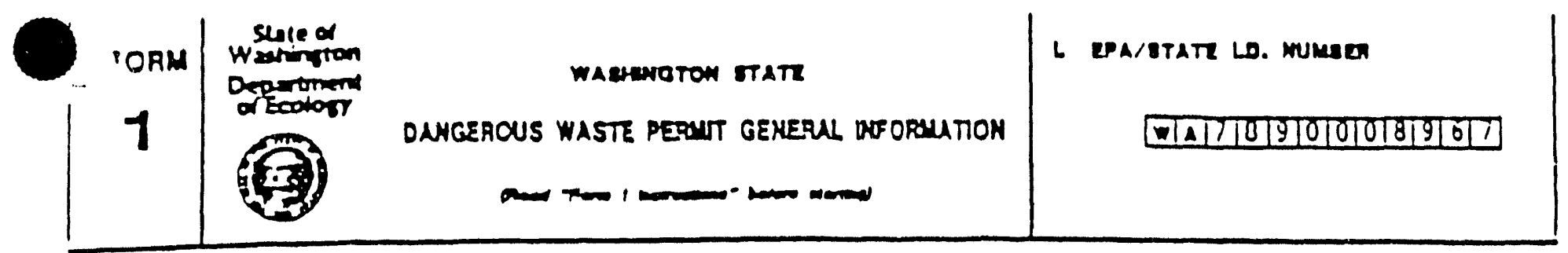

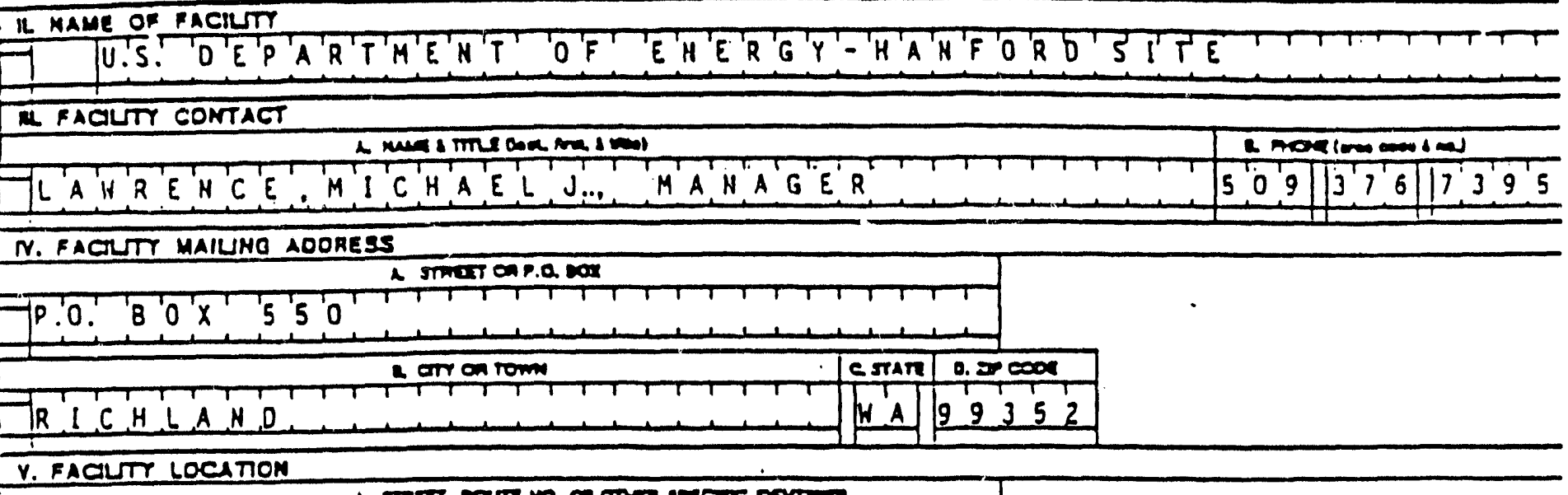

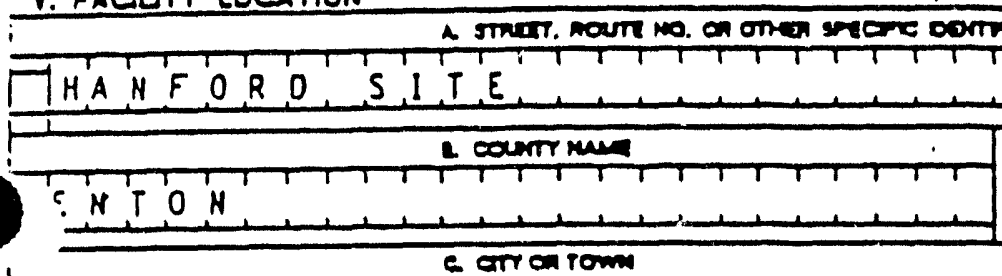

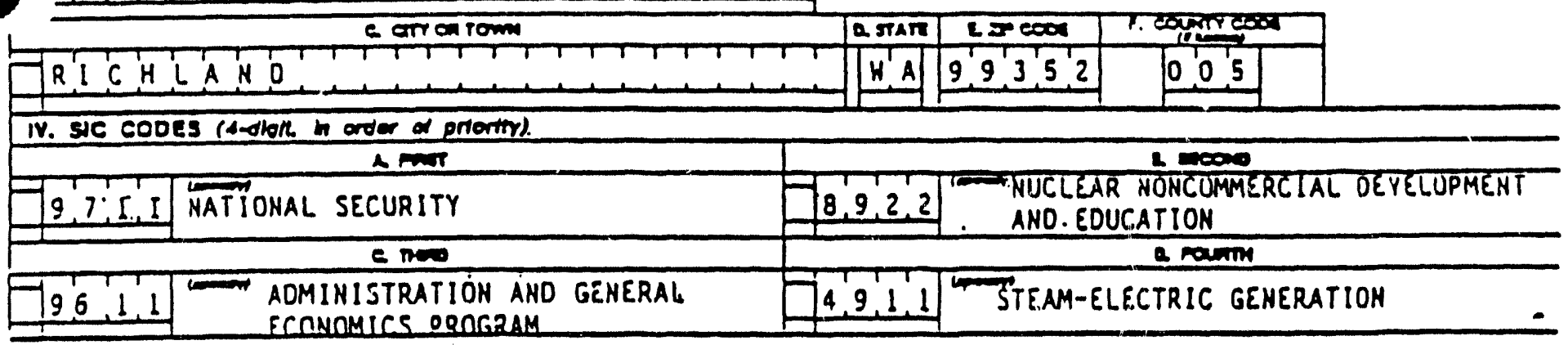

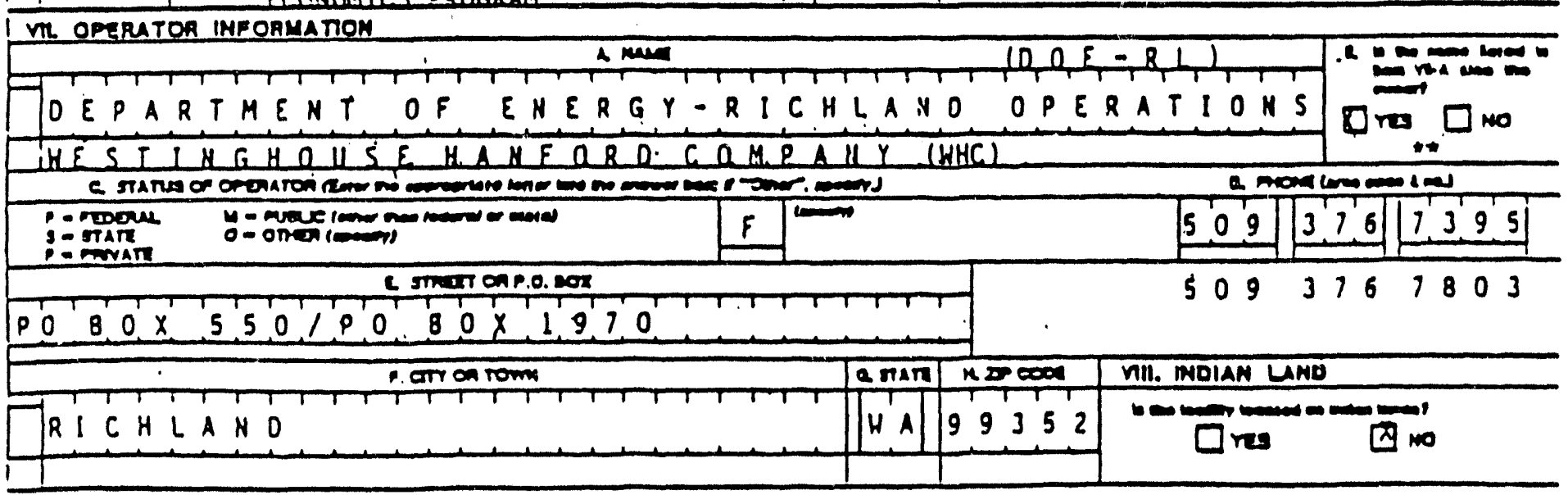

- $D O E-R L:$ OWİER/CO-OPERATOR: HHC: CO-OPERATOR FOR CERTAIN UNITS ON THE HANFORD SITE. 


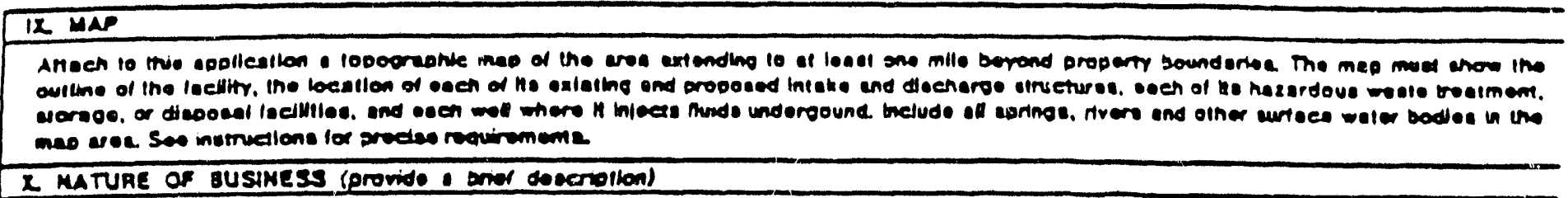

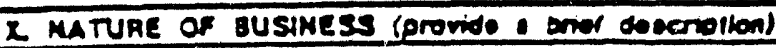

- NATIONAL DEFENSE NUCLEAR MATERIAL PRODUCTION

- ENERGY RESEARCH ANO TECHNOLOGY DEYELOPMENT

- DEFENSE NUCLEAR haSTE MANAGEMENT

- BYPRODUCT STEAM, SOLD FOR ELECTRIC POWER GENERATION

ANO SIC 15: BUILOING CONSTRUCTION - GENERAL CONTRACTORS AND OPERATIVE BUILDERS

2. CERTFCATION (100 hrimetion)

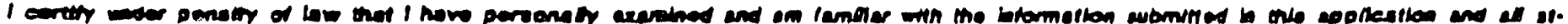

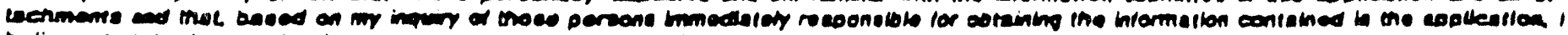

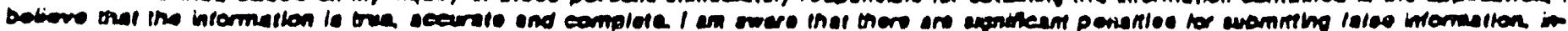

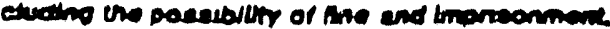

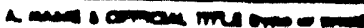

a seannen

cour mon

SEE ATTACHMENT

asmong


FORM 1

DANGEROUS WASTE PERMIT GEHERAL INFORMATION

\section{CERTIFICATION}

I cartify under penalty of law that I have personally examined and am familiar with the information submitted in this application and all attachments, and that based on my inquiry of those individuals immediately responsible for obtaining the information, I believe that the submitted information is true, accurate, and complete. I am aware that there are significant penalties for submitting false information including the possibility of fine and imprisonment.

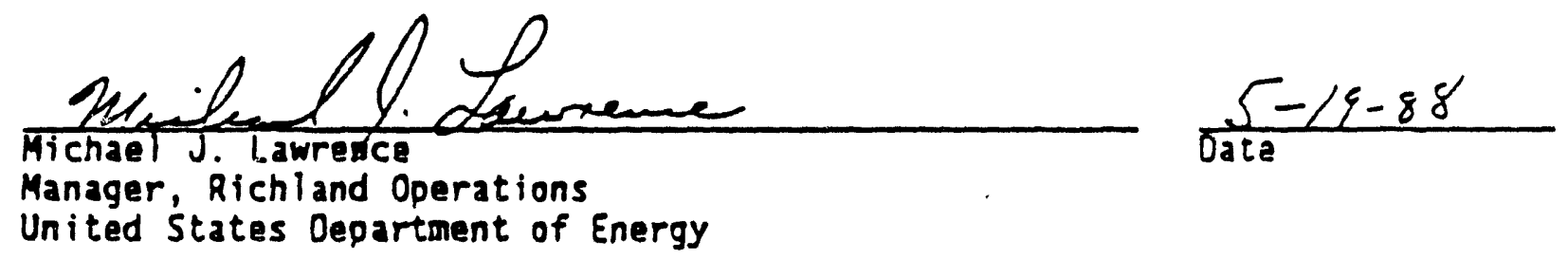

$$
\text { W.m-lach. }
$$

William M. Jadedi

President

Hestinghouse Hanford Company

Co-operator 
Phece print of type in the unahaded aroses only

(filith areas are speced for alte type, l.e., 12 cheracter/inch).

HM

DANGEROUS WASTE PERMIT APPLICATION

1. EPA/STATE I.D. NUMBER

\begin{tabular}{|l|l|l|l|l|l|l|l|l|l|l|l|}
\hline$W$ & $A$ & 7 & 8 & 0 & 0 & 0 & 0 & 8 & 9 & 6 & 7 \\
\hline
\end{tabular}

FOR OFFICLAL USE ONLY

APPLCATION DATE RECEIVED

COMMENTS

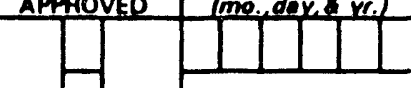

U. FIAST OA REVISED APPLICATION

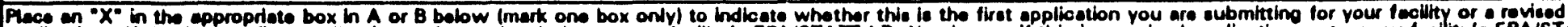

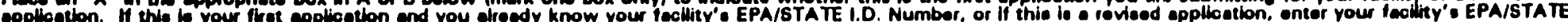
f.b. Number in Section I ebove.

A. FIRST APPLICATION Lbee en " $X$ " beisw and provide the eppropriate dole)

$\square$ 1. EXISTWNG FACILITY iseo instructions for detiontion of "existing * facllity. Complate hem below.)

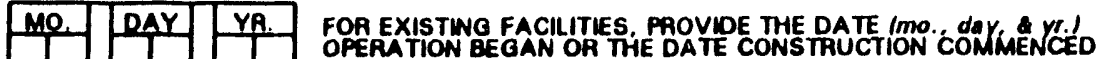
luse the boxee to the biti)

8. REVISED APPLICATION bolece on " $x$ " babw end complote Soction l above

D] 1. FaCILITV HAS AN WTEAM STATUS PEAMIT

2. NEW FACILITY (Complote hem below) \begin{tabular}{|l|l|l|l}
\hline MO. & FOA NEW FACILITLS \\
\hline 0 & YA. \\
\hline
\end{tabular}

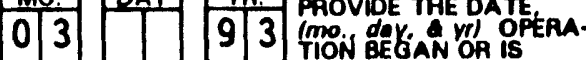
TION BEGAN OA IS

UI. PAOCESSES - CODES AND CAPACTTES

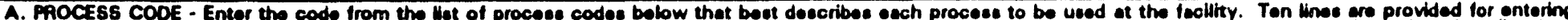

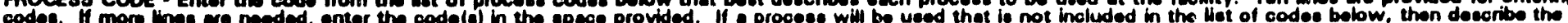
proceses (including the desion ceapecty) in the epece provided on the (Socth. II II-C).

8. PROCESS DESION CAPACITY - For each code entered in column A enter the capectty of the procees.

1. AMOUNT - Enter the amount.

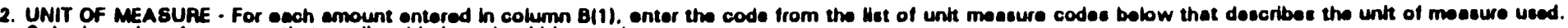
Onily the unite of measure that ere listed below should be uesd.

\section{PAO. APPAOPAIATE UNITS OF
PROCESS CODS AMAURE FOA PROCESS
DESION CAPACITY} storege:

CONTAWER (berTol, drum, ote)

WASTE PILE

SURFACE IMPOUNDMENT

Dlepoed:

NEECTION WELL

LANDFILL

LAND APPLICATION

SURFACE IMPOUNDMENT

\section{SO1 GALLONS OR LITEAS \\ $\mathrm{SO}_{2}$ GALLONS OA LITEAS \\ CUBMC YAROS OP \\ CUBIC METERS \\ SO4 OALLONS OR LITEAS}

D8O GALLONS OA LITERS

DE1 ACRE-FEET tethe volume that

mould cover one eare to

depth of one foot

OP HECTAPE-ME)

D82 ACAES OA HECTARES

DQ3 GALLONS PEA DAY OP

DE4 GITERS PER DAY

2. FACILITY HAS A FINAL PERMIT

UNIT OF MEASURE

UNIT OF MEASURE

COOE

GALLONS . ............

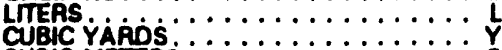

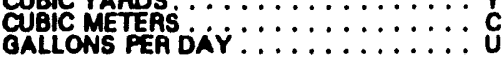

ITERS PER HOUR..............

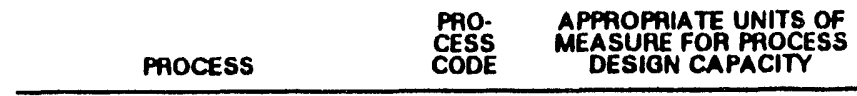

Treatmont:

TANK

SURFACE IMPOUNDMENT

NCWERATOR

TO1 GALLONS PEA DAY OR

TO2 LTERSE PEAY OY

LITERS PER DAY

TO3 TONS PEA HOUA OR

METAIC TONS PER HOUA GALIONS PEA HOUR OA ITEAS PEA HOUA

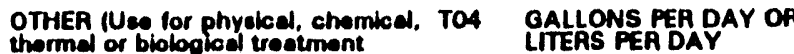
thermel or biologicel troetment

procaesese not occurring in tanks,

surf ece impoundments of hrciner:-

the epece provided; section III-C.I

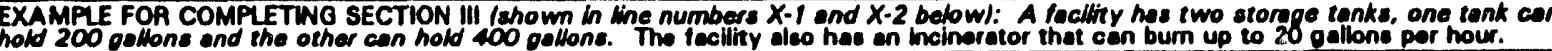

$\begin{gathered}\text { UNIT OF } \\ \text { MEASURE } \\ \text { CODE }\end{gathered}$
UNTT OF MEASURE $\quad \begin{gathered}\text { UNM OF } \\ \text { UNIT OF MEASURE }\end{gathered}$

\begin{tabular}{|c|c|c|c|c|c|c|c|c|c|c|c|}
\hline \multirow[b]{2}{*}{ 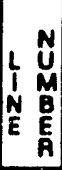 } & \multirow{2}{*}{\multicolumn{3}{|c|}{$\begin{array}{c}\text { A. PRO- } \\
\text { CESS } \\
\text { CODE } \\
\text { (from wot } \\
\text { abovel }\end{array}$}} & \multicolumn{2}{|c|}{ 8. PROCESS DESIGN CAPACITY } & \multirow[b]{2}{*}{$\begin{array}{c}\text { FOR } \\
\text { OFFICIAL } \\
\text { USEE } \\
\text { ONLY }\end{array}$} & \multirow[b]{2}{*}{ 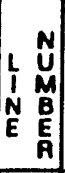 } & \multirow[b]{2}{*}{$\begin{array}{l}\text { A. PAO- } \\
\text { CESS } \\
\text { CODE } \\
\text { (trom wot } \\
\text { aboval }\end{array}$} & \multicolumn{2}{|c|}{ B. PROCESS DESION CAPACITY } & \multirow[b]{2}{*}{$\begin{array}{c}\text { FOA } \\
\text { OFFICIAL } \\
\text { USE } \\
\text { ONLY }\end{array}$} \\
\hline & & & & 1. AMOUNT & $\begin{array}{l}\text { 2. UNIT } \\
\text { OF MEA- } \\
\text { SUPE } \\
\text { (anter } \\
\text { codel }\end{array}$ & & & & 1. AMOUNT & $\begin{array}{l}\text { 2. UNIT } \\
\text { Of MEA. } \\
\text { SURE } \\
\text { lenter } \\
\text { codel }\end{array}$ & \\
\hline$x-1$ & $s$ & 0 & 2 & 600 & $\sigma$ & & 6 & & & & \\
\hline$x-2$ & $T$ & 0 & 3 & 20 & $E$ & & 6 & & & & \\
\hline 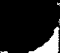 & $T$ & 0 & 1 & 216,000 & U & & 7 & & & & \\
\hline 2 & S & 0 & 2 & $2,010,000$ & G & & $\boldsymbol{8}$ & & & & \\
\hline 3 & $\mathbf{S}$ & 0 & 1 & 39,600 & G & & 9 & & & & \\
\hline 4 & & & & & & & 10 & & & & \\
\hline
\end{tabular}


Continused trom the front.

PAOCESSEs (conthued)

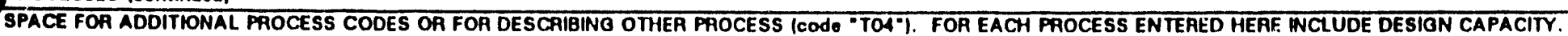
101. $\mathrm{SO2}$

The 200 Area Effluent Treatment Facility (ETF) is being constructed to treat and store process condensate from the

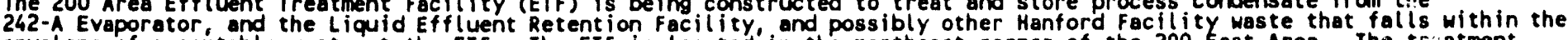
envelope of acceptable waste at the ETf. The ETF is located in the northeast corner of the 200 East Area. The tr atment

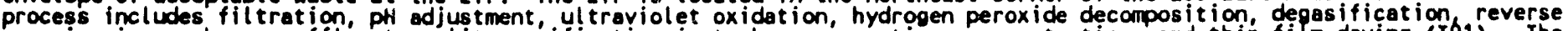
osmosis, ion exchange, effluent quality verification in tanks, evaporation, concentrat $j$ on, and thin film drying (To1). The treated effluent is stored in three verification tanks ( 502 ) and sampled to determine if the effluent meets reguired

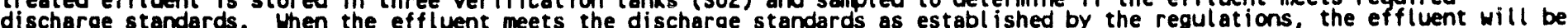
discharged to the $80: 1$. If the sample analysis of the eflluent in the verification tanks does not meet the discharge standards, the effluent will be sent back through the system for further treatment.

The treatment process is designed to treat a maximum of $150 \mathrm{gallons}$ ( 5681 iters) per minute or $216,000 \mathrm{gall}$ (ons (817,650 (iters) per day. The tank storage is designed tc store a maximu of 2,010,000 gollons (7,610,000 liters).

S01

A secondary waste strean is generated during operation of the ETf. This secondary waste is concentrated into a pouder containerized, and transferred to the Central Maste Complex for storage wile disposal options are evaluated. Other mixed

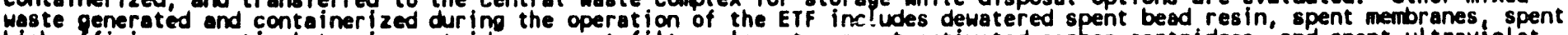

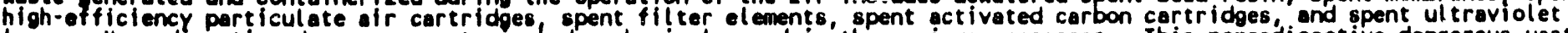

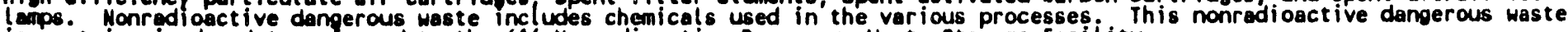
is containerized and transferred to the 616 Nonradioactive Dangerous Waste Storage Facility.

The container storage area is designed to store a maximn of 39,600 gallons $(150,000$ liters).

N. DESCRIPTION OF DANOEROUS WASTES

A. DANOEROUS WA8TE NUMBER - Enter the four dbht nimber from Chapter $173 \cdot 303$ WAC for each Hetod dengerous weote you will hendle. If you handle

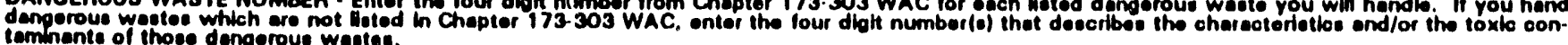

B. ESTIMATED ANNUAL QUANTITY. For esoh Mated weate entered in column A se. , nate the quenthy of that weote thet will be handied on an annual beals.

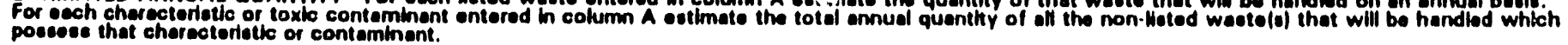

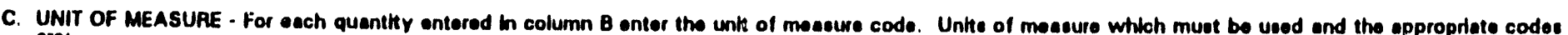
c.

$\frac{\text { ENGLISH UNIT OF MEASURE }}{\text { POUNDS } \ldots \ldots \ldots \ldots \ldots \ldots \ldots \ldots \ldots \text { P }}$

$\frac{\text { METRIC UNIT OF MEASURE }}{\text { KMOQRAMS } \ldots \ldots \ldots \ldots \ldots \ldots \ldots}$

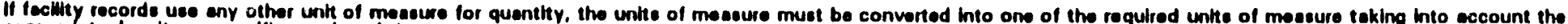
eppropriote denalty or epecille orevity of the weste.

D. PROCESSES

1. PROCESS CODES:

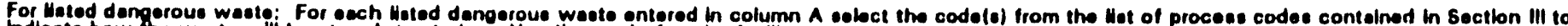
Indleate how the wate will be stored, troeted, end/or dieposed of ot the fectity.

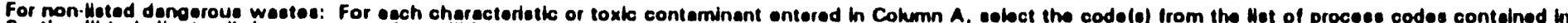

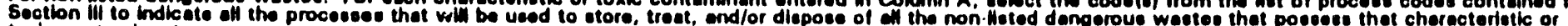
toxio conteminent.

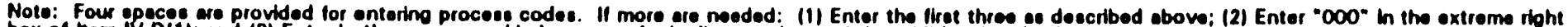
box of hom iV.D(1); and (3) Enter in the epece provided on pege 4, tho une number and the edditionel codolel.

2. PROCESS DESCRIPTION: If e code le not Meted for a procese that will be ueed, doecribe the procese in the epece provided on the form.

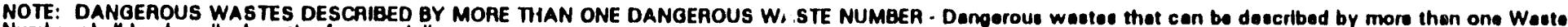
Number thell be described on the form a lollows:

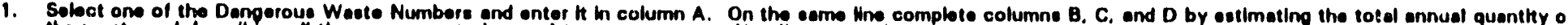
the weete end describine all the proceseses to be used to treet. etore, and/or diepose of the waete.

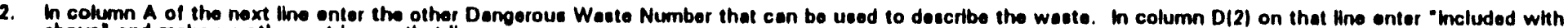
above" and make no other entrive on that line.

3. Repeat etep 2 for each other Dengerous Waste Number that cen be used to describe the dengeroue waste.

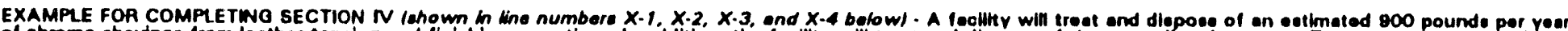

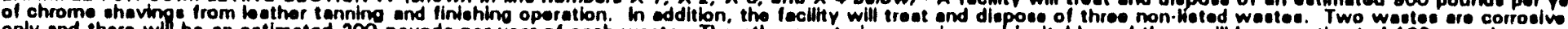

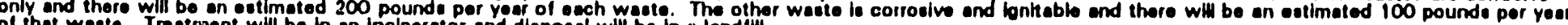
of that waste. Troatmont will bo in en incinerator and diapoeal will be in a landili.

\begin{tabular}{|c|c|c|c|c|c|c|c|c|c|c|c|}
\hline \multirow{3}{*}{$\mid \begin{array}{ll}L & \\
1 & N \\
N & 0 \\
E\end{array}$} & \multirow{2}{*}{\multicolumn{4}{|c|}{$\begin{array}{l}\text { PANOER } \\
\text { WASTE NOS } \\
\text { lonter codel }\end{array}$}} & \multirow{3}{*}{$\frac{\begin{array}{l}\text { B. ESTIMATED ANNUAL } \\
\text { QUANTIYY OF WASTE }\end{array}}{900}$} & \multirow{2}{*}{$\begin{array}{l}\text { C. UNIT } \\
\text { OF MEA } \\
\text { SURE } \\
\text { leneer } \\
\text { code) }\end{array}$} & \multicolumn{5}{|c|}{ D. PROCESSES } \\
\hline & & & & & & & \multicolumn{4}{|c|}{ 1. PAOCESS CODES } & \multirow[t]{2}{*}{$\begin{array}{l}\text { 2. PROCESS DESCAIPTION } \\
\text { "H code to not entered in DII }\end{array}$} \\
\hline & $x$ & 0 & 5 & 4 & & $P$ & $T_{0} 0_{3}$ & $0 \begin{array}{ll}0 & 0\end{array}$ & & & \\
\hline$x-2$ & 0 & 0 & 0 & 2 & 400 & $P$ & $T_{0}{ }_{0}$ & $D_{0}{ }_{0}$ & & $T T$ & \\
\hline$x \cdot 3$ & $D$ & 0 & 0 & 1 & 100 & $\boldsymbol{p}$ & $r_{0} 0_{3}$ & 000 & 11 & 11 & \\
\hline$x-4$ & 0 & 0 & 0 & 2 & & & $T 03$ & $D_{8} 0$ & 11 & 17 & inchuded whth above \\
\hline
\end{tabular}




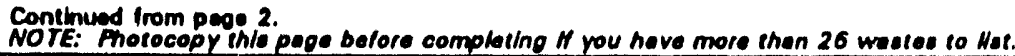

. NUMBEA lentered from pege 1)

\begin{tabular}{|l|l|l|l|l|l|l|l|l|l|l|}
\hline$A$ & 7 & 8 & 0 & 0 & 0 & 0 & 6 & 0 & 0 & 7 \\
\hline
\end{tabular}

N. DESCAIPTION OF DANOEROUS WASTES (continUed)

\begin{tabular}{|c|c|c|c|c|c|}
\hline \multirow[b]{2}{*}{$\begin{array}{ll}\mathbf{N} \\
\mathbf{1} \\
\mathbf{N} \\
\mathbf{E}\end{array}$} & \multirow{2}{*}{$\begin{array}{l}\text { PANGÉROUS } \\
\text { WASTE NOS } \\
\text { (enter codel }\end{array}$} & \multirow[b]{2}{*}{$\begin{array}{l}\text { B. ESTIMATED ANNUAL } \\
\text { GUANIIT OF WASTE }\end{array}$} & \multirow{2}{*}{$\begin{array}{l}\text { C. UNIT } \\
\text { OF MEA. } \\
\text { SURE } \\
\text { SOnter } \\
\text { code) }\end{array}$} & \multicolumn{2}{|c|}{ D. PAOCESSES } \\
\hline & & & & 1. PROCESS CODES & $\begin{array}{l}\text { 2. PhOCESS DESCAIPTION } \\
\text { II a coda la nol entered } \mathrm{h} \text { DIII) }\end{array}$ \\
\hline
\end{tabular}

\begin{tabular}{|l|l|l|l|l|}
\hline & F & 0 & 0 & 1 \\
\hline
\end{tabular}

$657,935,000$

$\begin{array}{llllll}2 & F & 0 & 0 & 2\end{array}$

$\begin{array}{llllll}3 & F & 0 & 0 & 3\end{array}$

\begin{tabular}{lllll}
4 & F & 0 & 0 & 4 \\
\hline
\end{tabular}

$\begin{array}{llllll}6 & F & 0 & 0 & 5\end{array}$

\begin{tabular}{llllll}
- & $\mathrm{H}$ & $\mathrm{T}$ & 0 & 0 & 2 \\
\hline
\end{tabular}

$\begin{array}{llllll}7 & F & 0 & 0 & 1\end{array}$

$67,094,000$

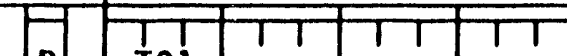

Treatment - Tank

- F 000,2

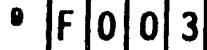

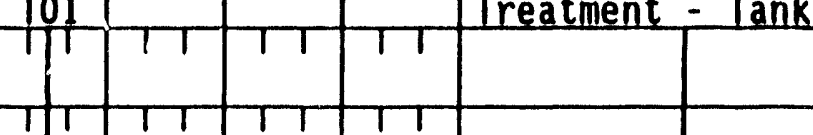

$\begin{array}{lllll} & F & 0 & 0 & 4\end{array}$

\begin{tabular}{lllll}
$M$ & $F$ & 0 & 0 & 5 \\
\hline
\end{tabular}

\begin{tabular}{ll|l|l|l}
12 & $\mathrm{~W}$ & $\mathrm{~T}$ & 0 & 2
\end{tabular}

\begin{tabular}{ll|l|l|l}
13 & 0 & 0 & 0 & 1 \\
\hline
\end{tabular}

$4,380,000$

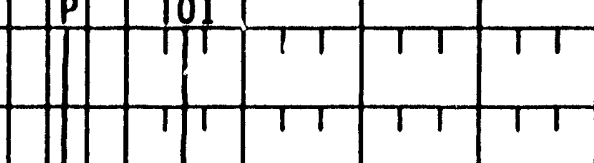

$14 \quad 0 \quad 00002$

$\begin{array}{llllll}16 & 0 & 0 & 0 & 3\end{array}$

$\begin{array}{llllll}16 & D & 0 & 0 & 4\end{array}$

$\begin{array}{llllll}17 & 0 & 0 & 0 & 5\end{array}$

$\begin{array}{llllll}18 & 0 & 0 & 0 & 6\end{array}$

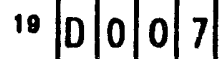

200010000

21000000

22000010

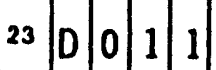

$\begin{array}{llll}0 & 0 & 1 & 8\end{array}$

$\begin{array}{llllll}25 & 0 & 0 & 1 & 9\end{array}$

\begin{tabular}{l|l|l|l|l|}
\hline 26 & 0 & 0 & 2 & 2 \\
\cline { 2 - 4 }
\end{tabular}

ECL30-271 . ECY 030-31 Form 3

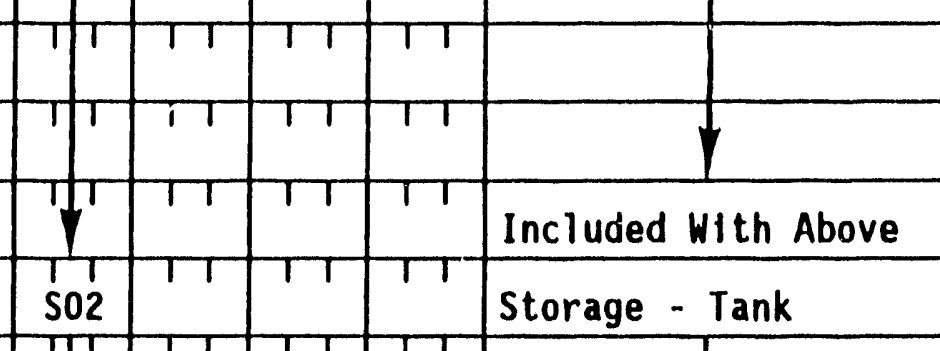

\begin{tabular}{lll|l|l|l|}
11 & 11 & 1 & 1
\end{tabular}

\begin{tabular}{|l|l|l|l|l|l|l|}
\hline 1 & 1 & 1 & 1 & 1 & \\
\hline 1 & 1 & 1 & 1 & 1 & \\
\hline 1 & 1 & 1 & 1 & 1 &
\end{tabular}

Included With Above

Storage - Container 
Continued trom peoe 2.

IE: Photocopy this page before completing if you have more than 26 westes to list.

NUMBER lentered from pego "I

\begin{tabular}{|l|l|l|l|l|l|l|l|l|l|l|l|}
\hline$W$ & $A$ & 7 & 8 & 9 & 0 & 0 & 0 & 8 & 9 & 6 & 7 \\
\hline
\end{tabular}

N. DESCRIPTION OF DANGEROUS WASTES (continLOd)

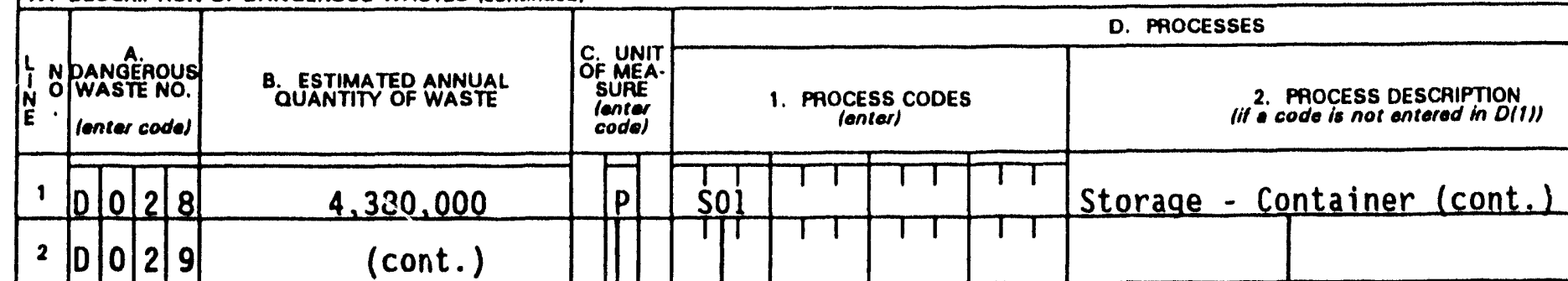

\begin{tabular}{l|l|l|l|l}
3 & 0 & 0 & 3 & 0 \\
\hline
\end{tabular}

\begin{tabular}{llllll}
4 & 0 & 0 & 3 & 3 \\
\hline
\end{tabular}

$\begin{array}{llllll}6 & 0 & 0 & 3 & 4\end{array}$

\begin{tabular}{llllll}
6 & $D$ & 0 & 3 & 5 \\
\hline
\end{tabular}

\begin{tabular}{lllll}
7 & 0 & 0 & 3 & 6 \\
\hline
\end{tabular}

\begin{tabular}{lllll}
8 & 0 & 0 & 3 & 8 \\
\hline
\end{tabular}

$\begin{array}{lllll}- & 0 & 0 & 3 & 9\end{array}$

(cont.)

$\begin{array}{llll}0 & 0 & 4 & 0\end{array}$

$\begin{array}{lllllll}11 & D & 0 & 4 & 1\end{array}$

\begin{tabular}{llllll}
12 & $D$ & 0 & 4 & 3 \\
\hline
\end{tabular}

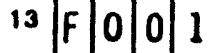

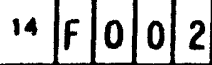

$\begin{array}{llllll}16 & F & 0 & 0 & 3\end{array}$

$\begin{array}{llllll}16 & F & 0 & 0 & 4\end{array}$

$\begin{array}{llllll}17 & F & 0 & 0 & 5\end{array}$

\begin{tabular}{l|l|l|l|l}
18 & $\mathrm{~W}$ & $\mathrm{~T}$ & 0 & 0 \\
\hline
\end{tabular}

19

20

21

22

\begin{tabular}{|l|l|l|l|l|l|}
\hline & & & & \\
\hline
\end{tabular}

FCI 30 - 271. ECY 030-31 Form 3 
Conthuad trom the tront.

W. DESCAIPTION OF DANGEROUS WASTES (OONUTMUOD)

UEE MIIS SPACE TO LIST ADOTIONAL PAOCESS CODES FROM SECTION DIII ON PAOE 3.

The ETF treats and stores process condensate from the 242-A Evaporator, and the Liquid Effluent Retention Facility, and possibly other dilute aqueous waste streams generated on the Hanford Facility. The efiluent stored in the verification tanks for sampling is regulated as a dangerous waste because of the possible presence of spent halogenated and nonhalogenated solvents (F001 through F005) and for the toxicity of ammonia (WT02, toxic state-only dangerous waste). The secondary waste stream is regulated as a dangerous waste berause of the presence of characteristic waste (D001, D002, and D003), toxic constituents (DL 04, D005, D006, D007, D008, D009, D010, D011, D018, D019, D022, D02E, D029, D030, D033, D034, D035, D036, D038, D039, D040, D041, and D043), spent halogenated and nonhalogenated solvents (F001 through F005), and toxic state-only extremely hazardous waste (WT01).

The annual quantity of waste listed under item IV.B was calculated using an operating schedule of 365 days per year. This calculation was done to provide a maximum annual estimated quantity of waste that might be treated and stored by the ETF.

FACIITY DRAWWO

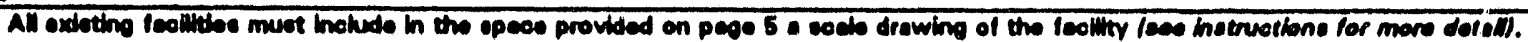

V. PHOTOGRAFH8

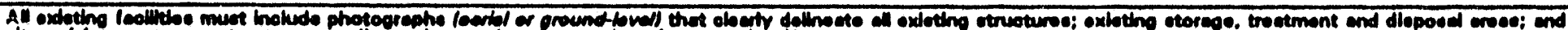

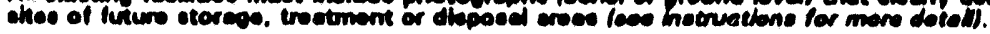

Vw. FACUIT aEOQMAPHIC LOCAnION This information is provided on the attached drawings and photos.

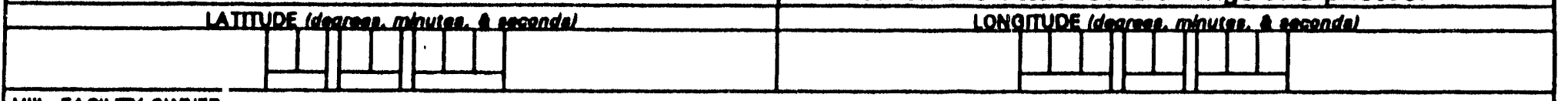

VHI. FACILTY OWNEA

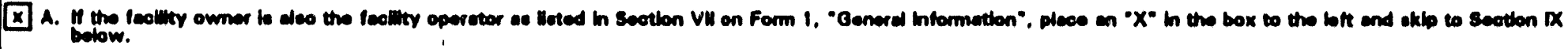

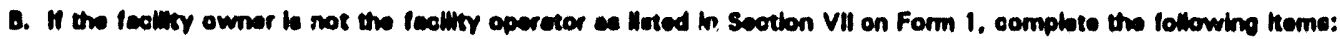

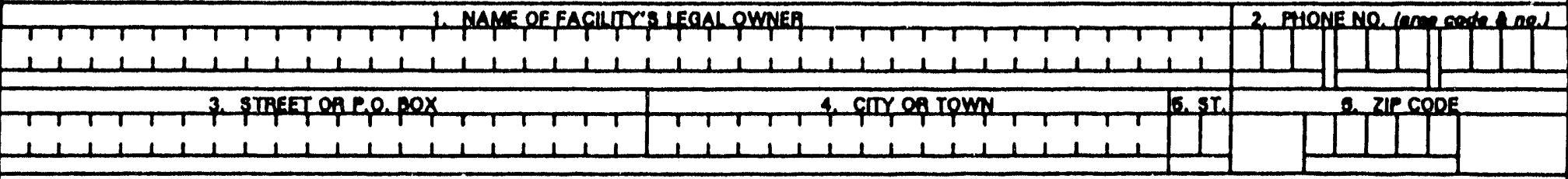

IX. OWIER CEATFICATION

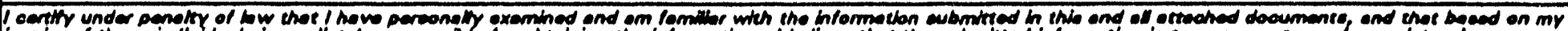

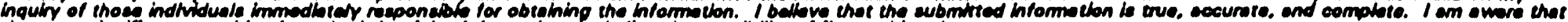

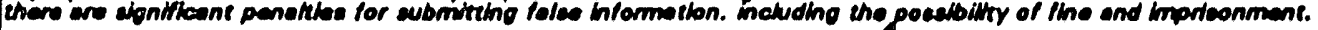

NAME (orint or rypel

John D. Hegoner. Menager

U.S. Department of Eneroy

Rlchlend Operatione office

OPERATOA CERTFICA TION

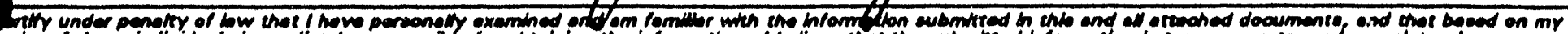

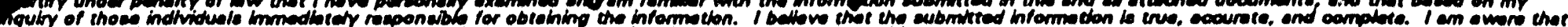

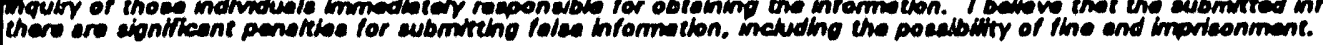

NAME (point or npel)

SIONATUR:

DATE SIONED

SEE ATTACHMENT

ECL30 - 271 - ECY 030-31 Form 3 


\section{$X$. OPERATOR CERTIFICATION}

I certify under penalty of law that I have personally examined and am familiar with the information submitted in this and all attached documents, and that based on my inquiry of those individuals immediately responsible for obtaining the information, I believe that the submitted information is true, accurate, and complete. I am aware that there are significant penalties for submitting false information including the possibility of fine and imprisonment.
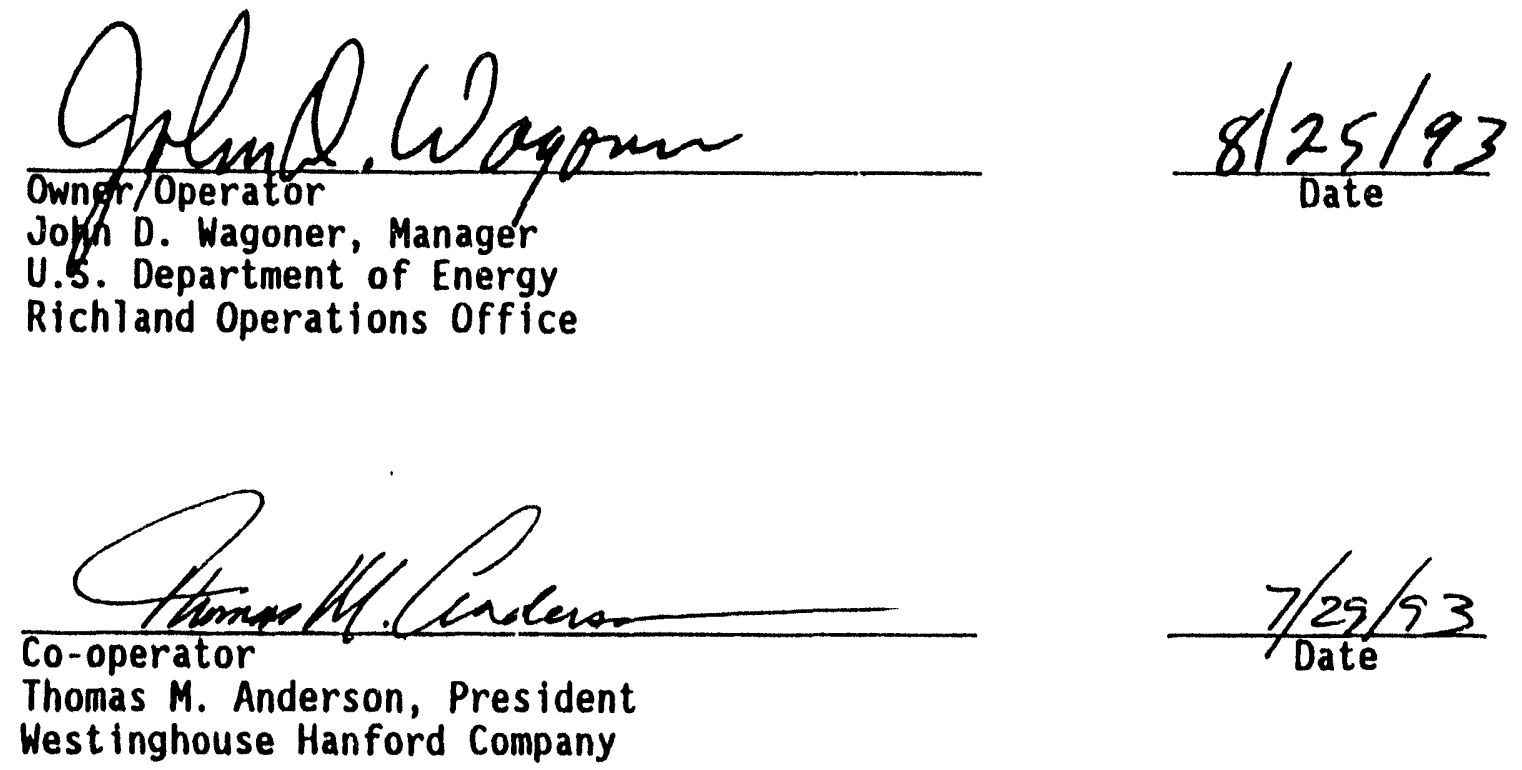

Thomas M. Anderson, President

encord 


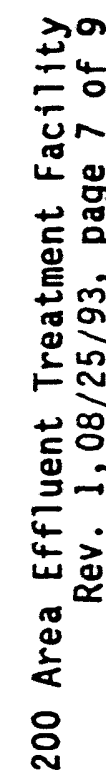

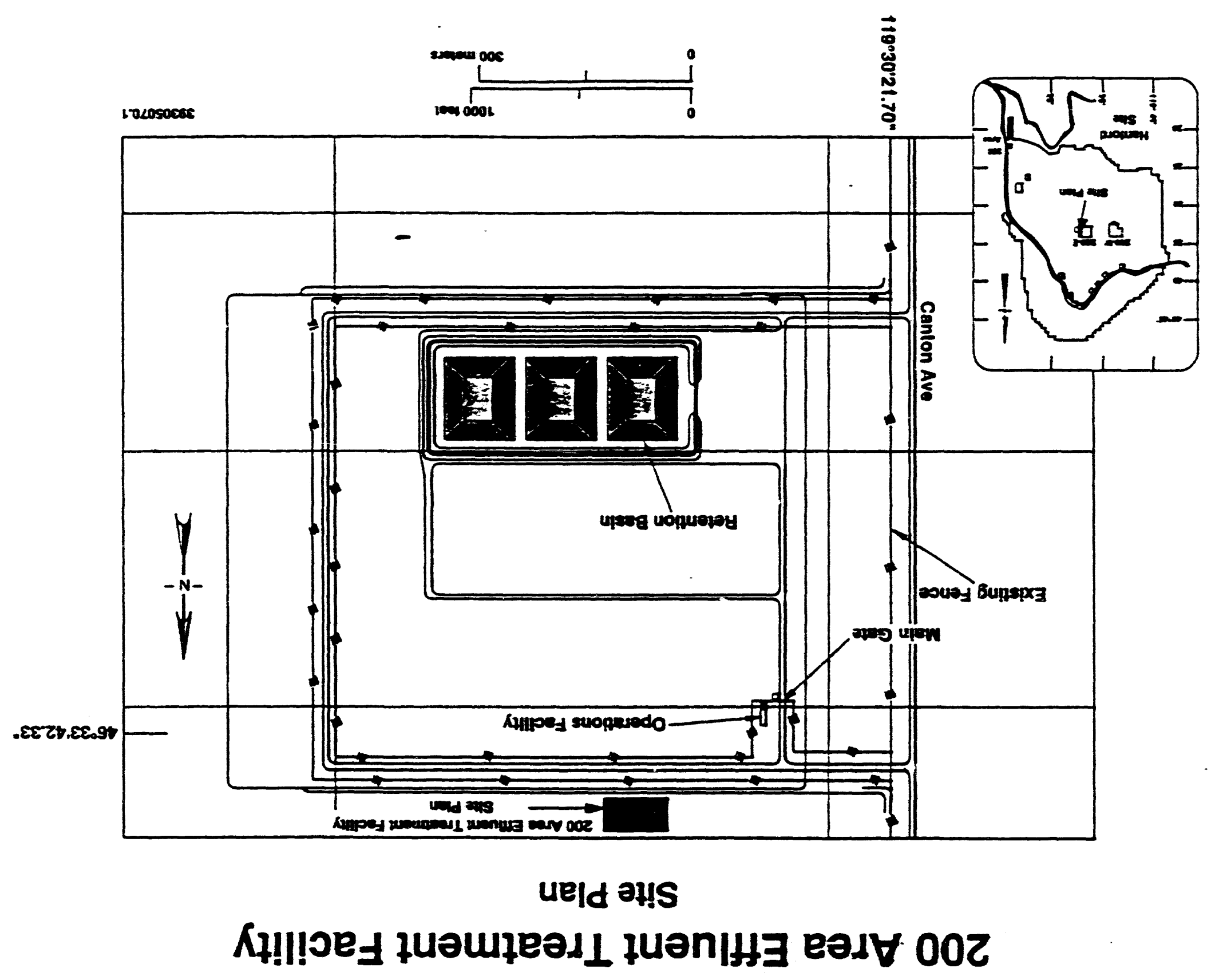




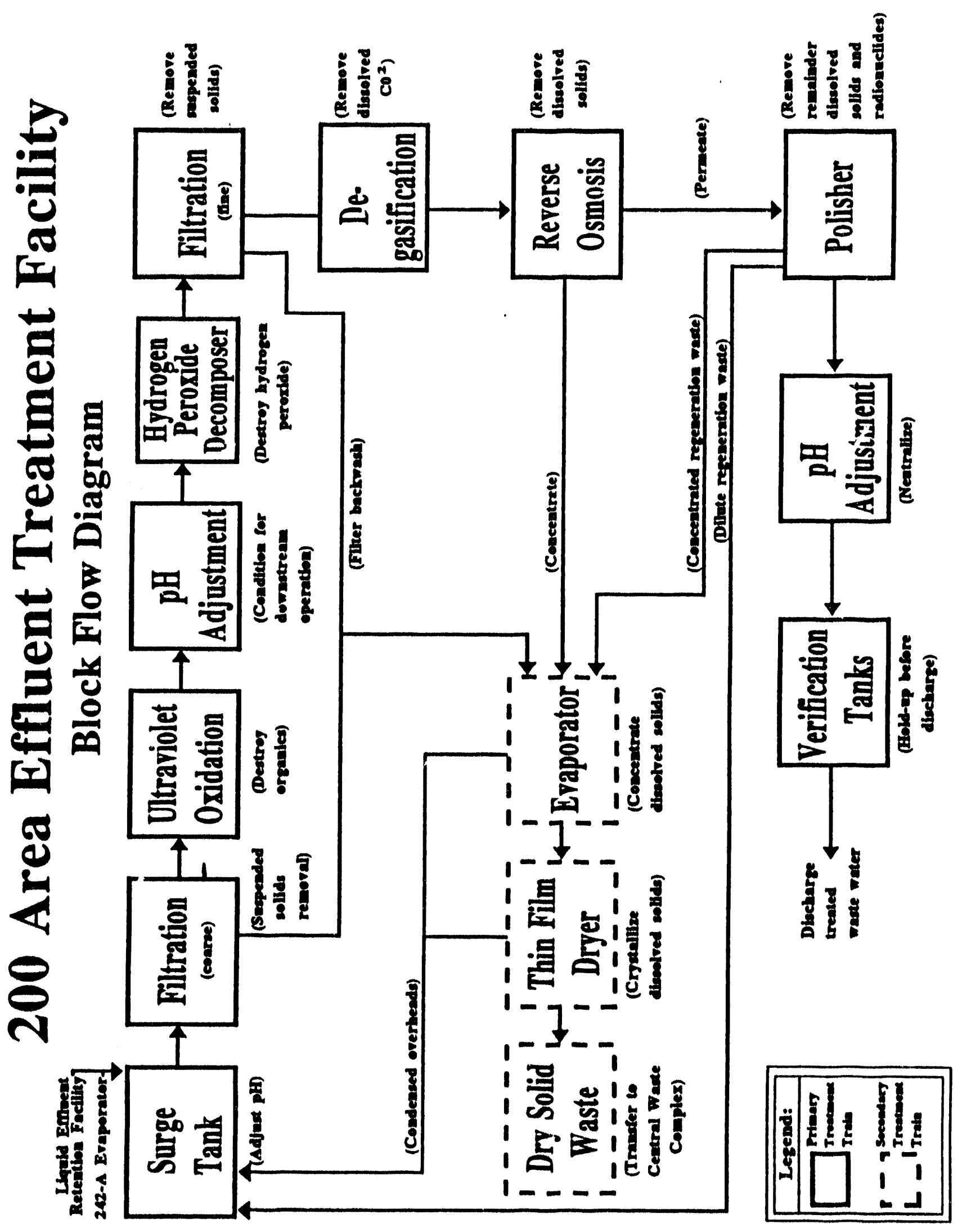




\section{AREA EFFLUENT TREATMENT FACILITY}

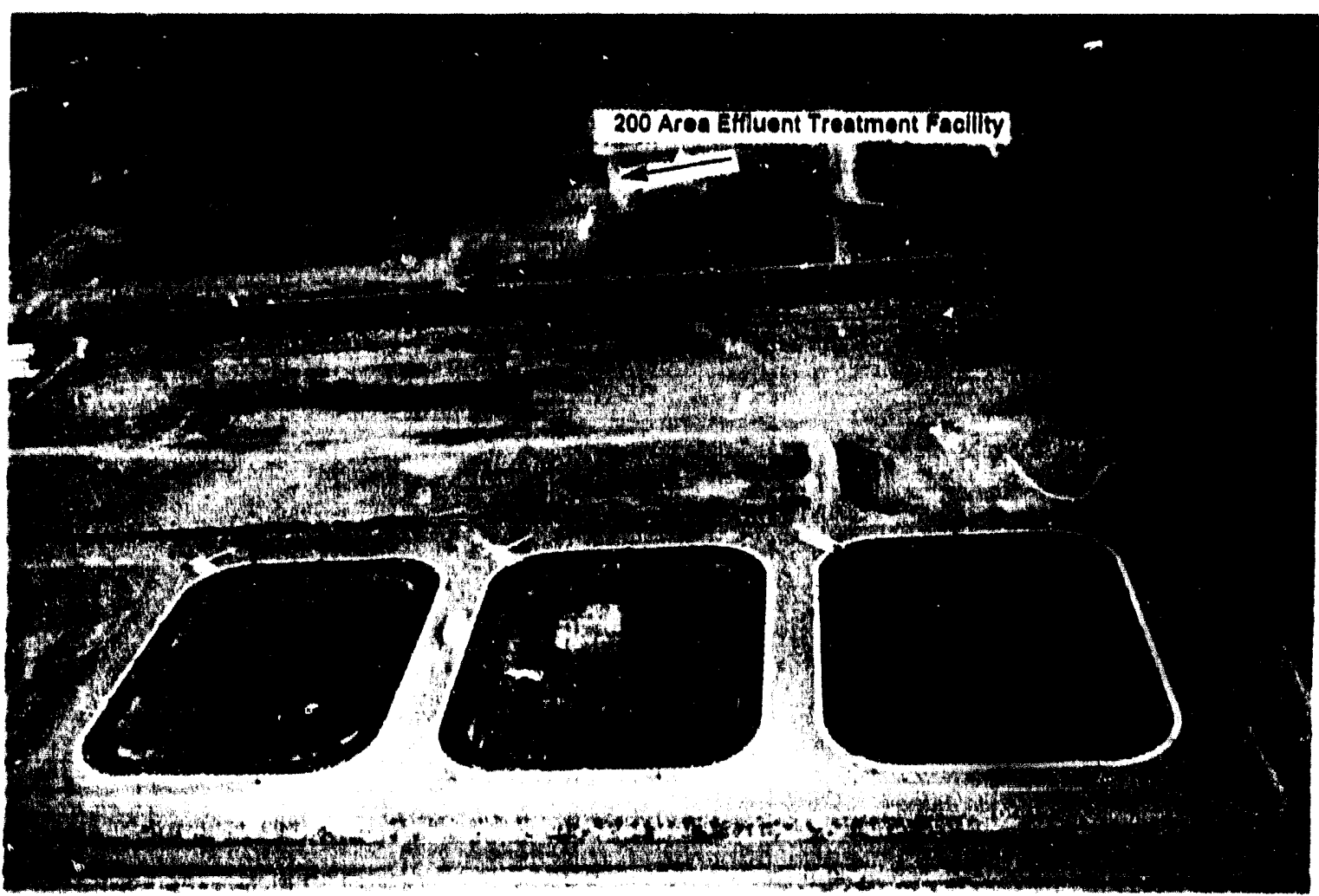

$46^{\circ} 33^{\prime} 42.33^{\prime \prime}$

$93030994-79 \mathrm{CN}$ $119^{\circ} 30^{\prime} 21.70^{\prime \prime}$ 
DOE/RL-93-03, ReV. 0

$08 / 31 / 93$

\section{PART B}

This Part B permit application documentation for the 200 Area Effluent
5 Treatment Facility consists of 15 chapters and 8 appendices. 


\section{DOE/RL-93-03, Rev. 0 $08 / 31 / 93$}

This page intentionally left blank. 
CONTENTS

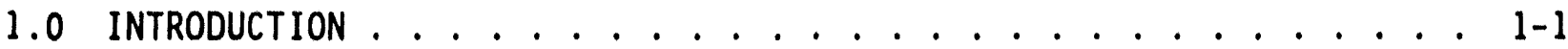

1.1200 AREA EFFLUENT TREATMENT FACILITY PERMITTING . . . . . . . . 1-1

1.2200 AREA EFFLUENT TREATMENT FACILITY PART B PERMIT

APPLICATION DOCLMENTATION CONTENTS . . . . . . . . . . . . . . 1-2

1.2.1 Facility Description and General Provisions . . . . . 1-2

1.2.2 Waste Characteristics . . . . . . . . . . . . 1-2

1.2.3 Process Information ................ 1-3

1.2.4 Groundwater Monitoring .............. 1-3

1.2.5 Procedures to Prevent Hazards ............ 1-3

1.2.6 Contingency Plan .............. 1-3

1.2.7 Personnel Training ................ 1-3

1.2.8 Exposure Information Report . . . . . . . . . . . 1-3

1.2.9 Waste Minimization ................. 1-3

1.2.10 Closure and Postclosure Requirements . . . . . . . . . 1-4

1.2.11 Reporting and Recordkeeping.............. 1-4

1.2.12 Other Relevant Laws ............... . . . 1-4

1.2.13 Certification ................... 1-4

1.2.14 References . . . . . . . . . . . . . . . . 1-4

1.3 ACRONYMS AND ABBREVIATIONS . . . . . . . . . . . . . . 1-4

1.4 DEFINITIONS . . . . . . . . . . . . . . 1-5

1.5 PERMIT MODIFICATIONS . . . . . . . . . . . . . . 1-6 
GAWN

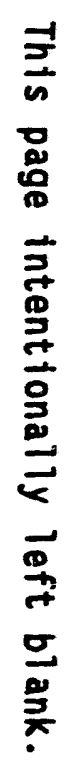

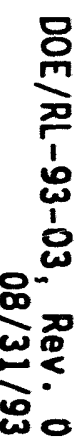


DOE/RL-93-03, Rev. 0

$08 / 31 / 93$

\subsection{INTRODUCTION}

This chapter briefly describes the permitting approach for the Hanford Facility Dangerous Waste Permit Application, 200 Area Effluent Treatment Facility (ETF), and provides an overview of the ETF Part B permit application documentation.

The ETF treatment concept originally was coupled with the storage aspect of the Liquid Effluent Retention Facility (LERF) and called the 200 East Area Liquid Effluent Retention and Treatment Facility [March 1990 Notice of Intent (DOE-RL 1990)]. Treatment and storage operations were separated and the treatment portion was called the 242-A Evaporator/Plutonium-Uranium Extraction (PUREX) Plant Condensate Treatment Facility, also referred to as Project C-018H.

Supporting documents refer to the ETF as the $\mathrm{C}-018 \mathrm{H}$ or $242-\mathrm{A}$ Evaporator/ PUREX Plant Condensate Treatment Facility. The use of ' $\mathrm{C}-018 \mathrm{H}$ ' and '242-A Evaporator/PUREX Plant Condensate Treatment Facility' refers to the ETF.

\subsection{AREA EFFLUENT TREATMENT FACILITY PERMITTING}

The ETF treats mixed waste in tanks and temporarily stores mixed waste in tanks and containers. The ETF is designed to initially treat 242-A Evaporator process condensate (PC); however, this unit al so may treat nonregulated waste water, e.g., groundwater. The ETF, located in the 200 East and 600 Areas, is being permitted under interim status expansion. Construction began in March of 1993 and the ETF is expected to come online in October 1994. This permit application documentation is written as if the ETF were operational.

The 242-A Evaporator (DOE/RL-90-42) is one step in an overall treatment process that reduces the volume of waste in the Double-Shell Tank (DST) System (DOE/RL-90-39) and in the single-shell tanks (SST). Tank waste is pumped to the 242-A Evaporator where the waste is concentrated and the overheads are condensed to make the 242-A Evaporator PC. The concentrate is returned to the DST System, and the 242-A Evaporator PC is treated in the ETF.

Treated waste water can be discharged to the soil column in the 600 Area, north of the 200 West Area of the Hanford Facility, following approval of a delisting petition by the U.S. Environmental Protection Agency (EPA) and issuance of a State Waste Discharge Permit by the Washington State Department of Ecology (Ecology).

The treated waste water contains tritium, a radioactive isotope of hydrogen. There is no viable treatment technology available to remove tritium. This document discusses the radioactive and dangerous waste removed from the waste water; however, these discussions do not apply to tritium. The tritium levels are not reduced by the ETF and the discharged water does contain tritium. 
In addition to the design and operating features of the ETF that are intended to meet the requirements of the Resource Conservation and Recovery Act (RCRA) of 1976 and the Washington Administrative Code (WAC)

Chapter 173-303 Dangerous Waste Regulations, other design and operating features are necessary to comply with radioactive waste management requirements. Although the treatment, storage, and/or disposal of radioactive waste (i.e., source, special nuclear, and by-product materials as defined by the Atomic Energy Act of 1954) is not within the scope of RCRA or WAC 173-303, information is provided for general knowledge where appropriate. The ETF design features and operational practices are intended to keep exposure to radionuclides and dangerous substances as low as reasonably achievable (ALARA) and to provide a disposal system that protects human health and the environment.

\subsection{AREA EFFLUENT TREATMENT FACILITY PART B PERMIT APPLICATION DOCUMENTATION CONTENTS}

The ETF Part B permit application documentation consists of the following 15 chapters:

- Introduction (Chapter 1.0)

- Facility Description and General Provisions (Chapter 2.0)

- Waste Characteristics (Chapter 3.0)

- Process Information (Chapter 4.0)

- Groundwater Monitoring (Chapter 5.0)

- Procedures to Prevent Hazards (Chapter 6.0)

- Contingency Plan (Chapter 7.0)

- Personnel Training (Chapter 8.0)

- Exposure Information Report (Chapter 9.0)

- Waste Minimization (Chapter 10.0)

- Closure and Postclosure Requirements (Chapter 11.0)

- Reporting and Recordkeeping (Chapter 12.0)

- Other Relevant Laws (Chapter 13.0)

- Certification (Chapter 14.0)

- References (Chapter 15.0). sections.

A brief description of each chapter is provided in the following

\subsubsection{Facility Description and General Provisions (Chapter 2.0)}

This chapter provides a general description of the ETF. A block flow diagram is provided.

\subsubsection{Waste Characteristics (Chapter 3.0)}

This chapter describes the chemical, biological, and physical characteristics of the waste treated and stored at the ETF. A waste analysis plan for process operation is included. Because dangerous waste does not 
1 include the source, special nuclear, and by-product material components of mixed waste, radionuclides are not within the scope of WAC 173-303 or of this permit application documentation. The information on radionuclides is provided only for general knowledge where appropriate.

\subsubsection{Process Information (Chapter 4.0)}

This chapter provides a detailed discussion of the ETF processes and equipment. A process flow diagram is provided.

\subsubsection{Groundwater Monitoring (Chapter 5.0)}

This chapter explains that the ETF is not operated as a dangerous waste surface impoundment, waste pile, land treatment unit, or landfill. Therefore, groundwater monitoring is not required.

\subsubsection{Procedures to Prevent Hazards (Chapter 6.0)}

This chapter discusses hazard prevention and emergency preparedness equipment, structures, and procedures.

\subsubsection{Contingency Plan (Chapter 7.0)}

This chapter provides information on contingency planning to ensure that the ETF has measures in place to lessen the potential impact on the human health and the environment in the event of an emergency.

\subsubsection{Personnel Training (Chapter 8.0)}

This chapter outlines the training program developed and implemented for ETF employees who have duties associated with dangerous waste management.

\subsubsection{Exposure Information Report (Chapter 9.0)}

This chapter explains that the ETF does not store, treat, or dispose of dangerous waste in a surface impoundment or a 1 andfil1. Therefore, exposure information is not required.

\subsubsection{Waste Minimization (Chapter 10.0)}

This chapter discusses the waste minimization requirements for the ETF. 


\subsubsection{Closure and Postclosure Requirements (Chapter 11.0)}

This chapter describes the planned activities for closing the ETF. The ETF is to be clean closed. Therefore, no postclosure plan is included.

\subsubsection{Reporting and Recordkeeping (Chapter 12.0)}

This chapter summarizes commitments for reporting and recordkeeping that are applicable to the ETF.

\subsubsection{Other Relevant Laws (Chapter 13.0)}

This chapter discusses federal and state laws that govern the ETF construction and operation, other than the RCRA, as amended, and the State of Washington Hazardous Waste Management Act of 1976, as amended.

\subsubsection{Certification (Chapter 14.0)}

This chapter contains the required certification signed by officials of the U.S. Department of Energy, Richland Operations Office (DOE-RL) indicating that the information provided is true, accurate, and complete.

\subsubsection{References (Chapter 15.0)}

References used throughout this Part B permit application documentation are listed in this chapter. All references listed here, which generally are not available from other sources, will be made avallable for review, upon request, to any regulatory agency or public commentor. References can be obtained by contacting the following:

Administrative Records Specialist

Public Access Room H6-08

Westinghouse Hanford Company

P.0. Box 1970

Richland, Washington 99352.

\subsection{ACRONYMS AND ABBREVIATIONS}

Acronyms and abbreviations used throughout this Part B permit application documentation are located at the beginning of the document between the Foreword and the Part A permit application section. 


\subsection{DEFINITIONS}

Definitions specific to this permit application documentation are provided in tin section. These definitions supplement those provided in WAC 173-303-040.

Contractor--Firm under contract to the U.S. Department of Energy to provide Hanford Site services. Currently, there are the following four Hanford Site prime contractors:

- An Operations and Engineering contractor

- A Research and Development contractor

- An Engineer and Construction contractor

- A Medical Health Services contractor.

Throughout the remainder of this permit application documentation, the term contractor, except where specified, is used to refer to the operations and engineering contractor. The use of the word 'operations' in 'operations and engineering contractor' is a contractual term, and is unrelated to the word 'operator' as defined by RCRA and WAC 173-303.

Dangerous or hazardous waste--In addition to the definition in WAC 173-303-040, means the nonradioactive dangerous component of waste commonly called mixed waste (i.e., waste that is both dangerous and radioactive). Dangerous waste commonly is used to refer to hazardous, dangerous, or extremely hazardous waste within this permit application documentation.

Facility--Dependent on context, the term 'facility', as used in this permit application documentation, could refer to:

- The Hanford Facility (refer to definition)

- Building nomenclature commonly used at the Hanford Facility. In this context, the term 'facility' remains as part of the title for various treatment, storage, and/or disposal (TSD) units (e.g., Grout Treatment Facility, and 616 Nonradioactive Dangerous Waste Storage Facility)

- For purposes of complying with RCRA corrective action provisions, all contiguous property under the control of the owner or operator seeking a permit under subtitle C of RCRA.

Generating Unit--Term inferred to have the same meaning as 'generator' as defined in WAC 173-303-040. For purposes of the RCRA and the Dangerous Waste Regulations, the Hanford Facility is considered to be a single generator comprised of a number of generating units.

Hanford Facility--A single RCRA facility identified by the EPA/State Identification Number WA7890008967 that consists of over 60 TSD units conducting dangerous waste management activities. These TSD units are included in the Hanford Facility Dangerous Waste Part A Permit Application (DOE/RL-88-21). The Hanford Facility consists of the contiguous portion of 
the Hanford Site that contains these TSD units and, for the purposes of the RCRA, is owned by the U.S. Government and operated by the DOE-RL (excluding lands north and east of the Columbia River, river islands, lands owned or used by the Bonneville Power Administration, lands leased to the Washington Public Power Suppiy System, and lands owned by or leased to the state of Washington).

Hanford Site--The approximately 560 square miles (1,450 square kilometers) in southeastern Washington State owned by the U.S. Government and sometimes referred to as the Hanford Reservation.

Treatment, Storage, and/or Disposal Unit--A unit used for treatment, storage, and/or disposal of dangerous waste that is required to be permitted and/or closed pursuant to RCRA and WAC 173-303 requirements as determined in the Hanford Federal Facility Agreement and Consent Order (Tri-Party Agreement) Action Plan (Ecology et al. 1992). Also refers to a grouping of TSD units for the purpose of preparing and submitting a permit application pursuant to the requirements under RCRA and WAC 173-303, as determined in the Tri-Party Agreement Action Plan.

Tri-Party Agreement--The term Tri-Party Agreement means the Hanford Federal Facility Agreement and Consent Order, dated May 1989, as amended, and as it may be amended from time to time, including the Tri-Party Agreement Action Plan incorporated in the Tri-Party Agreement.

\subsection{PERMIT MODIFICATIONS}

All modifications to the ETF Unit-Specific Portion of the Hanford Facility Permit will be made in accordance with the requirements identified in WAC 173-303-830, with the following exception. The notifications required by WAC 173-303-830(4)(a)( 1$)(A)$ and (B) for Class 1 changes will be submitted annually to the required regulatory arencies, appropriate units of state and local government, and individuals on the facility mailing list maintained by Ecology. These notifications will be submitted by March 1 of each year. 


\section{CONTENTS}

2.0 FACILITY DESCRIPTION AND GENERAL PROVISIONS [B] . . . . . . . . 2-1

2.1 DESCRIPTION OF THE 200 AREA EFFLUENT TREATMENT FACILITY . . . . 2-1

2.1.1 Transfer Piping System . . . . . . . . . . . . 2-2

2.1.2 Primary Treatment Train ............. . 2-2

2.1.2.1 Surge Tank.............. 2-2

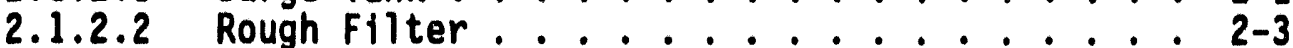

2.1.2.3 U1traviolet Oxidation System........ 2-3

2.1.2.4 pH Adjustment Tank ............. 2-3

2.1.2.5 Hydrogen Peroxide Decomposer......... 2-3

2.1.2.6 Fine Filter .............. 2-3

2.1.2.7 Degasification System ......... 2-3

2.1.2.8 Reverse Osmosis System ........... 2-3

2.1.2.9 Polisher.............. 2-4

2.1.2.10 Effluent pH Adjustment Tank . . . . . . . 2-4

2.1.2.11 Verification Tanks ............. 2-4

2.1.3 Secondary Treatment Train .............. 2-4

2.1.3.1 Secondary Waste Receiving Tank . . . . . . . 2-4

2.1.3.2 Effluent Treatment Facility Evaporator ... . 2-4

2.1.3.3 Concentrate Tank ............ 2-5

2.1.3.4 Thin Film Dryer .............. 2-5

2.1.3.5 Container Handling System ......... 2-5

2.1.3.6 Filled Container Storage .......... 2-5

2.1.4 Supporting Systems .............. 2-5

2.1.4.1 Chemical Reagent Feed System ......... 2-5

2.1.4.2 Sump Tank System . . . . . . . . . . . . 2-6

2.1.4.3 Vessel Offgas System . . . . . . . . . 2-6

2.1.4.4 Utilities ................ 2-6

2.2 TOPOGRAPHIC MAPS $[\mathrm{B}-2] \ldots \ldots \ldots \ldots \ldots$

2.3 LOCATION INFORMATION [B-3] . . . . . . . . . . 2-6

2.3.1 Seismic Consideration [B-3a] . . . . . . . . . 2-6

2.3.2 Floodplain Standard [B-3b] . . . . . . . . . 2-7

2.3.2.1 Demonstration of Compliance $[\mathrm{B}-3 \mathrm{~b}(1)]$. . . . 2-7

2.3.2.2 Plan for Future Compliance with Floodplain

Standard $[\mathrm{B}-3 \mathrm{~b}(2)]$........... 2-7

2.3.3 Shorel ine Standard [B-3c] . . . . . . . . . . 2-8

2.3.4 Sole Source Aquifer Criteria [B-3d] . . . . . . . 2-8

2.4 TRAFFIC INFORMATION [B-4] . . . . . . . . . . 2-8

2.4.1 Hanford Site Roadways . . . . . . . . . . . . 2-8

2.4.2 Traffic Control Signs, Signals, and Procedures . . . . 2-9

2.4.3 Transfer of Waste................ 2-9

2.5 PERFORMANCE STANDARDS [B-5] . . . . . . . . . . 2-9

2.5.1 Measures to Prevent Degradation of Groundwater

Quality ...............2-10 
2.5.2 Measures to Prevent Degradation of Air Quality by Open Burning or Other Activities . . . . . . . . . 2-10

2.5.3 Measures to Prevent Degradation of Surface Water Quality . . . . 2-10

2.5.4 Measures to Prevent Degradation of or Impairment of Flora and Fauna Outside the Unit . . . . . . . . 2-10

2.5.5 Measures to Prevent Excessive Noise ..........2-11

2.5.6 Measures to Prevent Negative Aesthetic Impact . . . . . 2-11

2.5.7 Measures to Prevent Unstable Hillsides or Solls ... . 2-11

2.5.8 Measures to Prevent the Use of Processes that Do Not Treat, Detoxify, Recycle, Reclaim, and Recover Waste Materials to the Extent Economically Feasible ... . . 2-11

2.5.9 Measures to Prevent Endangerment to the Health of Employees or the Public Near the Unit . . . . . . 2-12

2.6 BUFFER MONITORING ZONE $[\mathrm{B}-6] \ldots \ldots$. . . . . . . . . . . . .

2.7 SPILLS AND DISCHARGES INTO THE ENVIRONMENT [B-7] . . . . . . . 2-12 2.7.1 Notification [B-7a] . . . . . . . 2-12

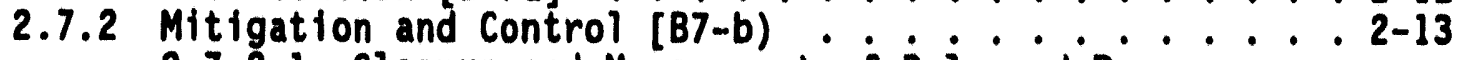
2.7.2.1 Cleanup and Management of Released Dangerous Wastes and Contaminated Soil, Water, or Other Materials ............ 2-13 2.7.2.2 Restoration of Impacted Area . . . . . . 2-13

2.8 MANIFEST SYSTEM [B-8] . . . . . . . . . . . . . 2-13

2.8.1 Onsite Waste Shipments . . . . . . . . . . . 2-14

2.8.2 Procedures for Receiving Shipments [B-8a] . . . . . 2-14 2.8.2.1 Transporter Responsibilities ........2-14 2.8.2.2 Receiving Untt Responsibilities.......2-15

2.8.3 Response to Significant Discrepancies [B-8b] . . . . 2-15 2.8.4 Provisions for Nonacceptance of Shipment [B-8C] $\cdot . \cdot 2-16$ 2.8.4.1 Nonacceptance of Undamaged Shipment [B-8c(1)] . 2-16 2.8.4.2 Activation of Contingency Plan for Damaged Shipment $[B-8 c(2)] \ldots$ 2-16

\section{APPENDIX}

2 A LOCATION MAPS .................................. APP $2 A-1$ 


\subsection{FACILITY DESCRIPTION AND GENERAL PROVISIONS [B]}

This chapter briefly describes the ETF location and operational information, including the following:

- General description

- Topography

- Location information

- Traffic information

- Performance standards

- Buffer monitoring zones

- Spills and discharges

- Manifest system.

A more detailed discussion of the waste types treated and the identification of the processes and equipment are provided in Chapters 3.0 and 4.0 , respectively. Because dangerous waste does not include the source, special nuclear, and by-product material components of mixed waste, radionuclides are not within the scope of WAC 173-303 or of this permit application documentation. The information on radionuclides is provided only for general knowledge where appropriate.

\subsection{DESCRIPTION OF THE 200 AREA EFFLUENT TREATMENT FACILITY}

The ETF is located in the 200 East Area and 600 Area (Figures 2-1 and 2-2). Appendix 2A provides a general overview of the Hanford Facility (Drawing H-6-958), and illustrates the following:

- Legal boundary

- Contours [at 20-foot (6.1 meter) intervals] sufficient to show surface water flow

- Fire control services

- Access roads, internal roads, railroads, perimeter gates, and barricades

- Longitudes and latitudes.

The purpose of the ETF is to receive and treat the 242-A Evaporator PC, the contents of the LERF, and possibly other Hanford Facility waste that fails within the envelope of acceptable waste as described in Chapter 3.0.

This permit application documentation is to permit the ETF treatment systems, including ancillary equipment and piping, from the surge tank to the verification tanks, and transfer piping connecting the LERF to the ETF. This permit application documentation does not include piping from the 242-A Evaporator to the LERF, nor does it include the piping from the ETF to 52 
200 West Area. The piping from the 242-A Evaporator to the LERF should be included in permit application documentation for the LERF, and the pipeline to the SALDS will be non-RCRA upon approval of the delisting petition.

The ETF consist of two treatment processes, called treatment trains, a primary and a secondary train (Figure 2-3). Incoming waste water to the ETF is referred to as 'waste water'; the effluent leaving the ETF is referred to as 'treated waste water'. Within the treatment trains, the waste water entering an individual treatment system is called 'feed' and the waste exiting a treatment system is called 'discharge'. The primary treatment train removes most radioactive and dangerous waste from the waste water. Treated waste water is then discharged to the soll column in the 600 Area, north of the 200 West Area. The secondary treatment train processes the waste removed by the primary treatment train. The secondary waste is dried to a powder, containerized, and transferred to a TSD unit.

Each treatment train consists of a serles of connected treatment systems (Chapter 4.0 describes the treatment trains in detail). The ETF uses skid-mounted, commerclally avallable, modular treatment systems wherever possible. The primary treatment train consists of the following systems:

- Surge tank

- Rough filter

- Uitraviolet oxidation (UV/OX)

- $\mathrm{pH}$ adjustment

- Hydrogen peroxide decomposer

- Fine filter

- Degasification

- Reverse osmosis (RO)

- Poltsher [ion exchange (IX) column]

- Final pH adjustment and verification.

The secondary treatment train processes waste removed from the waste water in the primary treatment train. The secondary treatment train consists of the following:

- Secondary waste receiving tanks

- ETF evaporator (forced circulation evaporator)

- Concentrate tank

- Thin film dryer

- Container handiing

- Supporting systems.

The following sections provide a general description of the ETF system components.

\subsubsection{Transfer Piping System}

Waste water from the 242-A Evaporator and the LERF is pumped to the ETF surge tank through two pipelines. Waste water from other TSD units and 
48

49

50

51 52

non-RCRA regulated sources, e.g., groundwater, may be treated at the ETF in the future. The mechanism for accepting waste other than from the 242-A Evaporator or the LERF has not been identified.

\subsubsection{Primary Treatment Train}

The purpose of the primary treatment train is to remove contaminants from the waste water so that the treated waste water can be discharged to the soil in compliance with a Washington State waste discharge permit. The primary treatment train consists of the components described in the following sections. Detalled descriptions are provided in Chapter 4.0.

2.1.2.1 Surge Tank. Waste water from the 242-A Evaporator and the LERF is delivered by way of pipelines into the surge tank. The surge tank also receives some waste generated during the treatment process. The pH of the waste water is adjusted in the surge tank.

2.1.2.2 Rough Filter. The waste water from the surge tank is fed to the rough filter. A backwashable 2-micron filter element is used to remove coarse suspended solids.

\subsubsection{U1 traviolet Oxidation System. The UV/OX system decomposes organic constituents in the filtered waste water.}

The waste water is mixed with hydrogen peroxide in the UV/OX system, then flows past long, cylindrical UV light tubes. The UV light reacts with the hydrogen peroxide creating 'hydroxyl radicals'. The UV light and the hydroxyl radicals together destroy the organic materials in the waste water.

2.1.2.4 $\mathrm{pH}$ Adjustment Tank. The $\mathrm{pH}$ is adjusted to (1) convert ammonia into an ammonium fon that can be removed by the RO system and (2) lower the solubility of carbonate ion allowing carbon dioxide to be released in the degasification system.

2.1.2.5 Hydrogen Peroxide Decomposer. The hydrogen peroxide decomposer reduces the level of hydrogen peroxide in the waste water to avoid damaging other systems in the treatment train.

2.1.2.6 Fine Filter. A backwashable 0.5-micron filter element is used for removal of suspended solids from the waste water.

2.1.2.7 Degasification System. The function of the degasification system is to prevent the formation of carbonate by removing carbon dioxide from the waste water. If left in the waste water, carbonate would increase the chance of fouling the RO system, the polisher, and equipment in the secondary treatment train.

2.1.2.8 Reverse Osmosis System. The function of the RO system is to reduce the concentration of dissolved solids, radionuclides, and any remaining large organic materia?s in the waste water. 
The RO system consists of cylinders containing membranes that work like fliters. The membranes are of a composite polyamide type. Waste water passes through the membranes leaving behind waste materlals, called concentrate. The waste water discharged from the system, called permeate, continues on to the polisher.

2.1.2.9 Polisher. Three IX columns with mixed beds of cation and anion resins remove the remaining dissolved solids from the waste water. In normal operation, two of the three IX columns are used in series for dissolved solids removal, and the third IX column is isolated from the treatment line for regeneration.

2.1.2.10 Effluent $\mathrm{pH}$ Adjustment Tank. The waste water $\mathrm{pH}$ is adjusted for the final time within the range of 6.5 to 8.5 .

2.1.2.11 Vorffication Tanks. The treated waste water is held in the verification tanks whlle a sample is analyzed to ascertain that discharge limits have been achleved. The waste water sample is taken between the final $\mathrm{pH}$ adjustment tank and the verification tanks. The treated waste water is pumped back into the treatment train for additional treatment if the analysis shows that the water exceeds the state waste discharge permit limits.

of the three verification tanks, one tank receives the waste water from the $\mathrm{pH}$ adjustment tank, one tank is used for verffying that treatment 1 imits have been met, and one tank feeds the treated waste water that has been approved for discharge to the SALDS. Each tank has a capacity of 670,000 gallons $(2,536,218$ liters), which represents 72 hours of operational flow at 150 gallons (568 itters) per minute.

Some treated waste water from the verification tanks is used within various systems in the ETF to minimize the addition of fresh water.

\subsubsection{Secondary Treatment Train}

The purpose of the secondary treatment train is to process waste (e.g., primarily inorganic compounds and radionuclides) removed from the waste water in the primary treatment train. The secondary treatment train consists of the components described in the following sections.

2.1.3.1 Secondary Waste Receiving Tank. Liquid waste removed froin the waste water in the primary treatment train is collected in two secondary waste receiving tanks. The main sources of secondary waste are the backwash from the rough and fine filters, the reject stream from the first $R O$ stage, and regeneration waste from the polisher. During the feed mode, a sample is taken from the recirculation line to ensure that the concentration factor for the ETF evaporator is appropriate.

2.1.3.2 Effluent Treatment Facility Evaporator. The ETF evaporator concentrates, by evaporation, the waste in preparation for drying. This evaporator system was selected to reduce energy consumption. 
2.1.3.3 Concentrate Tank. The concentrate generated by the ETF evaporator is a) ternately discharged to one of two concentrate tanks. One tank receives the concentrate from the ETF evaporator while the other tank feeds material to the thin film dryer.

A sample of the liquid is taken from the concentrate tank to characterize the waste before it is dried. Analys is of the liquid provides a conservative and complete characterization of the powdered waste. Worker exposure and contamination are minimized by avoiding handling the powdered waste.

2.1.3.4 Thin Film Dryer. The purpose of the thin film dryer system is to dry the concentrated waste to a powder and then drop the powder into 55-gallon (208-1iter) lined containers for short-term storage before transfer to a TSD unit.

2.1.3.5 Container Handling System. Empty 55-gallon (208-1iter) containers with liners and lids are positioned under the dryer powder hopper and filled. The container is filled to a predetermined weight and then capped.

2.1.3.6 Filled Container Storage. The storage area meeis secondary containment requirements for storing dry and liquid mixed waste. Containers are stored temporarily until transported for long-term storage or disposal.

\subsubsection{Supporting Systems}

The supporting systems for the ETF consist of the chemical reagent feed system, sump tank system, vessel offgas system, and utilities.

2.1.4.1 Chemical Reagent Feed System. The chemical reagent feed system provides solutions of 92 weight percent and 4 weight percent sulfuric acid and 50 weight percent and 4 weight percent sodium hydroxide to various points in the treatment process.

The 92 weight percent sulfuric acid and 50 weight percent sodium hydroxide are delivered by trucks to the ETF. These chemicals are stored in the 92 weight percent sulfuric acid storage tank and the 50 weight percent sodium hydroxide storage tank located outside, on the south side of the ETF Building.

The 92 weight percent sulfuric acid and the 50 weight percent sodium hydroxide are pumped directly to the surge tank.

In the dilute chemical storage tanks, 92 weight percent sulfuric acid and 50 weight percent sodium hydroxide are diluted by treated waste water from the verification tanks to produce 4 weight percent solutions in each tank. The acid and base solutions are distributed to the $\mathrm{pH}$ adjustment tank, effluent $\mathrm{pH}$ adjustment tank, secondary waste receiving tanks, concentrate tanks, and for regeneration of the polisher by dedicated pumps. 
2.1.4.2 Sump Tank System. Overflow, pressure valve release, and spilled waste are collected in two sump tanks. Collected Ilcidids are transferred to the surge tank.

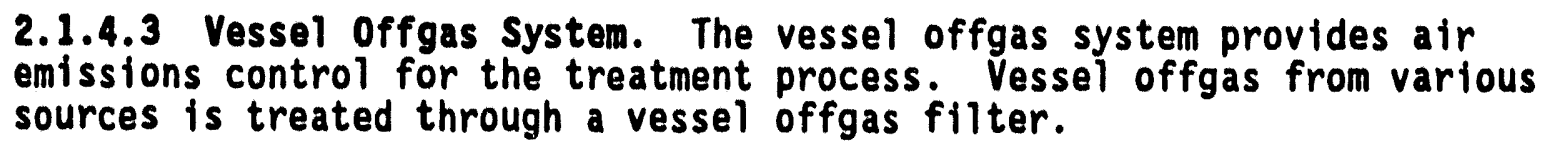
emissions control for the treatment process. Vessel offgas from various sources is treated through a vessel offgas filter.

2.1.4.4 Utilities. The ETF is supplied with the following utility systems: raw water, cooling water, steam, compressed air, seal water for pumps, and demineralized water.

\subsection{TOPOGRAPHIC MAPS [B-2]}

A topographic map (H-13-000081), showing a distance of at least 1,000 feet ( 305 meters) around the ETF, is provided in Appendix 2A. This map is drawn at a scale of 1 inch equals 180 feet (1 centimeter equals 20 meters). The contour interval ( 1.6 feet or 0.5 meter) clearly shows the pattern of surface water flow in the vicinity of the ETF. The map contains the following information:

- Map scale

- Date

- Prevailing wind speed and direction

- A north arrow

- Surrounding land use

- Access road location

- Access control.

\subsection{LOCATION INFORMATION [B-3]}

This section describes the location of the ETF in relation to seismic, floodplain, and shoreline considerations.

\subsubsection{Seismic Consideration [B-3a]}

The ETF is located in Zone 2B as identified in the Uniform Building Code (ICBO 1991). The ETF was designed in accordance with the regulations of Section 2312 of the Uniform Building Code (ICBO 1991) for earthquake Zone 2. The design of the ETF for seismic considerations is in accordance with the Hanford Plant Standards, Standard Design Criteria - 4.1 (DOE-RL 1988a). This plant standard provides seismic load criteria specific for the Hanford Site and is more restrictive than the Uniform Building Code.

No active faults, or evidence of a fault that has had displacement during Holocene times, have been found at the Hanford Site (DOE 1988; WHC 1991). The youngest faults recognized at the Hanford Site occur on Gable Mountain, 51 approximately 1 air-mile (1.6 kilometers) north of the 200 East Area [well 
over 500 feet (152 meters) from the ETF]. These faults are of Quaternary age and are considered 'capable' by the Nuclear Regulatory Commission (NRC 1982).

\subsubsection{Floodplain Standard [B-3b]}

Three sources of potential flooding of the ETF were considered: (1) the Columbia River, (2) the Yakima River, and (3) storm-induced run-off in ephemeral streams draining the Hanford Facility. No perennial streams occur in the central part of the Hanford Facility.

The Federal Emergency Management Agency has not prepared floodplain maps for the Columbia River through the Hanford Site. The flow of the Columbia River largely is controlled by several upstream dams that are designed to reduce major flood flows. Based on a U.S. Army Corps of Engineers study of the flooding potential of the Columbia River that considered historic data and water storage capacity of the dams on the Columbia River (COE 1969), the U.S. Department of Energy (ERDA 1976) has estimated the probable maximum flood (Figure 2-4). The estimated probable maximum flood would have a larger floodplain than either the 100- or 500-year flood. The ETF is well above the elevation of the Columbia River probable maximum flood and, therefore, is not within the 100- or 500-year floodplain.

The 100-year floodplain for the Yakima River, as determined by the Federal Emergency Management Agency (FEMA 1980), is shown in Figure 2-5. The ETF is not within this floodplain.

The only other potential source of flooding of the ETF is run-off from a large precipitation event in the Cold Creek watershed. This event could result in flooding of the ephemeral Cold Creek. Skaggs and Walters (1981) have estimated the probable maximum flood using conservative values of precipitation, infiltration, surface roughness, and topographic features. The resulting Cold Creek flood area (Figure 2-6) would not affect the ETF. The 100-year flood would be less than the probable maximum flood.

2.3.2.1 Demonstration of Compliance [B-3b(1)]. The ETF is not located within a 100-year floodplain. Therefore, no demonstration of compliance is required.

2.3.2.1.1 Flood Proofing and Flood Protection Measures [B-3b(1)(a)]. The ETF is not located within a 100-year floodplain. Therefore, no demonstration of compliance is required.

2.3.2.1.2 Flood Plain $[B-3 b(1)(b)]$. The ETF is not located within a 100-year floodplain. Therefore, no demonstration of compliance is required.

2.3.2.2 Plan for Future Compliance with Floodplain Standard [B-3b(2)]. The ETF is not located within a 100-year floodplain. Therefore, no demonstration of compliance is required. 


\subsubsection{Shorel ine Standard [B-3C]}

The ETF is not located within regulated 'shorelines of the state' or 'wetlands' as defined in the Shoreline Management Act of 1971. The ETF is located on the Hanford Facility, which is owned by the U.S. Government and operated by the DOE-RL. The Hanford Site is not classified as natural, conservancy, rural, or residential.

\subsubsection{Sole Source Aquifer Criteria [B-3d]}

The ETF is not located over a 'sole-source' aquifer as defined by Section 1424(e) of the Safe Drinking Water Act of 1974. Therefore, no demonstration of compliance is required.

\subsection{TRAFFIC INFORMATION [B-4]}

The regional highway network traversing the Hanford Site (Washington State Highways 24 and 240), nonrestricted access roadways (Route 10 and portions of Route 4S located south of the Wye Barricade), and the restricted access roadways are shown in Figure 2-7.

Roadways on the Hanford Site east of the Yakima Barricade and north of the Wye Barricade, and within the 300 and 400 Areas, are restricted to authorized personnel only. Other U.S. Department of Energy roadways are subject to such restrictions or closure as the U.S. Department of Energy might require. Estimated traffic volumes, in vehicles per day, are shown in Figure 2-7. The majority of traffic is passenger vehicles used for commuting and conducting company business. Approximately 10 percent of the traffic volume is trucks, and these trucks are mainly delivery, construction, and maintenance vehicles.

\subsubsection{Hanford Site Roadways}

Drawing H-6-958 in Appendix 2A and Figure 2-7 show the major roads through the Hanford Site. These roads are classified as either primary or secondary routes. The primary routes include Routes $4 \mathrm{~N}, 4 S, 10,2 \mathrm{~N}, 3,6$, and $11 \mathrm{~A}$, as well as various avenues within each area. The primary routes are constructed of bituminous asphalt [usually 2 inches (5.08 centimeters) thick, but the thickness of the asphalt layer will vary with each road] with an underlying aggregate base in accordance with U.S. Department of Transportation requirements. The secondary routes are constructed of layers of an oil and rock mixture with an underlying aggregate base. The aggregate base consists of various types and sizes of rock found onsite. Currently, no load-bearing capacities of these roads are available; however, loads as large as 140 pounds per square inch (9.87 kilograms per square centimeter) have been transported without observable damage to road surfaces. All roads meet the requirements for the American Association of State Highway and Transportation Officials HS-20-44 load rating (AASHTO 1983). An HS-20-44 loading represents 
a two-axle tractor [front axle loading of 8,000 pounds $(3,633$ kilograms) and rear axle loading of 32,000 pounds $(14,535$ kilograms $)]$ plus a single-axle trailer with a 32,000-pound (14,535-kilogram) axle loading.

\subsubsection{Traffic Control Signs, Signals, and Procedures}

Standard traffic control signs are used throughout the Hanford Site (e.g., hexagonal stop signs, triangular yield signs). Speed limits are posted throughout the Hanford Site, and the maximum posted speed is 55 miles (88 kilometers) per hour on major thoroughfares. Inside the various areas, posted speeds are reduced to a maximum of 35 miles (56 kilometers) per hour and held to speeds as low as 15 miles ( 24 kilometers) per hour.

\subsubsection{Transfer of Maste}

Waste from the 242-A Evaporator and the LERF is transferred to the ETF via pipelines. Dangerous and mixed waste generated by the ETF, including powdered waste, dewatered spent resin, and maintenance waste (such as spent filter media, RO membranes, and UV lamps) is placed in containers and transported to a TSD unit.

The transport of dangerous and/or mixed waste is performed in accordance with applicable onsite shipping requirements. Although onsite waste transfers are exempt from the manifest requirements of WAC 173-303-370, onsite waste tracking is applied as a matter of good management practice. These onsite shipping requirements are designed to ensure that personnel exposures are maintained ALARA, that loss of contamination control is prevented, and that applicable transportation regulations are obeyed. Information on the transport of dangerous and/or mixed waste is provided for general knowledge.

\subsection{PERforMance StandardS [B-5]}

The ETF is designed to minimize the exposure of personnel to dangerous waste and hazardous substances and to prevent dangerous waste and hazardous substances from reaching the environment. In addition, measures are taken to ensure that the ETF is maintained and operated in a manner that prevents the following:

- Degradation of groundwater quality

- Degradation of air quality

- Degradation of surface water quality

- Destruction or impairment of flora or fauna outside of the ETF

- Excessive noise 
DOE/RL-93-03, Rev. 0

$08 / 31 / 93$

- Negative aesthetic impacts

- Unstable hillsides or soils

- Use of processes that do not treat, detoxify, recycle, reclaim, and recover waste material to the extent economically feasible

- Endangerment to the health of employees or the public near the ETF.

The measures taken to prevent each of the negative effects from occurring are described in the following sections.

\subsubsection{Measures to Prevent Degradation of Groundwater Quality}

The ETF is designed to prevent significant degradation of groundwater quality. Degradation of groundwater quality is prevented primarily through tank and ancillary equipment secondary containment, with leak detection between the primary and secondary containment systems. The secondary containment and other pertinent systems designed to prevent releases to groundwater are described in detail in Chapter 4.0.

\subsubsection{Measures to Prevent Degradation of Air quality by Open Burning or Other Activities}

No open burning occurs at the ETF. The arid climate 1 imits vegetation within the boundaries of the Hanford Site. The vegetation is removed routinely so that almost no potential exists for accidental open burning. Transfer 1 ines are underground and would not be impacted by accidental open burning. Ventilation systems (described in Chapter 4.0) control air emissions from the tanks and ancillary equipment. Control of air emissions regulated by RCRA are discussed in Chapter 4.0. Appropriate air permit applications have been submitted for monitoring and controlling air emissions.

\subsubsection{Measures to Prevent Degradation of Surface Mater Quality}

The ETF prevents degradation of surface water by not discharging dangerous waste to the environment, and by the use of secondary containment of tanks and ancillary equipment. Measures to prevent releases to the environment are discussed in detall in Chapter 4.0. There is no surface water in proximity to the ETF; the nearest surface water (the Columbia River) is approximately 6 air miles from the ETF.

\subsubsection{Measures to Prevent Degradation of or Impairment of Flora and Fauna Outside the Unit}

The existing areas used for mixed and dangerous waste management at the Hanford Facility already have undergone some environmental modification, and the additional impact on plants and wildlife from ETF operations is minimal 
(DOE 1987). Plant and animal communities have undergone temporary disruption during construction phases, but operation of the ETF does not result in any significant impact to plant and wildlife communities or to their habitats.

The security fences in the 200 Areas serve as a barrier to large land animals and, therefore, 1 imit these animals from accessing the ETF operations.

\subsubsection{Measures to Prevent Excessive Noise}

Nearly all operations are located within the ETF, thus preventing excessive noise to the surrounding environment. The only noise to the outside environment is that of heating, ventilation, and air conditioning blowers and occasional pump noises, typical for a building of this size in an industrial setting. There are no nearby residential and industrial areas (Figure 2-1) that could be disturbed by noise.

\subsubsection{Measures to Prevent Negative Aesthetic Impact}

The ETF was constructed to prevent negative aesthetic impact. The design of the ETF provides for an orderly arrangement of load-in and load-out areas. Areas affected by construction were stabilized with gravel to prevent soil erosion. The ETF and all exterior operations are painted or constructed with noncorrosive materials.

\subsubsection{Measures to Prevent Unstable Hillsides or Solls}

There are no naturally unstable hillsides or solls near the ETF. The climate is arid to semiarid as a result of being in the rain shadow of the Cascade Mountain Range. The Hanford Site is blanketed by a thin veneer of wind-blown sediments. Vegetation on the ETF site consists of sagebrush and other common central Washington desert plant species. The soil is classified as sandy gravel with excellent drainage characteristics. Water erosion on the plateau is minor because of the minimal precipitation, high soll porosity, and relatively flat topography.

\subsubsection{Measures to Prevent the Use of Processes that Do Not Treat, Detoxify, Recycle, Reclaim, and Recover Waste Materials to the Extent Economically Feasible}

The ETF treats, detoxifies, recycles, and reclaims waste materials to the extent economically feasible. A detailed description of the ETF process is provided in Chapter 4.0 . 


\subsubsection{Measures to Prevent Endangerment to the Health of Employees or the Public Near the Unit}

Human health and the environment are protected primarily by the use of double containment, the isolation of the ETF, and the distance groundwater must travel to reach drinking water supplies. Employee and public protection are enhanced further by administrative measures, i.e., fences, security.

The overall goal is to limit radiation and chemical exposure to ALARA. A combination of features was used in the design and is used in the operation of the ETF to ensure stringent confinement of radioactive and dangerous materials. The principal preventive measures include the use of shielding, maximizing the distance from radiation sources, restricting the time of occupancy in radiation zones, and using protective clothing. Employee training includes dangerous materials and waste awareness, emergency response, and workplace safety (Chapter 8.0). Protective equipment, safety data, and hazardous materials information are readily available for employee use.

A building emergency plan is implemented for spill prevention, containment, and countermeasures to reduce safety and health hazards to humans and the environment (Chapter 7.0).

\subsection{BUFFER MONITORING ZONE [B-6]}

The ETF does not store ignitable or reactive waste in tanks. Therefore, the requirements of WAC $173-303-640(9)(b)$ do not apply to the ETF.

\subsection{SPILLS AND DISCHARGES INTO THE ENVIRONMENT [B-7]}

Actions to be taken in the event of noncompliance with final status requirements that may endanger human health and the environment, including any incidence of noncompliance resulting from release or discharge of dangerous waste that could threaten human health and the environment outside the ETF, are documented in Chapter 7.0.

\subsubsection{Notification [B-7a]}

Reporting of any noncompliance with final status requirements that might endanger human health and the environment will be made to Ecology in accordance with the immediate reporting provisions of WAC 173-303-810(14)(f) and includes any information on the following:

- Release of dangerous waste that may cause an endangerment to drinking water supplies or ground or surface waters

- Any information of a release or discharge of dangerous waste, a fire, or an explosion that could threaten the human health and the environment outside the Hanford Facility 
- Name, address, and telephone number(s) of the owner or operator

- Date, time, and type of incident

- Name and quantity of material(s) involved

- The extent of injuries if any

- An assessment of actual or potential hazards to the environment and human health outside the Hanford Facility, where this is applicable

- The estimated quantity and disposition of recovered material that resulted from the incident.

In addition, an oral report and written submission or written report that contains a description of the noncompliance and its cause; the period of noncompliance, including exact dates and times, and if the noncompliance has not been corrected, the anticipated time it is expected to continue; and steps taken or planned to reduce, el iminate, and prevent reoccurrence of the noncompliance will be submitted in accordance with the provision of WAC $173-303-810(14)(f)$.

\subsubsection{Mitigation and Control [B7-b)}

Releases or discharges of dangerous waste that endanger human health or the environment will be dispositioned in accordance with the applicable provisions of Chapter 7.0 and the applicable provisions of WAC 173-303-600.

\subsubsection{Cleanup and Management of Released Dangerous Wastes and Contaminated} Soil, Nater, or Other Materials [B7-b(1) and (2)]. Provisions for dispositioning of recovered material resulting from an incident that endangers human health and the environment will be in accordance with the applicable provisions of Chapter 7.0 and the applicable provisions of WAC 173-303-600.

2.7.2.2 Restoration of Impacted Area [B7-b(3)]. Restoration of property outside the ETF that is impacted by releases or discharges of dangerous waste, a fire, or an explosion will be accomplished in accordance with the applicable provisions of WAC $173-303-600$.

\subsection{MANIFEST SYSTEM [B-8]}

Onsite waste transfers are exempt from the manifest requirements of WAC 173-303-370. However, onsite waste tracking is applied as a matter of good management practice at the Hanford Facility. This section briefly discusses the system that is in place to track waste shipments. 


\subsubsection{Onsite Waste Shipments}

The Hanford Facility has one EPA/State identification number as required by WAC 173-303-060, and all TSD units on the Hanford Facility are part of a single dangerous waste facility. Therefore, onsite shipments of dangerous or mixed waste are not subject to the manifesting requirements specified in WAC 173-303-370 and -180. However, all onsite waste shipments are conducted in a manner to ensure protection of human health and the environment. Four onsite waste tracking systems are voluntarily used for transporting waste on the Hanford Facility. Internal tracking systems document the following four methods of waste transfer:

- Liquid mixed waste via underground pipelines

- Liquid mixed waste via rallroad tank car or tank truck or via barrels transported by truck

- Containerized mixed waste (e.g., rags, failed equipment, contaminated soil) via trucks and railroad cars

- Containerized nonradioactive dangerous waste via truck before being shipped offsite for treatment, storage, and/or disposal at a TSD facility.

Specific waste tracking forms for the movement of waste destined for the ETF are used. These waste tracking forms effectively track chemical inventories from procurement through disposal at the ETF. Waste water from the 242-A Evaporator and the LERF treated at the ETF is transferred via pipelines. No incompatible waste is processed by the ETF.

\subsubsection{Procedures for Receiving Shipments [B-8a]}

The onsite generating unit is responsible for accurately identifying waste composition and arranging for the transport of the waste. A file of the original copy of each transfer data sheet and any other pertinent operating records are maintained by the ETF.

\subsubsection{Transporter Responsibilities. The 242-A Evaporator operations} organization is responsible for transferring waste from the 242-A Evaporator to the LERF and to the ETF. The ETF operations organization is responsible for transferring waste (by pumping) from the LERF to the ETF.

The following are the specific transporter responsibilities:

- Ensuring that the shipments of waste are accompanied by a properly completed data sheet

- Dating and signing the data sheet and obtaining the receiving unit operator's signature

- Maintaining a file of the data sheets 
- Ensuring that the entire quantity of waste is delivered to the receiving unit

- Ensuring leak detection.

2.8.2.2 Receiving Unit Responsibilities. The waste tracking methods used are as follows.

- The ETF personnel sign and date the data sheet for waste pumped from the 242-A Evaporator and the LERF, and for waste that falls within the envelope of acceptable waste (Chapter 3.0).

- Significant discrepancies (Section 2.8.3) in the data sheet are noted on each copy of the data sheet. The material balance calculation shown on the data sheet verifies that the volume of dangerous waste covered by the data sheet was received. A discrepancy exists when there is a significant volumetric difference between the amount of waste sent and the amount received that cannot be explained by the volume held within the process equipment.

- The waste transporter retains at least one copy of the signed data sheet.

\subsubsection{Response to Significant Discrepancies [B-8b]}

The waste tracking methods are as follows for waste transfer discrepancies.

- Discrepancies in the quantity of dangerous waste received are determined using material balances required on the data sheet. A material balance is the difference between the volume of waste taken from the 242-A Evaporator, the LERF, or other waste within an envelope acceptable to the ETF (Chapter 3.0), and the volume of waste introduced to the ETF. The volume of waste sent to the ETF is measured by flowmeters as explained in Chapter 4.0. A significant discrepancy will be a volumetric difference between the amount of waste sent and the amount received that cannot be explained by the volume held within the process equipment or by expansion/contraction explanations.

- Actions taken to deal with significant discrepancies are as follows. - Leak detectors, interlocks, and alarms are checked to ensure that the equipment functions properly.

- Transfer records are checked and examined.

- Other tanks in the system are checked for an incorrectly routed transfer. 
DOE/RL-93-03, Rev. 0

$08 / 31 / 93$

\footnotetext{
1 2.8.4 Provistons for Nonacceptance of Shipment [B-8c]

2

Provisions for nonacceptance of shipments are discussed in the following sections.

2.8.4.1 Nonacceptance of Undamaged Shipment $[B-8 c(1)]$. If the waste is not suitable for treatment in the ETF, the waste is not transferred to the ETF.

2.8.4.2 Activation of Contingency Plan for Damaged Shipment [B-8C(2)]. This section is not applicable. Damaged shipments are not possible in pipeline transfers. The butlding emergency plan would be activated if some fallure of the transfer system were detected (Chapter 7.0).
} 


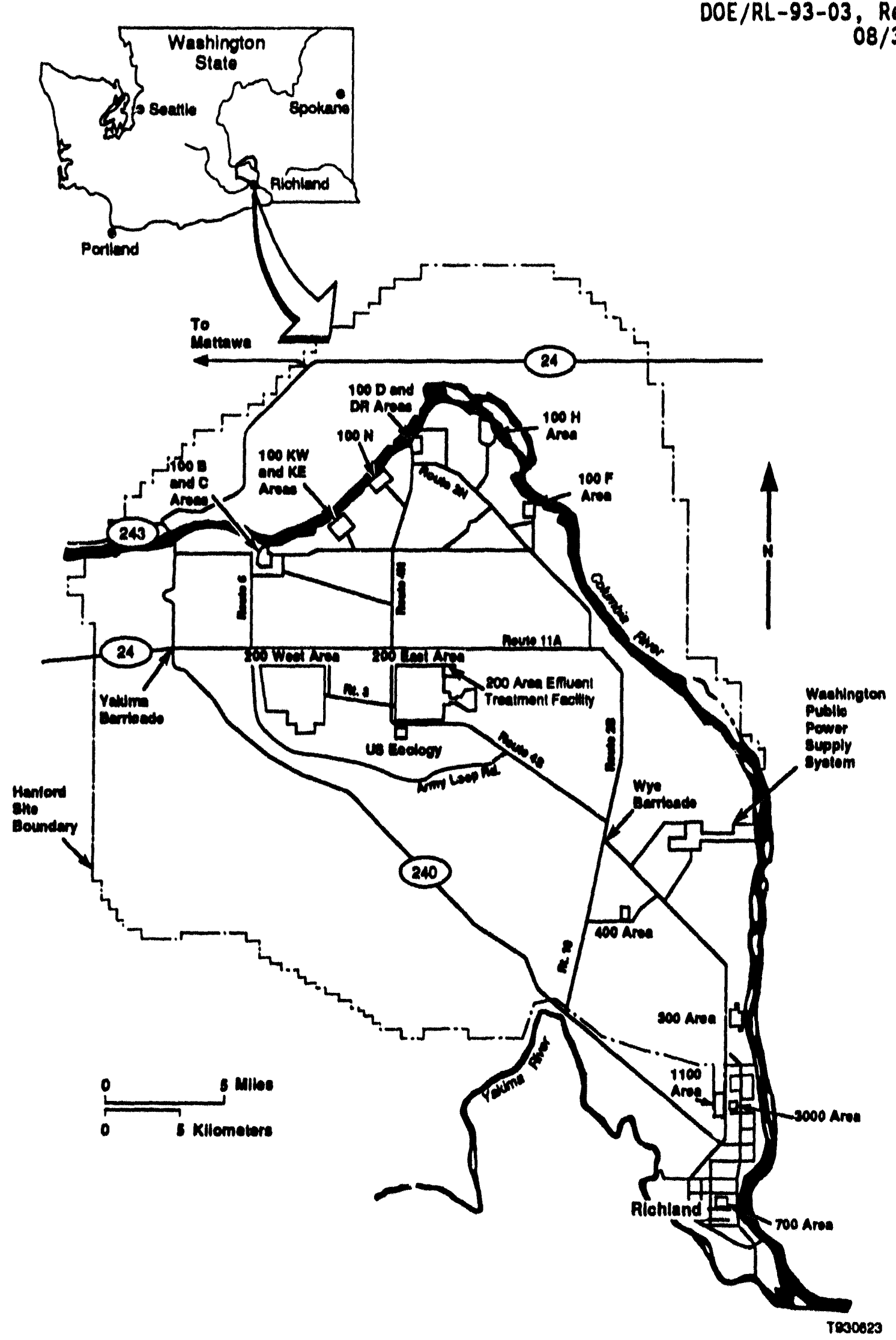

Figure 2-1. Hanford Site. 
DOE/RL-93-03, Rev. 0 $08 / 31 / 93$

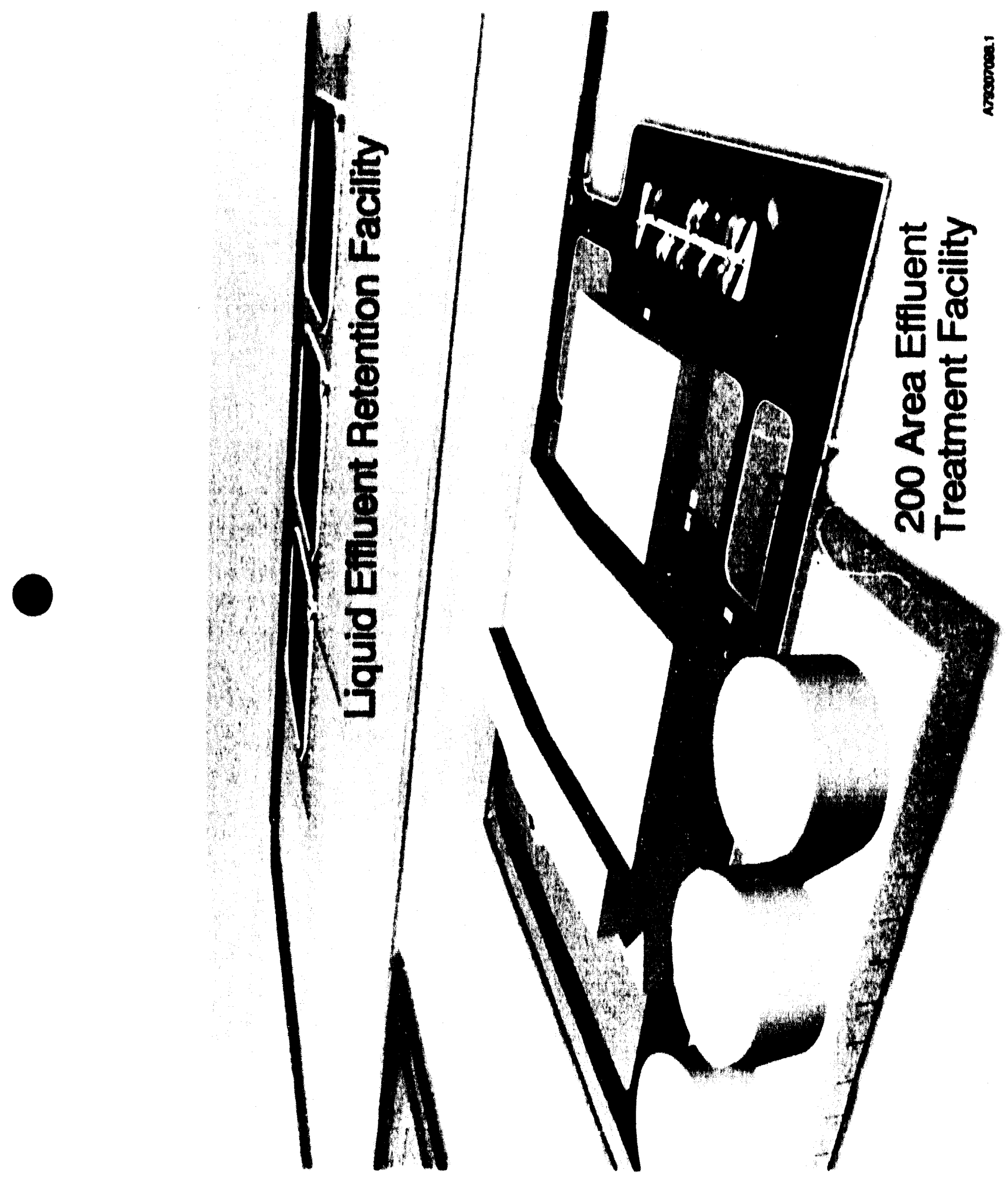

Figure 2-2. 200 Area Effluent Treatment Fac1lity Layout. 


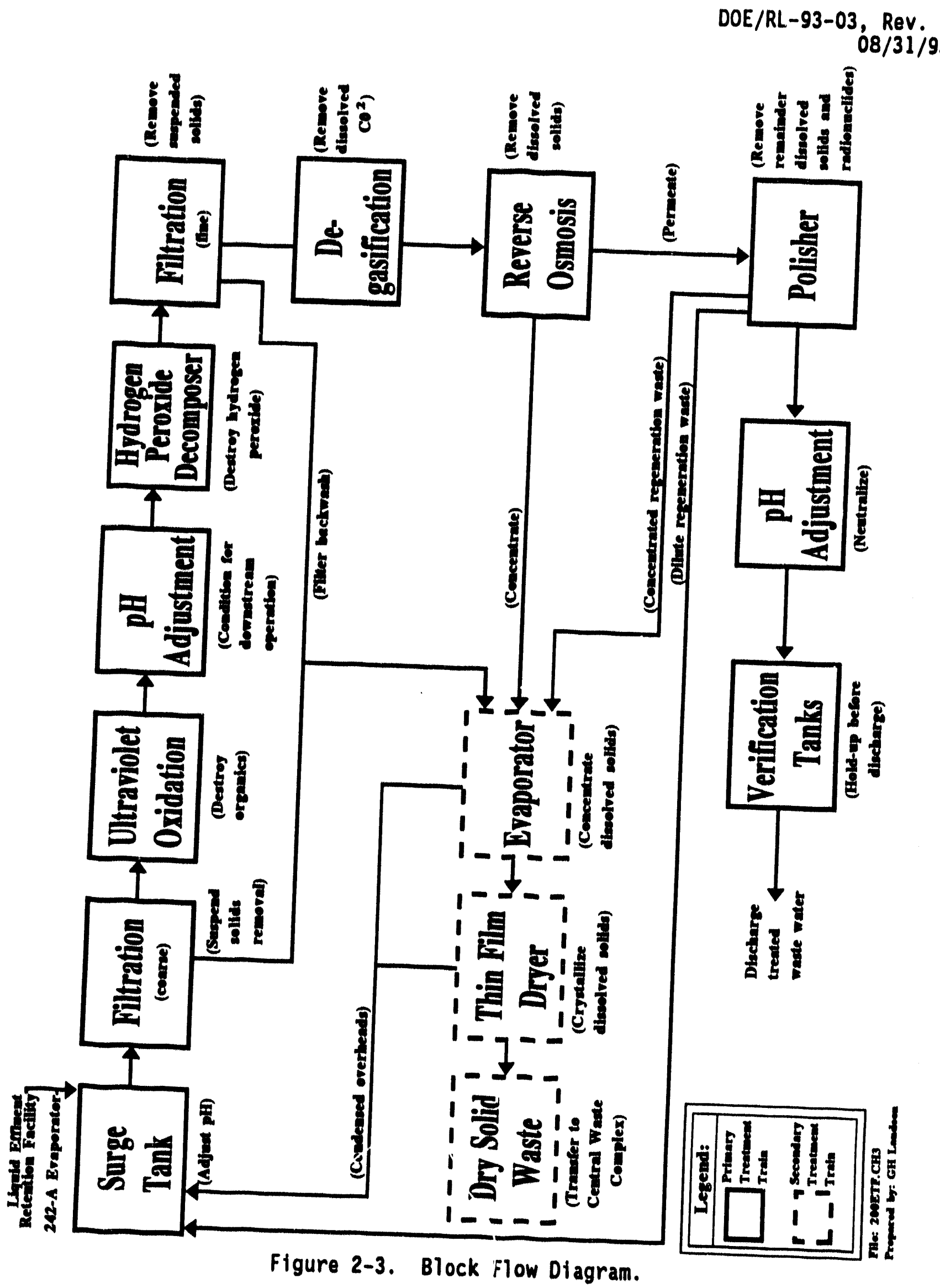


DOE/RL-93-03, Rev. 0 $08 / 31 / 93$

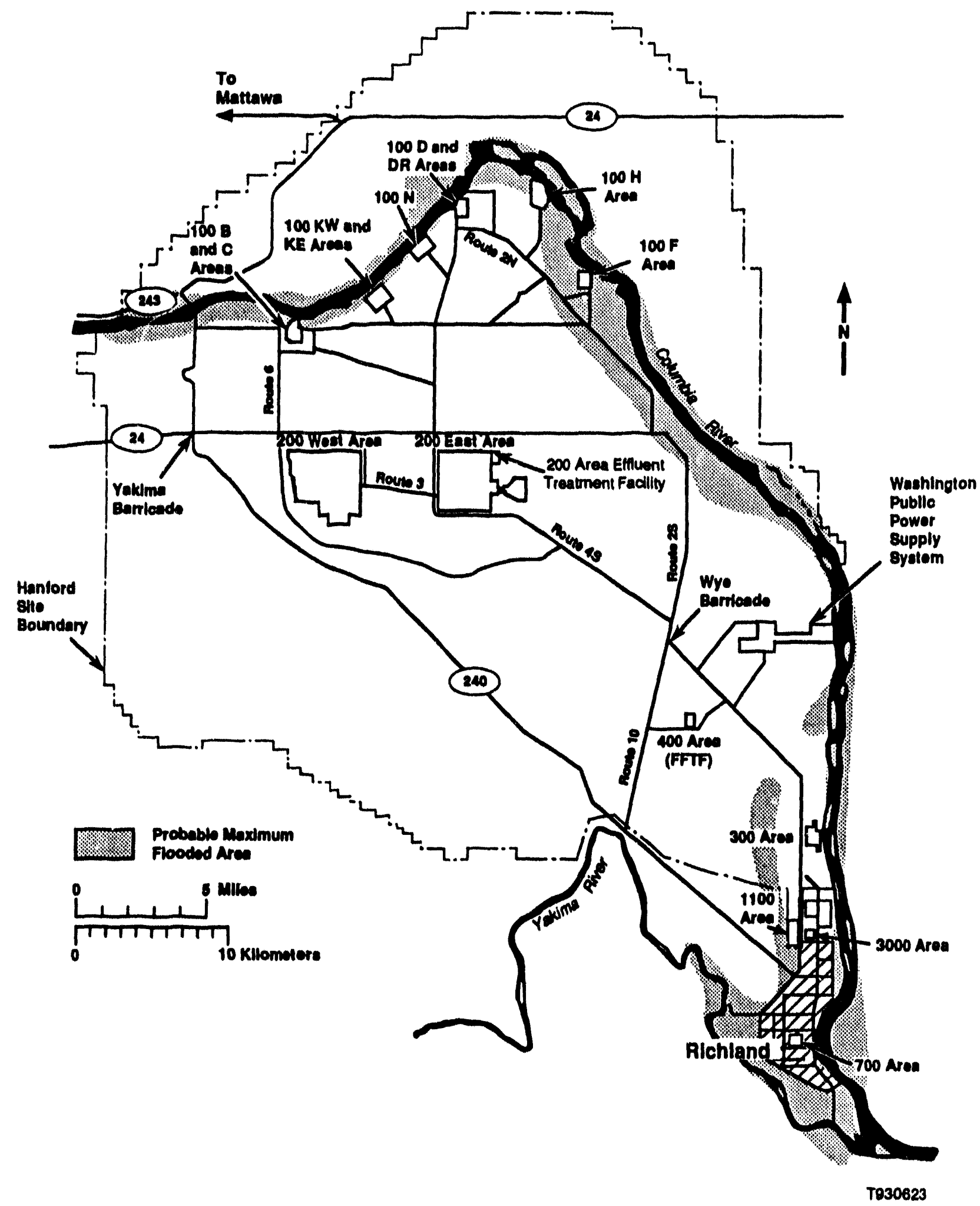

Figure 2-4. Columbia River Floodplain (probable maximum flood). 
DOE/RL-93-03, Rev. 0

$08 / 31 / 93$

T030623

Figure 2-5. Yakima River Floodplain. 
DOE/RL-93-03, Rev. 0

$08 / 31 / 93$

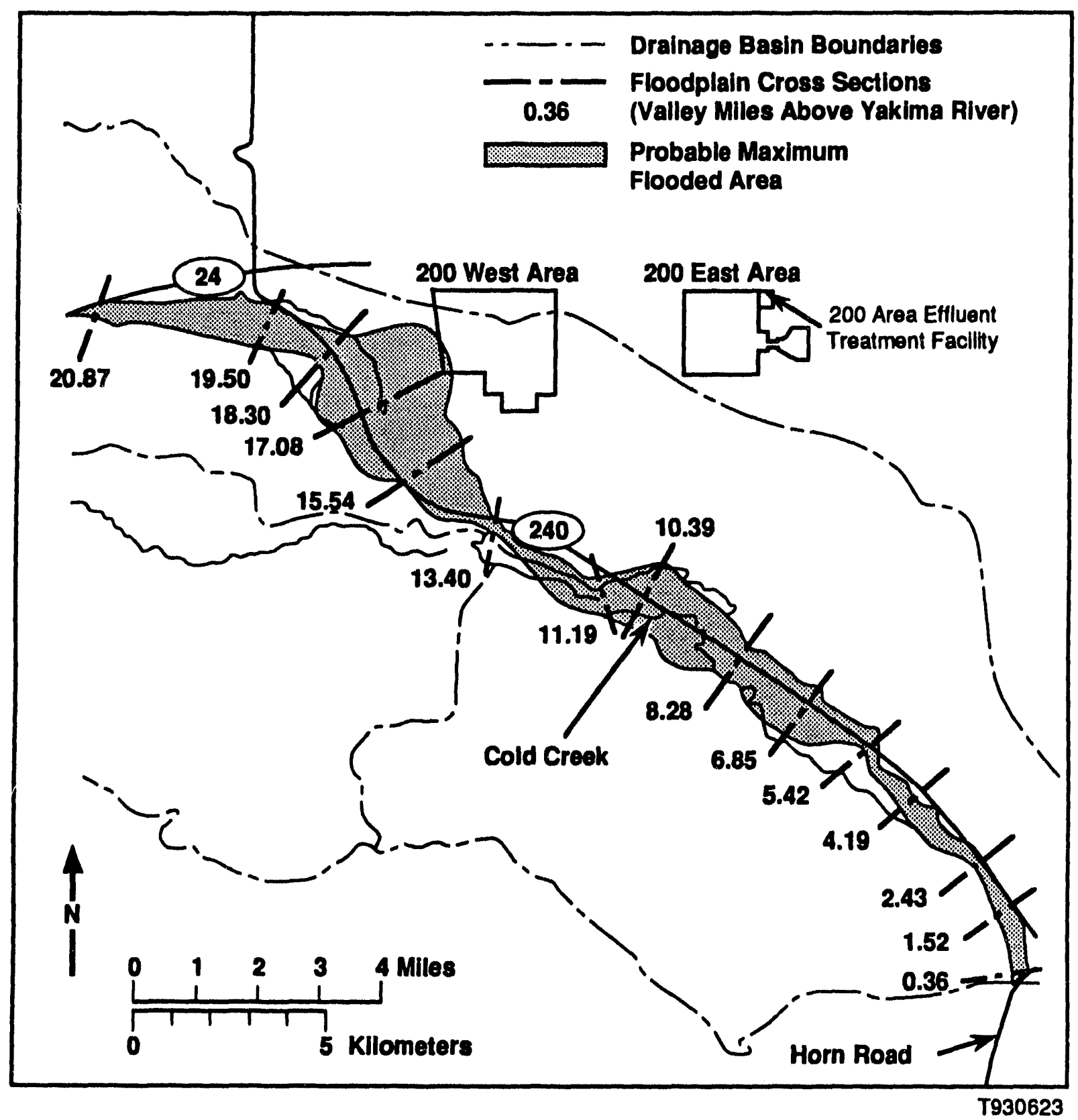

1 Figure 2-6. Cold Creek Watershed Floodplain (probable maximum flood). 


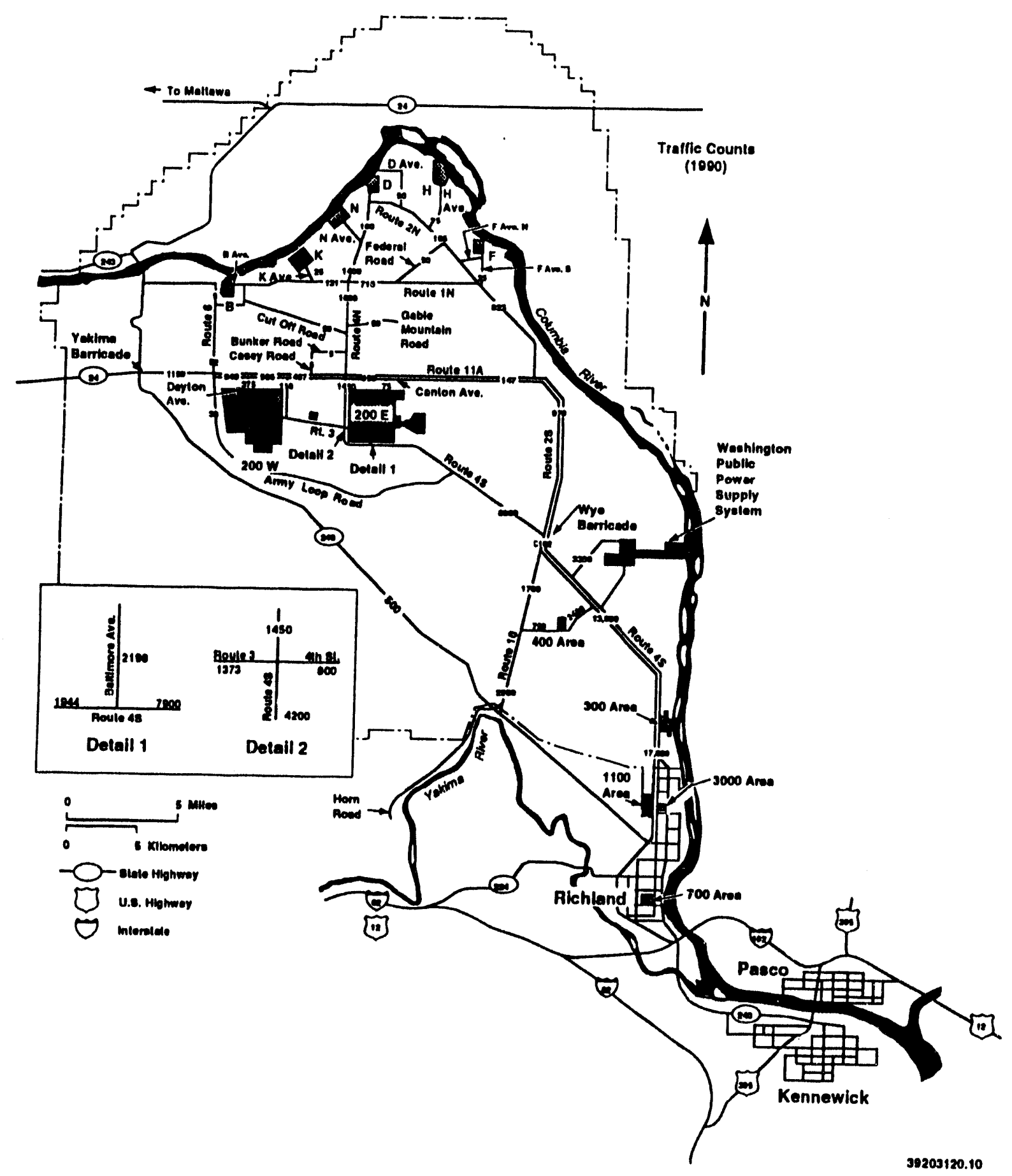

Figure 2-7. Estimated Traffic Volumes (vehicles per day). 
3.0 WASTE CHARACTERISTICS [C] ................

3.1 CHEMICAL, BIOLOGICAL, AND PHYSICAL ANALYSIS [C-1] . . . . 3-1 3.1.1 200 Area Effiuent Treatment Facility Treatment and Verification Tank Storage ............ 3-1

3.1.2 Secondary Waste Storage Area $\therefore . \ldots 3-2$

3.1.3 Containerized Waste $[\mathrm{C}-1 \mathrm{a}] \ldots \ldots$. ..................

3.1.4 Waste in Tank Systems $[\mathrm{C}-1 \mathrm{~b}] \ldots \ldots$ 3-2 3.1.4.1 242-A Evaporator Process Condensate ... 3-. 3-2 3.1.4.2 Process Condensate Waste Analysis ..... 3-3

3.1.4.3 Waste Characterization .......... 3-3

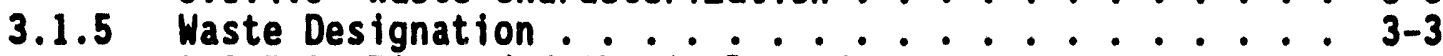

3.1.5.1 Discarded Chemical Products ....... 3-4

3.1.5.2 Dangerous Waste Sources ......... 3-4

3.1.5.3 Infectious Dangerous Waste . . . . . 3-6

3.1.5.4 Dangerous Waste Mixtures ........ 3-6

3.1.5.5 Dangerous Waste Characteristics . . . . 3-7

3.1 .6 Occasional Waste ............. 3-9

3.1.7 Waste in Piles [C-ic] . . . . . . . . . . 3-9

3.1 .8 Landfilled Waste $[C-1 d] \ldots 3-9$

3.1.9 Waste Incinerated and Waste Used in Performance

Tests $[C-1 e] \ldots 3-9$

3.1.10 Waste to be Land Treated [C-if] $\ldots 3-9$

3.1.11 Envelope of Waste Characteristics Allowed as Feed to the 200 Area Effluent Treatment Facility ... . . 3-9

3.1.12 Delisting of Treated Waste Water ........ 3-10

3.2 WASTE ANALYSIS PLAN [C-2] ............. 3-10 3.2.1 Parameters and Rationale $[\mathrm{C}-2 \mathrm{C}] \ldots \ldots$. . . . . . 3-11

3.2.2 Test Methods [C-2b] ................ 3-11

3.2.3 Sampling Methods [c-2c] ................

3.2.4 Frequency of Analysis [C-2d] ...............

3.2.5 Liquid Effluent Discharge Limits ........ 3-11

3.2.6 Quality Assurance Program ............ 3-12

3.3 ADDITIONAL REQUIREMENTS FOR WASTE GENERATED OFFSITE [C-2e] • 3-12

3.4 ADDITIONAL REQUIREMENTS FOR IGNITABLE, REACTIVE, OR INCOMPATIBLE WASTE $[\mathrm{C}-2 \mathrm{f}] \ldots \ldots$ 3-12

3.5 LAND DISPOSAL RESTRICTIONS . . . . . . . . . . 3-12

$3 A$ WASTE ANALYSIS PLAN .......................... $3 A-i$ 
DOE/RL-93-03, Rev. 0

This page intentionally left blank. 


\subsection{WASTE CHARACTERISTICS [C]}

This chapter provides information on the chemical, biological, and physical characteristics of the waste to be treated and stored at the ETF including waste descriptions, designations, and a waste analysis plan for treatment and storage.

\subsection{CHEMICAL, BIOLOGICAL, AND PHYSICAL ANALYSIS [C-1]}

This section describes the chemical, biological, and physical characteristics of the waste treated and stored at the ETF. This discussion includes the following:

- A description of the waste types, including an estimate of the chemical and physical composition

- A description of the characteristics of the dangerous waste and a basis for the designation of the waste as dangerous.

Additional information on sampling methods is provided in the ETF waste analysis plan (Appendix 3A).

\subsubsection{Area Effluent Treatment Facility Treatment and Verification Tank Storage}

The ETF treats waste water containing very small concentrations of volatile and nonvolatile substances. Volatile substances consist of organic compounds, ammonia, and radionuclides. Nonvolatile substances consist of organic compounds, inorganic salts, and radionuclides.

Waste acceptance criteria are based on laboratory tests performed on a neinradioactive, surrogate test solution; these tests are referred to as the pllot plant testing. The results of the pilot plant testing were used to develop an operating envelope. The operating envelope defines a waste water feed concentration range that allows for treatment of the waste water to concentrations that will be regulated by the Washington State waste discharge permit (WAC 173-216). The ETF is designed to treat waste within the operating envelope from sources other than the 242-A Evaporator.

The feed material for the pilot plant testing consisted of several surrogate test solutions that were formulated from PC characterization data, Hanford Site chemical inventory, and constituents of regulatory concern. Surrogate test solutions were used because the 242-A Evaporator stopped operation in 1989. The LERF was constructed for the proper storage of the waste water until the ETF was operational. The surrogate solution was tested using scaled-down versions of the treatment systems designed for the ETF, such as UV/OX, RO, and IX. 
Treated waste water from the ETF is stored in one of three 670,000-galion $(2,536,000-1 i t e r)$ verification tanks until sampling and analysis confirms permit conditions are met. Treated waste water from the ETF process is discharged to the soil coilumn, subject to approval of the Delisting Petition (DOE/RL-92-72) and receipt of the Washington State waste discharge permit (WAC 173-216). Treated waste water not meeting discharge standards is retreated through the ETF until the waste water meets discharge 1 imits, or stored in the verification tanks while other treatment or disposal options are determined. The ability to store dangerous waste in the verification tanks is necessary should the waste water need to be stored longer than 90 days.

\subsubsection{Secondary Waste Storage Area}

The ETF primary treatment train process generates a secondary liquid mixed waste. This liquid mixed waste is dried to a powder in the secondary treatment train, accumulated in U.S. Department of Transportation-approved containers, sealed for proper disposal, and stored within the storage area until transferred to a TSD unit. A description of the secondary waste is provided in Chapter 4.0.

\subsubsection{Containerized Waste [C-1a]}

The ETF incorporates a secondary containment system as described in Chapter 4.0. Therefore, the requirements of this section are not applicable to the ETF.

\subsubsection{Waste in Tank Systems [C-1b]}

A detailed description of the ETF verification tanks and associated processes is provided in Chapter 4.0. Information is summarized in this section to describe the origin of the waste water, the general characteristics of the waste water, and the general characteristics of the treated waste water.

\subsubsection{242-A Evaporator Process Condensate. The 242-A Evaporator treats} mixed waste stored as alkaline liquids and solids in underground DSTs located within the 200 East and 200 West Areas. Waste stored in the DST System and treated by the 242-A Evaporator includes the following:

- PUREX nonaging waste or low-level waste

- Plutonium Finishing Plant low-level processing waste supernate

- B Plant process and miscellaneous waste including cell drainage and vessel clean out waste

- 222-S Laboratory Complex laboratory and decontamination waste

- T Plant spent decontamination solutions 
- 300 Area laboratory waste

- 300 Area fuels fabrication waste (no longer generated)

- 400 Area laboratory waste

- 100-N dilute phosphate decontamination waste and 100 Area spent fuel storage basin sulfate waste from IX regeneration and sand filter backwashing (no longer generated)

- Single-shell tank salt well pumping waste.

Additional details on the waste streams and the bases for their designation as dangerous waste are presented in the Hanford Facility Dangerous Waste Permit Application, DST System documentation (DOE/RL-90-39). The 242-A Evaporator PC is generated from treatment of waste taken from the DST System.

3.1.4.2 Process Condensate Maste Analysis. As identified in Section 3.1.4.1, different types of waste feed are treated in the 242-A Evaporator. The analytical data represent 34 grab samples taken of the PC between August 1985 and March 1989 at four sampling locations. Ammonia, butyl alcohol, acetone, methyl ethyl ketone (2-butanone), and tetrahydrofuran were detected in over 20 of the 34 samples. The 242-A Evaporator PC stream-specific report (WHC 1990a) discusses the results in detail.

Raw water from the 200 East Area is used in the operation of the 242-A Evaporator and is a contributor to the 242-A Evaporator PC waste stream. The pump seal water and deentrainment components basically are raw water and are integral to the proper operation of the 242-A Evaporator. Comparison of the analytical data for all 34 242-A Evaporator $\mathrm{PC}$ samples with respect to raw water samples is presented in the stream-specific report (WHC 1990a). Evaluation of the data indicates 43 analytes (10 inorganic and 33 organic) were detected in the 242-A Evaporator PC that were not detected in the raw water.

3.1.4.3 Waste Characterization. The chemical composition of waste water that can be treated in the ETF is based on the results of pilot plant testing. Characterization of waste water proposed for treatment at the ETF is discussed in the waste analysis plan (Appendix $3 A$ ). The sampling and analysis of treated waste water and secondary waste, and the proper management of secondary waste also is discussed in the waste analysis plan (Appendix 3A).

\subsubsection{Waste Designation}

The ETF mixed waste is designated as toxic and listed mixed waste according to WAC 173-303-070. 


\subsubsection{Dangerous Waste Sources. The second category for waste designation} is comparison of the waste sources to the "Dangerous Waste Sources List" (WAC 173-303-9904). The 242-A Evaporator PC potentially contains 1isted waste sources with the following listed waste codes:

- F001 - Because of the presence of spent halogenated solvent $1,1,1$-trichloromethane

- F002 - Because of the presence of spent halogenated solvent methylene chloride

- F003 - Because of the presence of spent nonhalogenated solvents acetone, butyl alcohol, and methyl isobutyl ketone

- F004 - Because of the presence of spent nonhalogenated solvent cresylic acid

- F005 - Because of the presence of spent nonhalogenated solvent methyl ethyl ketone (2-butanone).

The waste was designated through evaluation of both process information and sampling data. Processes were revlewed and compared with the discarded chemical products 1 ist and the dangerous waste source 1 ist. The process evaluation included a review of the following information sources:

- Material safety data sheets

- Hanford Site emergency and hazardous chemical inventory report

- Operating procedures

- Process chemical inventories

- Physical inspections where possible. 
Sampling data were used as screening tools to enhance and support the results of the process evaluation. This screening was compared with the results of the sampling data against the waste lists contained in WAC 173-303-9903 and WAC 173-303-9904. If a constituent was cited on one or both of these lists, an engineering evaluation was performed to determine if the constituent had entered the waste stream as a discarded chemical product or as a dangerous waste source.

A procedure was developed for combining anton and cation data to identify possible inorganic compounds (Jungfleisch 1990). The listing of inorganic substances developed by this screening procedure is not intended to be de facto indication that the substance was discharged to the waste stream, only that the specific cations and anions are present. The right physical conditions must exist for a certain inorganic compound to be present; this screening procedure cannot predict such conditions. The designation is discussed in greater detail in the following sections. A further discussion of the PC designation is provided in Appendix 3B of the Hanford Facility Dangerous Waste Permit Application, 242-A Evaporator Dangerous Waste Permit Application documentation (DOE/RL-90-42).

3.1.5.2.1 1,1,1-Trichloromethane. 1,1,1-trichloromethane was used for crane decontamination and/or degreasing operations at B Plant and was determined to be a spent halogenated solvent discharged to the DST System. Consequently, the $\mathrm{PC}$ is an FOOl waste by applying the 'derived-from' rule [WAC $173-303-070(2)(a)]$.

3.1.5.2.2 Methylene Chloride. Methylene chloride was used for nonmechanical cleaning operations at $T$ Plant and was determined to be a spent halogenated solvent discharged to the DST System. Consequently, the PC is an F002 waste by applying the 'derived-from' rule [WAC 173-303-070(2)(a)].

3.1.5.2.3 Acetone. Acetone was used in laboratories to dry glassware and could have been disposed of through drains to the DST System. Acetone was detected in all 34 samples of 242-A Evaporator PC (WHC 1990a). The average concentration of acetone in these samples was 980 parts per billion. Acetone in the form of a discarded chemical product has not been discharged to the DST System. However, acetone as a spent nonhalogenated solvent was determined to be present in the DST System. Consequently, the PC is an F003 waste by applying the 'derived-from' rule [WAC 173-303-070(2)(a)].

3.1.5.2.4 Butyl Alcohol. Butyl alcohol is an impurity and degradation product from tributyl phosphate used in the PUREX Plant. Butyl alcohol was detected in 30 of the 34 samples at an average concentration of 9,800 parts per billion ( 9.8 parts per million). It is not known to be a discarded chemical product or a spent solvent.

3.1.2.5.5 Methyl Isobutyl Ketone. Methyl isobutyl ketone (hexone) was detected in 10 of the 34 samples at an average concentration of 11 parts per billion (WHC 1990a). Between 1951 and 1966, the Reduction-Oxidation Plant used a distillation process to clean hexone for reuse in the solvent extraction process. The hexone was first washed with sodium carbonate to remove the radiation-produced degradation products, and distilled to remove 
DOE/RL-93-03, Rev. 0

$08 / 31 / 93$

the water that had dissolved in it during washing. The water left behind was combined with the high-level waste stream for final steam stripping in the Reduction-0xidation Plant waste concentrator. This step recovered any hexone dissolved in the high-level waste stream or in water from the distillation process. After steam stripping, the concentrated high-level waste was sent to botling waste SSTs in the 241-S and 241-SX Tank Farms.

The high-level concentrate is considered a secondary waste from the hexone recovery process. The hexone recovery process was used to recover an F003 solvent. Hexone is not known to be a discarded chemical product. The content of the DSTs is a listed waste by applying the mixture rule [40 CFR 261.3(a)(2)(11i)]. Consequently, the PC is an F003 waste by applying the 'derived-from' rule [WAC 173-303-070(2)(a)].

3.1.5.2.6 Crosylic Acid. A chemical cleaning agent containing cresylic acid (20 percent) was used for various cleaning operations at $T P 1$ ant and was determined to be a spent nonhalogenated solvent discharged to the DST System. Consequently, the $P C$ is an F004 waste by applying the 'derived-from' rule [WAC $173-303-070(2)(a)]$.

3.1.5.2.7 Methyl Ethyl Ketone (2-butanone). Methyl ethyl ketone (2-butanone) was detected in 25 of the 34 samples at an average concentration of 51 parts per billiton (WHC 1990a). Methyl ethyl ketone (2-butanone) was used in the Reduction-0xidation Plant process, and is determined to be a spent nonhalogenated solvent discharged to the DST System. Consequently, the PC is an F005 waste by applying the 'derived-from' rule [WAC 173-303-070(2)(a)].

3.1.5.2.8 Pyridine. Pyridine was detected in 1 of 34 samples at a concentration of 550 parts per billion (WHC 1990a). Pyridine was not used in Hanford Site chemical reprocessing. Therefore, it is neither a discarded chemical product nor a spent solvent.

3.1.5.3 Infectious Dangerous Naste. The third category for waste designation is "Infectious Dangerous Wastes" (WAC 173-303-083). Operation of the ETF does not involve the treatment or storage of infectlous waste. Therefore, the requirements of WAC 173-303-083 are not applicable to the ETF.

3.1.5.4 Dangerous Waste Mixtures. The fourth category for waste designation is "Dangerous Waste Mixtures" (WAC 173-303-084). The ETF verification tanks could have constituents that are identified in 40 CFR 302.4 (Spill Table) and in the Registry of Toxic Effects of Chemical Substances (NIOSH 1990). Toxicity, persistence, and carcinogenicity are the three criteria considered in dangerous waste mixture designation, as discussed in the following sections. The designation procedures used to analyze concentrations of dangerous waste mixtures were calculated as the upper limit of the one-sided 90 percent confidence interval (DOE/RL-90-43).

3.1.5.4.1 Toxicity. To determine the ETF verification tank waste toxicity, the toxic dangerous waste designation was determined by following the procedure set forth in WAC 173-303-084(5). The procedure calculates the equivalent concentration percentage of the waste stream. As defined in WAC 173-303-9906, a waste stream is a toxic dangerous waste if the calculated 
DOE/RL-93-03, Rev. 0

$08 / 31 / 93$

equivalent concentration percent sum of all applicable constftuents is greater than 0.001 percent. Forty-seven substances associated with toxic categories were identified as potential constituents of the PC. These 47 subsiances contribute to the calculated equivalent concentration percent sum. Of these substances, ammonia is the largest contributor to the equivalent concentration percent sum (WHC 1990a). The calculated equivalent concentration percent sum of the PC varies between 0.000093 percent and 0.00108 percent. The high end of this range exceeds the designated limit of 0.001 percent, and therefore, the $P C$ is a toxic dangerous waste (WTO2).

3.1.5.4.2 Persistence. The ETF verification tanks do not use, treat, store, or dispose of polycyclic aromatic hydrocarbons. A review of existing processes and analytical data indicated the PC is not a persistent dangerous waste. Therefore, the waste managed at the ETF verification tanks is not designated a persistent dangerous waste mixture.

3.1.5.4.3 Carcinogenicity. The carcinogenic dangerous waste designation was determined by following the procedure set forth in WAC 173-303-084(7). Three substances potentially present in the PC were determined to be carcinogenic chemical compounds: cadmium chloride, nickel (II) hydroxide, and n-nitrosodimethylamine (WHC 1990a). Because none of the compounds exceeded 0.01 percent, and the sum was less than 1.0 percent of the waste quantity, the waste is not a carcinogenic dangerous waste.

\subsubsection{Dangerous Waste Charactoristics. The fifth category for waste} designation is "Dangerous Waste Characteristics" (WAC 173-303-090). Evaluation of process and analytical data indicated the $P C$ is not designated as a characteristic waste (WHC 1990a). The four characteristics, ignitability, corrosivity, reactivity, and toxicity, are discussed in the following sections.

3.1.5.5.1 Ignitability. The $P C$ is a dilute aqueous waste. Although flash point testing was not performed, the waste is not expected to be ignitable. Dissolved nitrate is present in the waste but at very low levels. According to the description of ignitable properties in WAC 173-303-090, a waste is ignitable if defined as an oxidizer in accordance with 49 CFR 173.151 .

Nitrate is an example oxidizer. However, nitrate is in the waste in such a dilute form (average of 2.8 parts per millition), it is not expected to stimulate the combustion of organic matter. The requirement for nitrate to be present in a concentration and form to warrant the ignitable characteristic designation is supported in the Federal Register (52 FR 22520).

The only chemical in an aqueous mixture similar to nitrate that has a concentration limit set for oxidizer classification is nitric acid. In the 49 CFR 173.101 "Hazardous Materials Table," nitric acid is given an oxidizer hazard class when the concentration exceeds 40 weight percent (1.e., 400,000 parts per million). Using this limit as a basis, the waste does not exhibit the characteristic of ignitability due to the presence of an oxidizer. 
Furthermore, an ignitabllity index was calculated for the samples based on the sum of the percent concentrations of all ignitable contributors in the waste. Pure substances with a flash point less than $140^{\circ} \mathrm{F}\left(60^{\circ} \mathrm{C}\right)$ were considered ignitable. Samples with an ignitability index below 1 percent were not considered ignitable.

One or more chemical compounds potentlally present in the PC are ignitable substances. The value of the index calculated from these constituents is between 0.000192 percent and 0.00786 percent, well below the 1 percent threshold level. Therefore, the PC is not an ignitable waste.

3.1.5.5.2 Corrosivity. Measurements of $\mathrm{pH}$ for the different waste types ranged from 9.72 to 10.83 . For $P C$ to be corrosive dangerous waste [WAC 173-303-090(6)], the PH must be less than 2 or greater than 12.5. The PC is, therefore, not a corrosive dangerous waste.

3.1.5.5.3 Reactivity. For $P C$ to be a reactive dangerous waste [WAC 173-303-090(7)], it must: (1) readily undergo violent chemical change; (2) react violently or form potentially explosive mixtures with water: (3) generate toxic fumes when mixed with water or in the case of cyanide or sulfide-bearing waste, when exposed to mild acidic conditions; (4) explode when subjected to a strong inftiating force; (5) explode at normal temperatures and pressures; or (6) fit within the U.S. Department of Transportation forbidden explosives, Class A explosives or Class B explosives definitions. The PC is dilute aqueous waste stream and clearly does not meet definitions (1), (2), (4), (5), or (6).

Analysis was performed to determine the cyanide and sulfide concentrations, and whether the PC contains quantities of cyanide or sulfide to generate sufficient toxic gases to threaten human health and the environment. The unofficial threshold levels, as stated in SW-846 (EPA 1986), for hydrogen cyantde gas and hydrogen sulfide gas are 250 millitgrams per kllogram and 500 milligrams per kllogram, respectively. From the analytical resuits, cyanide was not detected in any of the samples. Only one sample showed a total sulfide concentration of 14 milligrams per kilogram, which is equivalent to 14.9 milligrams per kllogram of hydrogen sulfide. Therefore, the $P C$ is not a reactive dangerous waste.

3.1.5.5.4 Toxicity. The PC is a toxic dangerous waste if contaminant results from toxicity characteristics leaching procedure (TCLP) testing exceed the limits set in WAC 173-303-090(8)(c). In the absence of specific TCLP test results, total analyte concentrations were used. Four analytes with concentrations above detection limits are on the TCLP toxic list and were found in the waste. The PC is not a toxic dangerous waste because none of the total analyte concentrations exceeded the TCLP toxic threshold levels. The levels in leachate derived from the TCLP are not expected to be greater than the total analyte concentrations.

It should be noted that some DSTs are known or suspected to contain organic TCLP toxics as identified in accordance with EPA "Final Rule Change" (55 FR 11798). It is unknown at this time which DSTs contain these organic TCLP toxic constituents. The waste analysis plan of the Hanford Facility 
DOE/RL-93-03, Rev. 0

$08 / 31 / 93$

1 Dangerous Waste Permit Application, DST System documentation (DOE/RL-90-39)

2 outilines the proposed sampling plan and should provide future data to

3 determine which DSTs contain the TCLP toxics.

\subsubsection{Occasional Waste}

Occasional waste includes mixed and nonradioactive dangerous waste such as rags, paper towels, disposable pipettes, contaminated gloves, and other miscellaneous materials associated with the performance of the ETF processes. This type of waste is collected separately, segregated from nondangerous dry waste, and stored in the storage area until transferred to a TSD unit. The nonradioactive dangerous waste generated during ETF operations also is stored in the ETF storage area until transferred to the 616 Nonradioactive Dangerous Waste Storage Facility.

\subsubsection{Waste in Piles [C-1C]}

Operation of the ETF does not involve the placement of dangerous waste in piles. Therefore, the requirements of WAC 173-303-660 are not applicable to the ETF.

\subsubsection{Landfilled Waste [C-1d]}

Operation of the ETF does not involve the placement of dangerous waste in landfills. Therefore, the requirements of WAC 173-303-665 are not applicable to the ETF.

\subsubsection{Waste Incinerated and Waste Used in Performance Tests [C-1e]}

Operation of the ETF does not involve the incineration of dangerous waste. Therefore, the requirements of WAC 173-303-670 are not applicable to the ETF.

\subsubsection{Waste to be Land Treated [C-1f]}

Operation of the ETF does not involve the land treatment of dangerous waste. Therefore, the requirements of WAC 173-303-655 are not applicable to the ETF.

\subsubsection{Envelope of Waste Characteristics Allowed as Feed to the 200 Area Effluent Treatment Facility}

The operating envelope defines the range of constituents and concentrations in a waste water that can be treated by the ETF. This operating envelope was developed through pilot plant tests using a surrogate test solution. Although the operating envelope design was directed at 
DOE/RL-93-03, Rev. 0

$08 / 31 / 93$

treating 242-A Evaporator process condensate, the 1 ist of constituents composing the surrogate test solution was expanded to include constituents that represent additional chemical groups that could be treated at the ETF. The surrogate test solution constituents were based on the 242-A Evaporator PC characterization data, a Hanford Site chemical inventory, and constituents of regulatory concern. The additional constituents were tested to demonstrate the flexibility of the ETF in treating a variety of contaminants.

The operating envelope for the organic constituents was developed using the destruction efficiency determined from UV/OX pilot plant test data. The organic constituent destruction efficiency was measured by determining the oxidation rate (the rate at which an organic constituents was destroyed). The operating envelope for the inorganic constituents was developed using removal efficiencies determined from RO and IX pilot plant test data. The removal efficiency for each inorganic constituent from each surrogate test solution test was determined by comparing the constituent concentration in the RO feed to the constituent concentration in the IX discharge. In the ETF, a verification sampling program following the treatment process monitors the efficiency of the treatment process, as well as verifies that the treated effluent meets regulatory criteria before disposal.

\subsubsection{Delisting of Treated Waste Water}

The testing described in Section 3.1.11 is used to support a delisting petition currently before the EPA (DOE/RL-92-72). When granted, the delisting petition will affirm that the ETF treatment processes are robust enough to ensure removal or destruction of contaminants to delisting criteria levels. This means that the treated waste water from the ETF no longer requires management as a dangerous waste.

\subsection{WASTE ANALYSIS PLAN [C-2]}

The waste analysis $p l a n$ (Appendix $3 A$ ) discusses the sampling and analysis of waste treated and generated at the ETF. Waste generated at the ETF includes the treated waste water, powdered solids from the ETF dryer, spent IX resins, spent offgas filters, expended or fouled equipment (e.g., spent RO membrane cartridges and used UV lamps), and miscellaneous radioactive and nonradioactive maintenance waste. Only the treated waste water, powdered solids, and spent IX resins are sampled routinely and analyzed. The ETF does not store ignitable, reactive, or incompatible waste. Therefore, it is not necessary for this waste analysis plan to address waste-to-waste compatibility. With regard to routine sampling and analysis, details are provided in this section for the following:

- Parameters and rationale

- Test methods

- Sampling methods

- Frequency of analysis. 


\subsubsection{Parameters and Rationale [C-2a]}

The parameters and rationale were selected to characterize the waste based on historical waste analyses of the 242-A Evaporator PC and associated process knowledge. These same parameters were used in part to develop the operating envelope. The analytical parameters, along with the approved methods of analysis and the rationale for selection, are presented in the waste analysis plan (Appendix 3A).

\subsubsection{Test Methods [C-2b]}

Approved analytical test methods are based on WAC 173-303-110 and are described in the waste analysis plan (Appendix $3 A$ ).

\subsubsection{Sampling Methods [C-2c]}

Sampling methods are as follows.

- A flow proportional sampler is used to sample treated waste water before filling one of the three verification tanks [675,000 gallons $(2,551,500$ liters) each]. When the first tank is full, a second tank receives the treated waste water. When the second tank is full, a third tank receives the treated waste water. Hence, typical operations have one tank in the fill mode, one tank in the standby mode while sample analyses are being run, and a third tank in the discharge mode. Required volumes, preservation techniques, and holding times of the different analytical methods are detailed in the waste analysis plan (Appendix 3A). Chain-of-custody procedures are followed.

- A sampler is used to sample liquid feed to the ETF dryer at the location of the two concentrate tanks.

- The spent IX resin sample is taken from each container of waste.

- Non-PC alternative feeds to the ETF are sampled.

\subsubsection{Frequency of Analysis [C-2d]} analysis.

The ETF waste analysis plan (Appendix 3A) establishes the frequency of

\subsubsection{Liquid Effluent Discharge Limits}

Discharge limits are set in the State Waste Discharge Permit Program (WAC 173-216). 


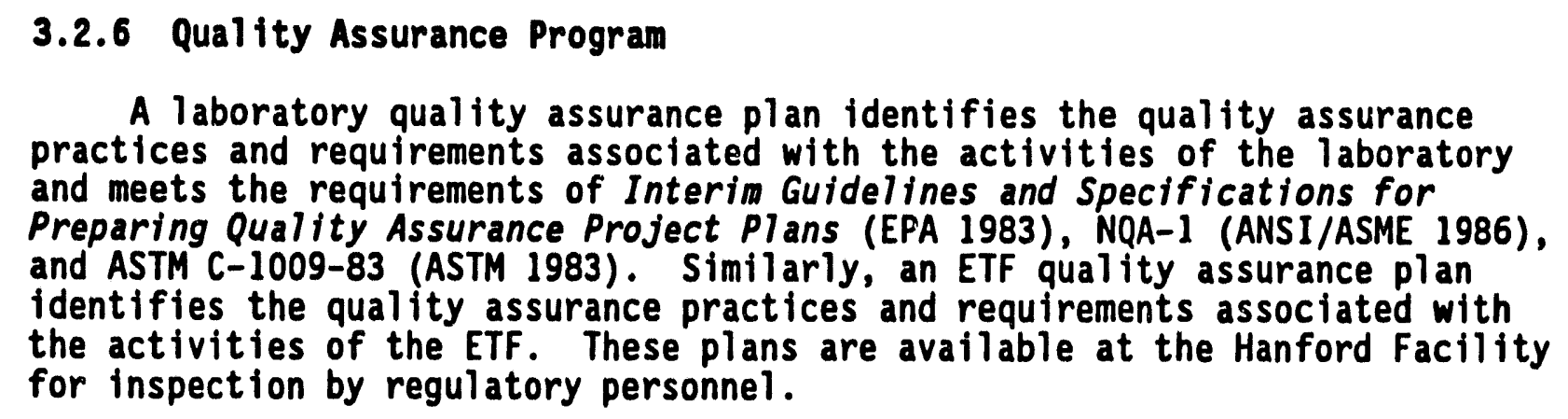

A laboratory quality assurance plan identifies the quality assurance practices and requirements associated with the activities of the laboratory and meets the requirements of Interim Guidelines and Specifications for Preparing Quality Assurance Project Plans (EPA 1983), NQA-1 (ANSI/ASME 1986), and ASTM C-1009-83 (ASTM 1983). Similarly, an ETF quality assurance plan identifies the quality assurance practices and requirements associated with the activities of the ETF. These plans are available at the Hanford Facility for inspection by regulatory personnel.

\subsection{ADDITIONAL REQUIREMENTS FOR MASTE GENERATED OFFSITE [C-2e]}

If a decision is made to treat or store dangerous and mixed waste generated offsite, a permit modification will be sought.

\subsection{ADDITIONAL REQUIREMENTS FOR IGNITABLE, REACTIVE, OR INCOMPATIBLE WASTE [C-2f]}

Ignitable, reactive, or incompatible waste is not treated or stored in the ETF. Section 3.1.5.5 discusses the dangerous characteristics of the PC. Therefore, requirements imposed on ignitable, reactive, or incompatible waste are not applicable to the ETF.

\subsection{LAND DISPOSAL RESTRICTIONS}

Treated waste water from the ETF will be a delisted waste (by EPA approval of the delisting petition), and will not be subject to LDR. However, any waste that contacts untreated waste will be listed waste. Although the Tri-Party Agreement grants the U.S. Department of Energy a variance in the LDR requirements, the appropriate constituents subject to the requirements are tracked. 
4.0 PROCESS INFORMATION $[0] \ldots \ldots$ 4-1 . . . . . . . . . . . .

4.1 PROCESS DESCRIPTION ................. . . . . .

4.1.1 Primary Treatment Train ............ 4-1

4.1.1.1 Surge Tank ............. 4-2

4.1.1.2 Coarse Filtration .......... 4-2

4.1.1.3 Ultraviolet Oxidation System. ....... 4-2

4.1.1.4 pH Adjustment ............. 4-3

4.1.1.5 Hydrogen Peroxide Deromposer. ....... 4-3

4.1.1.6 Fine Filtration .......... 4-3

4.1.1.7 Degasification ............. 4-4

4.1.1.8 Reverse 0smosis System . . . . . . . . 4-4

4.1.1.9 Polisher............... 4-5

4.1.1.10 pH Adjustment ............ 4-6

4.1.1.11 Verification Tanks ........... 4-6

4.1.1.12 Cooling Tower ............. 4-6

4.1.2 Secondary Treatment Train ............ 4-6

4.1.2.1 Secondary Waste Receiving Tanks ..... 4-6

4.1.2.2 200 Area Effluent Treatment Facility

4.1.2.3 Evaporator Concentrate Receiving Tanks $\ldots \ldots \ldots$ 4-7

4.1.2.4 Thin Film Dryer ........... 4-8

4.1.2.5 Container Handling System ........ 4-8

4.2 CONTAINERS $[D-1] \ldots \ldots \ldots$ 4-9

4.2.1 Containers with Free Liquids [D-1a] ...... 4-10

4.2.2 Containers Without Free Liquids [D-1b] $\ldots$ 4-10

4.2.2.1 Tests for Free Liquids $[D-1 b(1)] \ldots$. . 4-10

4.2.2.2 Description of Containers [D-1b(2)] .. 4-10

4.2.2.3 Container Management Practices [D-1b(3)] . . 4-11

4.2.2.4 Container Storage Area Drainage $[D-1 b(4)]$. . 4-12

4.2.3 Protection of Extremely Hazardous Waste in

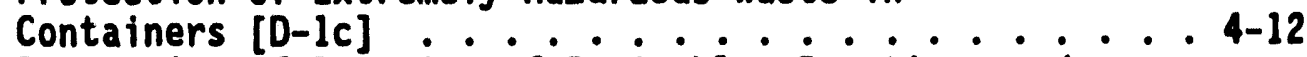

4.2.4 Prevention of Reaction of Ignitable, Reactive, and

Incompatible Waste in Containers [D-1d] ...... 4-12

4.3 TANK SYSTEMS $[0-2 a,-2 a(1)] \ldots$. . . . . . . . . . .

4.3.1 Description of Feed Systems, Safety Cutoffs, Bypass

Systems, and Pressure Controls [D-2a(2)] ..... 4-13

4.3.1.1 Tanks .............. 4-13

4.3.1.2 Filter Systems . . . . . . . 4-14

4.3.1.3 Uitraviolet Oxidation System

4.3.1.4 Degasification System $\ldots \ldots$. . . .

4.3.1.5 Reverse 0smosis System .......... 4-15

4.3.1.6 Polisher .............. 4-15

4.3.1.7 200 Area Effluent Treatment Facility

Evaporator ............ . 4-15

4.3.1.8 Thin Film Dryer $\ldots \ldots$ 4-15 
4.3.2 Piping, Instrumentation, and Process Flow [D-2a(3)] . 4-16

4.3.3 Ignitable, Reactive, and Incompatible Waste $[D-2 a(4)] \ldots \ldots \ldots . \ldots . \ldots . \ldots . . \ldots$

4.3.4 Labels or Signs .............. . . . . . . . . . .

4.3.5 Existing Tank Systems $[0-2 b] \ldots 4-18$

4.3.6 Assessment of New Tank System Integrity $[D-2 c(1)] \ldots$ 4-18 4.3.6.1 Design Standards for New Tank and Process System Construction ..... 4-18

4.3.6.2 Compatibility of Tanks with Waste to be Handled .............. 4-21

4.3.6.3 Corrosion Assessment and Protection.... 4-21

4.3.6.4 Protection of Underground Tanks from

Vehicular Traffic Damage ....... . 4-21

4.3.6.5 Assessment of Adequacy of Tank Foundation and Anchoring ............ 4-21

4.3.6.6 Protection Against Frost Heave ..... 4-22

4.3.7 Description of Tank System Inspection, Verification, and Testing Procedures $[D-2 c(2)] \ldots$ 4-22 4.3.7.1 Inspection, Verification, and Testing Phases . . . . . 4-22

4.3.7.2 Backfill Procedures for Underground Tanks . 4-24

4.3.7.3 Tightness Testing Plans and Procedures . . . 4-24

4.3.7.4 Support and Protection of Ancillary Equipment ............. 4-24

4.3.8 Design of Secondary Containment system [D-2d-D-2d(2)] ....... 4-25 4.3.8.1 Design Requirements for Specific Secondary Containment Type (D-2d(1)(C)] . . . 4-25

4.3.8.2 Ability to Prevent Releases to Environment . 4-26 4.3.8.3 Compatibility of Materials of Construction with Waste ........... 4-26

4.3.8.4 Adequacy to Prevent Failure . $\ldots$ 4-26

4.3.8.5 Adequacy of Foundation ......... 4-27

4.3.8.6 Leak Detection System . . . . . . . . 4-28

4.3.8.7 Collection and Removal of Waste ...... 4-28

4.3.9 Secondary Containment and Leak Detection for

Ancillary Equipment [D-d(1)(d)] . . . . . 4-29

4.3.9.1 Description of Secondary containment for

Ancillary Equipment.......... 4-29

4.3.9.2 Transfer Piping .......... 4-29

4.3.9.3 Ability to Prevent Releases to the

Environment... 4-30

4.3.9.4 Compatibility of Materials of Construction with Waste .......... 4-30

4.3.9.5 Adequacy to Prevent Failure . . . . . 4-30

4.3.9.6 Adequacy of Foundation ........... 4-31

4.3.9.7 Leak Detection System . ........ 4-31

51

4.3.9.8 Collection and Removal of Waste ...... 4-31 


\section{APPENDICES}

4 A ENGINEERING DESIGN REPORT ....................... APP 4A-1 4B CERTIFICATION OF NEW TANK SYSTEM INTEGRITY . . . . . . . APP 4B-i $4 C$ SEISMIC ANALYSIS ........................... APP 4C-1 4D CORROSION ANALYSIS ........................... 4D-1 
4-1. 200 Area Effluent Treatment Facility Layout ............ . F4-1

4-2. 200 Area Effluent Treatment Facility Floor Plan . . . . . . . . . F4-2

4-3. 200 Area Effluent Treatment Facility Process Flow Diagram . . . . F4-3

4-4. Plan View of Container Handling Room . . . . . . . . . . . F4-4

4-5. Side View of Dryer Powder Hopper and Container Handling Room . . F4-5

4-6. Capping Station....................... F4-6

4-7. Container Washing and Drying Station ............. . F4-7

4-8. Example Storage Configuration in the Filied Container

Storage Area . . . . . . . . . . . . . . . . F4-8

\section{TABLES}

4-1. 200 Area Effiuent Treatment Facility Tank Systems Information . . T4-1

4-2. Process Equipment, Usage, and Material Data . . . . . . . . . T4-2

4-3. 200 Area Effiuent Treatment Facility Pump Information . . . . . T4-3

4-4. Summary of Construction Inspection and Testing for the 200 Area Effluent Treatment Facility ............ . T4-4

4-5. Secondary Containment Systems ................. T4-5

4-6. Concrete and Masonry Coatings . . . . . . . . . . . . . . T4-6

4-7. Volume of Secondary Containment Systems ........... . T4-7 
DOE/RL-93-03, Rev. 0

$08 / 31 / 93$

\subsection{PROCESS INFORMATION [D]}

This chapter provides a detailed discussion of the ETF processes and equipment.

The ETF receives waste water from the 242-A Evaporator, the LERF, and potentially may receive waste water from other sources in the $100,200,300$, and 400 Areas of the Hanford Facility. The waste water is treated in a series of process units, or systems, extracting or destroying essentially all of the dangerous waste and radioactive constituents except tritium. Before discharge, the quality of the treated waste water is analyzed to verify that the discharge 1 imits have been met. The treated waste water is piped to a SALDS north of the 200 West Area, where the treated waste water is discharged to the ground under the authority of a Washington State waste discharge permit and an approved hazardous waste delisting petition.

\subsection{PROCESS DESCRIPTION}

The ETF contains several tanks and process unit systems for the treatment of dilute waste water generated on the Hanford Facility. Figure 4-1 provides an overview of the layout of the ETF Building, Figure 4-2 shows the ETF floor plan, and Figure 4-3 is the ETF process flow diagram.

Waste water to the ETF from the 242-A Evaporator and the LERF is piped to the surge tank. The waste water passes from the surge tank into the primary treatment train where the organic, inorganic, and radioactive constituents are removed from the waste water. Waste generated during the primary process passes into the secondary treatment train where the waste is processed and prepared for final transfer to a TSD unit. The primary and secondary treatment trains are described in the following sections.

\subsubsection{Primary Treatment Train}

The primary treatment train receives waste water in the surge tank, processes the waste water, and discharges the treated waste water to the soil column. The primary treatment train consists of the following systems:

- Surge tank (pH adjustment)

- Coarse filtration

- UV/OX system

- $\mathrm{pH}$ adjustment

- Hydrogen peroxide decomposer

- Fine filtration

- Degasification

- RO system

- Polisher (IX columns)

- $\mathrm{pH}$ adjustment

- Verification tanks

- Cooling tower. 
4.1.1.1 Surge Tank. The waste water enters the ETF at the surge tank, located outside the ETF Building on the south side. The surge tank also receives waste extracted by various systems within the primary treatment train, such as sumps, regeneration rinsing water from the polisher, and the distillate from the ETF evaporator and the thin film dryer.

The surge tank is insulated and the contents heated to prevent freezing. The $\mathrm{pH}$ of the contents is adjusted to about 6.0 by the metered addition of 92-weight percent sulfuric acid $\left(\mathrm{H}_{2} \mathrm{SO}_{4}\right)$ or 50-weight percent sodium hydroxide $(\mathrm{NaOH})$. The main purpose of $\mathrm{pH}$ control in the surge tank is to change free ammonia into ammonium ion to prevent ammonia from being discharged into the vessel ventilation system. This $\mathrm{pH}$ range also corresponds to the operation range for the UV/OX system. A titration analyzer is used to adjust and maintain the $\mathrm{pH}$.

One of the three surge tank pumps circulates the contents, mixing the sulfuric acid or the sodium hydroxide and the waste water to a uniform $\mathrm{pH}$. A second pump forces the $\mathrm{pH}$ adjusted waste water through the rough filter. The remaining pump serves as a spare.

4.1.1.2 Coarse Filtration. The 2-micron rough filter removes the larger particulates from the waste water. The solids accumulating on the filter element are backwashed to the secondary waste receiving tanks with pulses of compressed air, forcing water back through the filter. The backwash operation is started automaticaliy by a rise in differential pressure across the filter. The backwash operation is accomplished in 5 minutes, at an expected frequency of less than once a week. The filter medium is expected to operate for at least 1 year between replacements. The filtered waste water then passes through a plate cooler, to reduce the temperature to less than $100^{\circ} \mathrm{F}\left(38^{\circ} \mathrm{C}\right)$, before entering the UV/OX chambers.

4.1.1.3 U1traviolet Oxidation System. The purpose of the UV/OX system is to break down the organic compounds in the waste water, producing carbon dioxide, water, and inorganic ions. The UV/OX system uses the photochemical reaction of UV light on hydrogen peroxide to decompose the organic constituents.

Hydrogen peroxide is mixed with the waste water, and then exposed to UV 1ight. The photochemical reaction of UV light and hydrogen peroxide causes the formation of hydroxyl radicals and other reactive species that cause the decomposition of organics.

Organic destruction is accomplished in two UV/OX units operating in series. During the UV/OX process, the waste water passes through mixing and dosing chambers within reaction chambers where hydrogen peroxide is added.

In each reaction chamber, a high-intensity UV lamp is covered by a quartz tube with a tube-cleaning device. Cleaning of the quartz tube exteriors and reaction chamber interiors is performed automatically by rubber rings that slide across the surface of the quartz tubes. This cleaning process occurs in a stand-by mode as necessary without process shutdown. 
DOE/RL-93-03, Rev. 0

$08 / 31 / 93$

The UV/OX system is equipped with automatic shutdown should the following circumstances occur: overpressurization, molsture in lamp end enclosure, high temperature, low water, fallure of the hydrogen peroxide storage/feed module, high lamp drive enclosure temperature, and open access door. Also provided is a level sensor to protect the UV lamps against the risk of exposure to air. Should the liquid levels fall low enough to expose the lamps to air, the UV lamps are shut down automatically. After shutdown, the UV lamps cannot be restarted until the lamp temperature decreases to a specififed level. The waste water is received next in the $\mathrm{pH}$ adjustment tank.

4.1.1.4 pH Adjustment. The $\mathrm{pH}$ adjustment chemically alters the ammonia and carbonate fons in the waste water. The waste water $\mathrm{pH}$ is adjusted with a solution of 4-weight percent sulfuric acid or 4-weight percent sodium hydroxide to a $\mathrm{pH}$ of approximately 4.0. In this acidic solution, ammonia is converted to an ammonium ion specie that is removed downstream by the RO system. Acidification also changes the chemistry of the carbonate ion, causing it to form carbon dioxide, a gas with low solubility that can be removed from the waste water.

The $\mathrm{pH}$ adjustment tank has two pumps, one of which operates as a spare. A constant liquid level is maintained in the tank to facilitate an even and constant pH of the waste water. The waste water is pumped through the hydrogen peroxide decomposer.

4.1.1.5 Hydrogen Peroxide Decomposer. The purpose of the hydrogen peroxide decomposer is to reduce the amount of hydrogen peroxide left in the waste water from the UV/OX system. The hydrogen peroxide injected for the UV/OX system is not completely consumed in the process of organic destruction, leaving approximately 100 to 200 parts per million in the waste water. A strong oxidant, hydrogen peroxide could harm the membranes in the RO system. Therefore, the waste water is sent through a simple packed column that breaks down the hydrogen peroxide into water and oxygen.

The residual hydrogen peroxide is decomposed by flowing through one of two vessels containing packed beds of catalyst. A safety rel lef valve on each vessel opens to relieve excessive system pressure to sump tank No. 2. The break down of hydrogen peroxide forms water and oxygen as the waste water flows through the catalyst bed. The gas generated by the decomposition of the hydrogen peroxide accumulates at the top of the hydrogen peroxide decomposer column where it is diluted with piped-in air. Diluting the oxygen protects the piping and equipment from oxidation. The mixed gas is then discharged to the sump tank, which is vented to the vessel offgas system. The waste water discharge flows from the decomposer to the fine filter.

4.1.1.6 Fine Filtration. The fine filter removes suspended solids larger than approximately 0.5 micron. The filter is designed to operate at up to 150 pounds per square inch gauge.

Differential pressure between the inlet and outlet of the fine filter is monitored. When the differential pressure reaches a predetermined value, the filter goes into the backwash operation automatically. Solids accumulating on 
the filter element are backwashed to the secondary waste receiving tank with pulses of compressed air that force water back through the filter. The backwashing operation is expected to last 5 minutes and to occur less than once a week. The filter is expected to operate for at least 1 year before replacement. The waste water discharged through the filter then undergoes degasification.

\subsubsection{Degasification. The function of the degasification column is to} remove the carbon dioxide formed when the waste water was acidified in the $\mathrm{pH}$ adjustment tank. Carbonate ions are removed to prevent increasing the contaminant loading to the RO system and other downstream ETF processes (i.e., IX, evaporation, and drying).

A plate-type heat exchanger is provided for cooling the waste water fed to the degasification column. The carbon dioxide-laden waste water passes down through a packed bed at a slight vacuum [approximately 2 inches of water (0.051 kilogram per square centimeter)] with air blowing up through the packed bed. Because of the low solubllity of the carbon dioxide, contact with the countercurrent air purges the waste water of the carbon dioxide molecules. offgas from the degasification column is discharged by the degasification blower to the vessel offgas system.

Extremely low pressure developed by the column blower that could compromise column integrity is relieved by a pressure relief safety valve. The column liquid level is controlled automatically. The degasified waste water is fed to the first stage RO feed tank by the degasification pump.

4.1.1.8 Reverse Osmosis System. The function of the RO system is to reduce the concentration of dissolved solids, radionuclides, and any remaining large molecular weight organic materials in the waste water.

Reverse osmosis is a process that uses pressure to force clean water molecules through special membranes while keeping the larger molecule contaminants within the membranes. The waste water passes through two or more of the pressure vessels containing the RO membranes before going to the next system.

The membranes are of a composite polyamide type that are nearly impermeable to ammonium ions. Contaminants, including the ammonium, are removed from the waste water as the fluid moves through the membranes. The cleaned waste water discharged from the system is referred to as the permeate, while the contaminated waste is called the reject itream, concentrate, retentate, or brine.

The RO system enhances contaminant removal by using two stages (instead of one) and by a crossflow pattern through the membrane modules. The concentrate from the first stage RO membranes is collected in the secondary waste receiving tanks, and the permeate (the waste water that has passed through the membranes) is routed to the second stage RO for additional treatment before being discharged to the polisher. Concentrate from the second stage RO is routed back to the first stage RO feed tank. Note that the 
DOE/RL-93-03, Rev. 0

$08 / 31 / 93$

complete RO system is designed with 50 percent excess capacity (1.e., one third of the system is always in a cleaning or standby mode, while the other two-thirds are in operation).

\subsubsection{Polisher. The polisher is for final removal of residual dissolved solids from the waste water.}

The permeate discharge from the second RO stage is pumped to the polisher, which consists of three IX columns, each with mixed beds of cation and anton resin. Two of the columns operate while the third is regenerated, or cleaned. The IX columns operate in series, ineaning waste water flows down through one IX column and then down through the second.

When the capacity of the resin in the first of the two online columns is exceeded, as detected by an increase in the conductivity of the IX column discharge, the column is removed froin service for regeneration. The third unit, which was offiline, is placed in service (to become the second of two onl ine columns).

The column removed from service is prepared for regeneration by separating the resins into a layer of anion resin and a layer of cation resin. The resins are separated by an upflow of clean water from the verification tank, which floats the lighter anion resin to the top of the resin bed. The contaminants in the cation resin are eluted with dilute (4 weight percent) sulfuric acid and the anion resin with dilute (4 weight percent) sodium hydroxide. The resulting concentrated (salt-loaded) regeneration waste streams are collected in the secondary waste receiving tanks. Thereafter, a dilute rinsing of both the anion and cation resins occurs, producing a solution (rinse waste) that is collected in the surge tank. Compressed air is used to remix the cation and anion bed after regeneration is complete.

Eventually, the IX resins become exhausted so that further regeneration is inefficient. When that happens, the spent resins are slurried, or washed, with water from the IX vessels into a disposal container. The container is sealed with a special lid that allows the following: spent resin to go in the containers, resin dewatering and water removal, and television monitoring of the resin and water levels within the container. Slurried resin enters the container through the lid to displace air that is removed by a blower. The air flows through an entrainment separator to remove water drops and then flows through a high-efficiency particulate air (HEPA) filter into the vessel ventilation system. Liquid is pumped from the container and sent to the surge tank as required to remove water from the resin.

The IX vessels are equipped with visual inspection ports that allow observation during resin separation, bed expansion, and operation. Each vessel outlet is monitored for conductivity and $\mathrm{pH}$ to prevent overloading of the resin beds between regeneration cycles. Automatically operated valves recycle poor quality effluent back to the surge tank, if needed, to prevent contamination of the verification tanks. Resin traps and a resin strainer prevent resin loss into the verification tanks. The waste water discharged from the polisher system is piped to the effluent pH adjustment tank. 
4.1.1.10 pH Adjustment. This final $\mathrm{pH}$ adjustment tank neutralizes the waste water for discharge. A small flow of dilute sulfuric acid or dilute sodium hydroxide is used to adjust the $\mathrm{pH}$ to between 6.5 and 8.5. An eductor in the tank ensures adequate mixing of the added chemicals. The $\mathrm{pH}$ of the waste water is monitored and controlled continuously.

The liquid level in the effluent pH adjustment tank is kept at a constant level to facilitate the $\mathrm{pH}$ adjustment process. A signal from the tank liquid level sensor transmitted to the flow control valve on the tank outlet adjusts the level in the tank by causing a corresponding increase or decrease in the flow to the verification tanks. Should an overflow occur, the waste water is collected in sump tank No. 2.

4.1.1.11 Verification Tanks. Three verification tanks, constructed of carbon steel and lined with epoxy, hold the treated waste water while a laboratory analysis is performed to determine if treatment is complete. The verification sample is taken by a flow proportional sampler as the treated waste water is pumped from the effluent $\mathrm{pH}$ adjustment tank to the verification tanks (Figure 4-1). The treated waste water can be pumped back into the treatment train if the water does not meet the Washington State waste discharge permit ilmits.

The three verification tanks al ternate between three operating modes: receiving treated waste water, holding treated waste water during laboratory analysis and verification, or discharging verified waste water.

All of the verification tanks have a liquid level sensor, a liquid level indicator, and a high-level alarm. The verification tank system includes three pumps: one delivers treated waste water to the SALDS, one pump circulates the treated waste water through tank eductors and serves as a water supply to various processes within the ETF, and one pump is a spare on standby.

4.1.1.12 Cooling Tower. The UV/OX and RO systems have upper temperature limitations for the waste water being treated. Heat exchangers and a cooling tower are used to control the temperature of the waste water.

\subsubsection{Secondary Treatment Train}

The following waste, generated by the primary treatment train systems, is processed in the secondary treatment train:

- Concentrate from the first RO stage

- Backwash from the rough and fine filters

- Regeneration waste from the polisher. 
DOE/RL-93-03, Rev. 0

$08 / 31 / 93$

The secondary treatment train collects, concentrates, dries, and packages the waste in 55-gallon (208-liter) lined steel containers. The secondary treatment train consists of the following:

- Secondary waste receiving tanks

- ETF evaporator

- Concentrate receiving tanks

- Thin film dryer

- Container handling system.

4.1.2.1 Secondary Waste Receiving Tanks. Secondary waste is collected in two secondary waste receiving tanks. The tanks alternate between receiving the secondary waste generated, and serving as a feed tank for the ETF evaporator feed tank. The rising liquid in the tank activates a high-level switch that diverts the flow to the other tank. Each secondary waste receiving tank has a pump on the tank outlet that can be used to circulate the tank contents or to supply feed to the ETF evaporator. A high-level alarm indicates an abnormal situation. Secondary containment for these tanks routes 1 iquids to sump tank No. 1.

Chemical pH adjustment of the tank contents is accomplished by the controlled addition of dilute sulfuric acid or dilute sodium hydroxide. The $\mathrm{pH}$ is adjusted to approximately 6.0 to optimize conditions in the ETF evaporator and thin film dryer equipment and to minimize any ammonia generation.

4.1.2.2 200 Area Effluent Treatment Facility Evaporator. The purpose of the ETF evaporator is to reduce the volume of waste before drying.

Feed from the secondary waste receiving tank is pumped through a preheater (feed/distillate exchanger) to a forced circulation evaporator loop. In the evaporator loop, concentrate is produced as the water is driven off overhead.

Water vapor in the overheads from the ETF evaporator passes through an entrainment separator, which removes entrained water droplets and solid particulates, returning them to the evaporator loop. The cleaned vapor is condensed and fed to the distillate flush tank. Some condensate from this tank is sprayed into the entrainment separator to scrub out particulates. Finally, the condensate is cycled back to the surge tank for further processing.

4.1.2.3 Concentrate Receiving Tanks. The ETF evaporator concentrate is pumped to the two concentrate tanks. These concentrate tanks function alternately between concentrate receiver and feed tank for the thin film dryer. The rising liquid level in the tank receiving concentrate actuates a high-level switch that diverts the flow to the other concentrate tank. Secondary containment for these tanks routes liquids to sump tank No. 1.

Both concentrate tanks have a circulation pump on the tank outlet that can be used to circulate the tank contents or to supply feed to the thin film dryer via the concentrate feed pump. Dilute sulfuric acid and dilute sodium 
1 hydroxide can be added to the tanks for $\mathrm{pH}$ adjustment. Homogenization by an eductor and $\mathrm{pH}$ adjustment (if necessary) is completed before the tank is filled and enters the feed mode. The concentrate tank circulation pump feeds the concentrate feed pump, which in turn supplies the thin film dryer.

A sample from the recirculation line is taken to characterize the tank contents; characterization of the liquid is representative of the powder produced by the dryer. (Application of ALARA principles showed this method of characterization to be preferred, as opposed to sampling powder.) This provides complete characterization of the container contents and minimizes exposure to workers.

The temperature of the concentrate is increased by a steam preheater to enhance the operation of the thin film dryer.

4.1.2.4 Thin Film Dryer. The purpose of the thin film dryer is to dry the concentrated secondary waste into a powder. Concentrate is distributed on the inner cylinder of the thin film dryer by wiper blades that rotate on a shaft centered in the cylinder (Figure 4-5). The shaft is driven by an electric motor. The concentrate is dried by steam heat introduced into a annular space (steam jacket) between the outer shell and the inner cylinder. Steam heat transferred across the inner cylinder wall heats the concentrate as it flows down the inside surface. Heating is controlled by regulating the steam pressure to the steam jacket. Condensate from the steam is returned to a steam boiler dedicated to the dryer. A safety valve on the thin film dryer steam and vapor lines vent independently to sump tank No. 1.

Overhead vapor released by the drying of the concentrate is condensed in a spray condenser. The condensed vapor forms a distillate by direct contact witnin a spray condenser. The distillate flow is circulated by a dryer distillate pump. Excess heat is removed from the distillate by a water-cooled heat exchanger. Part of the distillate is circulated back to the condenser spray nozzles. The remaining distillate is pumped to the surge tank. Any noncondensible vapors and particulates from the spray condenser are exhausted by a vacuum blower to the vessel ventilation system.

The concentrate dries to a film as it flows down the length of the dryer. The dried film, or powder, is scraped off the dryer cylinder by blades attached to the rotating shaft. The powder is funnelled through a cone-shaped powder hopper at the bottom of the dryer and into a rotary valve that feeds the powder into a container. An air-driven vibrator mounted on the cone section assists powder movement out of the thin film dryer into a 55-galion (208-liter) container.

4.1.2.5 Container Handling System. Empty containers with liners and lids are removed from empty-container storage and placed on a conveyor. The containers are moved into the container filling area after passing through an air lock. An empty container located under the powder port of the thin film dryer is raised into position by an elevator. The container is sealed to the thin film dryer and the rotary valve begins the transfer of powder out of the thin film 
dryer into the empty container. Air displaced from the container is vented to the extrainment separator attached to the ETF evaporator that exhausts to the vessel ventilation system.

The container is filled to a predetermined weight, then moved along the conveyor to the smear station airlock. At the smear station airlock, the container is moved onto the discharge conveyor by remote control. The airlock is opened and the smear sample (surface wipe) is taken and the radionuclide contamination level is counted. If the container has contaminated material on the outside, the container is moved to the washdown station where the container is washed with treated water from the verification tanks. The container wash water drains to sump tank No. 1 . The washed container is air-dried and retested. Filled containers that pass the smear test are labeled, placed on pallets, and moved by forklift to the filled storage area. Section 4.2 provides a more vetailed discussion of container handling.

\subsection{CONTAINERS [D-1]}

A container handling and filling system and a separate filled container storage area are located along the east wall of the ETF building. Powdered waste, consisting primarily of ammonium sulfate and/or other salts, is loaded from the powder hopper beneath the thin film dryer into 55-galion (208-1iter) lined containers.

The operating sequence begins with loading empty steel containers onto the empty conveyor. The conveyor takes a container through an airlock and positions the container under the dryer powder hopper. The container is filled to a predetermined weight, conveyed to the capping station, and another empty container is positioned under the dryer powder hopper.

At the capping station, a 1 id is positioned and affixed. The closed container is moved to the filled container conveyor area. The container is moved onto the discharge conveyor, at the smear station airlock, via controls on the local control panel. The airlock is opened and the smear sample (surface wipe) is taken and the radioactive contamination level is counted. Radioactive contamination is used as an indicator that the waste has contaminated the exterior surface of the container. If the smear is below limits, the container is labeled and moved to the filled container storage area. If the container fails the smear test, the container is conveyed to the washdown station, washed, and returned to the smear station and tested again.

Containers are moved into the filled container storage area by forklift. Approximately 720 containers can be stored in the storage area. The containers are stored on pallets, stacked thiree high, providing 30 inches ( 76.2 centimeters) of aisle space on both sides of each pallet. Secondary containment in both the filled container storage area and the container handling room consists of a 6-inch- (15.24-centimeter-) thick concrete floor, sealed joints, waterstops between the floor and curbs, 6-inch(15.24-centimeter-) high curbs, and chemical-resistant sealant applied to all concrete containment surfaces. 
Additional dangerous waste, processing equipment, or media generated at the ETF includes spent resin from the polishers, spent RO membranes, spent HEPA cartridges, spent filter elements, and UV 1amps. This waste, except for the UV lamps, is considered mixed waste because of possible radioactive contamination and because these materials might have been in contact with listed waste. These waste materials, except for spent resin, are contained in new 30-, 55-, or 85-gallon (113-, 208-, or 322-1iter) steel containers and stored in the filled container storage area until shipped for long-term storage or disposal.

In the following sections, characteristics of the container storage area and container management practices are described.

\subsubsection{Containers With Free Liquids [D-1a]}

Most regulated waste generated at the ETF is dry; however, some containerized waste might contain free liquids, e.g., dewatered spent resin. The filled-container storage area is designed to meet requirements for storage of free liquids in containers (Section 4.3.8).

\subsubsection{Containers Without Free Liquids [D-1b]}

The majority of waste generated and stored at the ETF is the solid waste from the secondary treatment train. This material is a powder, consisting of inorganic constituents such as ammonium sulfate and sodium sulfate with less prevalent constituents including nitrate/nitrite, sodium, silicon, carbonate, potassium, calcium, fluorine, and chlorine, with trace amounts of radioactive elements. Organic constituents are removed during the treatment process.

Small quantities of other miscellaneous waste generated indirectly from the processing of the waste water stream are stored as needed in the filled container storage area. This waste includes spent resin from the polishers, spent RO membranes, spent HEPA cartridges, spent filter elements, and UV lamps. None of this waste contains free liquids.

4.2.2.1 Tests for Free Liquids $[D-1 b(1)]$. Waste stored in the filled container storage area is a dry powder; however, the filled-container storage area is designed to meet requirements for storage of free liquids in containers (Section 4.3.8). Tests for free 1 iquids are performed before transfer for long-term storage or disposal.

4.2.2.2 Description of Containers $[0-1 b(2)]$. The containers used to collect the powdered waste material from the thin film dryer are new U.S. Department of Transportation 7A Type A Specification $17 C$ galvanized 55-gailon (208-1iter) steel containers (WHC 1992, D. 5-3). Only new containers are used tc collect this waste material; no reused or reconditioned contajners are used. The miscellaneous waste mentioned previously also is placed in galvanized steel containers, U.S. Departmen: of Transportation 7A Type A Specification 17C, of $30-, 55-$, or 85-galion $(114-, 208-, 322-1$ iter) capacity. The one exception to this type of container is the container used for storage of spent resin. 
DOE/RL-93-03, Rev. 0

$08 / 31 / 93$

Each container is handled, packaged, and shipped in accordance with onsite procedures (WHC 1988).

A filled and closed container of powdered waste that has passed the smear test is labeled before transport to the filled container storage area. A hazardous waste label with the appropriate waste code(s) is affixed to the container (WHC 1988). Therefore, routine removal of old labels will not be performed. However, if a label is damaged or new information needs to be added, the old label will be completely removed and a new label will be affixed to the container.

4.2.2.3 Container Management Practices [D-1b(3)]. Empty containers, four to a pallet, are moved from storage to the empty container conveyor area using a forklift. The forklift raises the pallet to the height of the conveyor and the containers are loaded manually onto the conveyor. Usually 8 , but no more than 12 containers are loaded in this manner each day, so that the empty containers are ready to be moved through the airlock on the conveyor. The empty pallets are stacked next to the exit airlock where filled containers leave the dryer hopper.

Containers are filled via a remotely controlled system that is synchronized with the dryer operating sequence. The container handling room is illustrated in Figure 4-4. The empty airlock front door opens and the empty conveyer moves one container into the airlock compartment. The empty airlock conveyor receives the container and centers the container within the airlock. The front airlock door closes. The rear door of the empty airlock opens and the empty airlock conveyor moves the container to the container filling conveyor, which moves the container to the capping station. At this point, the container 1 id is removed and loaded into the capper. The filling conveyor moves the container backwards to the filling station (Figure 4-5). The container is raised into the fill head that seals against the top of the container, ensuring that no waste material escapes from the container. The discharge valve on the dryer hopper is opened and the dry waste powder from the dryer falls into the container, which is gently vibrated to level the powder. When the quantity of waste in the container reaches a predetermined level (as detected by container weight), the discharge valve is closed and the container lowered. To prevent overfilling the container, a heat probe positioned under the fill head shuts the fill valve if the level of powder [at a temperature of approximately $210^{\circ} \mathrm{F}\left(99^{\circ} \mathrm{C}\right)$ ] reaches the probe. The filling conveyor moves the filled container to the capping station (Figure 4-6) where the lid is affixed and bolted. The conveyor then moves the container to the cleaning conveyor.

When the filled and closed containers are parked in front of the cleaning conveyor, the filled containers are moved, one at a time, through the airlock onto the rotator. A manual smear sample is taken to check for radioactive surface contamination. If no contamination is present, the container is labeled and removed from the airlock by conveyer. Labeled containers are weighed, loaded onto pallets, banded, and moved to the filled container storage area using forklifts and container handlers. 
If radioactive contamination is found on the surface of a container, the container is moved by conveyor to the remotely operated washdown station (Figure 4-7). The container is washed with water from the verification tanks and dried with hot air. A manual smear sample is taken again and, if free of contamination, the container is labeled and moved to the filled container storage area. This process can be repeated as needed.

Additional miscellaneous waste generated by the ETF processes (spent RO membranes, spent resin, used filter elements, spent UV lamps and used HEPA filters) are placed into lined containers, the liner closed, and the container sealed (WHC 1988). These containers are handled in a similar manner to the containers of powdered waste, including being smear tested, labeled, and transferred to the filled container storage area. If a container should fail the smear test, the container either will be washed down to remove the radioactive surface contamination, or the container will be placed in an overpack container.

Filled containers are closed, labeled, palletized, strapped, and moved into the filled container storage area where the containers remain until transferred to a TSD unit. While stored in the filled container storage area, palletized containers are stacked no more than three pallets high, in rows separated with a minimum of 30-inch (76-centimeter) aisle space. An example storage configuration is shown in Figure 4-8. Palletized containers are moved by forklift.

\subsubsection{Container Storage Area Drainage [D-1b(4)]. All of the containers} piaced in the filled container storage area are placed on pallets and are kept from contact with any liquid that could be on the floor. The floors of the handling and storage areas are designed as secondary containment systems that slope to drains into sump tank No. 1. The drainage system is designed to avoid standing liquid in the storage area.

\subsubsection{Protection of Extremely Hazardous Waste in Containers [D-1c]}

The powered secondary waste that exits the thin film dryer might designate as an extremely hazardous waste because of toxicity; the waste analysis plan (Appendix $3 A$ ) describes the waste designation process. All dangerous waste generated by the ETF is stored within the ETF building in the filled-container storage area. The filled-container storage area has a roof, walls, and a concrete floor, providing complete protection from the weather.

\subsubsection{Prevention of Reaction of Ignitable, Reactive, and Incompatible Waste in Containers [D-1d]}

The major waste stream generated at the ETF is an ac'Jic inorganic salt. This waste is a dry powder that is collected in lined steel containers that remain closed once filled. Any miscellaneous waste generated at the ETF, produced in far smaller quantities, is compatible with the powdered waste. The additional miscellaneous waste is primarily spent process equipment materials that has been in contact with the waste water being treated. One 
exception is spent UV lamps, which, encased in a quartz sheath, normally do not come in contact with the waste water. Neither the spent materials nor the dangerous constituent (mercury) in the UV lamps are incompatible with other waste generated in the ETF. There is no potential for reaction of ignitable, reactive, or incompatible waste at the ETF.

\subsection{TANK SYSTEMS $[\mathrm{D}-2 \mathrm{a},-2 \mathrm{a}(1)]$}

All storage and process tanks within the ETF are on or above ground and operate at near atmospheric pressure. Specific tank data, including volume, material of construction, and tank dimensions, are provided in Table 4-1. In addition to these tanks, there are eight process units in the ETF. Table 4-2 presents information on fabrication materials, operating temperatures and pressures, corrosivity and radioactivity for waste, and process liquids in these process units. The approximate location of each tank and process unit is shown in Figure 4-2.

\subsubsection{Description of Feed Systems, Safety Cutoffs, Bypass Systems, and Pressure Controls [D-2a(2)]}

Descriptions of feed systems, safety cutoff devices, bypass systems, and pressure controls for the tanks and process systems are provided in the following sections.

4.3.1.1 Tanks. All tanks are equipped with liquid level sensors that give a reading of the tank liquid volume. The surge tank, the verification tanks, the secondary waste receiving tanks, and the concentrate tanks are further equipped with liquid level alarms that are actuated if the liquid volume is near the tank overflow capacity. In the actuation of the surge tank alarm, a liquid level switch trips, sending a signal to the valve actuator on the tank influent lines, causing the influent vaives to close.

The operating mode for each verification tank, i.e., receiving, holding, or discharging, can be designated through the control system; modes also switch automatically. When the high-level set point on the receiving verification tank is reached, the flow to this tank is diverted and another tank becomes the receiver. The full tank is switched into verification mode. The third tank is reserved for discharge mode.

The liquid levels in the first and second RO feed tanks are maintained within predetermined operating ranges. The RO feed pumps for both the first and second RO feed tanks are designed to operate at 600 pounds per square inch gauge. Should the second RO feed tank overflow, the excess waste water is piped along with any leakage from the feed pump to sump tank No. 2.

The secondary waste receiving tanks receive secondary waste streams and feed the ETF evaporator. When the waste in the designated receiving tank reaches the high-level set point, the influent flow of waste is redirected to the second tank and the first tank becomes the feed tank for the ETF evaporator. 
In a similar fashion, the concentrate tanks switch modes when the high-level set point of one tank is reached. The other tank switches from a discharging mode to a receiving mode and the first tank becomes the discharge tank feeding waste to the thin film dryer.

\subsubsection{Filter Systems. The rough filter removes the particulates that are} greater than approximately 2 microns and the fine filter removes suspended solids larger than approximately 0.5 micron. The rough filter is supplied by the surge tank feed pumps and the fine filter is supplied by the feed pump on the $\mathrm{pH}$ adjustment tank. Both the rough filter and fine filter are in leak-tight steel casings. High pressure, which could damage the filter element, deactivates a valve that shuts off liquid flow to protect the filter element from possible damage. Cleaning the filter is accomplished by pulses of compressed air that force water back through the filter. The cleaning operation takes about 5 minutes and occurs about once a week when the ETF is operating. Cleaning is terminated automatically by shutting off the compressed air supply if high pressure develops.

4.3.1.3 U1traviolet Oxidation System and Decomposers. A rupture disc on the inlet piping to each of the UV/OX reactors relieves to the $\mathrm{pH}$ adjustment tank in the event of excessive pressure developing in the piping system. Should the rupture disk fall, treated water would trip the moisture sensor, shut down the UV lamps, and close the surge tank feed valve. Also provided is a level sensor to protect UV lamps against the risk of exposure to air. Should those sensors be actuated, the UV lamps would be shut down immediately.

The piping and valving for the decomposers are configured to split the waste water flow: half flows to one decomposer and half flows to the other decomposer. Alternatively, the total waste water flow can be treated in one decomposer or both decomposers can be bypassed. A safety relief valve on each decomposer vessel can relieve excess system pressure to sump tank No. 2 .

4.3.1.4 Degasification System. The degasification column is supplied waste water feed by the pH adjustment tank feed pump. This pump transfers waste solution through the hydrogen peroxide decomposer, the fine filter, and the degasification column to the first RO feed tank.

The degasification column is designed for operation at a partial vacuum. A pressure sensor in the column detects the column pressure. The vacuum in the column is regulated by the pressure controller that adjusts the opening of the air supply valve. The degasification column is exhausted to a blower connected to the heating, ventilation, and air conditioning supply air. If extremely low pressure is developed by the column blower, a situation that could compromise column integrity, a pressure relief safety valve is activated. The column liquid level is regulated by a flow control system with a high- and low-level alarm. A plate-type heat exchanger cools the waste solution fed to the degasification column.

4.3.1.5 Reverse Osmosis System. The flow through the first stage and second stage RO modules is controlled to maintain constant liquid levels in the first and second stage RO feed tanks as described in Section 4.3.1.1. 
4.3.1.6 Polisher. The permeate from the second stage Ro unit is pumped to the polisher for removal of dissolved solids. The waste water flows through one IX bed and then through the second IX bed, while the third column is isolated from the treatment line for regeneration.

When the capacity of the resin in the first column is exceeded, as detected by an increase in the conductivity of the column effluent, the third column, containing freshly regenerated $I X$ resin, is brought online. The first column is taken offline, and the waste water rerouted to the second column, and then to the third. The outlet of each IX vessel is monitored with radiation alarms. Additional monitoring equipment is located at the exit of the RO system. Automatically operated valves are provided to recycle poor quality treated waste water (not meeting the discharge limits) back to the surge tank, if needed, to prevent contamination of the verification tanks.

\subsubsection{200 Area Effluent Treatment Facility Evaporator. The ETF evaporator is fed alternately by the two secondary waste receiving tanks. One tank serves as a waste receiver while the other tank is operated as the ETF evaporator feed tank.}

Liquid level instrumentation in the secondary waste receiving tanks is designed to preclude a tank overflow. A liquid level switch actuated by a high-tank liquid level causes the valves to reposition, closing off flow to the secondary waste receiving tanks. Secondary containment for these tanks routes 1 iquids to sump tank No. 1 .

Valves in the ETF evaporator feed line can be positioned to bypass the secondary waste around the ETF evaporator and to transfer the secondary waste to the concentrate tanks.

4.3.1.8 Thin Film Dryer. The two ETF evaporator concentrate tanks alternately feed the thin film dryer. One tank serves as a concentrate waste receiver while the other tank serves as the dryer feed tank. Liquid level instrumentation prevents tank overflow by diverting the concentrate flow from the full concentrate tank to the other concentrate tank. Secondary containment for these tanks routes liquids to sump tank No. 1 .

An alternate route is provided from the concentrate receiver tank to the secondary waste receiving tanks. Dilute concentrate in the concentrate receiver tank can be reprocessed through the ETF evaporator by transferring the concentrate back to the secondary waste receiving tank.

\subsubsection{Piping, Instrumentation, and Process Flow [D-2a(3)]}

Drawings showing piping and instrumentation for each tank and process system are found in Appendix 4A. Specific pump data are found in Table 4-3. A schematic process flow diagram is provided in Figure 4-3. 
DOE/RL-93-03, Rev. 0

$08 / 31 / 93$

\subsubsection{Ignitable, Reactive, and Incompatible Waste [D-2a(4)]}

There is no ignitable or reactive waste treated, generated, or stored in the ETF. High and low pH materials are stored within the ETF, and incoming waste streanis might also be of high or low $\mathrm{pH}$. The potential risks of the mixture of incompatible high and low $\mathrm{pH}$ materials are discussed for three areas within the ETF where such mixing might occur: (1) the secondary containment of the concentrated chemical ieed tanks, (2) the secondary containment of the dilute chemical feed tanks, and (3) the surge tank.

Two concentrated chemical feed tanks on the outside of the south wall of the ETF Building store 92 weight percent sulfuric acid and 50 weight percent sodium hydroxide. These chemicals are used in various steps of the waste water treatment process to adjust $\mathrm{pH}$. The commingling of spilled material from both tanks would constitute the mixture of incompatible waste. To prevent this occurrence, the tanks are separated by a 4-foot- (1.2-meter-) high concrete berm, and have completely separate concrete secondary containment systems.

Two smaller tanks insid? the ETF Building on the south side contain solutions of 4 weight percent sulfuric acid and 4 weight percent sodium hydroxide. Such dilute concentrations of these acidic and basic materials do not pose any danger to personnel or equipment if spilled material from both tanks were commingled. For this reason, the two tanks are located within a single secondary containment area consisting of a 6-inch- (15.2-centimeter-) high concrete curb and the concrete floor.

It is possible that a combination of high- and low-pH waste waters could enter the surge tank for treatment, because variability might exist in the waste transferred to the surge tank. To evaluate potential excess heat generated from the mixing of high- and low-pH waste waters, the following scenario is used. (Note that no PUREX waste streams are anticipated for treatment in the ETF; however, to demonstrate the safety of the ETF with a worst-case scenario of potentially incompatible waste, a PUREX waste stream is used in these calculations.) The PC from the 242-A Evaporator and process distillate discharge (PDD) from the PUREX Plant are mixed in the surge tank. The PC has a PH of 11.3. The PDD from the PUREX PIant has a PH of 2.28. The temperature rise from the mixing of PC and PDD was analyzed and found to result in an insignificant rise in surge tank temperature.

In this scenario, the surge tank is receiving the $\mathrm{PC}$ at a rate of 75 gallons (284 liters) per minute and the PDD at a rate of 37.5 gallons (142 liters) per minute. The details of these calculations are provided in Appendix 4A. The hydroxyl ion $\left(\mathrm{OH}^{-}\right)$in the high $\mathrm{pH}$ solution from the $\mathrm{PC}$ reacts with the hydrogen ion $\left(\mathrm{H}^{+}\right)$in the acidic distillate from PDD to form water. The limiting reactant is the hydroxyl ion. By doubling the flow rate of the 242-A Evaporator PC, the moles of hydroxyl ion in the influent aimost are equivalent to the moles of hydrogen ion in the PDD (a worst-case scenario). If the total volume of $P C$ is 60,000 gallons $(227,124$ 1iters) and the volume of the PDD is 30,000 gallons $(113,562$ iiters), the neutralization reaction would generate 6,059 kilocalories of heat causing the tank 
temperature to rise a fraction of a degree. Therefore, there would be no risk to equipment or personnel from the combination of high- and low-pH waste waters entering the surge tank.

Beginning at the surge tank, the $\mathrm{pH}$ of the waste water being treated is carefuliy monitored and controlled. There are no other points in either the primary or secondary treatment train where potentially incompatible waste are managed.

\subsubsection{Labels or Signs}

Each piece of equipment in the ETF is identified by a nameplate attached in a readily visible location. Equipment procured as a packaged unit also has a nameplate attached. Included on the nameplate are the equipment number, the equipment title, the manufacturer and the manufacturer's model number, a serial number, and a rating (i.e., capacity, revolutions per minute, torque, range, span, etc.). Nameplates are mounted between control switches and status lights and below other devices on front panels of cabinets and control boxes to identify controls and indicators.

Caution plates are used to show possible hazards and warn that precautions are necessary. Caution signs have a yellow background and black panel with yellow letters and bear the word "CAUTION". Danger signs show immediate danger and signify that special precautions are necessary. These signs are red, black, and white and bear the word "DANGER".

Component numbers consist of a five-character alpha numeric string designating the building number followed by a three-character system number, a two-character component-type designator, a one-character sequential number, and a possible letter designator used for identical components performing the same function. (Example: 2025E-60F-TK-2D.)

Instrument equipment numbers consist of a two-character instrument type, and below this a three-character system number, a three-character sequential number, and a letter designator used for identical components performing the same function.

$$
\text { EXANTPLE: } \quad \frac{P I}{60 F 204 G}
$$

Equipment numbers for valves consist of a three-character system number and a two-character sequential number. Specialty valves (e.g., air-operated valve, solenoid-operated valve) follow the format for instrument equipment numbers. (Example: 60F-11.)

Line designation numbers for piping consist of a two-character piping size, a three-character system number, a two-character sequential number, and a four-character piping class number. (Example: $4^{n-60 F-27-1503 .) ~}$ 
Tanks and vessels containing corrosive waste or corrosive chemicals are posted with black and white signs bearing the word "CORROSIVE". Tanks and vessels containing dangerous waste are posted with hazardous waste labels. In addition, "NO SMOKING" and "DANGER - UNAUTHORIZED PERSONNEL KEEP OUT" signs are posted on all exterior doors of the ETF Building, and on each interior door leading into the process area.

\subsubsection{Existing Tank Systems [D-2b]}

All tank systems in the ETF are newly constructed. The requirements for existing tank systems are not applicable.

\subsubsection{Assessment of New Tank System Integrity [D-2C(1)]}

The ETF tank systems for handling dangerous waste are certified by a professional engineer for adequate structural integrity and suitability for the type of waste being handled and the type of treatment process contained (Appendix 4B). Various features of the tank systems are described in the following sections to support this certification.

For the 'packaged systems' procured for use in the ETF, including the filter systems, UV/OX system, degasification system, RO system, ETF evaporator, thin film dryer, and resin dewatering system, the system is required to meet national codes and standards and manufacturers' standards as listed in the following section. In addition, a thorough quality assurance program ensures that the equipment meets all specifications, is tested before shipment, and is inspected and retested before operation. Specific design standards for each of the major systems are discussed in the following section.

4.3.6.1 Design Standards for New Tank and Process System Construction. Specific standards for the manufacture of tanks and process systems installed in the ETF are briefly discussed in the following sections. In addition to these codes and industrial standards, a seismic analysis for each tank and process system is required [173-303-806(4)(a)(xi)]. The seismic analysis is performed in accordance with UCRL-15910 Design and Evaluation Guidelines for Department of Energy Facilities Subjected to Natural Phenomena Hazards, Section 4 (UCRL 1987). The ETF is classified as Hanford Safety Class 3, which corresponds to a Low Hazard/Important Facility Use category in UCRL-15910. Results of the seismic analyses are provided in Appendix $4 C$.

4.3.6.1.1 Storage and Treatment Tanks. The vertical storage tanks, maintained at or near atmospheric pressure for the storage of liquids within the ETF are specified to meet a series of design standards. The tanks to which these standards apply are as follows:

Surge tank

pH adjustment tank

Effluent $\mathrm{pH}$ adjustment tank

First RO feed tank
2025E-60A-TK-1

2025E-60C-TK-1

2025E-60C-TK-2

2025E-60F-TK-1 
Second RO feed tank

Verification tanks (3)

Secondary waste receiving tanks (2)

Concentrate tanks (2)

92-weight percent $\mathrm{H}_{2} \mathrm{SO}_{4}$ storage tank

50-weight percent $\mathrm{NaOH}$ storage tank

4-weight percent $\mathrm{H}_{2} \mathrm{SO}_{4}$ solution tank

4-weight percent $\mathrm{NaOH}$ solution tank

Sump tanks (2)

Distillate flush tank

Separation tank

\author{
2025E-60F-TK-2 \\ 2025E-60H-TK-1A/1B/1C \\ 2025E-60I-TK-1A/1B \\ 2025E-60J-TK-1A/1B \\ 2025E-65C-TK-1 \\ 2025E-65C-TK-2 \\ 2025E-65C-TK-3 \\ 2025E-65C-TK-4 \\ 2025E-20B-TK-1/2 \\ 2025E-60I-TK-2 \\ 2025E-60J-TK-2
}

The codes and standards applicable to the design, construction, and testing of these tanks and ancillary piping systems are as follows:
ASME - B31.3
Chemical Plant and Petroleum Refinery Piping
ASME Sect. VIII, (ASME 1990)
Division I
AWS - D1.1
Pressure Vessels (ASME 1992a)
ANSI - B16.5
Structural Welding Code - Steel (AWS 1992)
ASME Sect. IX
Pipe Flanges and Flanged Fittings (ANSI 1992)
API 650
Welding and Brazing Qual ifications (ASME 1992b)
API 620
Welded Steel Tanks for 011 Storage (API 1988)
Design and Construction of Large Welded Low

$$
\begin{aligned}
& \text { AWWA - D100 } \\
& \text { AWWA - D103 } \\
& \text { AWWA - D120 }
\end{aligned}
$$
Pressure Storage Tanks (API 1990)
Welded Steel Tanks for Water Storage (AWA 1989)
Factory-Coated Bolted Steel Tanks for Water
Storage (AWWA 1987)
Thermosetting Fiberglass-Reinforced Plastic
Tanks (AWWA 1984).

The application of these standards to the construction of ETF tanks and independent verification of completed systems ensures that the tank and tank supports have sufficient structural strength and that seams and connections are adequate to ensure tank integrity. In addition, each tank must meet strict quality assurance requirements. Each tank constructed offsite has been tested for integrity and leak tightness before shipment to the Hanford Facility. Following installation, the systems are inspected for damage to ensure against leakage and to verify proper operation. If a tank were damaged during shipment or installation, leak tightness testing was repeated onsite.

4.3.6.1.2 Filters. The filter vessels are designed to comply with the ASME Section VIII, Division I, Pressure Vessels (ASME 1992a). The filter piping system is designed to withstand the effects of internal pressure, weight, thermal expansion and contraction, and any pulsating flow. The application of these standards to the construction of the ETF filter system and independent inspection ensures that the filter and filter supports have sufficient structural strength and that the seams and connections are adequate to ensure the integrity of the filter vessels. 
4.3.6.1.3 U1traviolet Oxidation System. The UV/OX reaction chamber is designed to comply with manufacturers standards. The piping system is designed to withstand the effects of internal pressure, weight, thermal expansion and contraction, and any pulsating flow.

4.3.6.1.4 Degasification system. The codes and standards applicable to the design, fabrication, and testing of the degasification column are identified as follows.

ASME Section VIII, Division I, Pressure Vessels (ASME 1992a)

ASME - B31.3, Chemical Plant and Petroleum Refinery Piping (ASME 1990)

AWS - D1.1, Structural Welding Code - Steel (AWS 1992)

ANSI - B16.5, Pipe Flanges and Flanged Fittings (ANSI 1992)

The piping for the degasification system is designed to withstand the effects of internal pressure, weight, thermal expansion and contraction, and any pulsating flow.

4.3.6.1.5 Reverse Osmosis System. The pressure vessels are designed to comply with ASME Section VIII, Division I, Pressure Vessels (ASME 1992a), and applicable codes and standards. The piping system is designed to withstand the effects of internal pressure, weight, thermal expansion and contraction, and any pulsating flow.

4.3.6.1.6 Polisher. The IX columns are designed in accordance with ASME Section VIII, Division I, Pressure Vessels (ASME 1992a), and applicable codes and standards. The piping system is designed to withstand the effects of internal pressure, weight, thermal expansion and contraction, and any pulsating flow. Polisher piping is fabricated of type 304 stainless steel or polyvinyi chloride (PVC) and meets the requirements of ASME B31.3, Chemical Plant and Petroleum Refinery Piping (ASME 1990).

4.3.6.1.7 200 Area Effluent Treatment Facility Evaporator. The ETF evaporator is designed to meet the requirements of ASME Section VIII, Division I, Pressure Vessels (ASME 1992a), and applicable codes and standards. The piping is designed to withstand the effects of internal pressure, weight, thermal expansion and contraction, and any pulsating flow. The ETF evaporator piping meets the requirements of ASME B31.3, Chemical Plant and Petroleum Refinery Piping (ASME 1990).

4.3.6.1.8 Thin Film Dryer System. The thin film dryer is designed to meet the requirements of ASME Section VIII, Division I, Pressure Vessels (ASME 1992a), and applicable codes and standards. The piping is designed to withstand the effects of internal pressure, weight, thermal expansion and contraction, and any pulsating flow. The piping meets the requirements of ASME - B31.3, Chemical Plant and Petroleum Refinery Piping (ASME 1990).

4.3.6.2 Compatibility of Tanks with Waste to be Handled. The tank and process systems are constructed of materials that are compatible with the corrosive and radioactive characteristics of the waste. In general, equipment and piping that contain radioactive fluids are made of type 304 or 316L stainless steel, PVC, fiberglass-reinforced plastic, or lined with a 
material that can be decontaminated (e.g., Teflon ${ }^{1}$ ). Where radioactive concentration is very low, carbon steel is acceptable. For equipment and piping that contain highly corrosive fluids, such as the ETF evaporator bottoms, either $316 \mathrm{~L}$ stainless steel or Inconel $625^{2}$ was used. Valves provided at the interface between different piping matertals are made of the higher grade material at the interface. Table 4-2 identifies the materials used in fabrication of the tanks, process equipment, piping, and pumps.

4.3.6.3 Corrosion Assessment and Protection. A detailed corrosion potential analysis will be conducted by a National Association of Corrosion Engineers (NACE)-certified corrosion expert. The corrosion analysis report is provided in Appendix 40.

4.3.6.4 Protection of Underground Tanks from Vehicular Traffic Damage. The only underground tanks at the ETF are the sump tanks, which are part of the secondary containment system described in Section 4.3.8. These tanks are protected by the concrete vaults that contain them, the concrete floor of the ETF Building, and by the building itself. The sump tanks are not vulnerable to damage from vehicular traffic.

4.3.6.5 Assessment of Adequacy of Tank Foundation and Anchoring. Classical theories of structural analysis, soil mechanics, and concrete and structural steel design were used in the design calculations for the foundations and structures of the ETF. Structural calculations are provided in Appendix $4 A$. In each of the analyses, the major design criteria from the following documents were included:

- $\quad \mathrm{C}-\mathrm{C018HC1-001}$

- DOE Order 6430.1A

- $S D C-4.1$

- UCRL-15910

- UBC-91
Design Construction Specification, Project C-018H, 242A Evaporator/PUREX Plant Process Condensate Treatment Facility (WHC 1992)

\section{General Design Criteria}

Standard Architectural-Civil Design Criteria, Design Loads for Facilities (DOE-RL 1988a)

Design and Evaluation Guidelines for Department of Energy Facilities Subjected to Natural Phenomena Hazards (UCRL 1987)

Uniforn Building Code, 1991 Edition (ICBO 1991).

${ }^{1}$ Teflon is a trademark of E.I. DuPont de Nemours \& Company, Wilmington, Delaware.

${ }^{2}$ Inconel is a trademark of Inco Alloys International, Incorporated, Huntington, West Virginia. 
The calculations presented in Appendix 4A substantiate the structural designs presented in the construction drawings and specifications. The conclusions drawn from these calculations indicate that the designs are sound and that the specified structural design criteria were met.

4.3.6.6 Protection Against Frost Heave. All tanks at the ETF, other than the sump tanks, are located above ground, on concrete pads, or platforms. All outside tanks are equipped with heaters to prevent the contents from freezing. All piping outside the ETF Building that is not buried below the frost level is heat traced. The sump tanks are located well below the frostline, which is at approximately 18 inches ( 46 centimeters) below ground surface. In addition, the sump tanks are located within the perimeter of the ETF Building, which has frost barriers on all outside walls and footings. Heat loss through the floor of the building also aids in protecting the sump tanks from frost heave or other damage caused by freezing.

\subsubsection{Description of Tank System Inspection, Verification, and Testing Procedures [D-2C(2)]}

Tanks, piping, and process systems in the ETF were subject to several inspections and tests before waste water was processed. These activities include factory verifications and testing of major tank system components, module functional testing, site installation verifications and testing, module functional testing, and acceptance test procedures, which include operations test procedures as described in the following sections.

\subsubsection{Inspection, Verification, and Testing Phases. Three phases of} construction inspection, verification, and testing were performed on the ETF equipment and systems before the ETF processed waste water. The first phase (onsite) was construction inspection, verification, and testing of components and equipment. In this step, various aspects of the construction of the ETF Building, such as soil and concrete testing, welding inspection, electrical testing, and verification of approved material, equipment, components, configuration, and dimensions were evaluated against applicable codes and standards and the approved design documents. This phase is summarized in Table 4-4. Information presented in Table 4-4 includes various aspects of construction (e.g., soils, concrete, structural steel, instrumentation, piping) and associated codes and standards.

For each of the 'packaged' systems fabricated offsite, the manufacturer was required to submit a factory inspection and test plan for approval before construction of the unit. This factory inspection and test plan includes verification tests to ensure compliance with codes and standards and proper operation of the equipment, crmponents, and modules that might include testing at full flow and pressures. Factory testing was in accordance with industry standards. Nondestructive examination and testing personnel are required to be qualified in accordance with American Society for Nondestructive Testing recommended practice No. SNT-TC-IA (ASNT 1988). 
The factory acceptance test for each unit was performed to demonstrate the ability of the system to meet the required specifications, and to demonstrate the proper functioning of the electrical instruments and controls. A leak test was required on all piping to confirm leak tightness. Repair was required for any leaks. To pass, the piping must have no leaks. Electrical examinations include continuity checks and functional tests of controls and instrumentation.

The second phase of the inspection, verification, and testing procedure was onsite verification and testing. The onsite verification and testing $p l a n$ includes all process and auxiliary systems assembly and hookup verification, preliminary equipment and module testing, and verifications. The acceptance test procedure includes ensuring that ail equipment, components, and systems are properly cleaned, lubricated, supported, and otherwise ready to be functionally tested. Electrical equipment was energized to ensure proper phasing and motor rotation, and other mechanical equipment was operated through applicable ranges to affirm operability. Calibration, grooming, and alignment of equipment also were performed at this time.

The third phase of inspection, verification, and testing was the onsite acceptance test procedure. The purpose of the acceptance test procedure is to ensure that all software, equipment, and modules function correctly as a system and as intended by the design. Site acceptance testing encompasses all vendor-furnished equipment.

The acceptance test simulates the actual operating conditions and demonstrates the completeness of the operating manuals for the equipment. Initially, the test was performed with water, followed by testing with a synthetic nonradioactive liquid waste feed containing 430 parts per million of ammonium ion and 110 parts per million of tributyl phosphate, and having a pH of 10.9. Testing with the synthetic feed is conducted over a specified operating range. The acceptance test includes startup, normal operation, demonstration of all abnormal operating conditions, safe shutdown, system flushing, and decontamination.

Included in the tests are the following equipment:

- Process treatment modules/systems

- Integrated test for operation of computer control system

- Electrical substation and switchgear

- Emergency/backup/safety power

- Fire detection and alarm

- ETF evaporator and other specialty process equipment

- Heating, ventilation, and air conditioning system

- Leak detection

- Utilities.

Complete documentation is required of the acceptance testing. This documentation included a narrative that describes in detail the purpose of the test and the expected results, a step-by-step description of procedures, 
DOE/RL-93-03, Rev. 0

$08 / 31 / 93$

actual results, and an indicator of acceptable performance. Any deficiencies that might be evident in the design or fabrication of the ETF equipment during the test were documented and corrected.

4.3.7.2 Backfill Procedures for Underground Tanks. The sump tanks are the only ETF tanks that are installed below grade. Backfill under the slab and around the concrete vaults that contains the sump tanks are installed and compacted according to the requirements of Washington State Department of Transportation regulations M41-10-88, Section 2-03.3(14)C (WAC 296-155). A11 other tanks at the ETF are on or above ground.

4.3.7.3 Tightness Testing Plans and Procedures. Examination of all piping systems, joints, and welds was performed before leak/pressure testing was conducted. Methods outlined in ASME B31.3, paragraphs 341 and A341 (ASME 1990) (normal service), are used for this examination. Randomly selected finished welds are examined radiographically in accordance with ASME B31.3, paragraph 344.5 (ASME 1990). Leak/pressure testing is performed according to ASME B31.3, paragraph 345 (ASME 1990). Hydrostatic testing is performed before lining the tanks. Hydrostatic testing of piping is conducted in accordance with ASME B31.3, paragraph 345.4 (ASME 1990). Pneumatic testing is performed per ASME B31.3, paragraph 345.5 (ASME 1990), using oil-free air or high-purity nitrogen.

4.3.7.4 Support and Protection of Anctllary Equipment. Pumps are rated for continuous duty and capable of pumping the specified flow range without surging, cavitation, or vibration (WHC 1991). Stable pump operation is provided by motors sized to operate on the pump curve within the limits of stable pump operation. Rotative components of pumps are statically balanced. Mass of a pump and its distribution are such that resonance at normal operating speed is avoided.

Pipe hangers and supports meet the requirements of Hanford Plant Standard SDC-4.1 (DOE-RL 1988a) and UCRL 15910 (UCRL 1987). Piping systems are designed to withstand the effects of internal pressure, weight, thermal expansion and contraction, and any pulsating flow. All piping is supported and protected using pipe hangers and supports as indicated in the piping drawings. Standard types of manufactured pipe hanger components meet the requirements of MSS SP-58, Hanford Plant Standard SDC-4.1, Section C.2, or as otherwise specified on the design drawings. (Refer to Drawings $\mathrm{H}-2-89803$ through $H-2-89811$ in Appendix 4A). Supports for fiber-reinforced piping and PVC piping are spaced no further than 5 feet (1.5 meters) on center.

\subsubsection{Design of Secondary Containment System [D-2d-D-2d(2)]}

Secondary containment is provided for all tanks and process piping by a coated concrete floor and bermed area. The transfer piping that carries waste water into the ETF is pipe-within-a-pipe construction, and is buried approximately 4 feet (1.2 meters) below ground surface. The pipes between the verification tanks and the verification tank pumps are located in a concrete pipe trench that runs below the road. 
For the purposes of this discussion, the five secondary containment systems within the ETF are described individually. Each containment area has been given a name associated with the tank or process area it contains. Table 4-5 shows the five containment systems, the equipment each contains, and the relevant materials to be contained.

\subsubsection{Design Requirements for Specific Secondary Containment Type} $(D-2 d(1)(C)]$. The process area and dilute chemical storage containment systems are housed within the ETF Building, which has a jointed concrete slab floor. This floor is 6 inches ( 15 centimeters) thick with fillers and sealant in all floor joints and at floor/wall joints. There are waterstops at all floor/wall joints and all floor/berm joints. The floors are coated with a multiple-1ayer chemical-resistant sealant (Appendix 4A). Table 4-6 summarizes the specifics types of filler, primer, second, and finish coats specified for the concrete and masonry surfaces in the ETF. This coating protects the concrete floors and berms from contact with any chemical materials that might be harinful to concrete.

The process area floor is sloped to two separate trenches that each drain to a sump tank located under the floor of the ETF Building (Drawing H-2-89071 in Appendix 4A). One trench runs the length of the primary treatment train and drains to sump tank No. 2 located underneath the verification tank pump room floor (Figure 4-2). The second trench collects spillage from the secondary treatment train and flows to sump tank No. 1 located near the ETF evaporator. Both sump tanks are 800-gallon $(3,028-1$ iter) double-walled steel tanks, placed inside concrete vaults (Drawing H-2-89065 in Appendix 4A).

The dilute chemical storage containment system is separated from the process area containment system by a 6-inch- (15-centimeter-) high concrete curb. Waste material from this containment area flows to the sump tanks.

The concentrated chemical storage containment system is divided into two separate containment areas, one for the sulfuric acid tank and the other for the sodium hydroxide tank. The two areas are defined by a 4-foot(1.2-meter-) high concrete berm and 6 inch- (15 centimeter-) thick concrete slab on grade that is constructed and coated in the same manner as the ETF Building floor. Each containment area is sloped to a small sump in the corner of the diked area. This containment system is not covered.

The secondary containment systems for the verification tanks and the surge tank are similar. Each tank is mounted on a concrete ring wall as shown in Drawing H-2-89070, Section 3 (Appendix 4A). Inside the ringwall, the flat-bottomed tank is supported by a bed of compacted sand and gravel. Underneath this sand and gravel bed is a high density polyethylene liner placed on grade and continuously bonded to the ringwall. A drain pipe extends from the sand and gravel bed through the ringwall to the concrete slab surrounding the tank. This pipe collects any leaked material from under the tank and allows for the visual detection of a leak. In each of these containment systems, the concrete slab is sloped to a sump. Liquid collected in the verification tank containment system sump is pumped to sump tank No. 2. Liquid collected in the surge tank containment system sump is pumped to sump tank No. 1. A concrete wall defines the perimeter of both containment 
1 systems. The height of the verification tank containment system wall is 8 feet 6 inches (2.6 meters). The wall around the surge tank containment area is 9 feet 6 inches (2.9 meters) high.

Each of these containment areas is designed to contain more than 100 percent of the volume of the largest tank in each respective system. Secondary containment systems for the surge tank, verification tanks, and the concentrated chemical storage tanks, which are outside the ETF Building, also are large enough to include the additional volume from a 100-year, 24-hour storm eveni: 2.1 inches (5.3 centimeters) of precipitation. Information regarding tank and containment system volume is presented in Table 4-7. The calculations supporting this information are provided in Appendix 4A.

4.3.8.2 Abllity to Prevent Releases to Environment. The base of each containment system is a steel-reinforced concrete slab. All slab joints and floor and wall joints have waterstops installed at the mid-depth of the slab [Drawing H-2-89067, Detail C (Appendix 4A)]. In addition, filler was applied to each joint, and the entire floor and curb surfaces were coated with an impervious, chemical-resistant sealant (Appendix 4A). This coating is not affected by corrosive materials and prevents the concrete from being in contact with waste material. Table 4-6 presents the coating schedule for concrete and masonry surfaces in the ETF. The concrete bases and curbs are free of cracks, gaps, holes, and other imperfections. Thus, the concrete containment systems do not allow spilled liquid to reach soil or groundwater.

There are a number of personnel doorways and vehicle access points into the process area. The 6-inch (15-centimeter) concrete curbs are continuous across these access points, preventing the release from the process area of any spilled or leaked material outside the ETF Building.

\subsubsection{Compatibility of Materials of Construction with Haste. All of the} concrete surfaces in the secondary containment systems are coated with a multiple-layer, chemical-resistant epoxy coating (Appendix 4A). This coating material is compatible with the waste being treated in the ETF, and with the sulfuric acid, sodium hydroxide, and hydrogen peroxide additives to the process. The coating protects the concrete that, if not coated, could be affected by continuous or repeated contact with a strong acid.

4.3.8.4 Adequacy to Prevent Failure. All of the secondary containment systems are designed with sufficient reinforcing steel and base and berm thickness to prevent failure caused by pressure gradients, physical contact with the waste, climate conditions, and daily operational stress. Classical theories of structural analysis, soil mechanics, and concrete and structural steel design were used in the design calculations for the foundations and 
concrete slabs of the ETF secondary containment structures. Structural calculations are provided in Appendix 4A. In each of the analyses, the major design criteria from the following documents were included:

- V-C018HC1-001

- DOE Order 6430.1A

- $S D C-4.1$

- UCRL-15910

- $S-1312-001$

- UBC-91
Design Construction Specification, Project C-018H, 242A Evaporator/PUREX Plant Process Condensate Treatment Facility (WHC 1992)

General Design Criteria

Standard Architectural-Civil Design Criteria, Design Loads for Facilities (DOE-RL 1988a)

Design and Evaluation Guidelines for Department of Energy Facilities Subjected to Natural Phenomena Hazards (UCRL 1987)

Procedure for Seismic Analysis (JGC 1992)

Uniform Building Code, 1991 Edition (ICBO 1991).

The calculations presented in Appendix $4 \mathrm{~A}$ substantiate the structural designs presented in the construction drawings and specifications. The conclusions drawn from these calculations indicate that the designs are sound and that the specified structural design criteria have been met. Calculations demonstrating design adequacy for the high containment walls and the concrete slabs are located in Appendix $4 A$.

4.3.8.5 Adequacy of Foundation. A soil analysis was conducted to determine allowable soil bearing pressure and soil compaction potential (Dames and Moore 1992). The soil composition was found to include 2 to 3 feet $(0.61$ to 0.91 meter) of loose sand at the surface, about 25 feet ( 7.6 meters) of dense gravel beneath the sand, and a sequence of very dense we1l graded sand below the gravel. The bearing capacity of the soil was calculated to be approximately 7,000 pounds per square foot $(34,174 \mathrm{kilograms}$ per square meter). The total estimated settling potential is 0.2 to 0.5 inch $(0.5$ to 1.3 centimeters). The total potential differential between footings was calculated to be 0.2 inch ( 0.5 centimeter). Shear testing indicated that there was no impending shear failure at a maximum applied pressure of 10,000 pounds per square foot $(48,820$ kilograms per square meter) (Dames and Moore 1992).

Recommendations in the geotechnical report directed that the footings be constructed on the gravel layer, with a minimum size of 2 feet by 2.5 feet ( 0.61 by 0.76 meter); and that the slabs be constructed on sand or gravel compacted to the 95 percent compaction level (Dames and Moore 1992).

As mentioned in Section 4.3.8.4, structural theory and specified codes were applied to the design of ETF structures. Design calculations demonstrating the adequacy of the foundation are presented in Appendix $4 A$. 
4.3.8.6 Leak Detection System. Process unit or tank leaks in the process area are detected visually or electronically. Spilled or leaked material in this area is collected in the two trenches that slope to the sump tanks. Sump pumps are activated by liquid level sensors in the sump tanks. The concrete vaults that house the sump tanks are equipped with moisture detectors (Drawing H-2-88991 in Appendix 4A).

Leak detection in the dilute chemical storage containment system is accomplished by daily visual inspection. Leak detection in the secondary containment systems for the surge tank, verification tanks, and concentrated chemical storage tanks is accomplished by moisture detectors in the sumps located in the corners of each of these containment areas.

In addition, the collection pipe located in the sand and gravel bed under the surge tank and the verification tanks is used to visually determine whether these tanks are leaking. Dally visual inspection of the outside of the tanks, the collection pipes, and the concrete base of the secondary containment systems is conducted.

Leak detection in the transfer lines between the ETF and the 242-A Evaporator and the LERF is described in Section 4.3.9.7.

4.3.8.7 Collection and Removal of Waste. Spilled or leaked material from the process area is collected in two trenches that are sloped to the sump taniks. Each sump tank is equipped with two pumps, one of which is activated automatically if the liquid level reaches a preset point. The pumps are intended to alternate operation. If the rate of liquid accumulation in the sump tank is greater than the capacity of one pump to remove it, the second pump can be operated simultaneously. Collected material is pumped from the sump tanks to the surge tank.

Any accumulation of liquid in the dilute chemical storage containment system is detected visually by process operators. This liquid is characterized and pumped to the appropriate tank using a portable vacuum pump.

If liquid accumulates in the outdoor secondary containment areas (surge tank, verification tanks, and concentrated chemical tanks), moisture sensors in the sumps activate an alarm light in the control room. The liquid is characterized and pumped out of the containment system by a dedicated, locally operated pump. Liquid collected in the verification tank containment system is pumped into sump tank No. 2. Collected liquid from the surge tank containment system is pumped into sump tank No. 1. Sodium hydroxide is pumped into a portable holding tank or container for disposal. If the liquid is determined not to be dangerous waste, such as clean rain water, the liquid is pumped to the storm drains. 
DOE/RL-93-03, Rev. 0

$08 / 31 / 93$

\subsubsection{Secondary Containment and Leak Detection for Ancillary Equipment [D-d(1)(d)]}

For nearly all of the ancillary equipment, the secondary containment provided for the tanks and process systems also serves the ancillary equipment associated with these systems. For all of the ancillary equipment housed within the ETF Building, the floor, trenches, and sump tanks comprise the secondary containment system. Piping to and from the dilute and concentrated chemical storage tanks is contained by the respective containment curbs for those four storage tanks. The transfer piping and pipes between the verification tanks and the verification tank pump room are contained in a different manner, as explained in the following sections.

\subsubsection{Description of Secondary Containment for Ancillary Equipment.}

Section 4.3.8.1 describes the secondary containment systems that also serve most of the ancillary equipment for the ETF. Between the ETF Building and the verification tanks, there are four pipe trenches that comprise the secondary containment for four lines connecting equipment in the ETF Building with the verification tanks. Treated waste water flows through this piping from the process area to the verification tanks. In addition, there are return lines provided to handle treated waste water that must be reprocessed. Waste accumulated by the secondary containment system for the verification tanks also returns via piping. These pipes are contained in concrete trenches that cross under the road and enter the verification tank pump room.

The four pipe trenches are each 4 feet (1.2 meters) across, 2.5 feet ( 0.76 meter) deep, and almost 50 feet (15.2 meters) long. The sides of the trenches are 6-inch- (15-centimeter-) thick concrete, and the concrete bases are 12 inches ( 30 centimeters) thick. Each pipe trench is covered by a 2-inch- (5-centimeter-) high cast iron grating.

4.3.9.2 Transfer Piping. The transfer piping consists of one 3-inch to 6-inch pipe-within-a-pipe 7 ine that extends from the 242-A Evaporator 1 ine to the ETF surge tank, and one 4-inch to 8-inch pipe-within-a-pipe line that runs directly from the LERF to the ETF. These lines each are comprised of a small-diameter inner carrier pipe inside a larger diameter containment pipe. The pipes are made of fiberglass, with leak detection elements located in the annulus between the inner and outer pipes. The leak detectors are located at every 1,000 feet (305 meters) of pipe length. Should moisture be detected, alarms annunciate in the ETF operations room and at the 242-A Evaporator simultaneously, and the influent supply pump shuts off automatically. Leaked material drains into the sump near the surge tank.

Pipe supports are fabricated of the same material as the pipe, and meet the strength requirements of ASME B31.3 (ASME 1990) for pipe within the containment (outer) piping to prevent sagging or buckling failure under thermal expansion. Containment pipe and carrier pipe have a design pressure of 60 pounds per square inch (7.0 kilograms per square centimeter) gauge, and can accommodate fluid temperatures from 40 to $120^{\circ} \mathrm{F}\left(4\right.$ to $\left.49^{\circ} \mathrm{C}\right)$. 
4.3.9.4 Compatibility of Materials of Construction with Waste. The compatibility of the concrete base and berm systems with the waste materials is discussed in Section 4.3.8.3. The interior pipe trench walls and base are coated with the same multiple-layer, chemical-resistant sealant as described in Section 4.3.8.3. Moreover, the treated waste water is expected to be clean water by the time it reaches the pipeline to the verification tank, containing less than 11 parts per million of organics, no dissolved or suspended solids, and having a total radioactivity of less than 35 picocuries per cubic meter of material (Drawing H-2-88971 in Appendix 4A).

The piping material was tested previously using SW-846 Method 9090 (EPA 1986) to ensure the compatibility of the piping material with the waste water. Results of the 9090 testing are documented in the LERF Part B Permit Application (DOE/RL-90-43).

4.3.9.5 Adequacy to Prevent Faflure. The pipe trenches were designed to withstand the load of vehicular traffic. The assumptions used and calculations involved in the design of the pipe trenches are found in Appendix $4 \mathrm{~A}$. The transfer piping was designed, constructed, and installed according to industry standards. The purpose of these standards is to ensure against failure of the piping system once the system is loaded. In addition, construction inspections and verification testing affirm that the piping system operates as the design intended, that there are no leaks, and that the leak detection and collection systems are functional. 
4.3.9.6 Adequacy of Foundation. The calculations used to design the pipe trench can be found in the structural design calculations (Appendix 4A). The adequacy of the foundation of the major components of the secondary containment systems is discussed in Section 4.3.8.5.

The transfer piping is placed in a trench approximately 4 feet (1.2 meters) deep, lined with 8 inches (20 centimeters) of sand compacted to 95 percent. This installation was performed according to specifications. Trenches were kept free of standing water while pipe laying was in progress. In addition, procedures to prevent damage to the piping system were employed, including the use of tools specifically adapted for cutting and fitting fiberglass pipe, care in the making of joints, capping of pipe ends between workdays or when installation was not in progress, proper storage of bonding materials and adhesives, and avoidance of the pipeline/trench area by vehicular traffic. Pipe was protected from sharp objects, impact shocks, and dropping through careful storage and handling. The pipe was inspected visually for damage before laying and any damaged sections were discarded and replaced.

4.3.9.7 Leak Detection System. Leak detection in the major portions of the secondary containment systems is discussed in Section 4.3.8.6. If a leak should occur in one of the pipes in the pipe trench, the leak would be detected visually through the steel grating or at the entrance of the pipe trench through the pump room wall, by the moisture meter in sump pump No. 2, or by operation of the pump in sump tank No. 2. Visual examination of the pipe trenches, interior trenches, and sump pump operation are performed daily by operations personnel.

Leak detection in the transfer piping was accomplished by single-point electronic leak detection elements installed at 1,000-foot (305-meter) intervals along the two transfer lines. The leak detection elements are located in the bottom of specially designed test risers. The conductivity sensor in each element was connected via standard mating connectors and sensor cable to a jumper cable leading back to the 242-A Evaporator control room or to the ETF control room. The sensors are corrosion-resistant to acids, bases, and water, and are reusable after exposure to moisture. On detection of a leak in the line, an alarm/locator module sounds an audible alarm and a visual display of the zone number where the leak was detected is indicated. In addition, the pumps are interlocked to the leak detection system and are shut down automatically when a signal is received in the control room. Flow is diverted to a holding tank in the 242-A Evaporator. The transfer piping is equipped with a self-testing system. An external acknowledge button clears the alarm.

This leak detection system is similar to that employed on the transfer 1 ine between the 242-A Evaporator and the LERF (DOE/RL-90-43).

4.3.9.8 Collection and Removal of Waste. The pipe trenches are sloped to drain to the interior trench in the ETF Building, which drains to sump tank No. 2. Accumulated liquid is pumped automatically from the sump tank to the surge tank, as described in Section 4.3.8.7. 
If a leak were detected in one of the transfer lines, operations personnel would note the zone indicated by the alarm/locator module and mobilize to the affected zone. Swab risers are located every 100 feet (30 meters) along the transfer lines to facilitate pinpointing and repairing any leak detected by the electronic components, and to facilitate the removal of 242-A Evaporator PC. Starting at the nearest swab riser upstream from the affected leak detection element, maintenance and/or spill personnel would locate the damaged section of pipe. By lowering absorbent material on a rod into a swab riser and withdrawing it, personnel would determine whether any moisture were present at that point. Proceeding upstream, personnel would continue to monitor each swab riser until no fluid were found present at a swab point. The damaged pipe between the last wet swab riser and the first dry swab riser would be excavated and replaced, using proper decontamination and handling procedures.

\subsubsection{Variance from Secondary Containment Requirements [D-2d(3)] \\ A variance from secondary containment requirements is not requested.}

\subsubsection{Spil1 and Overflow Prevention [D-2C]}

Overfill prevention controls used in the ETF include liquid level sensing devices, high-liquid level alarms, automatic feed cutoffs, or other automatic valve controls for the process tanks. These are described in Section 4.3.1. Dry disconnect couplings are used on all chemical feed tank filling operations. A plan and schedule for inspection of this spill and overflow prevention equipment are included in the inspection procedures described in Chapter 6.0.

\subsubsection{Compliance With Air Quality Regulations}

The requirements in 40 CFR 264, Subpart AA, apply to permitting for process vents associated with distillation, fractionation, thin film evaporation, solvent extraction, or air or steam stripping operations that manage hazardous waste with organic concentrations of at least 10 parts per million by weight. The ETF includes an evaporation and thin film drying process. However, the concentration of organics in the waste water entering these processes is well below 10 parts per million. Nearly all of the organics will have been destroyed in the UV/OX process, which is upstream of the ETF evaporator and thin film dryer. Therefore, the requirements of Subpart AA do not apply to process vents in the ETF.

The requirements in 40 CFR 264, Subpart BB, apply to hazardous waste facilities that manage waste streams containing organic concentrations of at least 10 percent by weight. The waste waters entering the ETF will not contain 10 percent or more organics by weight. Therefore, the requirements of Subpart BB do not apply to the ETF. 
The DOE-RL has submitted three air permit applications to the Washington State Department of Health, Washington State Department of Ecology, and EPA, Region 10. Detalled discussions of potential air emissions from the ETF are included in these permit applications and are beyond the scope of this Part B permit application documentation.

\subsection{MASTE PILES [D-3]}

Operation of the ETF does not involve the placement of dangerous waste in waste piles. Therefore, the requirements of WAC 173-303-660 are not applicable to the ETF.

\subsection{SURFACE IMPOUNDMENTS [D-4]}

Operation of the ETF does not involve the placement of dangerous waste in surface impoundments. Therefore, the requirements of WAC 173-303-650 are not applicable to the ETF.

\subsection{INCINERATORS [D-5]}

Operation of the ETF does not involve the incineration of dangerous waste. Therefore, the requirements of WAC 173-303-670 are not appilicable to the ETF.

\subsection{LANDFILLS [D-6]}

Operation of the ETF does not involve the placement of dangerous waste in landfills. Therefore, the requirements of WAC 173-303-665 are not applicable to the ETF.

\subsection{LAND TREATMENT [D-7]}

Dangerous waste constituents and residue have been removed from the ETF waste water by the time the treated waste water reaches the verification tanks. The treated waste water does not exhibit any dangerous waste characteristics and does not contain levels of organic compounds above the state waste discharge permit limits. Samples are collected regularly from the verification tanks and analyzed to verify the success of the treatment process and to confirm that the treated waste water is safe for discharge. The discharge of this waste water to ground is contingent upon approval of a federal delisting petition and regulated through a Washington State waste discharge permit under the authority of WAC 173-216. Thus, operation of the ETF does not involve land treatment of dangerous waste. Therefore, the requirements of WAC 173-303-655 are not applicable to the ETF. 
DOE/RL-93-03, Rev. 0 $08 / 31 / 93$

This page intentionally left blank. 


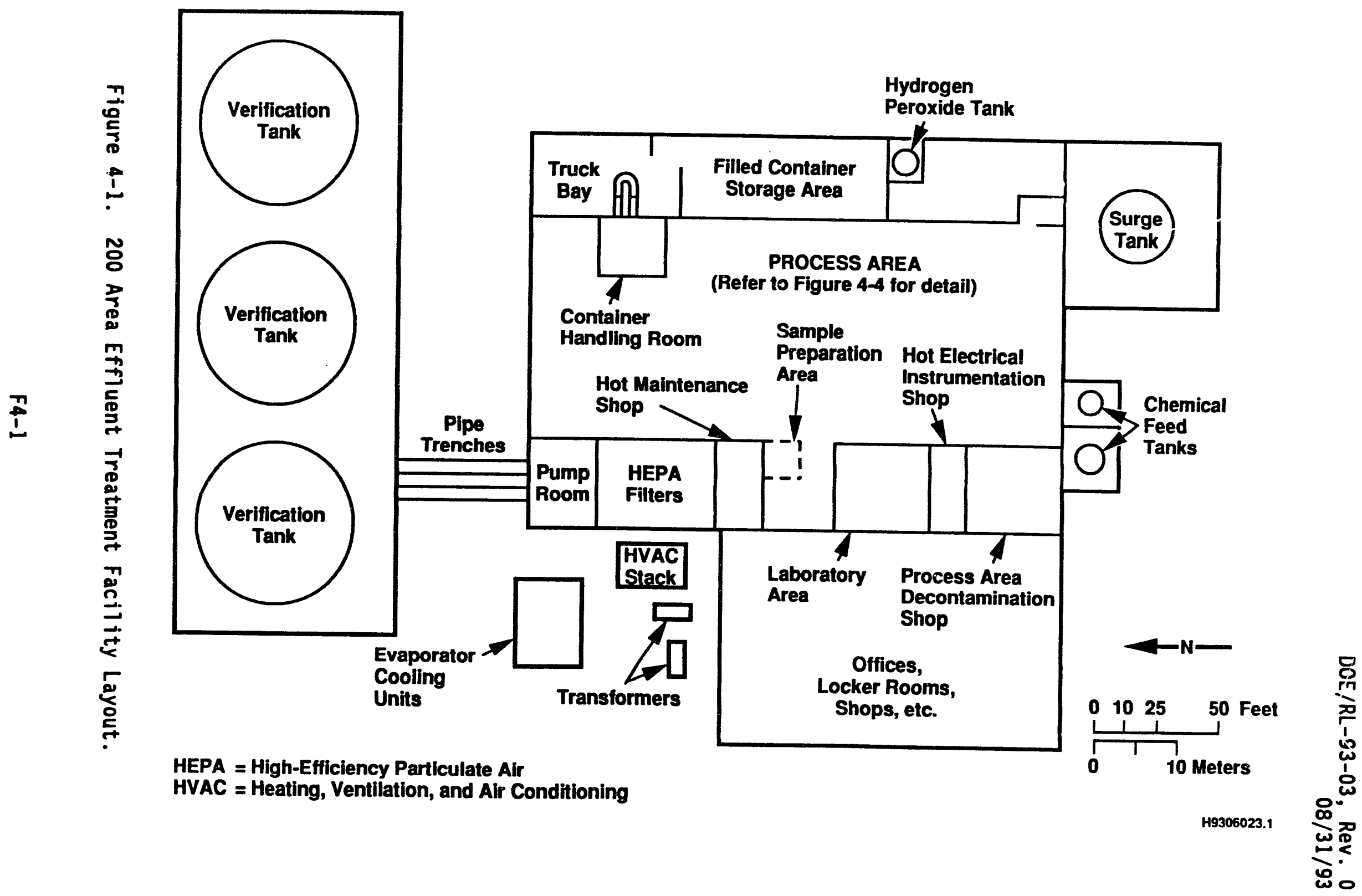




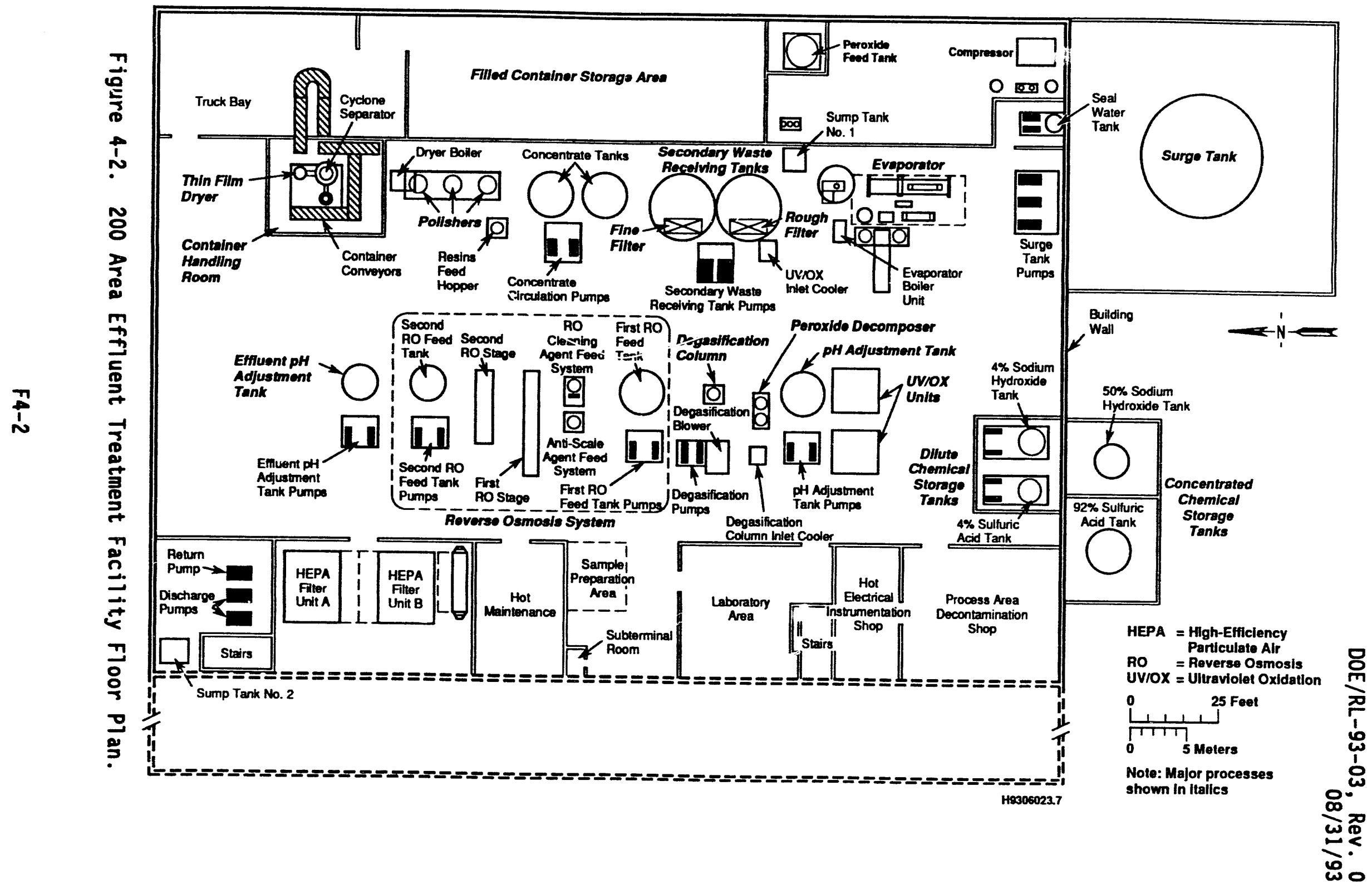


DOE/RL-93-03, Rev. 0

$08 / 31 / 93$

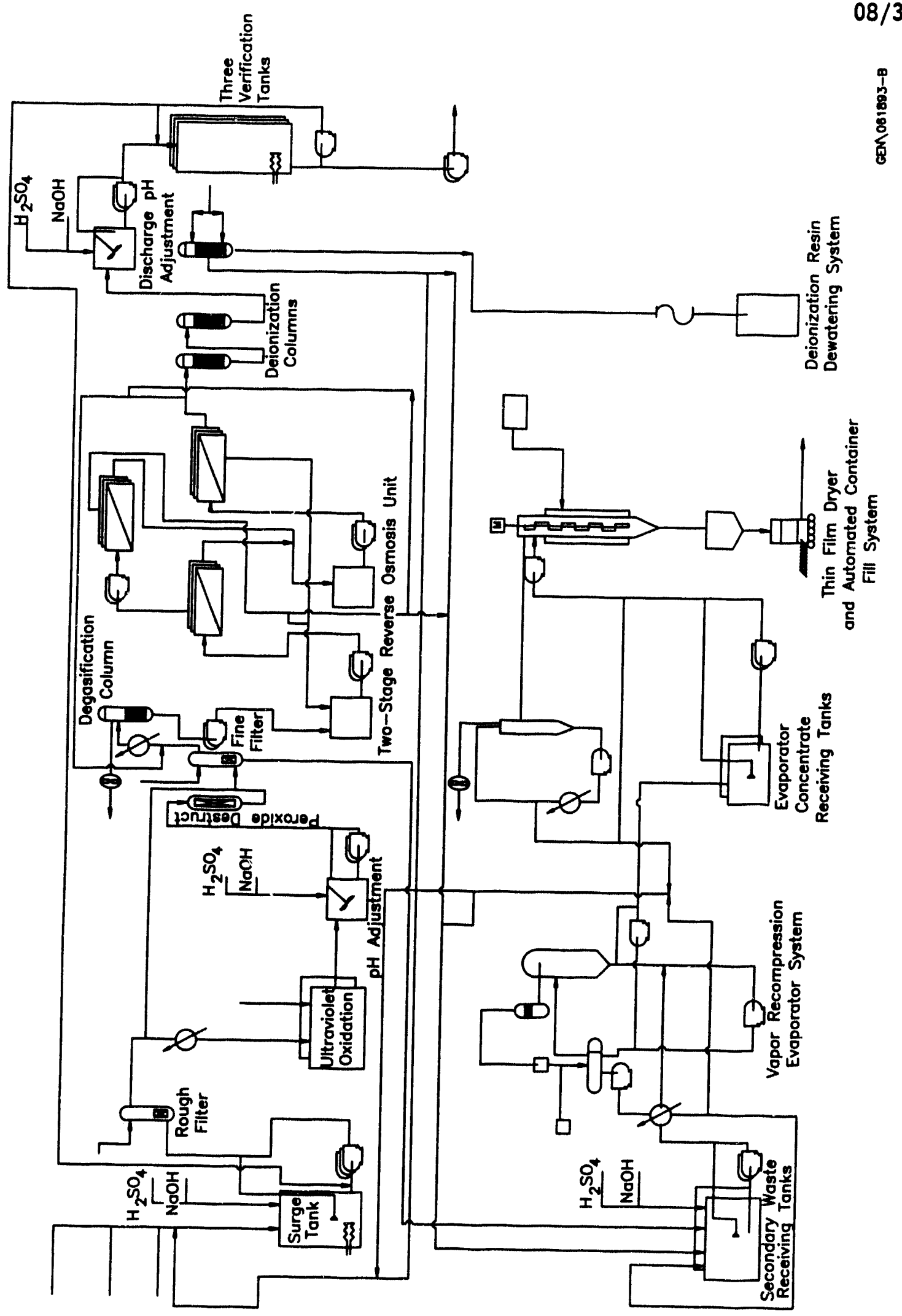

Figure 4-3. 200 Area Effluent Treatment Facility Process Flow Diagram. 
DOE/RL-93-03, Rev. 0

$08 / 31 / 93$

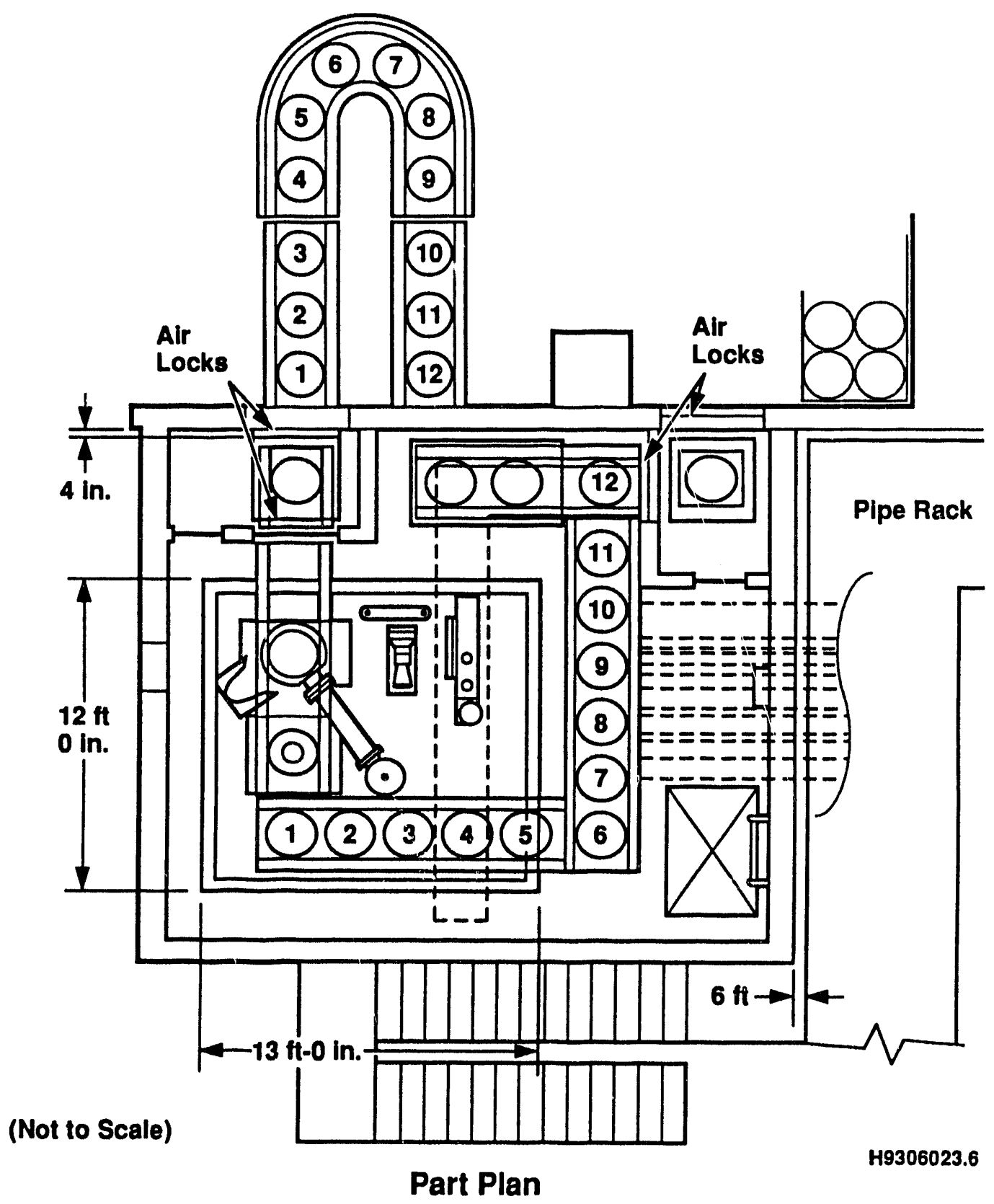

Figure 4-4. Plan View of Container Handling Room. 
DOE/RL-93-03, Rev. 0

$08 / 31 / 93$

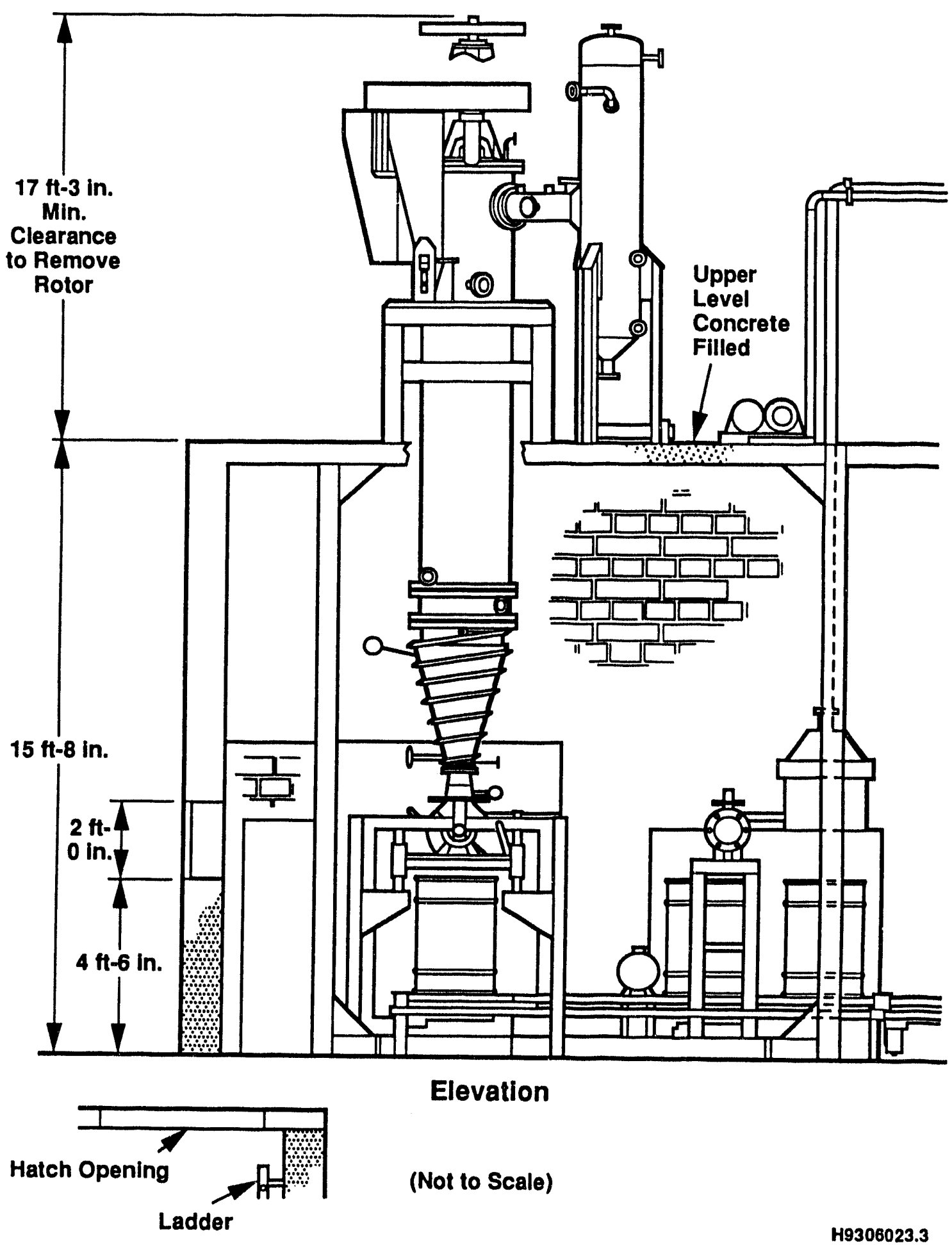

Figure 4-5. Side View of Dryer Powder Hopper and Container Handling Room. 


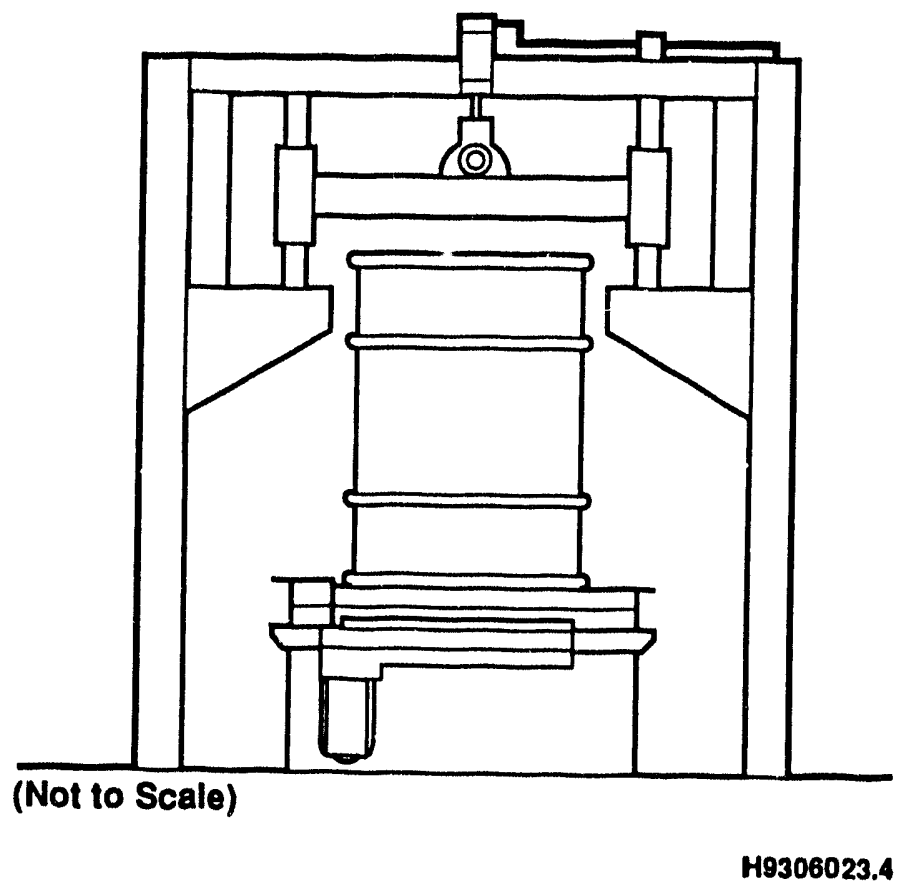

Figure 4-6. Capping Station. 
DOE/RL-93-03, Rev. 0

$08 / 31 / 93$

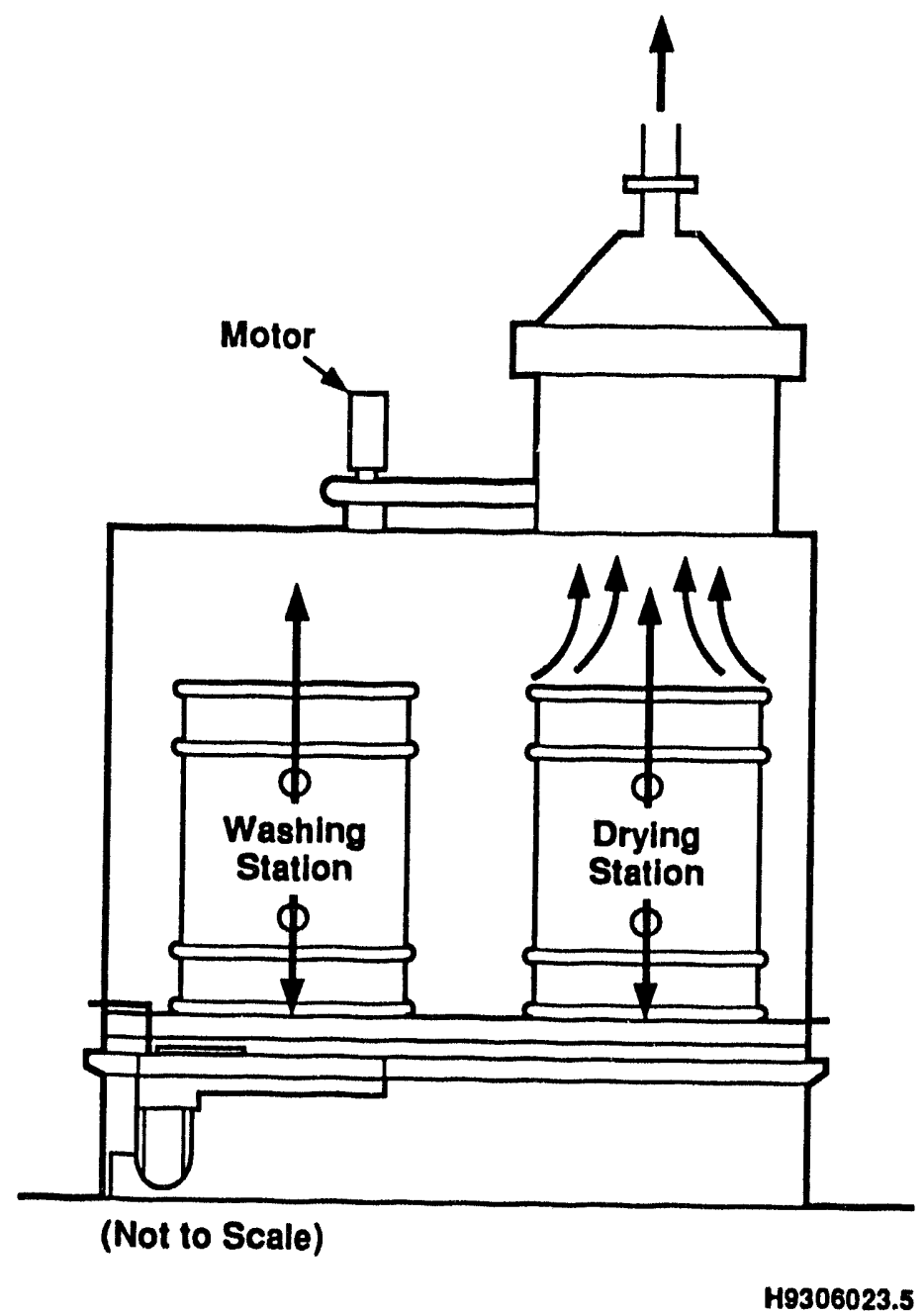

Figure 4-\%. Container Washing and Drying Station. 
DOE/RL-93-03, Rev. 0

$08 / 31 / 93$

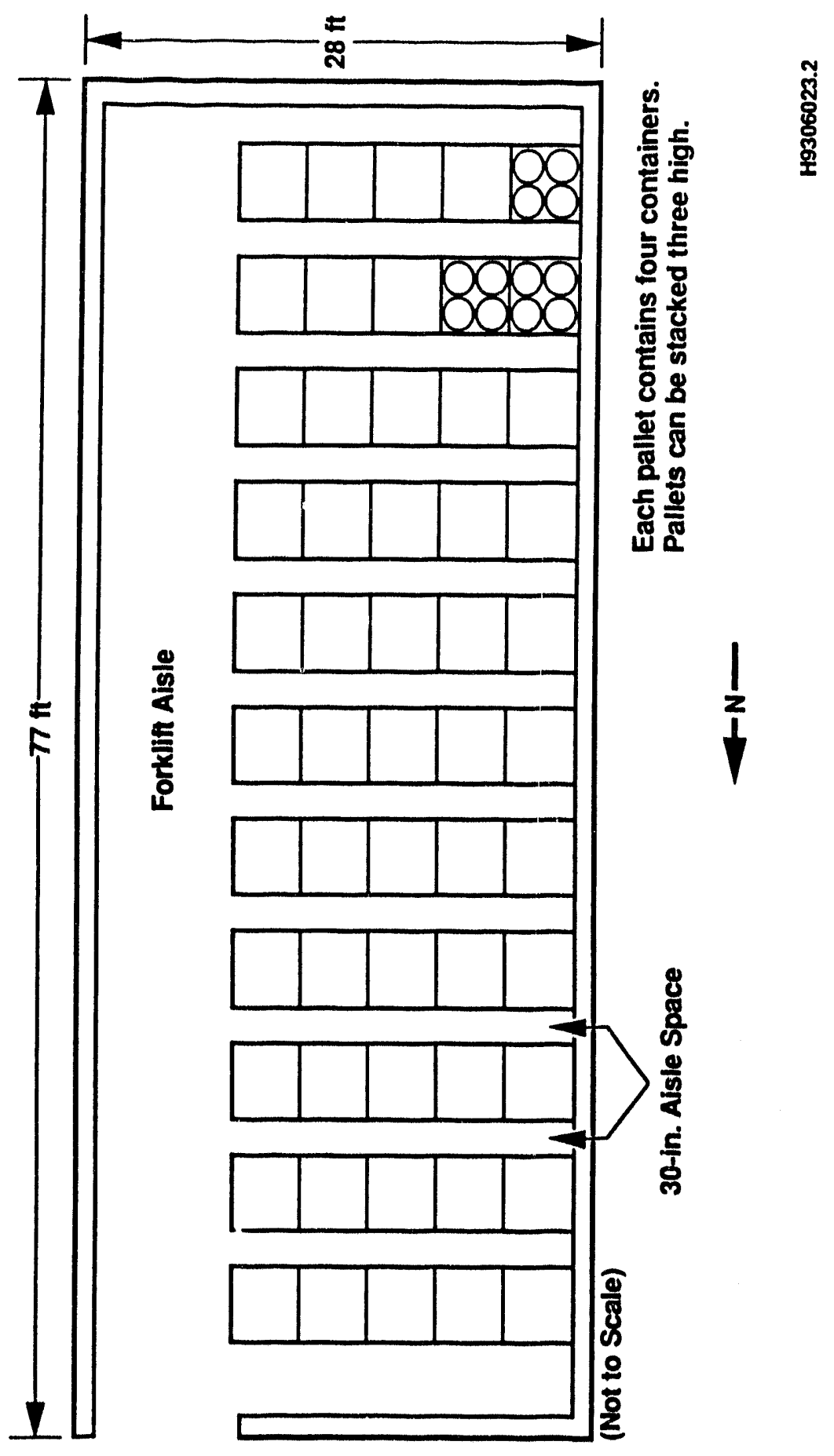

Figure 4-8. Example Storage Configuration in the Filled Container Storage Area. 
Table 4-1. 200 Area Effluent Treatment Facility Tank Systems Information.

\begin{tabular}{|c|c|c|c|c|c|}
\hline Tank description & Tank nuber & Material & $\begin{array}{l}\text { Volune in gallons } \\
\text { (liters) }\end{array}$ & $\begin{array}{c}\text { Imer dismeter } \\
\text { in feet } \\
\text { (meters) }\end{array}$ & $\begin{array}{l}\text { Height in } \\
\text { feet } \\
\text { (meters) }\end{array}$ \\
\hline Surge tonk & $2025 E-60 n-T K-1$ & 304 ss & $100,000(378,540)$ & $26.0(7.9)$ & $30.1(9.2)$ \\
\hline PH adjustrient tank & $2025 E-60 C-T K-1$ & 30455 & $2,600(9,842)$ & $10.0(3.0)$ & $8.2(2.5)$ \\
\hline First RO feed tank & 2025E-60F-TK-1 & $\begin{array}{l}304 \text { SS } \\
\text { Carbon steel (seddle) }\end{array}$ & $4,000(15,142)$ & $10.0(3.0)$ & $10.6(3.2)$ \\
\hline Second Ro feed tank & $2025 E-60 F-T K-2$ & $\begin{array}{l}304 \mathrm{SS} \\
\text { Carbon steel (sacdle) }\end{array}$ & $2,000(7,571)$ & $\begin{array}{l}\text { Nonround tank } \\
10 \text { feet }(3.0) \\
\text { long } \times 5 \text { feet } \\
\text { (1.5) wide }\end{array}$ & $5.0(1.5)$ \\
\hline Effluent pH odjustment tank & $2025 E-60 C-T K-2$ & 30455 & $2,500(9,464)$ & $10.0(3.0)$ & $8.2(2.5)$ \\
\hline $\mathrm{H}_{2} \mathrm{O}_{2}$ feed tank & $2025 E-600-T K-1 A$ & MDPE & $2,500(9,463)$ & TBD & TBD \\
\hline Verification tanks (3) & 2025E-60H-TK-1N/18/1C & $\begin{array}{l}\text { Carbon steel } \\
\text { epoxy lining }\end{array}$ & $670,000(2,536,218)$ & $60.0(18.3)$ & $37.5(11.4)$ \\
\hline $\begin{array}{l}\text { Secondery waste receiving } \\
\text { tenks (2) }\end{array}$ & $2025 E-601-T K-1 A / 1 B$ & 304 ss & $15,000(56,781)$ & $14.0(4.3)$ & $18.6(5.7)$ \\
\hline Concentrate tanks (2) & $2025 E-60 \mathrm{~J}-T K-1 \mathrm{~A} / 1 \mathrm{~B}$ & $316 \perp 55$ & $5,000(18,927)$ & $10.0(3.0)$ & $12.5(3.8)$ \\
\hline $92 \mathrm{H}_{2} \mathrm{SO}_{4}$ storage tenk & $2025 E-65 C-T K-1$ & $\begin{array}{l}\text { Corbon steel } \\
\text { epoxy lining }\end{array}$ & $7,500(9,464)$ & $10.3(3.1)$ & $16.3(5.0)$ \\
\hline $50 x$ NaOH storage tenk & 2025E-65C-TK-2 & $\begin{array}{l}304 \text { ss } \\
\text { Cartion steel (support) }\end{array}$ & $5,000(1,514)$ & $5.0(1.5)$ & $5.6(1.7)$ \\
\hline $4 \times \mathrm{H}_{2} \mathrm{SO}_{4}$ solution tank & 2025E-65C-TK-3 & $\begin{array}{c}\text { FRP } \\
\text { Cartion steel (support) }\end{array}$ & $600(2,271)$ & $5.5(1.7)$ & $6.3(1.9)$ \\
\hline $4 x$ reoh solution tenk & $2025 E-65 C-T K-6$ & $\begin{array}{c}\text { FRP } \\
\text { Cartbon steel (support) }\end{array}$ & $800(3,028)$ & $6.0(1.8)$ & $6.8(2.1)$ \\
\hline supp tenks (2) & 2025E-208-TK-1/2 & 30455 & $800(3,028)$ & $\begin{array}{c}\text { Nonround tenk } \\
5 \text { feet (1.5) } \\
\text { long } \times 5 \text { feet } \\
\text { (1.5) wide }\end{array}$ & $7.8(2.4)$ \\
\hline Distillate flush tank & $2025 E-601-T K-2$ & 30455 & $150(568)$ & TBD & TBD \\
\hline Separation tank & 2025E-60J-TK-2 & TED & TED & TBD & TBD \\
\hline
\end{tabular}

FRP a fibergless reinforced plestif.

WDPE = high density polyethylene.

TSD = to be determined. 
Table 4-2. Process Equipment, Usage, and Material Data. (sheet 1 of 4)

\begin{tabular}{|c|c|c|c|c|c|}
\hline System & Fluid & Equipment & Material & $\begin{array}{l}\text { Design temp } \\
{ }^{\circ} \mathrm{F}\left({ }^{\circ} \mathrm{C}\right)\end{array}$ & $\begin{array}{l}\text { Design } \\
\text { pressure } \\
\text { (psig) }\end{array}$ \\
\hline \multirow{2}{*}{ Surge tank } & \multirow{2}{*}{ Waste water } & Surge tank & 304 SS & $200(93.3)$ & 0 \\
\hline & & Feed pumps $(A, B, C)$; piping & 304 SS & $200(93.3)$ & 150 \\
\hline \multirow{2}{*}{ Rough filter } & \multirow{2}{*}{ Haste water } & Rough filter & 304 SS & $200(93.3)$ & 150 \\
\hline & & Piping & 304 SS & $200(93.3)$ & 150 \\
\hline \multirow{4}{*}{ UV oxidation } & \multirow{2}{*}{ Waste water } & $\begin{array}{l}\text { UV oxidizers (A, B) } \\
\text { (chamber) }\end{array}$ & 316 SS & $160(71.1)$ & 15 \\
\hline & & Piping & 304 SS & $160(71.1)$ & 15 \\
\hline & \multirow{2}{*}{$\begin{array}{l}\text { Hydrogen } \\
\text { Peroxide }\end{array}$} & Peroxide feed tank & $\begin{array}{l}\text { high density } \\
\text { polyethylene }\end{array}$ & $120(48.8)$ & 75 \\
\hline & & Piping & $\begin{array}{c}\text { Stainless } \\
\text { steel }\end{array}$ & $120(48.8)$ & 75 \\
\hline \multirow{2}{*}{$\begin{array}{l}\text { pH adjustment } \\
\text { tank }\end{array}$} & \multirow{2}{*}{ Waste water } & $\mathrm{pH}$ adjustment tank & 304 SS & $200(93.3)$ & 0 \\
\hline & & Feed pumps $(A, B)$; piping & 304 SS & $200(93.3)$ & 150 \\
\hline $\begin{array}{l}\text { Peroxide } \\
\text { decomposer }\end{array}$ & Waste water & $\mathrm{H}_{2} \mathrm{O}_{2}$ decomposer & $\begin{array}{l}\text { CS + epoxy } \\
\text { lining }\end{array}$ & $200(93.3)$ & 150 \\
\hline \multirow{2}{*}{ Fine filter } & \multirow{2}{*}{ Waste water } & Fine filter & 304 SS & $120(48.8)$ & 150 \\
\hline & & Piping & 304 SS & $120(48.8)$ & 150 \\
\hline \multirow{2}{*}{$\begin{array}{l}\text { Degasification } \\
\text { unit }\end{array}$} & \multirow{2}{*}{ Waste water } & Degasification column (body) & FRP & $120(48.8)$ & 150 \\
\hline & & Piping & 304 SS & $120(48.8)$ & 150 \\
\hline \multirow{4}{*}{$\begin{array}{l}\text { Reverse osmosis } \\
\text { system }\end{array}$} & \multirow{3}{*}{ Waste water } & Feed tank & 304 SS & $120(48.8)$ & 0 \\
\hline & & Feed pumps $(A, B)$; piping & 304 SS & $120(48.8)$ & 600 \\
\hline & & RO units (membranes) & Polyamide & $120(48.8)$ & 600 \\
\hline & $\begin{array}{l}\text { Cleaning } \\
\text { Agent }\end{array}$ & $\begin{array}{l}\text { RO cleaning agent feed } \\
\text { system }\end{array}$ & Polyethylene & $120(48.8)$ & 75 \\
\hline
\end{tabular}


Table 4-2. Process Equipment, Usage, and Material Data. (sheet 2 of 4)

\begin{tabular}{|c|c|c|c|c|c|}
\hline System & Fluid & Equipment & Material & $\begin{array}{l}\text { Design temp } \\
{ }^{\circ} \mathrm{F}\left({ }^{\circ} \mathrm{C}\right)\end{array}$ & $\begin{array}{l}\text { Design } \\
\text { pressure } \\
\text { (psig) }\end{array}$ \\
\hline \multirow{3}{*}{ Polisher unit } & \multirow{3}{*}{ Waste water } & Pol ishers $(A, B, C)$ & CS + epoxy & $120(48.8)$ & 75 \\
\hline & & Resins feed hopper & PVC & $120(48.8)$ & 0 \\
\hline & & Resins strainer & 304 SS & $120(48.8)$ & 75 \\
\hline \multirow{2}{*}{$\begin{array}{l}\text { Effluent } \mathrm{pH} \\
\text { adjustment tank }\end{array}$} & \multirow{2}{*}{ Waste water } & $\begin{array}{l}\text { Effluent pH adjustment tanks } \\
(A, B)\end{array}$ & 304 SS & $120(48.8)$ & 0 \\
\hline & & $\begin{array}{l}\text { Effluent pH adjustment pumps } \\
(A, B) \text {; return pump; piping }\end{array}$ & 304 SS/PVC & $120(48.8)$ & 150 \\
\hline $\begin{array}{l}\text { Verification } \\
\text { tanks }\end{array}$ & Waste water & Verification tanks $(A, B, C)$ & CS + epoxy & $120(48.8)$ & 0 \\
\hline \multirow{3}{*}{$\begin{array}{l}\text { Secondary waste } \\
\text { receiving tanks }\end{array}$} & \multirow{3}{*}{ Haste water } & $\begin{array}{l}\text { Secondary waste receiving } \\
\text { tanks }(A, B)\end{array}$ & 304 SS & $200(93.3)$ & 0 \\
\hline & & $\begin{array}{l}\text { Secondary waste feed pumps } \\
(\mathrm{A}, \mathrm{B})\end{array}$ & 304 SS & $200(93.3)$ & 150 \\
\hline & & $\begin{array}{l}\text { Piping (after feed/ } \\
\text { distillate exchanger) }\end{array}$ & 304 SS & $230(110)$ & 150 \\
\hline
\end{tabular}


Table 4-2. Process Equipment, Usage, and Material Data. (sheet 3 of 4)

\begin{tabular}{|c|c|c|c|c|c|}
\hline System & Fluid & Equipment & Material & $\begin{array}{l}\text { Design temp } \\
{ }^{\circ} \mathrm{F}\left({ }^{\circ} \mathrm{C}\right)\end{array}$ & $\begin{array}{l}\text { Design } \\
\text { pressure } \\
\text { (psig) }\end{array}$ \\
\hline \multirow{8}{*}{$\begin{array}{l}\text { ETF evaporator } \\
\text { system }\end{array}$} & \multirow{3}{*}{$\begin{array}{l}\text { Evaporator } \\
\text { bottoms }\end{array}$} & Evaporator body & Incone $1 * 625$ & $230(110)$ & 15 \\
\hline & & $\begin{array}{l}\text { Heater tubes; } \\
\text { recirculation piping }\end{array}$ & Incone $1 * 625$ & $230(110)$ & 15 \\
\hline & & Recirculation pump & $316 \mathrm{~L}$ SS & $230(110)$ & 15 \\
\hline & $\begin{array}{l}\text { Evaporator } \\
\text { vapor }\end{array}$ & $\begin{array}{l}\text { Entrainment separator } \\
\text { (bottom); evaporator- } \\
\text { separator piping }\end{array}$ & Inconel* 625 & $230(110)$ & 15 \\
\hline & $\begin{array}{c}\text { Evaporator } \\
\text { vapor }\end{array}$ & $\begin{array}{l}\text { Entrainment separator } \\
\text { (except for bottom) }\end{array}$ & $316 \mathrm{LSS}$ & $230(110)$ & 15 \\
\hline & $\begin{array}{l}\text { Evaporatar } \\
\text { vapor }\end{array}$ & $\begin{array}{l}\text { Vapor compressor; heater } \\
\text { (body); piping (heater- } \\
\text { distiliate flush tank) }\end{array}$ & 304 SS & $230(110)$ & 75 \\
\hline & \multirow[t]{2}{*}{$\begin{array}{l}\text { Evaporator } \\
\text { distillate }\end{array}$} & Dist 111 ate flash tank & 304 SS & $230(110)$ & 15 \\
\hline & & $\begin{array}{l}\text { Distillate flash tank pump; } \\
\text { piping }\end{array}$ & 304 SS & $230(110)$ & 75 \\
\hline \multirow{6}{*}{ Thin film dryer } & \multirow[b]{2}{*}{$\begin{array}{l}\text { Evaporator } \\
\text { bottoms }\end{array}$} & Concentrate tanks $(A, B)$ & $316 \mathrm{~L}$ SS & $230(110)$ & 0 \\
\hline & & $\begin{array}{l}\text { Concentrate circulation } \\
\text { pumps (A, B); piping; } \\
\text { concentrate feed pump }\end{array}$ & 316L SS & $200(93.3)$ & 75 \\
\hline & \multirow{2}{*}{$\begin{array}{l}\text { Waste } \\
\text { powder }\end{array}$} & Thin film dryer (inner wall) & Incone1* 625 & $400(204.4)$ & 0 \\
\hline & & Powder hopper & $316 \mathrm{~L} \mathrm{SS}$ & $370(187.7)$ & $\mathbf{0}$ \\
\hline & \multirow{2}{*}{ Dryer vapor } & $\begin{array}{l}\text { Spray condenser; piping } \\
\text { (dryer-spray condenser) }\end{array}$ & 316L SS & $230(110)$ & 0 \\
\hline & & $\begin{array}{l}\text { Piping (spray condenser } \\
\text { distillate) }\end{array}$ & 304 SS & $230(110)$ & 75 \\
\hline
\end{tabular}


Table 4-2. Process Equipment, Usage, and Material Data. (sheet 4 of 4)

\begin{tabular}{|l|l|l|c|c|c|}
\hline \multicolumn{1}{|c|}{ System } & \multicolumn{1}{|c|}{ Fluid } & \multicolumn{1}{|c|}{ Equipment } & Material & $\begin{array}{c}\text { Design temp } \\
{ }^{\circ} \mathrm{F}\left({ }^{\circ} \mathrm{C}\right)\end{array}$ & $\begin{array}{c}\text { Design } \\
\text { pressure } \\
(\mathrm{psig})\end{array}$ \\
\hline $\begin{array}{l}\text { Resin dewatering } \\
\text { system }\end{array}$ & Spent resin & $\begin{array}{l}\text { Resin dewatering unit; } \\
\text { piping }\end{array}$ & 304 SS/PVC & $120(48.8)$ & 0 \\
\hline \multirow{2}{*}{$\begin{array}{l}\text { Vessel offgas } \\
\text { system }\end{array}$} & & VOG filter unit & 304 SS/CS & $120(48.8)$ & 0 \\
\cline { 2 - 7 } & & VOG blowers (A, B); piping & 304 SS/CS & $120(48.8)$ & 2 \\
\cline { 2 - 7 }
\end{tabular}

CPVC = chlorinated polyvinyl chloride.

CS $=$ carbon steel.

FRP = fiberglass reinforced plastic .

PVC = polyvinyl chloride.

RO = reverse osmosis .

SS = stainless steel.

UV = ultraviolet.

VOG = vessel offgas.

*Inconel is a trademark of Inco Alloys International, Incorporated, Huntington, West Virginia. 
Table 4-3. 200 Area Effluent Treatment Facility Pump Information.

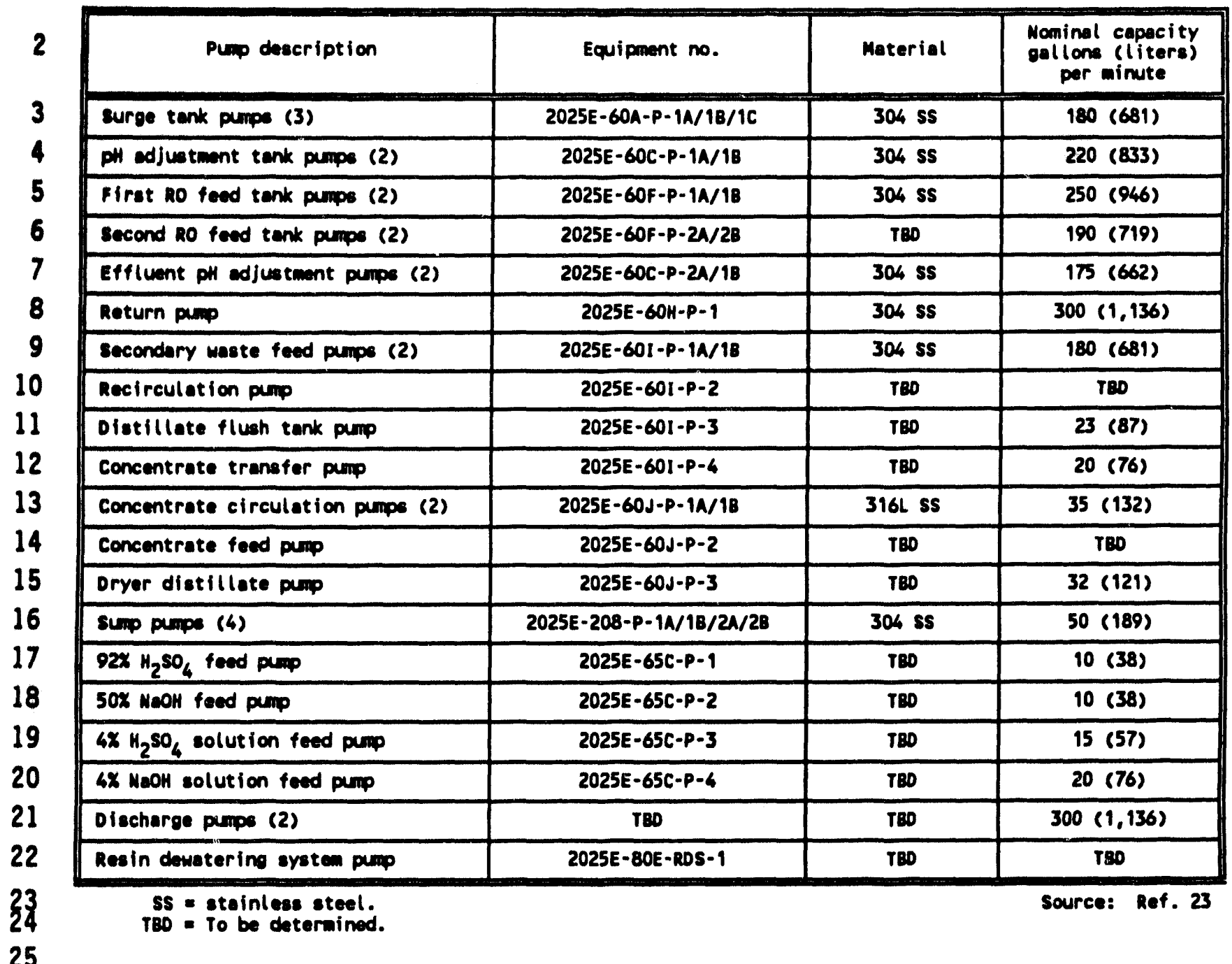


Table 4-4. Summary of Construction Inspection and Testing for the 200 Area Effluent Treatment Facility. (sheet 1 of 2)

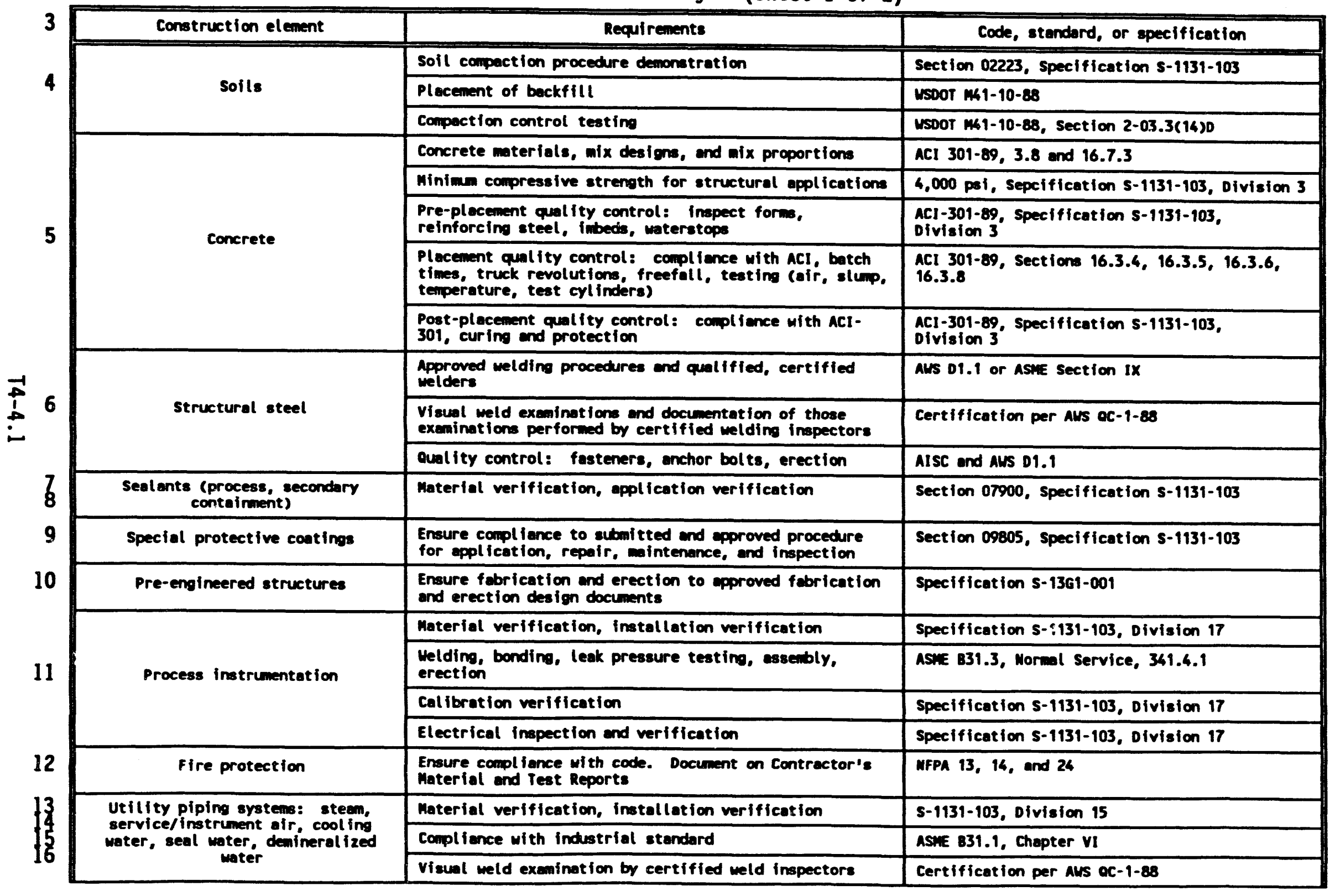


Table 4-4. Summary of Construction Inspection and Testing for the 200 Area Effluent Treatment Facility. (sheet 2 of 2)

\begin{tabular}{|c|c|c|c|}
\hline & Construction element & Requirements & Code, standard, or specification \\
\hline \multirow{5}{*}{$\begin{array}{l}1 \\
3 \\
3\end{array}$} & \multirow{5}{*}{$\begin{array}{l}\text { Process piping systens: primary and } \\
\text { secondary waste piping, tanks, } \\
\text { vessels, and chemical addition } \\
\text { piping and tanks }\end{array}$} & Piping: compliance with industrial standard & ASInE 831.3, 341.4.1, Mormal Service \\
\hline & & $\begin{array}{l}\text { Final visual weld/bond examination on all completed } \\
\text { welds/bonds, performed by certified welding inspectors }\end{array}$ & Certification per aus oc-1-88. \\
\hline & & Tenks: compl fence with standards & API 650, API 620; AMAA D100, 0103, D120 \\
\hline & & $\begin{array}{l}\text { Vessels: complience with standards. Code stamping } \\
\text { required }\end{array}$ & ASIEE Section VIII, Division 1 \\
\hline & & $\begin{array}{l}\text { Independent assessment of completed new tenk system } \\
\text { (tanks, vessels, ancill lary equipment) }\end{array}$ & Mac 173-303-640 \\
\hline \multirow{2}{*}{$\frac{5}{6}$} & \multirow{2}{*}{$\begin{array}{l}\text { Heat ing, ventilation, and air } \\
\text { conditioning (process area, } \\
\text { supply/exhaust, vessel offgas } \\
\text { system) }\end{array}$} & $\begin{array}{l}\text { Process exhaust and vessel of fase system complience with } \\
\text { standards }\end{array}$ & ASWE MSO9 and MS10 \\
\hline & & $\begin{array}{l}\text { Final visual weld examination by certified melding } \\
\text { inspectors }\end{array}$ & Certification per Aus aC-1-88 \\
\hline \multirow{2}{*}{9} & \multirow{2}{*}{ Electrical } & Compl fence with codes & 5-1131-103, Division 16 \\
\hline & & Inspection and testing & 5-1131-103, Division 16 \\
\hline 10 & Post-construction testing & $\begin{array}{l}\text { Onsite verification and testing and ETF ecceptence test } \\
\text { procedures }\end{array}$ & $S-1510-005$ \\
\hline \multirow[t]{2}{*}{$1 \frac{1}{3}$} & \multirow[t]{2}{*}{$\begin{array}{l}\text { Government acceptance inspection } \\
\text { (Kaiser Engineers Hanford } \\
\text { Coupany acceptance inspection) }\end{array}$} & $\begin{array}{l}\text { Kaiser Engineers Henford Conpony performed overview } \\
\text { verifications and tests during construction and } \\
\text { Acceptance Test Procedure to verify compl Iance with } \\
\text { approved design documents and ensure that systems } \\
\text { operate os intended by the des ign }\end{array}$ & $\begin{array}{l}\text { Kaiser Engineers Manford Compeny Independent } \\
\text { Assessiment Plans }\end{array}$ \\
\hline & & $\begin{array}{l}\text { Kaiser Engineers Henford Compeny performed the } \\
\text { Independent assessment of construction of the transfer } \\
\text { piping (LERF to ETF) }\end{array}$ & $\begin{array}{l}\text { Kaiser Engineers Hanford Company Independent } \\
\text { Assessment Plans }\end{array}$ \\
\hline
\end{tabular}

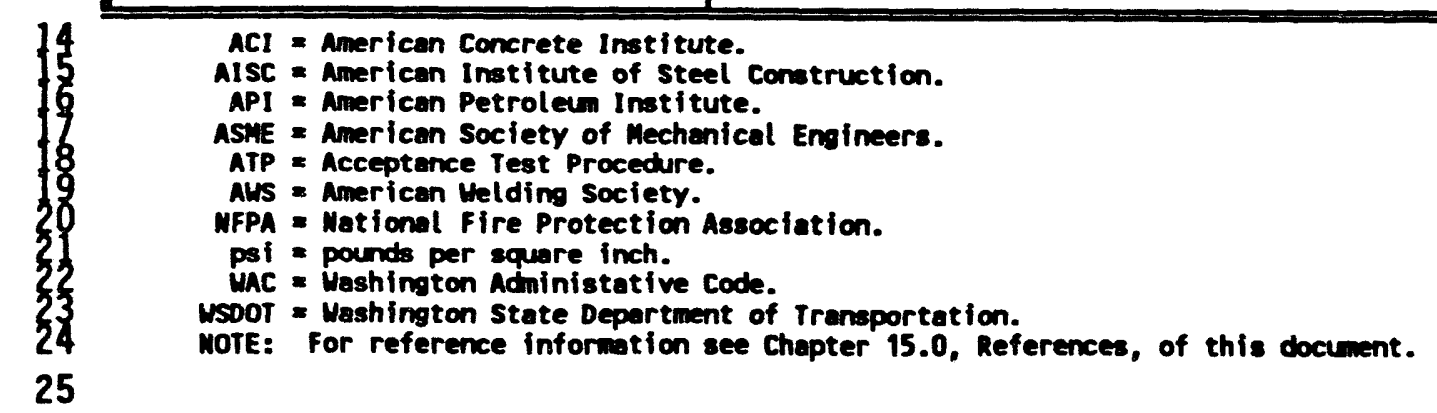


Table 4-5. Secondary Containment Systems.

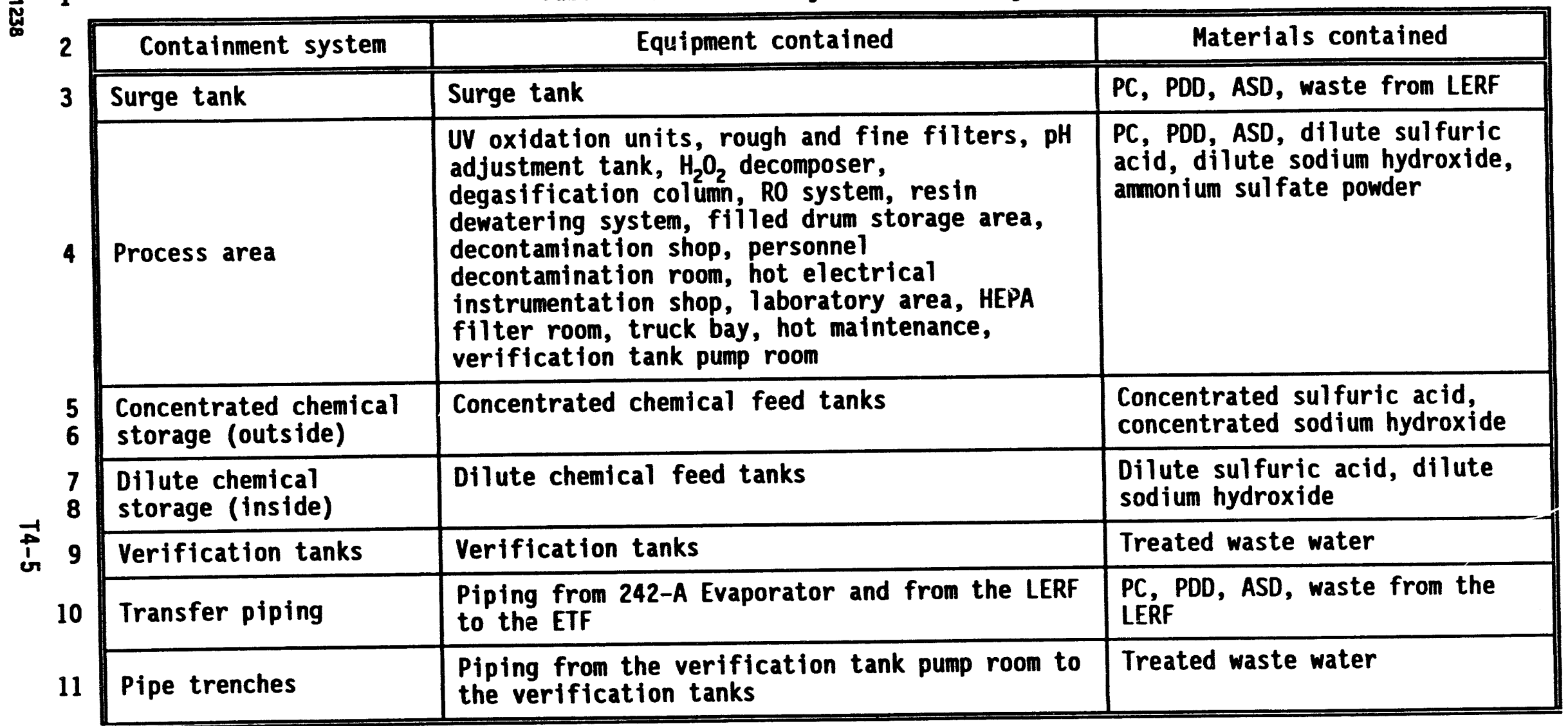

12 ASD = ammonia scrubber distillate.

$13 \quad$ ETF $=200$ Area Effluent Treatment Facility.

14 HEPA $=$ high-efficiency particulate air.

15 LERF = Liquid Effluent Retention Facility.

$16 \quad \mathrm{PC}=$ process condensate.

$17 \quad P D D=$ process distillate discharge.

$18 \quad \mathrm{RO}=$ reverse osmosis.

$19 \quad$ UV $=$ uitraviolet.

20 
Table 4-6. Concrete and Masonry Coatings.

\begin{tabular}{|c|c|c|c|}
\hline Coating & $\begin{array}{l}\text { Minimum wet } \\
\text { film } \\
\text { thickness } \\
\text { (mil) }\end{array}$ & $\begin{array}{l}\text { Percentage of } \\
\text { film forming } \\
\text { solids per } \\
\text { volume }(\%)\end{array}$ & $\begin{array}{l}\text { Minimum dry } \\
\text { film } \\
\text { thickness } \\
\text { (mil) }\end{array}$ \\
\hline \multicolumn{4}{|c|}{ Concrete and masonry } \\
\hline Prime: Amercoat-187* & 4.5 & 22.0 & 1.0 \\
\hline Second: Amercoat-33 & 6.4 & 23.46 & 1.5 \\
\hline Finish: Amercoat-33 & 6.4 & 23.46 & 1.5 \\
\hline \multicolumn{4}{|c|}{ or } \\
\hline Prime: Amercoat-385 & $5-6$ & 66 & $3-4$ \\
\hline Topcoat: Amercoat-45OHS & $3-4$ & 66 & $2-2.5$ \\
\hline \multicolumn{4}{|c|}{ High traffic, drum storage area } \\
\hline Filler: Ameron $\mathrm{Nu}-\mathrm{Kl}$ ad $114 A^{* \star}$ & -- & 100 & -- \\
\hline Prime: Amercoat-105A & $2-3$ & 100 & $2-3$ \\
\hline Topcoat: Amercoat-120 & $20-30$ & 100 & $20-30$ \\
\hline
\end{tabular}

*Amercoat is a trademark of Ameron, Incorporation.

$15 \quad \star * N u-K 1$ ad is a trademark of Ameron, Incorporation. 
Table 4-7. Volume of Secondary Containment Systems.

\begin{tabular}{|c|c|c|}
\hline Containment system & $\begin{array}{c}\text { Volume of containment } \\
\text { system in gallons } \\
\text { (1iters) }\end{array}$ & $\begin{array}{c}\text { Volume of largest } \\
\text { vessel in gallions } \\
\text { (1 iters) }\end{array}$ \\
\hline Surge tank & $195,380(739,600)$ & $100,000(378,540)$ \\
\hline Process area & $76,186(288,394)$ & $15,000(56,780)$ \\
\hline $\begin{array}{l}\text { Concentrated chemical } \\
\text { storage (outside) }\end{array}$ & $\begin{array}{l}9,574(36,241) \\
14,661 \quad(55,498)\end{array}$ & $\begin{array}{c}400(1,510) \\
2,500(9,460)\end{array}$ \\
\hline $\begin{array}{l}\text { Dilute chemical storage } \\
\text { (inside) }\end{array}$ & $1,563(5,917)$ & $800(3,028)$ \\
\hline Verification tanks & $1,012,320(3,832,000)$ & $670,000(2,536,200)$ \\
\hline Transfer piping & Not applicable & Not applicable \\
\hline Pipe trenches & $3,700(14,006)$ & Not applicable \\
\hline
\end{tabular}

12 
DOE/RL-93-03, Rev. 0 $08 / 31 / 93$

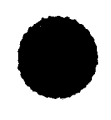

1

2

\section{CONTENTS}

45.0 GROUNDWATER MONITORING [E] . . . . . . . . . . . . . . . 5 . 1 
DOE/RL-93-03, Rev. 0

$08 / 31 / 93$

This page intentionally left blank. 
DOE/RL-93-03, Rev. 0

$08 / 31 / 93$

\subsection{GROUNDWATER MONITORING [E]}

The ETF is not operated as a dangerous waste surface impoundment, waste pile, land treatment unit, or landfill as defined in WAC 173-303-645(1)(a). Therefore, groundwater monitoring is not required. 
DOE/RL-93-03, Rev. 0

$08 / 31 / 93$

1

2

3

4

This page intentionally left blank. 


\section{CONTENTS}

6.0 PROCEDURES TO PREVENT hazARDS [F] . . . . . . . . . . . . . . 6-1

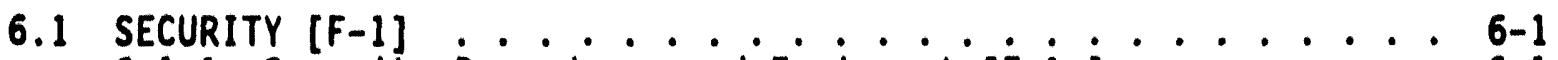

6.1.1 Security Procedures and Equipment [F-1a] . . . . 6-1

6.1.1.1 24-hour Survelllance System $[F-1 a(1)]$. . . 6-1

6.1.1.2 Barrier and Means to Control Entry $[F-1 a(2),(2 a),(2 b)], \ldots-\ldots-1$

6.1.1.3 Warning Signs [F-la(3)] ........ 6-1

6.1 .2 Waiver $[F-1 b, b(1), b(2)] \ldots . . . . . . . . .26-2$

6.2 INSPECTION SCHEDULE [F-2] . . . . . . . . . 6-2

6.2.] General Inspection Requirements $[\mathrm{F}-2 \mathrm{a}, \mathrm{a}(1), \mathrm{a}(2)] \ldots$. $6-2$

6.2.2 Specific Process Inspection Requirements [F-2b] $\cdot$. 6-2

6.2.2.1 Visual Inspection PIan $[F-2 b(1), F-2 b(2)(a)$,

$F-2 b(2)(b), F-2 b(2)(c), F-2 b(2)(d)]$ 6-2

6.2.2.2 Instrumentation Monitoring Inspection $P 7 a n$ $[F-2 b(2)(a), F-2 b(2)(b), F-2 b(2)(c)$, $F-2 b(2)(d) \ldots 6-3$

6.2.2.3 Preventive Maintenance pian ......... 6-3

6.3 WAIVER OR DOCUMENTATION OF PREPAREDNESS AND PREVENTION

REQUIREMENTS [F-3] ................... 6-4

6.3.1 Equipment Requirements [F-3a] . . . . . . . . .

6.3.1.1 Internal Communications $[F-3 a(1)]$. . . . 6-4

6.3.1.2 External Communications $[\mathrm{F}-3 \mathrm{a}(2)]$. . . . . 6-4

6.3.1.3 Emergency Equipment $[\mathrm{F}-3 \mathrm{a}(3)]$. . . . . 6-5

6.3.1.4 Water for Fire Control [F-3a(4)] . . . . . 6-5

6.3.2 Aisle Space Requirement [F-3b] ......... 6-6

6.4 PREVENTIVE PROCEDURES, STRUCTURES, AND EQUIPMENT [F-4] • . . 6-6

6.4.1 Sp111 Prevention and Control . . . . . . . . 6-6

6.4.1.1 Loading and Unloading Operations [F-4a] : . 6-6

6.4.1.2 Waste Transfer Lines . . . . . . . . . 6-6

6.4.2 Run-off [F-4b] ............... 6-7

6.4.3 Surface and Groundwater Contamination

Prevention [F-4c] . . . . . . . 6-7

6.4.4 Equipment and Power Fallures [F-4d] ....... 6-7

6.4.4.1 Equipment Fallure ........... 6-7

6.4.4.2 Power Fallure . . . . . . . . . . . 6-8

6.4.5 Personnel Protection Equipment $[F-4 e] . ; 6-8$

6.4.6 Prevention of Waste Ignition and Reaction [F-5,

F-5a, F-5b] ... . . 6-9

6.4.7 Prevention of Incompatible Waste Mixing [F-5b] ... 6-9 


\section{TABLES}

6-1. Visual Inspection Schedule for Process Equipment, Piping, Structures, and Areas . . . . . . . . . . . . T6-1

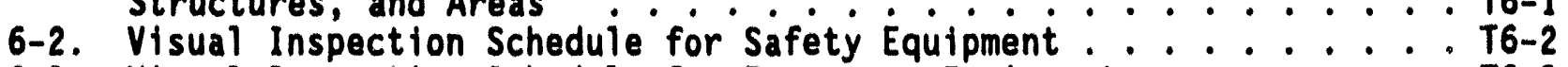

6-3. Visual Inspection Schedule for Emergency Equipment . . . . . . T6-3

6-4. Inspection Plan for Instrument Monitoring............. T6-4

9 


\subsection{PROCEDURES TO PREVENT HAZARDS [F]}

This chapter describes the security, inspection schedules, preparedness and prevention requirements, preventive procedures, structures, and equipment, and prevention of reaction of ignitable, reactive, and incompatible waste for the ETF.

\subsection{SECURITY [F-1]}

The following sections describe the security measures, equipment, and warning signs used to control entry to the ETF.

\subsubsection{Security Procedures and Equipment [F-1a]}

The following sections describe the 24-hour surveillance system, barriers, and warning signs used to provide security and control access to the ETF.

6.1.1.1 24-hour Surveillance Systen [F-1a(1)]. The entire Hanford Facility is a controlled-access area. The Hanford Facility maintains around-the-clock surveillance for protection of government property, classified information, and special nuclear material. The Hanford Patrol maintains a continuous presence of protective force personnel to provide additional security.

6.1.1.2 Barrier and Means to Control Entry [F-1a(2), (2a), (2b)]. Manned barricades are maintained around the clock at checkpoints on vehicular access roads leading to the 200 Areas of the Hanford Facility. All personnel accessing these areas must have a U.S. Department of Energy-issued security identification badge indicating the appropriate authorization. Personnel also might be subject to a search of ftems carried into or out of these areas.

The ETF has additional levels of protection. Persons desiring entry to the ETF are directed to pass through an additional checkpoint at the ETF control room. Personnel assigned to the ETF monitor all persons entering the ETF and notify the Hanford Patrol of any attempted unauthorized entry. Immediate Hanford Patrol response maintains the necessary ETF security.

The perimeter of the ETF is fenced to isolate the ETF from other areas on the Hanford Facility. Gates provide access for authorized vehicles and personnel.

6.1.1.3 Warning Signs $[F-1 \mathrm{a}(3)]$. Signs bearing the legend "DANGER-UNAUTHORIZED PERSONNEL KEEP OUT," are posted around the perimeter of the ETF. The signs are in English, legibie from a distance of 25 feet (7.6 meters), and are visible from all angies of approach. 
2

\subsubsection{Waiver $[F-1 b, b(1), b(2)]$}

Waivers of the security procedures and equipment requirements for the ETF are not requested. Therefore, the requirements of WAC 173-303-310(1)(a) and (b) are not applicable to the ETF.

\subsection{INSPECTION SCHEDULE [F-2]}

This section describes the method and schedule for inspection of the ETF. The purpose of inspections at the ETF is to help ensure that situations do not exist that might cause or lead to the release of dangerous and/or mixed waste that could pose a threat to human health and the environment.

\subsubsection{General Inspection Requirements [F-2a,a(1),a(2)]}

An inspection schedule is maintained at the ETF. This section describes the schedule for the inspection of monitoring equipment, safety and emergency equipment, security devices, and operating and structural equipment that are vital to prevent, detect, or respond to human health and environmental hazards. The inspection schedule identifies the types of problems and describes the frequency of inspection for items on the schedule. The frequency of inspection is based on the rate of possible deterioration of equipment and the probability of a human health and environmental incident if the deterioration, malfunction, or operator error goes undetected. Visual inspection schedules are provided in Tables 6-1 through 6-4.

\subsubsection{Specific Process Inspection Requirements [F-2b]}

The following sections describe specific process inspection requirements. The process equipment inspection plan consists of three inspection plans: a visual inspection plan, an instrumentation monitoring $p l a n$, and a preventive maintenance plan. These inspection plans are discussed in this section.

6.2.2.1 Visual Inspection Plan $[F-2 b(1), F-2 b(2)(a), F-2 b(2)(b), F-2 b(2)(c)$, $F-2 b(2)(d)]$. The visual inspection pian provides direction to the ETF process operators, outlines the frequency of inspections, Itemizes the components to inspect, and detalls the types of problems to inspect. An inspection $10 \mathrm{~g}$ is maintained and contains the following information at a minimum:

- Date of the visual inspection

- Time of the inspection

- Printed name of the inspector

- Signature of the inspector 
DOE/RL-93-03, Rev. 0

$08 / 31 / 93$

- Notations of the observations made

- Date and nature of any repair or remedial actions taken as a result of the inspection.

Any problems observed are remedied on a schedule that prevents hazards to human health and the environment. Imminent hazards are remedied immediately.

Wherever visual access is possible, inspections of the following equipment are performed regularly:

- Process equipment, tanks, containers, piping, structures

- Safety equipment, including safety showers and eyewashes

- Emergency equipment, including fire suppression systems.

6.2.2.2 Instrumentation Monitoring Inspection $P 1$ an $[F-2 b(2)(a), F-2 b(2)(b)$, $F-2 b(2)(c), F-2 b(2)(d)$. In radioactive areas, many inspections are performed remotely. Monitoring instruments are connected to audible alarms and the visual indicators track alarm status. The monitoring system provides trending of selected monitoring data, graphic, and equipment summary displays.

After an alarm is activated, the process operator responds in accordance with the applicable operating procedure. All system messages, alarm messages, operator iriput, and special messages are printed. Additionaliy, an alarm history file records all system events and the time of occurrence on a fixed-disk system. The file is downloaded to data storage disks.

6.2.2.3 Preventive Maintenance Plan. The ETF is maintained by maintenance personnel common to the 200 East Area, but with ETF-specific training. The maintenance personnel receive ETF-specific training to ensure they are familiar with the ETF operations and their specific tasks (Chapter 8.0).

A preventive maintenance recall system is employed as a tool to direct preventive maintenance activities at the ETF. Equipment requiring maintenance is checked at least annually and could be checked every 30,90, or 180 days depending on the maintenance history and the manufacturer's recommendations.

The preventive maintenance of certain equipment might not be possible if the ETF is in an operational mode. Thus, the preventive maintenance could be performed siightly earlier or later than planned to minimize impact on ETF operations.

The ETF instrumentation is calibrated regularly to ensure accuracy and reliability. All process control instrumentation is calibrated at least annualiy. Specific instruments are calibrated semiannually or monthly, depending on previous calibration experience. An instrument calibration and recall system is employed as a tool to manage plant calibrations. This system not only directs instrument technicians to perform regular calibrations but also evaluates the frequency of each instrument calibration. The frequency of caibration could be increased if a particular instrument often is found to be out of calibration. Likewise, a calibration frequency could be decreased if justified by a good calibration history. To prevent hazards resulting from 
operator or computer error, random calibration surveillances are performed by trained quality assurance inspectors independent of ETF operations.

\subsection{MAIVER OR DOCUMENTATION OF PREPAREDNESS AND PREVENTION REQUIREMENTS [F-3]}

The following sections document the preparedness and prevention measures used at the ETF.

\subsubsection{Equipment Requirements [F-3a]}

The following sections describe the internal and external communications and emergency equipment located at the ETF.

6.3.1.1 Internal Communications [F-3a(1)]. The ETF is equipped with an internal communication system to provide immediate emergency instruction to personnel. The onsite communication system at the ETF includes telephones, radios, a public address system, and alarm systems. The telephone and radio systems provide for intraplant communication as well as external communication. Provisions are made to appropriately respond to various emergencies, including the following alarm-activated emergency situations: building evacuations, fire and/or explosion, loss of essential services, loss of ventilation, radioactive discharges, and high airborne contamination. Chapter 7.0 contains reference to these response activities.

Immediate emergency instruction to personnel is provided by a public address system via speaker horns and celling-mounted speakers located throughout the building. The public address system is coupled to building telephone systems to provide telephone accessed voice paging. The ETF al arms are annunciated via elements of the public address system. The general telephone system, which carries various communication signals (e.g., telephone, crash alarm), is linked to the Hanford Site integrated voice data telecommunications system.

6.3.1.2 External Communications [F-3a(2)]. The ETF is equipped with devices for summoning emergency assistance from the Hanford Fire Department and/or local emergency response teams as necessary. External communication is made via a telephone communication system or two-way radios.

Telephones are provided at numerous locations throughout the ETF. In addition, the following external communication systems are available for notifying persons assigned to emergency response organizations:

- Fire alarm pull boxes and fire sprinkler flow monitoring devices-connected to a system monitored around the clock by the Hanford Fire Department

- Telephone number 911--contact point for the Hanford Site; on notification, the Hanford Patrol Operations Center notifies and/or dispatches required emergency responders 
- Telephone number 373-3800--single point of contact for the emergcicy duty officer; this number can be dialed from any Hanford Facility telephone

- Crash alarm telephone system--consists of selected telephones that automatically are disassociated from the regular system and connected to control stations

- Priority message system (Management Bulletin)--a network of telefax machines used to disseminate information to personnel

- The DOE-RL radio system--radio systems and frequencies available for emergency communications.

6.3.1.3 Emergency Equipment [F-3a(3)]. Emergency equipment is available for use throughout the ETF. The Hanford Facility relies primarily on the Hanford Fire Department to control fires. The Hanford Fire Department is capable of providing rapid response to fires within the 200 East Area. Portable fire extinguishers, fire control equipment, spill control equipment, and decontamination equipment are available at various locations in the ETF. Personnel are trained in the use of emergency equipment (Chapter 8.0). The Hanford Facility maintains a sufficient inventory of heavy equipment (i.e., bulldozers, cranes, road graders) for emergency response.

Fire control equipment is available at the ETF and could include the following:

- Fire extinguishers (all-utility use, dry chemical), good for use on small fires (Chapter 7.0)

- Automatic fire suppression systems installed in the ETF control room and electrical room

- Fire alarm pull boxes (Chapter 7.0)

- A water spray system is installed in the operating and administrative portions of the ETF.

Respirators, hazardous material protective gear, and special work procedure clothing for ETF maintenance personnel are kept in the change room at the ETF. Safety showers are located in convenient locations in the ETF. Portable emergency eye washes are used at the ETF. Water for these devices is supplied from the ETF sanitary water system.

6.3.1.4 Water for Fire Control [F-3a(4)]. Water for fire protection is supplied from the 200 East Area raw water system. The 200 Areas are serviced by two water distribution systems. One is for domestic water use (sanitary water) and one is for process and firewater (raw water).

The water is pumped from the Columbia River at the 1000 and 100B Areas and piped underground to the 200 East and 200 West Areas. The water from the Columbia River is received at the 200 East Area reservoir. The water in the 
reservoir is then pumped into the 200 East Area raw water distribution grid and to the 200 East Area filter house for treatment. The filtered water is then pumped to the 200 East Area sanitary water distribution grid.

The ETF is serviced by two 12-inch raw water lines that are tied into the 200 East Area raw water distribution grid. These lines provide a looped configuration that supplies two independent sources of raw water for fire protection and raw water uses. The ETF also is supplied with one 4-inch sanitary water line that provides domestic water. Connections from the ETF Building raw water system supply fire hydrants and the wet-pipe sprinkler systern.

\subsubsection{Aisle Space Requirement [F-3b]}

Sufficient aisle space (fire lanes) are maintained on the exterior of the ETF to allow unobstructed access of personnel and equipment responding to fires, spills, or other emergencies. Drawing H-2-69267 in Appendix 4A contains ETF site plans. Aisle space requirements are based on the National Fire Protection Association Codes or other national building standards as appropriate.

The ETF is designed with sufficient aisle space to allow access by emergency response personnel to all systems. Aisie space at the ETF meets the requirements of the National Fire Protection Association Life Safety Code (NFPA 1989) and WAC 173-303-630(5c).

\subsection{PREVENTIVE PROCEDURES, STRUCTURES, AND EQUIPMENT [F-4] \\ The following sections describe preventive procedures, structures, and equipment.}

\subsubsection{Spill Prevention and Control}

This section discusses the prevention of dangerous waste spills or leaks during the loading and unloading of chemicals and waste and during transfers into and out of the ETF. The potential for spills or leaks was considered during ETF design, and features were incorporated into the ETF to minimize the possibility of spills or leaks.

6.4.1.1 Loading and Unloading Operations [F-4a]. Trucks that transfer liquids into the chemical makeup tanks are equipped with spill collection or drip pans to catch minor leaks. The fill system is monitored continuously during tank-filling operations and filling is stopped immediately if leaks occur. Care is taken to ensure that even minor leaks are cleaned up immediately and disposed of in accordance with approved management procedures.

6.4.1.2 Waste Transfer Lines. Pipelines that transfer liquid waste are encased in a second pipe or contained in piping process pits and are equipped 52 with leak detection instruments to alert ETF operators of abnormal conditions. 
2

11

\subsubsection{Run-0ff $[F-4 b]$}

Run-on and run-off controls will be maintained throughout the life of the ETF. Dangerous waste and hazardous chemical handling areas are designed to contain spills, leaks, and wash water, thereby preventing run-off and subsequent releases. All dangerous waste and hazardous chemical loading and unloading areas are provided with secondary containment structures as described in Chapter 4.0. Chapter 2.0 contains additional discussion of the specific measures to prevent environmental contamination from run-off.

\subsubsection{Surface and Groundwater Contamination Prevention [F-4c]}

Water supplies for the Hanford Facility are taken from the Columbia River. There are no drinking water wells near the ETF or near the SALDS. Therefore, a release would not immediately contaminate drinking water supplies. The ETF uses procedures, structures, and equipment to prevent the contamination of natural water supplies (i.e., groundwater and surface water). The ETF is monitored during operation to detect abnormal conditions, and is inspected regularly to detect equipment and structural deteriorations that could allow water supply contamination. One function of the monitoring system is to detect releases or the potential for releases that could contaminate water supplies.

Because radiation exposure to operating personnel must be minimized, areas in contact with the waste are monitored remotely and continuously through a series of level and pressure indicators, leak and radiation detection alarms, equipment failure alarms, and control panel readouts. Data are fed to the distributed control system for review by operations and management personnel. Computerized data collection of all alarms and events, and air monitoring data are used to ensure that a complete record of the ETF operation is maintained. In addition, the ETF is inspected regularly for the presence of leaks or other offnormal conditions wherever possible.

In addition to detailed operating procedures, structures and equipment are used at the ETF to prevent contamination of water suppiles. The structures and equipment designed to prevent contamination of water supplies are the same as the structures and equipment used to prevent run-off from dangerous waste handling areas.

\subsubsection{Equipment and Power Failures [F-4d]}

The incidents considered in the design of the ETF include power loss or equipment failure. Equipment failure most often is isolated to a single piece of equipment unless that fallure triggers other failures. The procedures, structures, and equipment used to mitigate the effects of equipment failure and power outage are described in the following sections.

6.4.4.1 Equipment Failure. A combination of reliability, redundancy, maintenance, and repair features are used in the ETF equipment and systems to minimize random failure of equipment. 
For crucial systems such as ventilation filters, redundant trains are provided to mitigate equipment and system failure. Spare parts are maintained for essential production and safety equipment.

6.4.4.2 Power Fallure. The ETF does not have a standby power source. Selected lighting has a battery backup. Power to computers and process controls is configured with an uninterruptible power supply. During partial loss of normal power, the effected pumps and subsystems will be shut down. The subsystems are designed to be redundant (pumps, columns, and filters) to allow the process to continue to operate when only one component is out of service. The surge tanks provide time for the operators to switch-off and valve-out the pump shutdown because of an electrical failure and to valve-in and start the spare pump. This action restores the process to normal operation quickly and efficiently with inconsequential effect on the ability of the process to clean up the waste water flowing through the process.

Complete loss of power to the ETF shuts down the entire ETF except for the instruments in the control room connected to the uninterruptible power supply (10 minutes of operation). When power at the ETF is lost, the valves will return to the normal position to allow the process to remain in a safe shutdown mode until restoration of power. This action allows the operators to perform equipment surveys during shutdown and to confirm that there are no safety issues because the ETF is shut down.

When normal power is restored after a partlal or complete loss of power, the ETF processing rate will be increased to compensate for volume increases in any of the holdup basins, tanks, or systems. The time required for return to normal operation depends on the downtime and the flow rates during the downtime.

\subsubsection{Personnel Protection Equipment [F-4e]}

At the ETF, procedures, structures, and equipment are used to prevent undue exposure of personnel to dangerous waste and hazardous materials. All operations are conducted such that employee exposure to dangerous waste and hazardous and radioactive material are maintained ALARA. Aiso, the ETF has eyewash stations and safety showers in convenient locations for use by personnel. The following structures and equipment were incorporated into the ETF design to minimize personnel exposure.

- Offices, control room, clean- and soiled-clothes storage areas, change rooms, and the lunchroom are situated to minimize casual exposure of personnel.

- Building exit pathways are located to provide rapid egress in the event of emergency evacuations.

- Emergency lighting devices are located strategically throughout the ETF. 
- Audio and/or visual alarms are provided for all continuous air monitors, room air samplers, area alarms, and liquid monitors. Visual readouts for these alarm systems are located in less contaminated areas to minimize exposure to personnel.

- Areas for decontaminating and maintaining equipment are provided in contaminated areas to 1 imit the spread of contamination to uncontaminated areas such as the control room.

- Instrument interlock systems are provided that automatically return process operations to a safe condition if an unsafe condition should occur.

- The ETF ventilation systems are designed to provide air flow from uncontaminated zones to progressively more contaminated zones.

Protective clothing and equipment are prescribed for personnel handling chemicals or dangerous waste. Whenever possible, exposures to hazards are controlled by accepted engineering and/or administrative controls. Protective gear is used where effective engineering or administrative controls are not feasible.

\subsubsection{Prevention of Waste Ignition and Reaction [F-5, F-5a, F-5b]}

No ignitible or reactive waste is expected to be handled at the ETF (Chapter 3.0). Therefore, the requitrements of WAC 173-303-806(4)(a) are not applicable.

\subsubsection{Prevention of Incompatible Waste Mixing [F-5b]}

No incompatible waste is expected to be handled at the ETF (Chapter 3.0). Therefore, the requirements of WAC $173-303-806(4)$ (a) are not applicable. 
DOE/RL-93-03, Rev. 0

$08 / 31 / 93$

This page intentionally left blank.

930820.1231 
Table 6-1. Visual Inspection Schedule for Process Equipment, Piping, Structures, and Areas. (sheet 1 of 3 )

\begin{tabular}{|c|c|c|c|c|}
\hline 3 & Item & Inspection & Frequency & $\begin{array}{c}\text { Inspected } \\
\text { by }\end{array}$ \\
\hline 4 & \multicolumn{4}{|c|}{ Main Treatment Train } \\
\hline $\begin{array}{l}5 \\
6\end{array}$ & $\begin{array}{l}\text { Surge tank } \\
\text { system }\end{array}$ & $\begin{array}{l}\text { Inspect area for leaks. Wote any unusual } \\
\text { noises or vibration from the system pups. } \\
\text { Inspect secondary containuent system for signs } \\
\text { of deterioration. }\end{array}$ & Daily & $\begin{array}{l}\text { Process } \\
\text { operator }\end{array}$ \\
\hline 7 & Rough filter & Inspect wodule for leaks. & Daily" & $\begin{array}{l}\text { Process } \\
\text { operator }\end{array}$ \\
\hline $\begin{array}{l}8 \\
9\end{array}$ & $\begin{array}{l}\text { U1traviolet } \\
\text { oxidation systea }\end{array}$ & $\begin{array}{l}\text { Inspect module for leaks. } \\
\text { Inspect peroxide storage tank and pups for } \\
\text { leaks. }\end{array}$ & Daily" & $\begin{array}{l}\text { Process } \\
\text { operator }\end{array}$ \\
\hline$\underset{1}{i} 11$ & $\begin{array}{l}\text { pH adjustment } \\
\text { tank }\end{array}$ & Inspect rodule for leaks. & Dat1y" & $\begin{array}{l}\text { Process } \\
\text { operator }\end{array}$ \\
\hline-12 & $\mathrm{H}_{2} \mathrm{O}_{2}$ decomposer & Inspect wodule for leaks. & Dafly" & $\begin{array}{l}\text { Process } \\
\text { operator }\end{array}$ \\
\hline 13 & Fine filter & Inspect module for leaks. & Daily & $\begin{array}{l}\text { Process } \\
\text { operator }\end{array}$ \\
\hline $\begin{array}{l}14 \\
15\end{array}$ & $\begin{array}{l}\text { Degasification } \\
\text { systea }\end{array}$ & $\begin{array}{l}\text { Inspect module for leaks. Note any unusual } \\
\text { noises or vibration from the degasification } \\
\text { blower. }\end{array}$ & Daily" & $\begin{array}{l}\text { Process } \\
\text { operator }\end{array}$ \\
\hline $\begin{array}{l}16 \\
17\end{array}$ & $\begin{array}{l}\text { Reverse osmosis } \\
\text { system }\end{array}$ & $\begin{array}{l}\text { Inspect module for leaks. Mote any unusual } \\
\text { noises or vibration froe the syste pups. }\end{array}$ & Dafly" & $\begin{array}{l}\text { Process } \\
\text { operator }\end{array}$ \\
\hline 18 & Polishers & $\begin{array}{l}\text { Inspect sodule for leaks. Inspect polishers } \\
\text { for proper resin level and aixing. }\end{array}$ & Dally" & $\begin{array}{l}\text { Process } \\
\text { operator }\end{array}$ \\
\hline $\begin{array}{l}19 \\
20\end{array}$ & $\begin{array}{l}\text { Effluent pH } \\
\text { adjustuent tank }\end{array}$ & Inspect module for leaks. & Dally & $\begin{array}{l}\text { Process } \\
\text { operator }\end{array}$ \\
\hline
\end{tabular}


Table 6-1. Visual Inspection Schedule for Process Equipment, Piping, Structures, and Areas. (sheet 2 of 3 )

\begin{tabular}{|c|c|c|c|c|}
\hline & Iten & Inspection & Frequency & $\begin{array}{c}\text { Inspected } \\
\text { by }\end{array}$ \\
\hline $\begin{array}{l}1 \\
2\end{array}$ & $\begin{array}{l}\text { Yerification } \\
\text { tanks }\end{array}$ & $\begin{array}{l}\text { Inspect area for leaks. Wote any unusual } \\
\text { noises or vibration from the syste pups. } \\
\text { Inspect secondary containinent system for signs } \\
\text { of deterioration. }\end{array}$ & Daily & $\begin{array}{l}\text { Process } \\
\text { operator }\end{array}$ \\
\hline 3 & \multicolumn{4}{|c|}{ Secondary Treatuent Train } \\
\hline 4 & $\begin{array}{l}\text { Secondary waste } \\
\text { receiving tank }\end{array}$ & Inspect module for leaks. & Daily" & $\begin{array}{l}\text { Process } \\
\text { operator }\end{array}$ \\
\hline 6 & ETF evaporator & $\begin{array}{l}\text { Inspect module for leaks. Wote any unusual } \\
\text { noises or vibration from the system pups or } \\
\text { conpressor. }\end{array}$ & Dafly" & $\begin{array}{l}\text { Process } \\
\text { operator }\end{array}$ \\
\hline 7 & Concentrate tank & Inspect module for leaks. & Daily" & $\begin{array}{l}\text { Process } \\
\text { operator }\end{array}$ \\
\hline 8 & Thin file dryer & $\begin{array}{l}\text { Inspect ondule for leaks (viened through } \\
\text { window). Mote any unusual noises or vibration } \\
\text { for the systea pups or blower. }\end{array}$ & Datly" & $\begin{array}{l}\text { Process } \\
\text { operator }\end{array}$ \\
\hline $\begin{array}{r}9 \\
10\end{array}$ & $\begin{array}{l}\text { Container } \\
\text { handling }\end{array}$ & Inspect area for spillage. & Daily" & $\begin{array}{l}\text { Process } \\
\text { operator }\end{array}$ \\
\hline 11 & Resin dewatering & $\begin{array}{l}\text { Inspect oodule for leaks. Note any unusual } \\
\text { nolses or vibration form the systed pups or } \\
\text { blower. }\end{array}$ & Daily * & $\begin{array}{l}\text { Process } \\
\text { operator }\end{array}$ \\
\hline 12 & \multicolumn{4}{|c|}{ Support Systems } \\
\hline $\begin{array}{l}13 \\
14\end{array}$ & $\begin{array}{l}\text { Chealical reagent } \\
\text { feed systea }\end{array}$ & $\begin{array}{l}\text { Inspect } 928 \mathrm{H}_{2} \mathrm{SO}_{4} \text { and } 503 \mathrm{MaOH} \text { tanks for } \\
\text { leaks. }\end{array}$ & Dally & $\begin{array}{l}\text { Process } \\
\text { operator }\end{array}$ \\
\hline 15 & Sup tank system & $\begin{array}{l}\text { Inspect sup tanks and sup pups for leaks, } \\
\text { spillage, and proper levels. }\end{array}$ & Daily & $\begin{array}{l}\text { Process } \\
\text { operator }\end{array}$ \\
\hline $\begin{array}{l}16 \\
17 \\
18\end{array}$ & $\begin{array}{l}\text { Vessel } \\
\text { ventilation } \\
\text { system }\end{array}$ & $\begin{array}{l}\text { Inspect filter housings for leaks. Wote any } \\
\text { unusual noises from the blewers. }\end{array}$ & Datly & $\begin{array}{l}\text { Process } \\
\text { operator }\end{array}$ \\
\hline
\end{tabular}


Table 6-1. Visual Inspection Schedule for Process Equipaent, Piping, Structures, and Areas. (sheet 3 of 3 )

\begin{tabular}{|c|c|c|c|c|}
\hline & Iten & Inspection & Frequency & $\begin{array}{l}\text { Inspected } \\
\text { by }\end{array}$ \\
\hline 1 & Utilities & $\begin{array}{l}\text { Inspect deatheral ized water system for leaks. } \\
\text { Inspect compressed air system for leaks or } \\
\text { unusual noises. Inspect stean systea for } \\
\text { leaks. }\end{array}$ & Datly & $\begin{array}{l}\text { Process } \\
\text { operator }\end{array}$ \\
\hline 2 & \multicolumn{4}{|c|}{ Disposal Systea } \\
\hline 3 & Disposal pups & $\begin{array}{l}\text { Inspect disposal pups for leaks or unusual } \\
\text { noises. }\end{array}$ & Dat1y" & $\begin{array}{l}\text { Process } \\
\text { operator }\end{array}$ \\
\hline 4 & \multicolumn{4}{|c|}{ Ceneral } \\
\hline 5 & Roads & $\begin{array}{l}\text { Inspect all ETF roads for signs of subsidence, } \\
\text { bups, holes, cracks, or other damage. Look } \\
\text { for spillage from vehicles. }\end{array}$ & Ronthly & $\begin{array}{l}\text { Hanford } \\
\text { Facility } \\
\text { services } \\
\text { and truck } \\
\text { drivers }\end{array}$ \\
\hline $\begin{array}{l}6 \\
7 \\
8\end{array}$ & $\begin{array}{l}\text { Satellite } \\
\text { accululation } \\
\text { areas }\end{array}$ & $\begin{array}{l}\text { Inspect all satellite accualation areas for } \\
\text { container integrity and spill control. }\end{array}$ & Weekly & $\begin{array}{l}\text { Process } \\
\text { operator }\end{array}$ \\
\hline
\end{tabular}

- Stated inspection frequency to be performed only during ETF operations. 


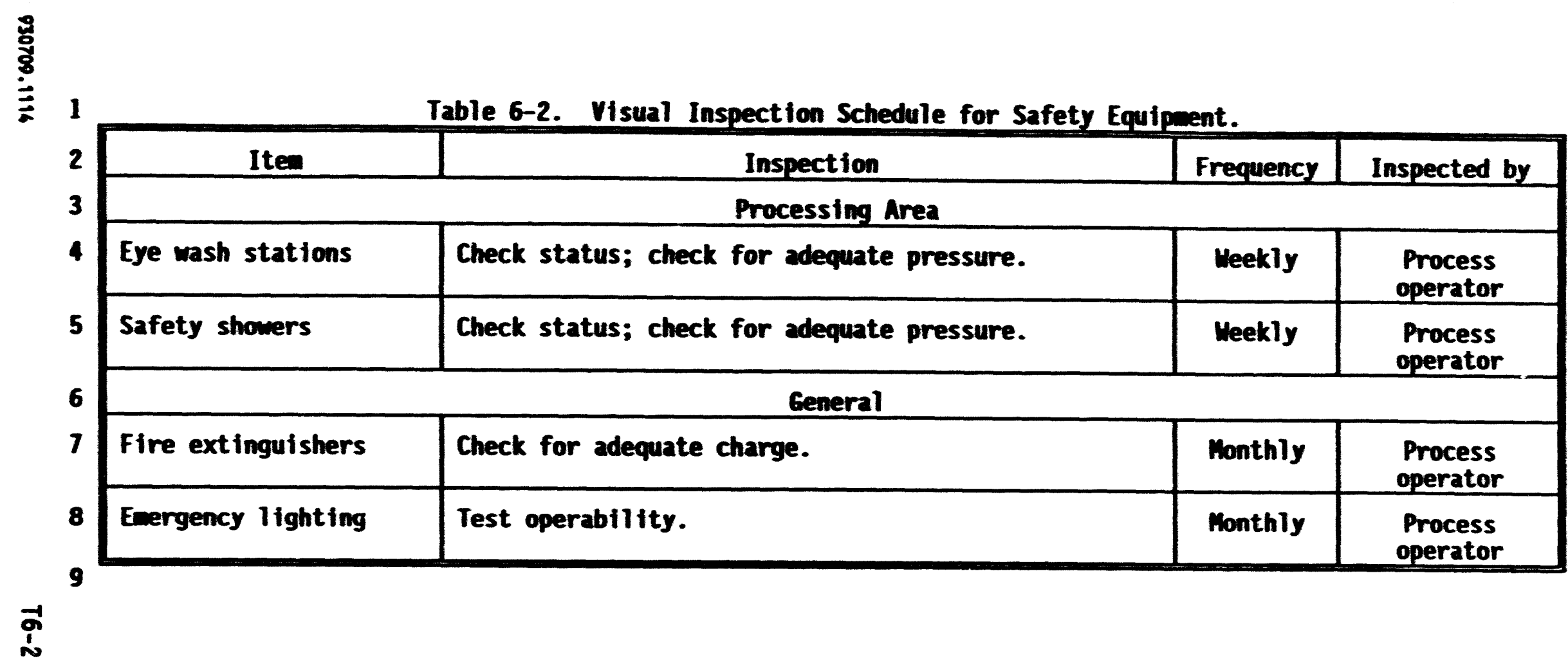




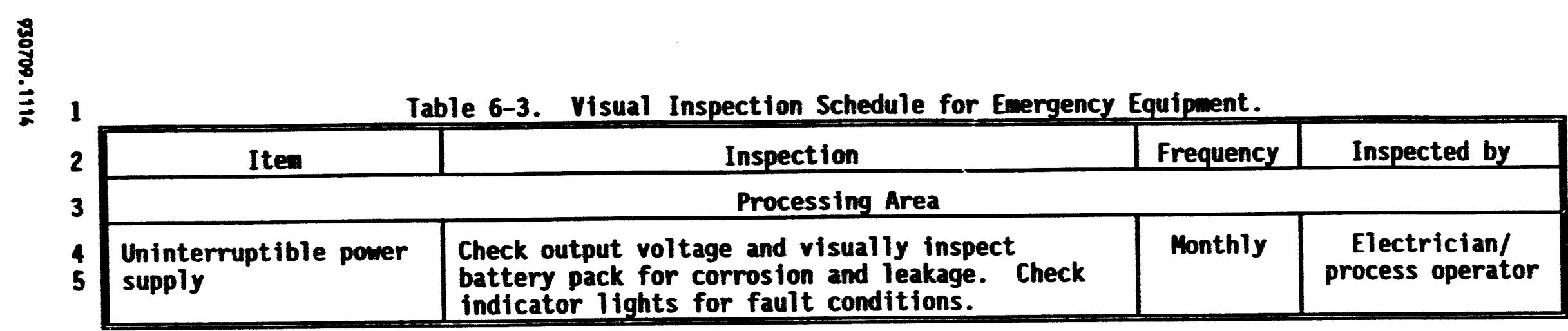

호 
Table 6-4. Inspection Plan for Instrumentation Monitoring. (sheet 1 of 3)

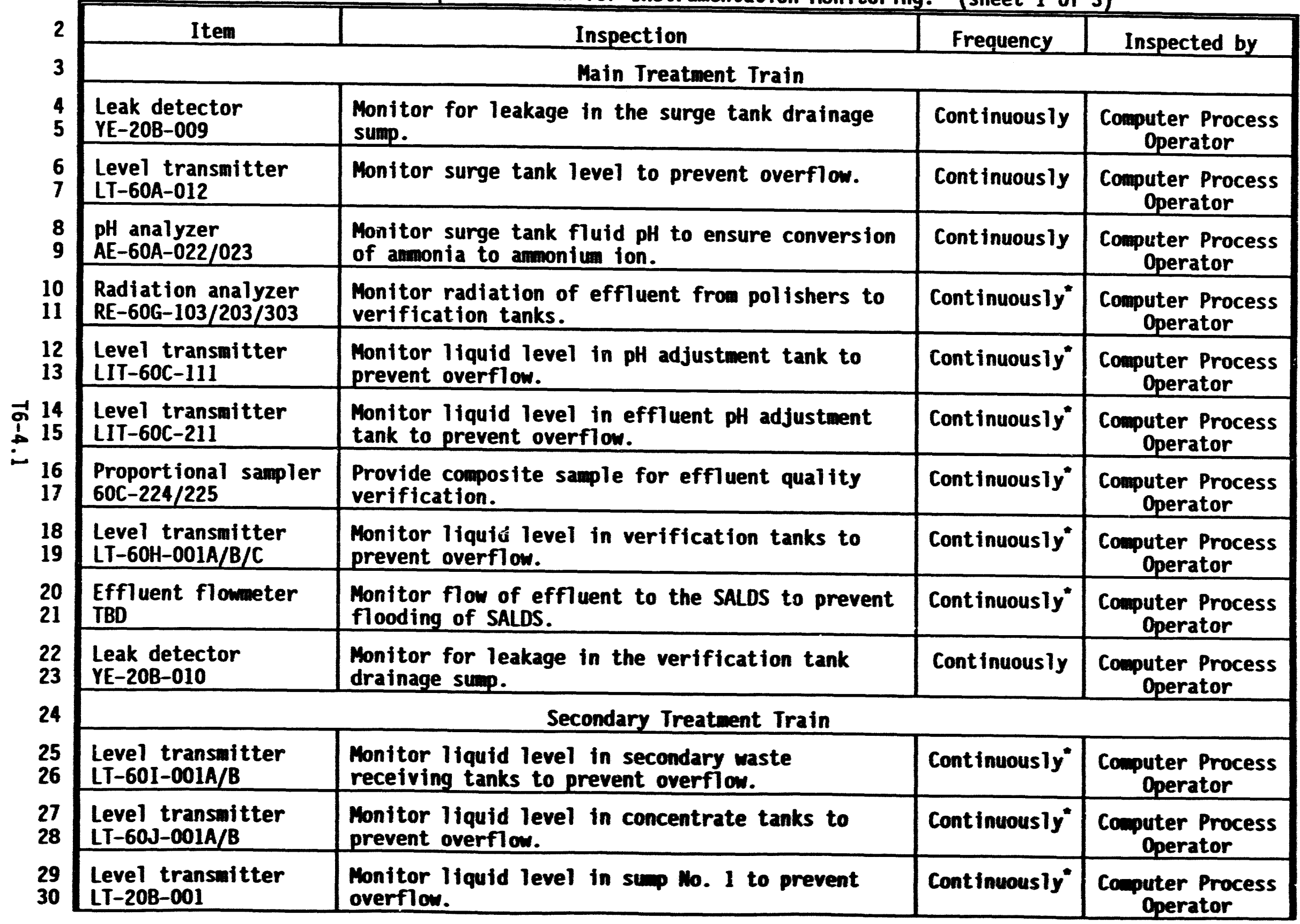


Table 6-4. Inspection Plan for Irstrumentation Monitoring. (sheet 2 of 3 )

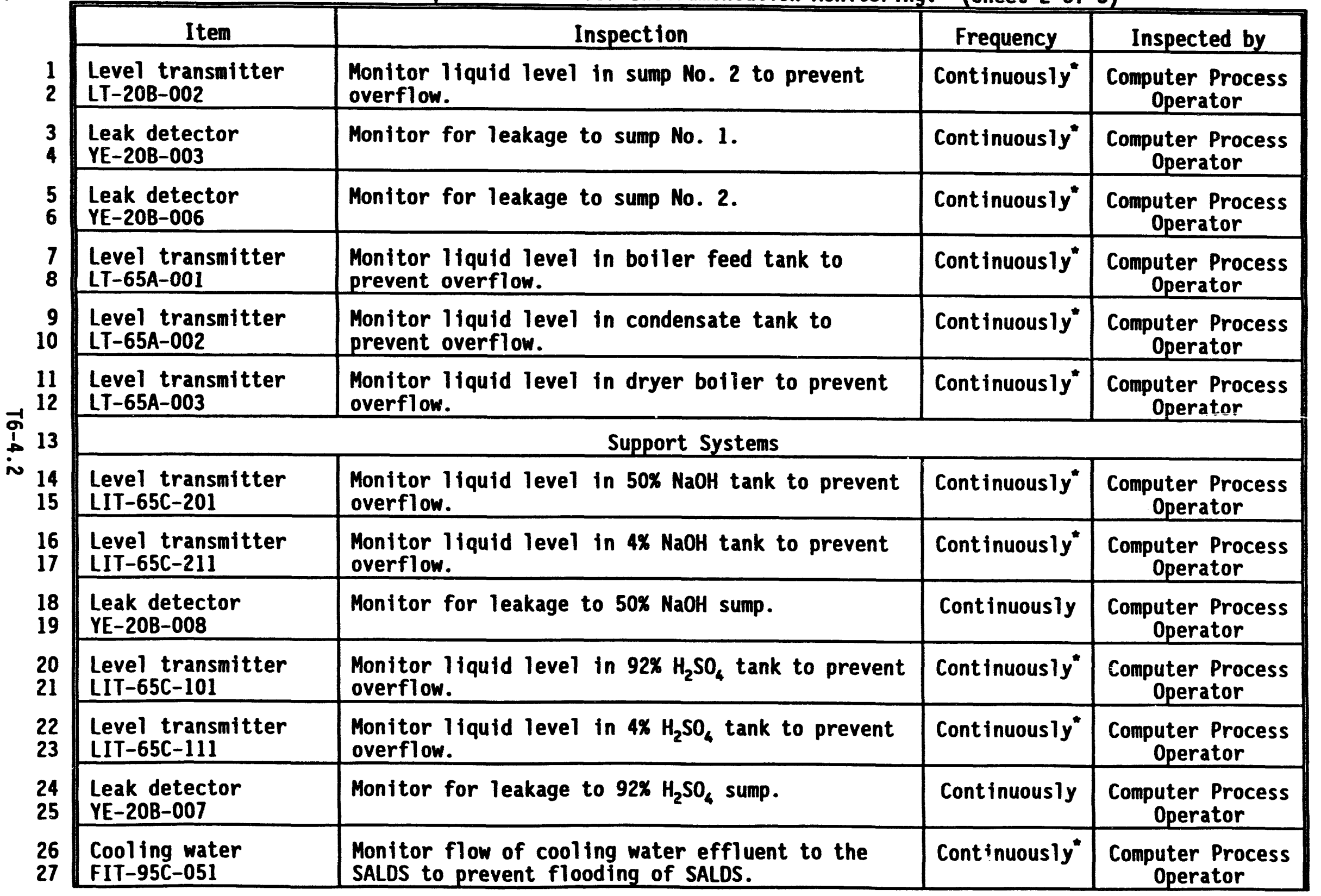


Table 6-4. Inspection Plan for Instrumentation Monitoring. (sheet 3 of 3)

\begin{tabular}{|c|c|c|c|}
\hline Item & Inspection & Frequency & Inspected by \\
\hline $\begin{array}{l}\text { Level transmitter } \\
\text { LT-95B-001 }\end{array}$ & $\begin{array}{l}\text { Monitor liquid level in seal water tank to } \\
\text { prevent overflow. }\end{array}$ & Continuously" & $\begin{array}{l}\text { Computer Process } \\
\text { Operator }\end{array}$ \\
\hline
\end{tabular}

3 "Stated inspection frequency to be performed only during ETF operations.

$4 \quad$ TBD $=$ to be determined.

$5 \quad$ SALDS $=$ State-Approved Land Disposal Site.

6

$\overrightarrow{1}$
1
w 
DOE/RL-93-03, Rev. 0 $08 / 31 / 93$

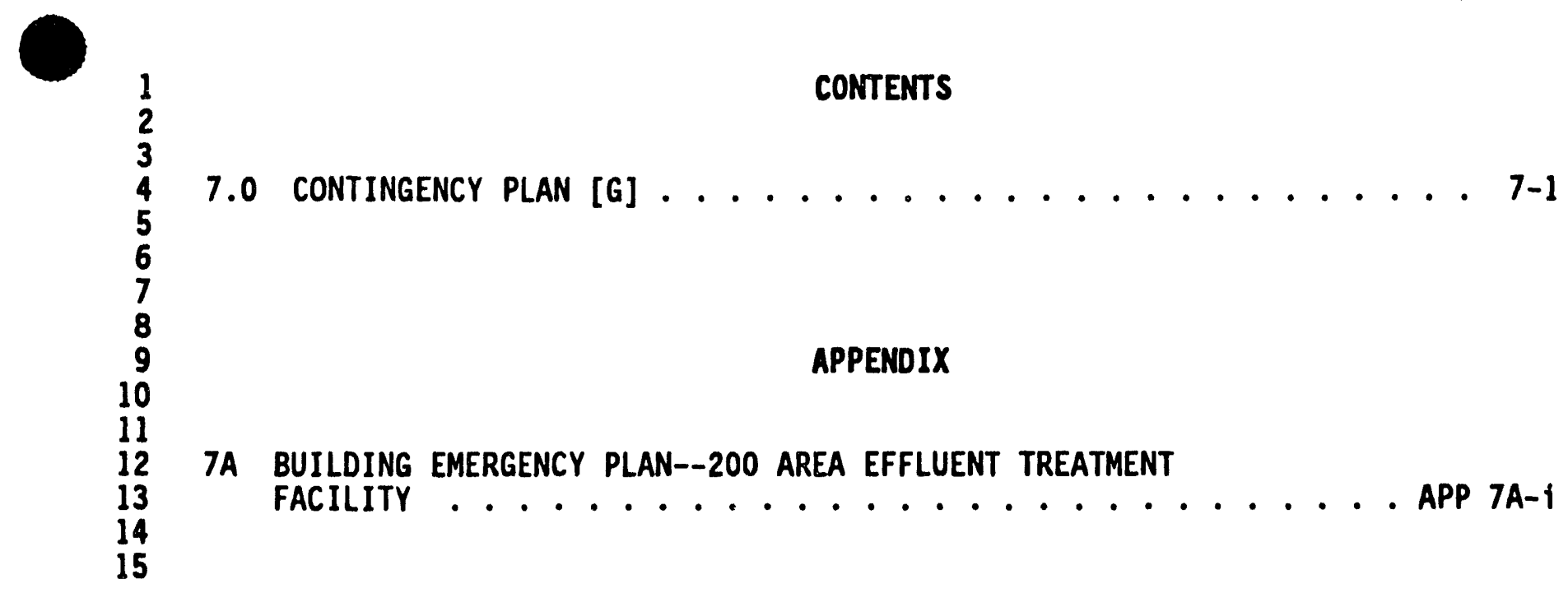


DOE/RL-93-03, Rev. 0 $08 / 31 / 93$

This page intentionally left blank. 
DOE/RL-93-03, Rev. 0 $08 / 31 / 93$

\subsection{CONTINGENCY PLAN [G]}

The WAC 173-303 requirements for contingency plans are satisfied in the following documents: the Building Emergency Plan--200 Area Effluent Treatment Facility (Appendix 7A) and the Hanford Facility Contingency Plan [Hanford Facility Dangerous Waste Permit Application, General Information, Chapter 7.0 (DOE/RL-91-28)]. Contingency $\mathrm{plan}$ documentation is kept at the ETF (Chapter 12.0).

The cited contingency plan documents also serve to satisfy a broad range of other requirements (e.g., Occupational Safety and Health Administration and U.S. Department of Energy Orders). Therefore, revisions made to portions of the contingency plan documents that are not governed by the requirements of WAC 173-303 will not be considered as a modification subject to review or approval by Ecology. 


$$
\text { DOE/RL-93-03, Rev. } 0
$$
$08 / 31 / 93$

This page intentionally left blank. 
DOE/RL-93-03, Rev. 0 $08 / 31 / 93$

CONTENTS

8.0 PeRSONNEL TRAINING $[H] \ldots \ldots \ldots$. . . . . . . . . . . .

8.1 OUTLINE OF THE TRAINING PROGRAM $[\mathrm{H}-1] \ldots \ldots$. . . . . . . 8-1

8.1.1 Job Positions and Descriptions [H-1a] ....... 8-1

8.1.1.1 Treatment, Storage, and/or Disposal Unit

8.1.1.2 Manager ........... 8-2

8.1.1.2 Treatment, Storage, and/or Disposal Unit . . 8-2

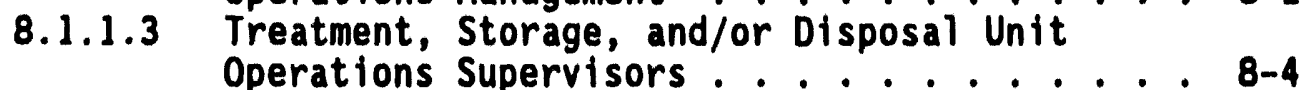

8.1.1.4 Treatment, Storage, and/or Disposal Unit

8.1.1.5 Treatment, Storage, and/or Disposal Unit

8.1.1.6 Engineering Managers and Engineers . . . 8-5

Maintenance Managers and Engineers . . . 8-7

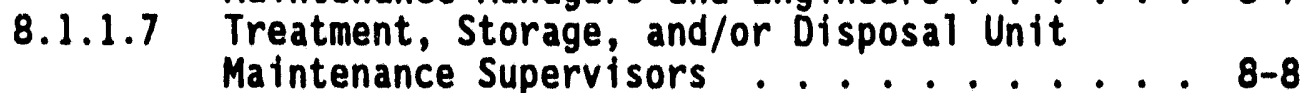

8.1.1.8 Treatment, Storage, and/or Disposal Unit . . 8-8

8.1.1.9 Treatment, Storage, and/or Disposal Unit

Environmental Compiliance Manager or

Officer . . . 8- . . . . . . . .

8.1.1.10 Treatment, Storage, and/or Disposal Unit Support Organizations Management and

Technical Support Personnel ...... 8-10

8.1.2 Employees Dangerous Waste Work Category

Classifications ............. 8-11

8.1.3 Training Content, Frequency, and Techniques [H-1b] . 8-11

8.1.3.1 Overview of Training for Specific Employee

Categories ............. 8-11

8.1.3.2 Overview of Training for Treatment, Storage, and/or Disposal Unit-Specific and Job-Specific Positions . . . . . . . . 12

8.1.3.3 Treatment, Storage, and/or Disposal Unit Support Organizations Management and Technical Support Personnel Training . . . 8-12

8.1.3.4 Visitor Training ........... 8-12

8.1.3.5 Subcontractor Training .......... 8-12

8.1.3.6 Training Matrix: Job Positions and

Training ..... . 8-13

8.1.3.7 Training Course Descriptions . . . . 8-13

8.1.4 Training Director $[\mathrm{H}-\mathrm{lc}] \ldots . . . . . . . .13$

8.1.4.1 Treatment, Storage, and/or Disposal Unit

Management Responsibilities ..... 8-14

8.1.4.2 Treatment, Storage, and/or Disposal Unit

Engineering Responsibilities ...... 8-14 


\section{coNTENTS (cont)}

8.1.4.3 Training Organizations Responsibilities . . 8-14 8.1.4.4 Support Organizations Management

Responsiblittles ........... 8-16

8.1.5 Relevance of Training to Job Positions [H-1d] . . . 8-16

8.1.6 Training to Emergency Response [H-le] . . . . . . . 8-17

8.2 IMPLEMENTATION OF TRAINING PROGRAM [H-2] . . . . . . . . 8-17

APPENDIX

8A TRAINING COURSE DESCRIPTIONS .............. APP 8A-1

\section{FIGURES}

8-1. Employee Work Category Decision Flow Diagram . . . . . . . . F8-1

8-2. Distribution of Training Responsibility for

Treatment, Storage, and/or Disposal Units . . . . . . . . F8-2

\section{TABLES}

8-1. Dangerous Waste Initial Training Requirements Matrix . . . . . . T8-1

8-2. Dangerous Waste Cont inuing Training Requirements Matrix . . . . . T8-2

8-3. Treatment, Storage, and/or Disposal Unit-Specific Training Matrix . . . . . . . . . . T8-3

8-4. Treatment, Storage, and/or Disposal Job-Specific Training Matrix ...................... . . T8-4 


\subsection{Personnel trainino [H]}

This chapter outlines the training program developed and implemented for employees who have duties assoclated with dangerous waste management.

The TSD unit training program uses existing training courses. The program is designed to ensure that the ETF (herelnafter reforred to as TSD unit) is operated and maintained in accordance with WAC 173-303 requirements.

\subsection{OUTLINE OF THE TRAINING PROGRAM [H-1]}

The TSD unit training program meets the requirements of WAC 173-303-330 and 40 CFR 264.16 for the development of written dangerous waste training program.

The TSD unit training program is designed to prepare employees to operate and maintain a TSD unit in a safe, effective, efficient, and environmentally sound manner. In addition to preparing employees to operate and maintain the TSD unit under normal conditions, the training program ensures that omployees are prepared to respond in a prompt and effect tve manner should offnormal or emergency conditions occur. Emergency response training is consistent with emergency responses outlined in the contingency plan (Appendix 7A).

The TSD unit management is responsible for identffying TSD unit- and job-specific training requirements for TSD unit employees. The TSD unit training program includes training courses that cover training requirements for employees who work in the TSD unit. The TSD unit management, in cooperation with other applicable organizations, is responsible for the development and administration of the comprehensive training program for employees assigned to, or involved with, the TSD unit. The TSD unit management is responsible for ensuring that employees complete the appropriate training. The responsibilities of the applicable organizations are discussed in Section 8.1.4.

The TSD unit management will reevaluate the TSD unit training program courses to ensure that dangerous waste training requirements cont inue to be met. These reevaluations could result in modifying or adding new material to the current training program.

\subsubsection{Job Positions and Descriptions [H-1a]}

Each employee is assigned a job title (from the salaried nonexempt or bargaining unit classifications) or position (from the exempt classifications). The specific job titles or positions, job or position descriptions, and names of the TSD unit and support organizations employees are maintained by or avallabl z from TSD unit management and TSD unit support organization management. The job or position descriptions include applicable desired requisite skills, work experience, education, and other 
qualifications, and a brlef 1 ist of dutles and/or rasponsfbllitles for ach job title or position. Training records are maintained by the contractors' organizations in accordance with the requirements of the Privacy Act of 1974 . Presently, the training records of individual employees are avallable for inspection purposes through the Freedon of Information Act of 1966 . The DOE-RL is seeking authorlzation through the U.S. Department of EnergyHeadquarters to amend the systems notice under the Privacy Act to allow regulatory agencles 'routine use' access to training records under this act. Training records on current and former employees will be maintained in accordance with Chapter 12.0 .

Brief job titles and position descriptions of employees associated with dangerous waste management at TSD units are ilsted in the following sections.

8.1.1.1 Traatmant, Storage, and/or O1sposal Unit Managor. Responsibllitles of TSD unit manager includes the following:

- Operating and maintaining the TSD unit in compliance with U.S. Department of Energy directives, applicable policies and procedures, and federal and state regulations

- Complying with all dangerous waste policies, procedures, and regulations

- Recrutting and developing a trained cadre of managers, profosstonals, and nonexempt and bargaining unit employees

- Ensuring safe and disciplined operations by trained personnel who implement policles and procedures

- Providing operational requirements for support organizations to plan and provide services and resources as applicable

- Promoting safe operations at the TSD unit

- Ensuring that TSD unit operating procedures are developed, reviewed, approved, and revised as applicable

- Responding to offnormal and/or emergency conditions according to established procedures

- Serving as the designated alternate to the bullding emergency director and the staging area manager as applicable

- Performing the duties of the bullding emergency director, as applicable, for the TSD unit during emergencies.

8.1.1.2 Treatmont, Storage, and/or Disposal Unit Operations Managoment. Responsibilities of the TSD unit operations management include the following:

- Supervising, coordinating, and directing the activities of TSD unit operations supervisors 
- Promoting safe operattons at the TSD unit

- Enforcing safoty, housakeoping, and general operating rules

- Maintaining control over TSD unit operations in accordance with established operating procedures and policles, U.S. Department of Energy Orders, and federal and state regulations

- Otrecting, controlling, and coordinating the recelpt, storage, transfer, and reprocessing of dangerous waste

- Ensuring TSD unit operations are conducted according to established procedures

- Ensuring compliance with TSO unit operating limits and specifications

- Ensuring that job safoty and planning meetings are conducted, as applicable, with personnel involved with the TSD unit operations

- Ensuring that supervisors and nuclear operators are trained

- Ensuring that dangerous waste exposure is maintained ALARA

- Ensuring that essential records are maintained

- Doturmining the status of and resolving action tems arising from audits, inspections, and unusual occurrences

- Developing, revising, and reviawing TSD unit operating procedures as applitcable

- Responding to and providing remedial guidance and dectstons for operational anomaltes, offnormal conditlons, and equipment malfunctions

- Responding to offnormal and/or emergency conditions according to established procedures

- Coordinating the recovery from, and masuring and reestabilishing control of, unplanned releases to the environment and other amergency conditions

- Notifying TSD unit management of any unplanned releases to the environment

- Serving as the designated alternate to the bullding emergency director and the staging area manager as applicable

- Performing the dutles of the bullding emergency director, as applicable, for the TSO unit during emergenctes. 
8.1.1.3 Treatment, Storage, and/or Disposal Unit Operations Suporvisors. Responsiblitties of the TSO unit operations supervisors include the following:

- Supervising, coordinating, and directing the activities of the nuclear operators

- Promoting safe operation at the TSD unit

- Enforcing safoty, housekeeping, and general operating rules

- Ensuring that TSO unit operations are in accordance with established operating procedures and polictes, U.S. Department of Energy Orders, and federal and state regulations

- Supervising and coordinating the recelpt, storage, transfer, and reprocessing of dangerous waste

- Conducting TSD unit operations according to established procedures

- Ensuring compliance with TSD unit operating limits and specifications

- Conducting pre-job safoty and planning meetings with personnel involved with TSD unit operations as applicable

- Training and/or arranging training for nuclear operators

- Ensuring that dangerous waste exposure is maintained ALARA

- Minimizing injuries and/or equipment damage

- Maintaining essential records

- Revising and reviewing TSD unit operating procedures as applicable

- Recognizing offnormal conditions and taking appropriate action

- Responding to offnormal and/or emergency conditions according to established procedures

- Notffying TSD unit management of any unplanned releases to the environment

- Serving as designated alternate to the butlding emergency director and the staging area manager as applicable

- Performing the dutles of the bullding emergency director, as applicable, for the TSD unit during emergencies. 


\subsubsection{Treatment, Storage, and/or Disposal Unit Nuclear Operators.} Responsibilities of the TSD unit nuclear operators include the following:

- Performing TSD unit work activities in accordance with current operating procedures

- Attending TSD unit operations work $p l$ an and pre-job safety meetings

- Escorting supporting crafts and visitors entering the TSD unit as applicable

- Reporting recommended changes to the TSD unit operating procedures to immediate supervisor

- Receiving, segregating, sorting, inventorying, storing, staging, and shipping dangerous waste

- Packaging and labeling dangerous waste for shipment

- Operating processes, systems, and equipment at the TSD unit

- Performing sampling as required by procedure

- Conducting routine inspections

- Providing survefllance of the TSD unit for offnormal conditions

- Performing nondestructive assaying activities at the TSD unit as applicable

- Assisting truck drivers in loading and unloading trucks at the TSD unit

- Ensuring that trucks transporting dangerous waste are placarded properly

- Responding to alarms at the TSD unit

- Responding to offnormal and/or emergency conditions according to established procedures

- Responding to dangerous waste leaks or spills .

8.1.1.5 Treatment, Storage, and/or Disposal Unit Engineering Managers and Engineers. Responsibilities of the TSD unit engineering managers and engineers include the following:

- Providing the TSD unit with equipment, buildings, and structures that can be operated safely and productively

- Recruiting, training, qualifying, appraising, and developing a highly competent and professional engineering staff 
- Ensuring that the staff is knowledgeable of procedures, equipment, buildings, and processes so that the staff can identify problem areas and provide remedial action in a timely fashion to keep the TSD unit operating safely and productively

- Overseeing and directing the activities of the cognizant/process engineering staff so that the TSD unit can be operated in a safe, efficient, and technically sound manner

- Ensuring that the TSD unit imergency and monitoring equipment, process equipment, procedures, designs, etc., comply with U.S. Department of Energy Orders, federal and state regulations, national standards, and applicable engineering procedures and management standards

- Issuing and maintaining or providing oversight and review of TSD unit operating documentation, operating procedures, flowsheets, sample schedules, specifications, process test plans and procedures, operational safety requirements, and other documents necessary to operate the TSD unit

- Performing routine and comprehensive evaluations of the TSD unit processes to ensure compl fance with process control requirements, procedure compliance, and equipment performance; assessing problem areas and implementing timely corrective actions

- Preparing, issuing, and reviewing TSD unit operating procedures, and preparing and issuing procedure departure authorizations

- Performing daily, routine, and comprehensive evaluations of TSD unit process parameters to ensure compliance with procedures

- Maintaining TSD unit instrument and equipment flow diagrams

- Preparing design criteria, and performing and approving design analysis

- Preparing and approving equipment and material specifications for new design

- Preparing and approving engineering design documents and drawings that are in compliance with applicable policies, procedures, and instructions and are in accordance with recognized national standards and codes

- Providing input to environmental permit applications

- Preparing and/or approving engineering change notices

- Preparing and approving TSD unit process memos, process test plans, and work plans 
- Reviewing and approving TSD unit work authorizations and assigning impact levels

- Providing technical direction for hazardous material and dangerous waste spill responses

- Responding to offnormal and/or emergency conditions according to establi shed procedures.

8.1.1.6 Treatment, Storage, and/or Disposal Unit Maintenance Managers and Engineers. Responsibilities of the TSD unit maintenance managers and engineers include the following:

- Supervising, coordinating, and directing the activities of the maintenance supervisors

- Inspecting and replacing emergency and monitoring equipment

- Ensuring compliance with requirements, applicable policies, programs, regulations, and U.S. Department of Energy Orders to ensure employee safety, environmental compliance, and public safety

- Assisting in the detailed planning of schedules and budgets to ensure that work is performed in accordance with established schedules and within budgets

- Evaluating and modifying maintenance procedures and work plans, and ensuring that procedures are current and accurate

- Ensuring that requirements are identified for each assigned TSD unit, giving particular attention to items supporting safety systems

- Identifying preventive maintenance requirements and deficiencies

- Conducting equipment and TSD unit walkdowns and providing recommendations for reliability improvements

- Providing for continued input and development of the equipment history file in support of trend analysis reviews and specific problem resolution

- Conducting critical equipment failure analysis with the cognizant system engineer

- Promoting safe maintenance practices at the TSD unit

- Ensuring that maintenance activities are conducted in accordance with procedures

- Ensuring that supervisors and crafts are trained 
- Ensuring pre-job safety and planning meetings are conducted with personnel involved with the TSD unit

- Ensuring that dangerous waste exposure is maintained ALARA

- Responding to offnormal and/or emergency conditions according to established procedures.

8.1.1.7 Treatment, Storage, and/or Disposal Unit Maintenance Supervisors. Responsibilities of the TSD unit maintenance supervisors include the following:

- Supervising, coordinating, and directing the activities of maintenance crafts

- Promoting safe maintenance practices at the TSD unit

- Enforcing safety, housekeeping, and general operating rules

- Conducting maintenance activities according to established procedures

- Training and/or arranging training for personnel

- Ensuring that maintenance crafts are trained

- Maintaining essential records

- Conducting pre-job safety and planning meetings with personnel involved with the TSD unit

- Minimizing injuries and/or equipment damage

- Ensuring that dangerous waste exposure is maintained ALARA

- Identifying offnormal conditions and taking appropriate action

- Responding to offnormal and/or emergency conditions according to established procedures.

8.1.1.8 Treatment, Storage, and/or Disposal Unit Maintenance Crafts. Responsibilities of the TSD unit maintenance crafts include the following:

- Providing routine scheduled and emergency maintenance services

- Providing dedicated scheduled and emergency state-of-the-art equipment and/or systems services

- Verifying and monitoring that instrumentation and equipment are functioning properly 
- Inspecting, repairing, and replacing emergency and monitoring equipment

- Responding to offnormal and/or emergency conditions according to establi ished procedures.

8.1.1.9 Treatment, Storage, and/or Disposal Unit Environmental Compliance Manager or Officer. Responsibilities of the TSD unit environmental compliance manager or officer include the following:

- Overviewing TSD unit environmental issues

- Assessing dangerous waste handling problem areas and implementing timely actions

- Ensuring that TSD unit management is in compliance with dangerous waste regulations

- Ensuring adherence to the EPA and Ecology reporting requirements

- Serving as the single point of contact for environmental and dangerous waste related matters

- Managing TSD unit environmental and dangerous waste program corrective actions status to achieve compliance with dangerous waste permits

- Coordinating the review and submittal of environmental data for the following:

- Annual dangerous waste report

- Waste minimization report

- Waste volume projections (solid and liquid)

- Superfund Amendments and Reauthorization Act (SARA) of 1986 312 Inventory

- SARA 313 releases

- EPA surveys

- Preparing and providing input for reporting the following:

- Spill information

- Interim status compliance

- Ecology and EPA reporting requirements

- Ensuring the development and review of new or revised permit applications including the following:

- Part A notifications

- Part B permit applications

- Closure plan applications

- Clean air permit applications

- National Pollution Discharge El imination System permit applications and well registrations

- Ensuring implementation of permitting requirements and conducting periodic surveillances of compliance assessment with permits 
- Ensuring the maintenance of active permits in an up-to-date condition

- Resolving regulatory interpretations required to operate TSD unit through interfacing with the applicable environmental organizations, DOE-RL, Ecology, EPA, and applicable health departments

- Preparing, issuing, reviewing, and approving dangerous waste handling procedures as appiticable

- Determining and issuing dangerous waste handling, packaging, and shipping requirements as applicable

- Assessing dangerous waste handling prov' am areas and implementing corrective action(s)

- Approving dangerous waste container control as applicable

- Ensuring that a tracking system for dangerous waste is maintained.

\subsubsection{Treatment, Storage, and/or Disposal Unit Support Organizations} Management and Technical Support Personnel. The TSD support organizations management and technical support personnel provide support as applicable to assist TSD unit management to operate and maintain the TSD unit in a safe, effective, efficient, and environmentally acceptable manner. This operation is in accordance with applicable dangerous waste management procedures, U.S. Department of Energy directives, applicable management policies, and federal and state regulations. The TSD unit management will provide a 1 ist of TSD unit support organizations when requested to do so by regulators on a demonstrated need-to-know basis. In addition, the TSD unit support organizations management will provide through RCRA Compliance support the applicable job tities and support responsibilities when requested to do so by the regulators. Responsibilities of the TSD unit support organizations management and technical support personnel include, but are not limited to, the following functions:

- Engineering

- Maintenance

- Transportation

- Safety

- Health physics

- Training

- Nondestructive examinations

- Oversite

- Overviews

- Inspections

- Surveillances

- Surveys

- Appraisals

- Audits

- Laboratory analysis

- Environmental issues

- Security 
DOE/RL-93-03, ReV. 0

$08 / 31 / 93$

- Fire protection

- Emergency medical services

- Dangerous waste accidents.

\subsubsection{Employees Dangerous Waste Work Category Classifications}

The TSD unit employees, including TSD urit support organizations employees, are classified into one of four categories with respect to their job titles, positions, and responsibilities or their involvement with dangerous waste management. This classification is determined by the employees manager using the Decision Flow Diagram in Figure 8-1.

The four categories of workers are as follows:

- All employees

- General worker

- General supervisor/manager

- General nonradiological shipper.

\subsubsection{Training Content, Frequency, and Techniques [H-1b]}

This section provides an overview of dangerous waste management, unit-specific, and job-specific training provided to employees in job titles and positions discussed in the previous sections. In addition to TSD unit normal operating corditions, employees are trained on emergency equipment and systems, and emergency procedures to include the following:

- Procedures for using, inspecting, repairing, and replacing TSD unit emergency and monitoring equipment

- Automatic or manual dangerous waste feed cut-off systems

- Communications and alarm systems

- Response to fires and explosions

- Response to dangerous waste contamination incidents and spills

- Shutdown of operation.

8.1.3.1 Overview of Training for Specific Employee Categories. The training program uses existing courses that includes general to specific dangerous waste training material. The courses are given through classroom instruction, on-the-job training, and self-study. The training requirements depend on the category in which the TSD unit employees, including TSD unit support

organizations employees, are classified by management. The work category initial and continuing training program course requirements are listed in Tables 8-1 and 8-2. 
8.1.3.2 Overview of Training for Treatment, Storage, and/or Disposal Unit-Specific and Job-Specific Positions. The TSD unit employees receive applicable unit-specific and job-specific training. The TSD unit-specific and job-specific qualifications and/or certifications are maintained according to union bargaining unit contracts and/or management policies or directions. The courses are given through classroom instruction, on-the-job training, self-study, and computer-based training. The TSD unit management and employees complete specific courses in preparation for work assignments, including hazardous material and dangerous waste training courses. The courses address the TSD unit management procedures, U.S. Department of Energy directives, applicable management policies, and federal and state regulations. The courses include implementation of the TSD unit contingency plan and use of emergency and monitoring equipment. The TSD unit designated management and employees are required to be qualified and/or certified for assigned jobs through a performance-based training process as determined by management. The TSD unit-specific and job-specific initial and continuing training program course requirements are listed in Tables 8-3 and 8-4.

\subsubsection{Treatment, Storage, and/or Disposal Unit Support Organizations} Management and Technical Support Personnel Training. The TSD unit support organizations employees might be required to complete selected TSD unit-specific and job-specific training courses as applicable to their involvement with dangerous waste management (refer to Tables 8-3 and 8-4 for initial and continuing training courses). The TSD unit support organizations management is responsible for determining employees job position training requirements and for ensuring that management and employees are trained.

8.1.3.4 Visitor Training. Visitors who must enter the TSD unit are required to complete the following training and/or must be escorted as applicable:

- Dangerous waste management courses according to their job assignments (Figure 8-1)

- TSD unit orientation

- General employee safety orientation

- Building emergency plan orientation.

The TSD unit management is responsible for determining visitor training and medical surveillance requirements before granting visitor access to the TSD unit. The TSD unit management is responsible for ensuring that the visitors have met all the requirements for access to the TSD unit (refer to Tables 8-1, 8-2, and 8-3 as applicable).

8.1.3.5 Subcontractor Training. Subcontractor personnel at the TSD unit must complete the appropriate level of training determined by employment, security, and TSD unit management. Refer to Section 8.1.3.4 for the training

requirements. Additional general training could be required when applicable.

Subcontractor personnel who have completed training offsite are required to provide a certificate or other suitable evidence of training course(s) that 
meet the requirements of WAC 173-303 and this section. The TSD unit management must verify the acceptability of offsite training as commensurate with subcontractor personnels' anticipated TSD unit job assignment and the minimum training requirements listed in Section 8.1.3.4.

8.1.3.6 Training Matrix: Job Positions and Training. The TSD unit management applicable dangerous waste training program encompasses general, unit-specific, and job-specific training courses. Tables 8-1 through 8-4 consist of matrices that relate work categories and job titles or positions to the training courses applicable to the TSD unit. The matrices indicate if the course is initial, introductory or continuing and also if the course is a part of a qualification or certification program required for specific job titles or positions or required only for new employees.

A computerized mandatory training matrix for all employees has been developed and interfaces with the training records information system. The mandatory training matrix 1 ists all training requirements for all individual employees and for each individual organization. The TSD unit management and support organizations are responsible for ensuring that the mandatory training matrix for their organization is updated when required and/or as changes occur. The mandatory training matrix provides real-time training requirement for each employee and records when training is complete and when retraining is due.

Some courses are initial or introductory and must be completed once only (often referred to as orientation), and other initial or introductory courses are the first course in a program. Continuing courses are those that must be repeated according to a specified frequency.

8.1.3.7 Training Course Descriptions. Appendix $8 \mathrm{~A}$ contains a brief description of the existing training courses selected for this program, including course title, course description, target audience, instructional delivery, evaluation method, length of course, and frequency of retraining.

\subsubsection{Training Director $[\mathrm{H}-1 \mathrm{C}]$}

There is no one individual designated as training director. The position is shared among the TSD unit management, training, and support organizations. The distribution of training responsibilities is provided in Figure 8-2. Using the system noted in Figure 8-2, the TSD unit management can access training resources and experts on many different areas of hazardous material, dangerous waste management, and safety rather than relying on the knowledge of one person or a smali number of individuals. This shared responsibility ensures the identification of training requirements and that the development and implementation of the dangerous waste management training program for the TSD units comply with U.S. Department of Energy directives, management policies, federal hazardous waste regulations, and WAC 173-303. The TSD unit management can provide through RCRA Compliance support the current list of organizations sharing training responsibilities when requested to do so by the regulators. General responsibilities for training are discussed in the following sections. 
8.1.4.1 Treatment, Storage, and/or Disposal Unit Management Responsibilities. The TSD unit management has the following responsibilities related to training:

- Determining training requirements and training compliance

- Requesting and/or conducting training

- Maintaining field training records and certifications

- Submitting training completion records to the training records information system

- Reporting training requirements for employees to the training records information system for updating the mandatory training matrix as required

- Tracking retraining requirements.

\subsubsection{Treatment, Storage, and/or Disposal Unit Engineering}

Responsibilities. Treatment, storage, and/or disposal unit engineering has the following responsibilities related to training:

- Determining engineering training requirements

- Developing and conducting training

- Maintaining field training records and certifications

- Submitting training completion records to the training records information system

- Reporting training requirements for engineers to the training records information system for updating the mandatory training matrix as required

- Tracking retraining requirements.

8.1.4.3 Training Organizations Responsibilities. Training organizations have the following responsibilities:

- Conducting job analysis

- Designing training programs

- Developing training programs

- Developing training courses

- Providing training program accreditation assistance 
- Providing consultation to other training organizations regarding training development

- Developing and implementing safety training courses to comply with federal and state regulations

- Conducting safety training courses

- Conducting respiratory protection classes

- Determining personnel training requirements

- Developing and providing certification training

- Determining dangerous waste management training requirements

- Developing and implementing environmental training courses to comply with U.S. Department of Energy directives and federal and state dangerous waste regulations

- Conducting hazardous material and dangerous waste handling and management courses

- Developing unit and specific training courses for the TSD untt management operations employees

- Developing and maintaining on-the-job training requirements

- Providing instruction for selected courses

- Developing and providing study material and examinations

- Preparing and administering examinations

- Developing and conducting on-the-job training

- Coordinating classes and other training requirements to complete and maintain certifications

- Tracking retraining requirements as required

- Operating and maintaining central training record files

- Maintaining the training records information system

- Maintaining the mandatory training matrix for all employees and organizations

- Processing training completion records received into the training records information system

- Notifying management of retraining requirements for employees. 


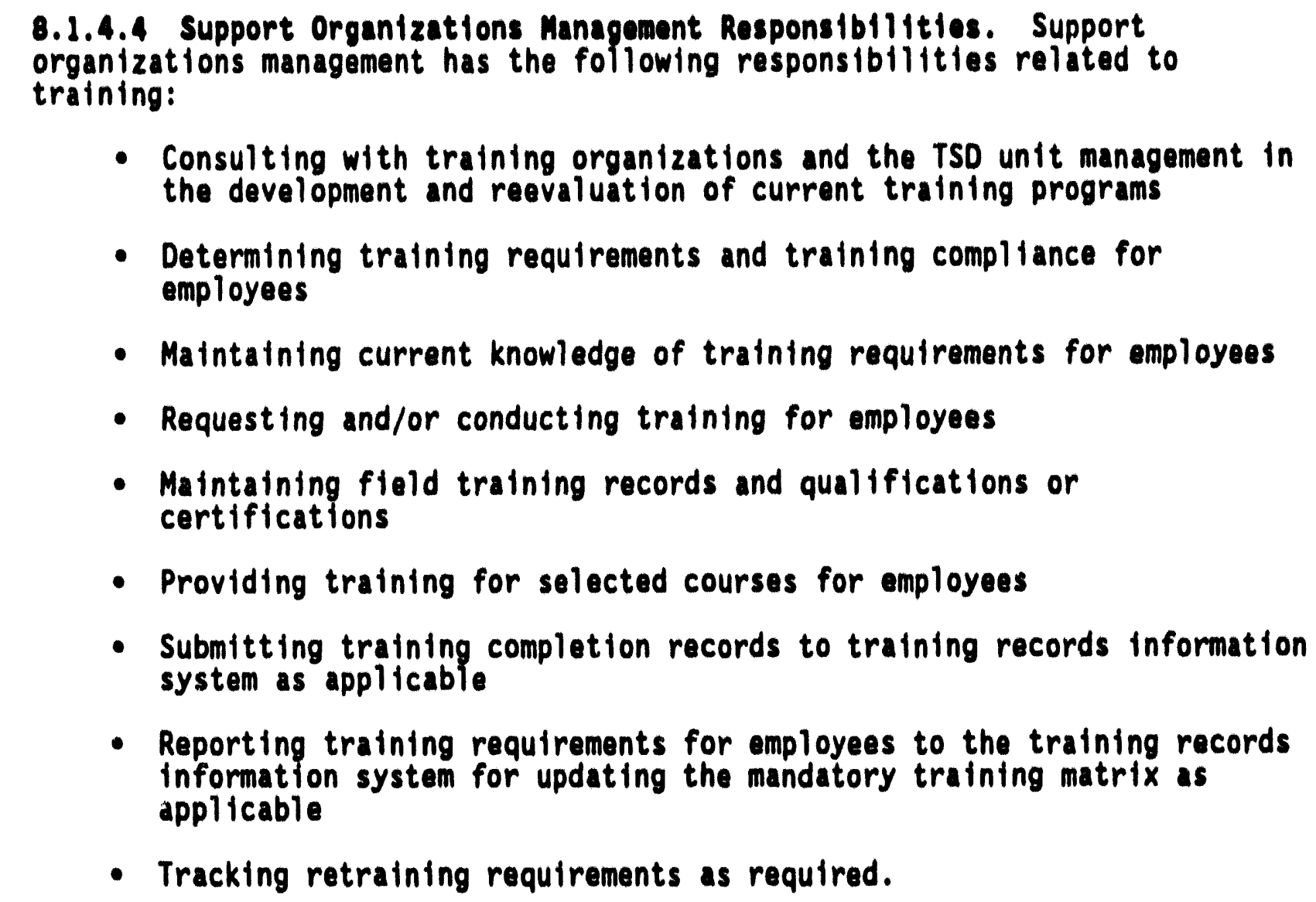

- Consulting with training organizations and the TSD unit management in the development and reevaluation of current training programs

- Determining training requirements and training compliance for employees

- Maintaining current knowledge of training requirements for employees

- Requesting and/or conducting training for employees

- Maintaining field training records and qualifications or certifications

- Providing training for selected courses for employees

- Submitting training completion records to training records information system as applicabie

- Reporting training requirements for employees to the training records information system for updating the mandatory training matrix as applicable

- Tracking retraining requirements as required.

\subsubsection{Relevance of Training to Job Positions [H-1d]}

The training program for the TSD unit management employees was developed after reviewing U.S. Department of Energy directives, federal and state regulations, and the completion of a job analysis for management-selected job positions. Tasks performed by employees in selected job positions were identified and evaluated to determine training requirements. In addition, training needs are evaluated continually in relation to current U.S. Department of Energy directives and federal and state regulations. These evaluations could result in modifying or adding new material to the current training program.

Certification is required for employees working in TSD units in selected job positions. To become certified, an employee must successfully complete classroom training, self-study, and on-the-job training as applicable. Classroom instruction and/or self-study is designed to provide selected employees with the fundamental knowledge required to work safely at the TSD unit.

On-the-job training requires selected employees of the TSD unit to gain experfence with the operating procedures. All work involving hazardous materials and dangerous waste management is performed according to approved operating procedures; therefore, an understanding of procedures is crucial to 
ensure the proper and safe operation of the TSD untt. Employees learn the procedures by performing, simulating, and/or describing a particular task as specified by the approprlate operating procedure. The employee demonstrating the required knowledge and skills is observed by another certified employee and the supervisor or manager before being certifled.

The TSD unit management training program outlined here ensures that employees are trained properly to perform the job positions pertinent to the handiing, storage, treatment, and/or disposal of dangerous waste.

The TSD unit employees and support organization employees also could and do recelve additional training in accordance with other regulations such as 29 CFR 1910.120, "Hazardous Waste Operations and Emergency Response" and 29 CFR 1910.1200, "Hazard Communtcation Program," and the U.S. Department of Energy directives and management policles.

\subsubsection{Training to Emergency Response [H-1e]}

Effective response to emergencles and famillarity with emergency equipment and emergency systems are covered under the classroom and on-the-job training requirements outilined in Tables 8-3 and 8-4, and Appendix 8A.

Federal and state regulations require that employees be able to respond effectively to emergencies and that employees be familiar with emergency procedures, emergency equipment, and emergency systems. Specific topics required by federal and state dangerous waste regulations if isted in Section 8.1 .3 are addressed where applicable and are included in the following training:

- Building emergency director training

- Bullding emergency plan checklist training (all employees)

- Emergency procedure and abnormal conditions training

- Treatment, storage, and/or disposal unit-specific training

- Treatment, storage, and/or disposal job-specific training.

\subsection{IMPLEMENTATION OF TRAINING PROGRAM [H-2]}

The TSD unit management training program is in place. Certification for designated employees of the TSD unit is required before working without supervision. Training content is reviewed and updated as applicable.

Training of new employees is completed within the first 6 months of assignment to the TSD unit. After the initial training, employees are required to recertify annually or biennially as applicable. Uncertified employees are not permitted to work at the TSD unit without supervision of a certified employee. The TSD unit operations management is responsible for ensuring that all designated employees are trained and that certifications are maintained. 
Officlal training record flles for the TSD unit managament employees are stored in the training records information system. This database is managed by the training records organization. The training records organization inputs the completed training records into a computer file. The computer file is accessible on local area network to allow remote accessing of employee training records by means of a computer terminal. A tickler file is avallable from the database to inform the TSD unit operations management when training is within 90 days of expiration. A computerized copy of completed training and qualifications or certifications for the TSD unit management employees is avallable at the TSD unit. These flles include employee training records, course attendance rosters, and course outlines. Training records are maintained by the contractors' organizations in accordance with the requirements of the Privacy Act of 1974. Presently, the training records of Individual employees are avallable for inspection purposes through the freedon of Information Act of 1966. The DOE-RL is seeking authorization through the DOE-Headquarters to amend the systems notice under the Privacy Act of 1974 to allow regulatory agencies 'rout ine use' access to training records under this act. Training records on current and former employees will be maintained in accordance with Chapter 12.0. 


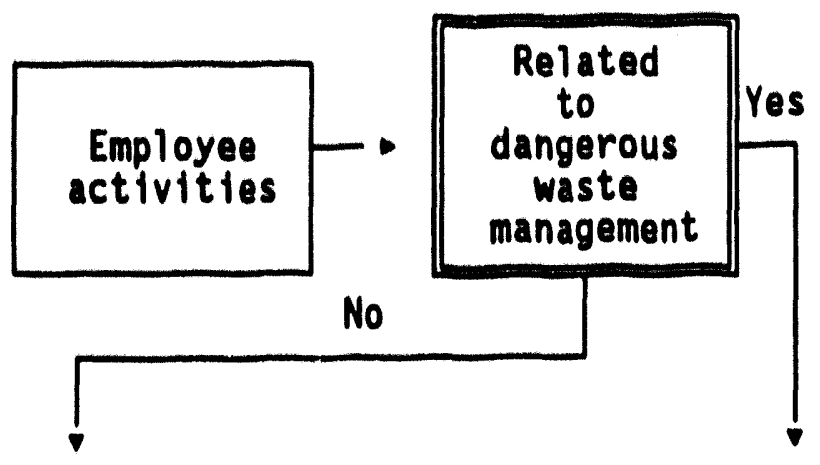

\begin{tabular}{|c|l|c|l|}
\hline Category & Definition/Example & Category & \multicolumn{1}{c|}{ Definition/Example } \\
\hline 1 & $\begin{array}{l}\text { All employees } \\
\text { All employees and } \\
\text { unescorted contract } \\
\text { personnel (e.g., } \\
\text { visitors, } \\
\text { subcontractor } \\
\text { personnel, } \\
\text { administrative, } \\
\text { clerical). }\end{array}$ & 2 & $\begin{array}{l}\text { General worker } \\
\text { Any employee who handles, } \\
\text { generates, packages, stores, } \\
\text { or ships hazardous } \\
\text { materials/dangerous waste or } \\
\text { directly affects the management } \\
\text { of dangerous waste (e.g., } \\
\text { visitors, contract and } \\
\text { subcontractor personnel, } \\
\text { maintenance shops, fabrication } \\
\text { shops, warehouse, paint shops). } \\
\text { General supervisor/manager } \\
\text { Supervisor/manager who has } \\
\text { employees that qualify as general } \\
\text { workers (category 2). } \\
\text { General nonradiological shipper } \\
\text { Employees who qual ify under } \\
\text { category 2, general worker, } \\
\text { and/or prepare and sign a uniform } \\
\text { hazardous waste manifest (e.g. } \\
\text { laboratory waste shipper, garage } \\
\text { waste shipper). }\end{array}$ \\
\hline
\end{tabular}

Figure 8-1. Employee Work Category Decision Flow Diagram. 


\section{Treatment, Storage, and/or Disposal Unit Management \\ Determines training requirements and training compliance \\ Training Organizations \\ Provide \\ - Job analysis \\ - Training records \\ - Computer-based training \\ - Training program evaluation \\ - Training program design \\ - Training program development \\ Support Organizations \\ - Provide technical consultations \\ - Determine training requirements for employees \\ - Develop and provides training for employees \\ - Reevaluate current training programs.}

- Training program accreditation

- Environmental hazardous material and dangerous waste training courses

- Safety training courses

- Laboratory training

- Maintenance training

- Operations training

- Supervisors training

- Respiratory protection training

- Heaith physics training

- On-the-job training

- Engineering training.

Figure 8-2. Distribution of Training Responsibility for Treatment, Storage, and/or Disposal Units. 
Table 8-1. Dangerous Waste Initial Training Requirements Matrix.

\begin{tabular}{|c|c|c|c|c|}
\hline \multirow[b]{2}{*}{ Employee category" } & \multicolumn{4}{|c|}{ Course title } \\
\hline & $\begin{array}{c}\text { Hazardous } \\
\text { communications } \\
\text { and waste } \\
\text { orientation } \\
\text { (1 hour) }\end{array}$ & $\begin{array}{l}\text { Generator } \\
\text { hazardous } \\
\text { safety } \\
\text { training } \\
\text { (4 hours) }\end{array}$ & $\begin{array}{c}\text { Facility } \\
\text { emergency and } \\
\text { hazard } \\
\text { information } \\
\text { checklist } \\
\text { training } \\
\text { (4-6 hours) }\end{array}$ & $\begin{array}{l}\text { Hazardous } \\
\text { waste } \\
\text { shipment } \\
\text { certification } \\
\text { (24 hours) }\end{array}$ \\
\hline 1. All employees & $x^{b}$ & & & \\
\hline 2. General worker & & $x^{b}$ & $x$ & \\
\hline $\begin{array}{l}\text { 3. General } \\
\text { supervisor/ } \\
\text { manager }\end{array}$ & & $x$ & $x$ & \\
\hline $\begin{array}{l}\text { 4. General } \\
\text { nonradiological } \\
\text { shipper }\end{array}$ & & $x$ & $x$ & $x$ \\
\hline
\end{tabular}

12

Category definitions are in Figure 8-1.

Required for visitors and subcontractors as determined by the TSD unit management.

$X=$ required.

17 
1 Table 8-2. Dangerous Waste Continuing Training Requirements Matrix.

\begin{tabular}{|c|c|c|c|}
\hline \multirow[b]{2}{*}{ Employee category } & \multicolumn{3}{|c|}{ Course title } \\
\hline & $\begin{array}{l}\text { Generator hazards } \\
\text { safety training } \\
\text { ( } 4 \text { hours } / 2 \text { years) }\end{array}$ & $\begin{array}{c}\text { Facility } \\
\text { emergency and } \\
\text { hazard } \\
\text { information } \\
\text { checklist } \\
\text { training } \\
\text { (4-6 hours / } \\
1 \text { year) }\end{array}$ & $\begin{array}{c}\text { Hazarjous waste } \\
\text { shipment } \\
\text { certification } \\
\text { (24 hours/l year) }\end{array}$ \\
\hline 1. All employees & \multicolumn{3}{|c|}{ (none required) } \\
\hline 2. General worker & $x^{b}$ & $x$ & \\
\hline $\begin{array}{l}\text { 3. General } \\
\text { supervisor/ } \\
\text { manager }\end{array}$ & $x$ & $x$ & \\
\hline $\begin{array}{l}\text { 4. General } \\
\text { nonradiological } \\
\text { shipper }\end{array}$ & $x$ & $x$ & $x$ \\
\hline
\end{tabular}

16

17

Category definitions are in Figure 8-1.

Required for visitors and subcontractors as determined by the TSD unit management.

$X=$ required.

20 
Table 8-3. Treatment, Storage, and/or Disposal Unit-Specific Training Matrix. 5

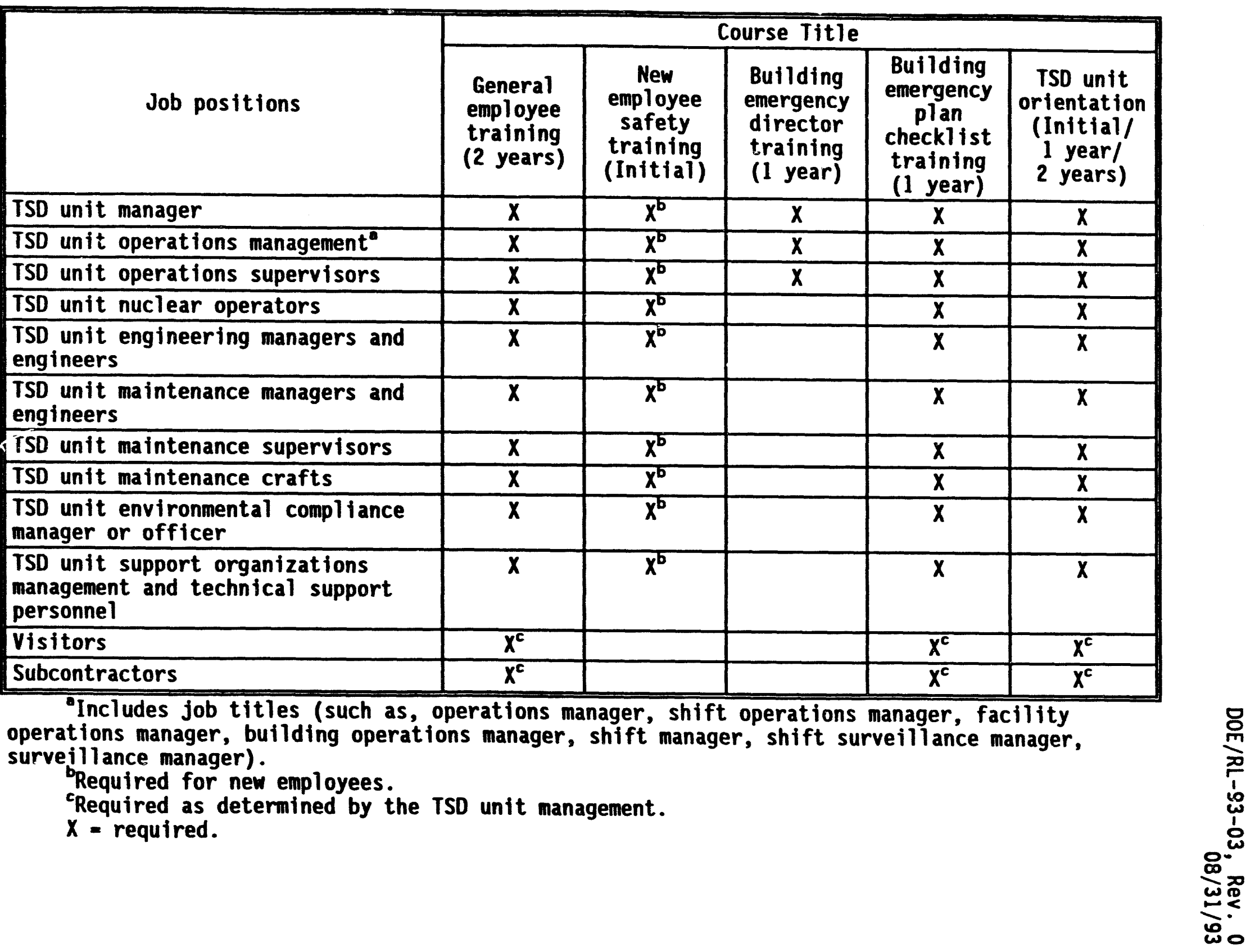


Table 8-4. Treatment, Storage, and/or Disposal Job-Specific Training Matrix.

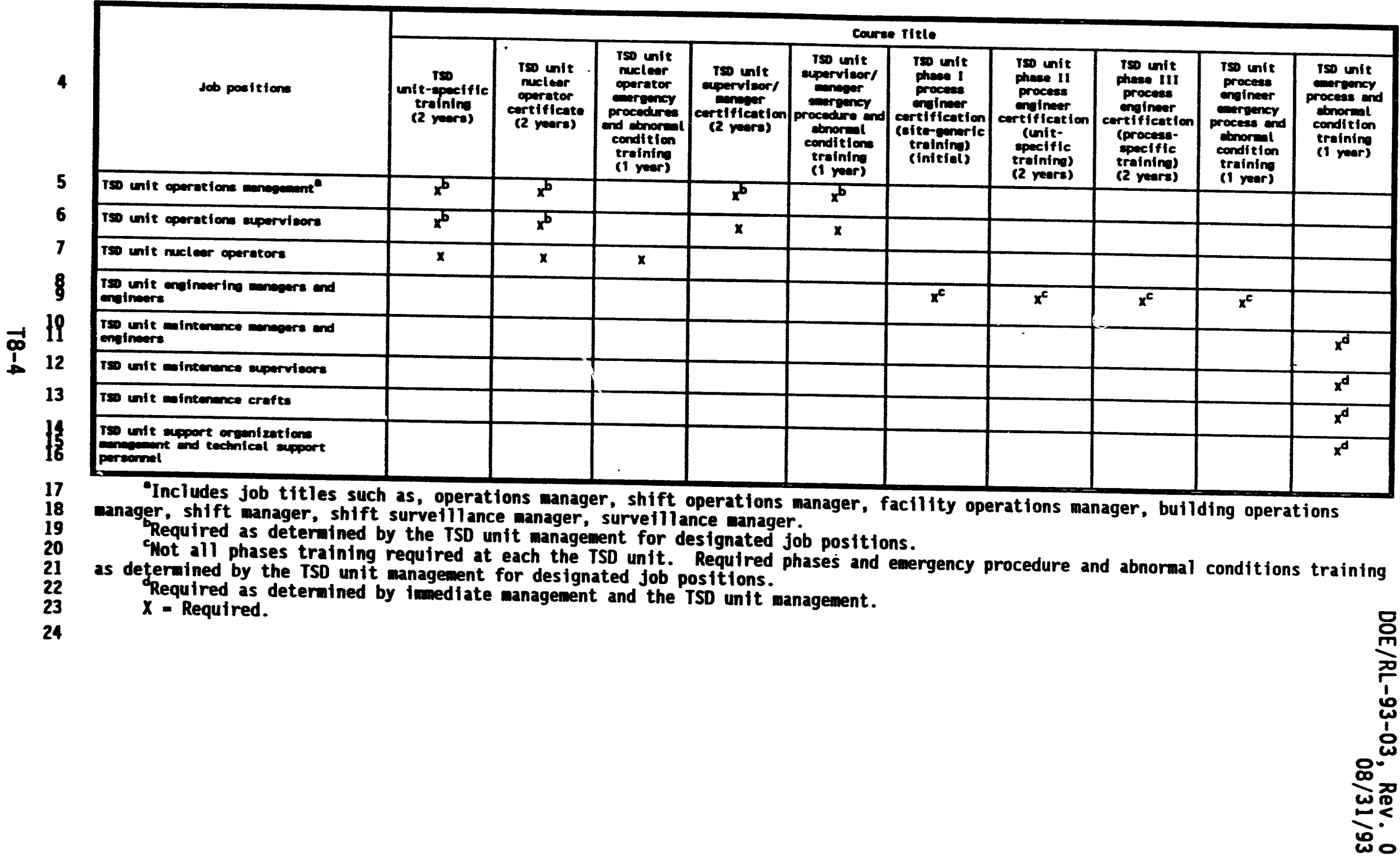


DOE/RL-93-03, Rev. 0

$08 / 31 / 93$

\section{CONTENTS}

9.0 EXPOSURE INFORMATION REPORT ................ . . . . . . 
DOE/RL-93-03, ReV. 0

$08 / 31 / 93$

This page intentionally left blank. 


\subsection{EXPOSURE INFORMATION REPORT}

The ETF does not store, treat, or dispose of hazardous waste in a surface impoundment or a landfill as defined in 40 CFR 270.10 and RCRA, Section 3019. Therefore, exposure information is not required. 
DOE/RL-93-03, Rev. 0

This page intentionally left blank. 
DOE/RL-93-03, Rev. 0

$08 / 31 / 93$

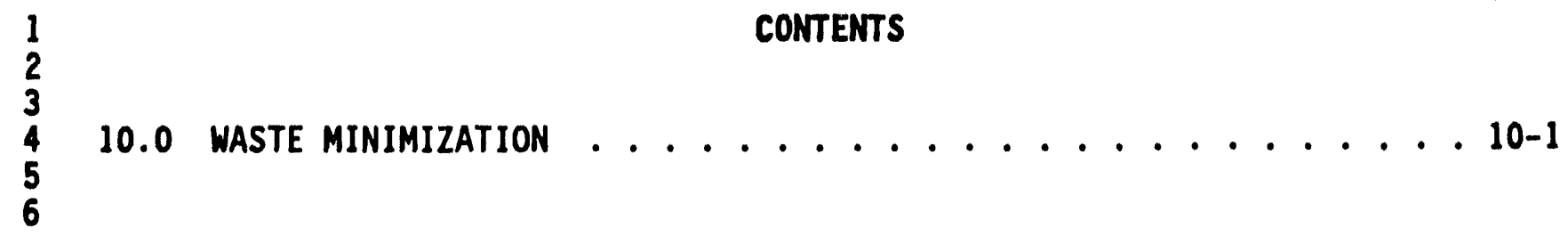


DOE/RL-93-03, Rev. 0 $08 / 31 / 93$

This page intentionally left blank.

1
2
3
4
5 


\subsection{MASTE MINIMIZATION}

Requirements relevant to waste minimization are contained in 40 CFR 264.73(a) and $264.73(\mathrm{~b})(9)$. The requirements of 40 CFR.264.73(a) state that the "owner or operator must keep a written operating record at his facllity." The requirements of $264.73(\mathrm{~b})(9)$ mandate the following:

"a certification by the permittee no less often than annually, that the permittee has a program in place to reduce the volume and toxicity of hazardous waste that he generates to the degree determined by the permittee to be economically practicable; and the proposed method of treatment, storage or disposal is that practicable method currently available to the permittee which minimizes the present and future threat to human heaith and the environment."

To fulfill the requirements of $264.73(\mathrm{~b})(9)$, a certification that the ETF has a waste minimization program in place will be entered, annually, into the ETF operating record (Chapter 12.0). 
DOE/RL-93-03, Rev. 0

$08 / 31 / 93$

This page intentionally left blank. 


\section{CONTENTS}

11.0 CLOSURE AND POSTCLOSURE REQUIREMENTS [1] . . . . . . . . 11-1

11.1 CLOSURE PLAN $[1-1] \ldots \ldots \ldots 11-1$

11.1.1 Closure Performance standard [I-1a] $\ldots \ldots$. . . 11-1

11.1.1.1 Performance Standard $[1-1 \mathrm{a}(1)] \ldots$... . 11-1

11.1.1.2 Removal or Decontamination Standard [I-1a(2)] ...............

11.1 .2 Partial closure Activities $[1-1 b] \ldots \ldots \ldots \ldots$

11.1 .3 Maximum Waste Inventory $[\mathrm{I}-\mathrm{I} \mathrm{I}] \ldots \ldots \ldots$ 11-2

11.1.4 Inventory Removal, Disposal, or Decontamination

of Equipment, Structures, and Soils [I-1d] . . . 11-3

11.1.4.1 Inventory Removal . . . . . . . . . . 11-3

11.1.4.2 Uncontaminated Equipment . . . . . 11-3

11.1.4.3 Contaminated Equipment and Structures .. 11-3

11.1.4.4 Decontamination of Equipment ...... 11-3

11.1.4.5 Soll Sampling . . . . . . . 11-3

11.1.4.6 Closure of Containers $[1-1 d(1)] \ldots$. . 11-4

11.1 .4 .7 Closure of Tanks [I-Id(2)] $\ldots . . .11-4$

11.1 .4 .8 Closure of Waste Piles [1-1d(3)] ... 11-4

11.1.4.9 Closure of Surface Impoundments

11.1.4.10 Closure of Incinerators $[1-1 d \dot{d}(5) j: \therefore .11-4$

11.1.4.11 Closure of Land Treatment Facilities

11.1 .5 Closure of Disposal Units $[\dot{i}-\dot{i}$ through $1-1 \dot{e}(\dot{8})]: 11-4$

11.1.6 Schedule for Closure [I-1f] $\ldots$.... 11-5

11.1 .7 Extension of Closure Time Frame $[1-1 g] \ldots \ldots \ldots$

11.1 .8 Amendments to Closure Plan ........... 11-5

11.1.9 Certification of Closure and Survey Plat ...... 11-5

11.1.9.1 Closure Certification ........ 11-6

11.1 .9 .2 Survey Plat . . . . . . . . . . 11-6

11.1.10 Notice to Local Land Authority .......... 11-6

11.2 POSTCLOSURE PLAN [I-2] . . . . . . . . . 11-6

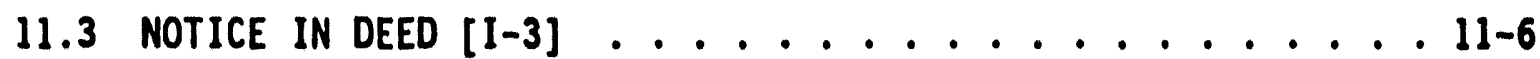

11.4 CLOSURE COST ESTIMATE $[1-4] \ldots \ldots$. . . . . . . . . . . . .

11.5 FINANCIAL ASSURANCE MECHANISM FOR CLOSURE [I-5] . . . . 11-6

11.6 POSTClOSURE COST ESTIMATE [1-6] . . . . . . . . . . 11-7

11.7 FINANCIAL ASSURANCE MECHANISM FOR POSTCLOSURE CARE [I-7] . . 11-7

11.8 LIABILITY REQUIREMENTS $[1-8] \ldots \ldots$. . . . . . . . . . . . .

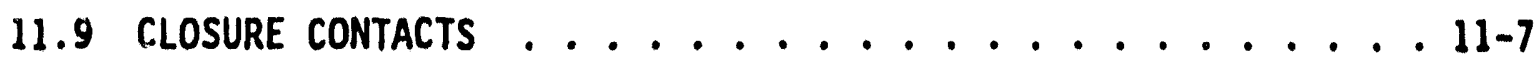


DOE/RL-93-03, ReV. 0

$08 / 31 / 93$

\section{FIGURE}

4 11-1. Typical Closure Certification Document ........... F11-1 


\subsection{CLOSURE AND POSTCLOSURE REQUIREMENTS [I]}

This chapter describes the planned activities and performance standards for closing the ETF. No postclosure activities are applicable or required for the closure because the ETF will be clean closed. Clean closure requires that all dangerous waste be removed and disposed of in accordance with applicable regulations. The ETF is in the process of final design and, therefore, this closure plan should be considered conceptual. Current regulations and 1 aws will be reviewed periodically and the closure plan modified as necessary. The intent is to clean close the ETF. However, if it is determined that clean closure is not possible or is environmentally impractical, the closure plan will be modified to address required postclosure activities.

\subsection{CLOSURE PLAN [I-1]}

As currently envisioned, closure activities will be conducted in two phases as follows.

- Phase 1 will consist of the decontamination or removal of all waste piping and equipment between the LERF and the 242-A Evaporator and the ETF. All waste piping and equipment will be transported to an appropriate disposal unit.

- Phase 2 will consist of the removal or decontamination of all contaminated equipment and structures with in the ETF. Equipment and structures will be transported to an appropriate disposal unit.

\subsubsection{Closure Performance Standard [I-1a]}

These sections describe the performance and removal or decontamination standards to be applied to the ETF.

11.1.1.1 Performance Standard [I-1a(1)]. This $p l$ an has been developed to close the ETF in a manner that meets the following closure performance standards of WAC 173-303-610(2)(a):

- Minimizes the need for future maintenance

- Controls, minimizes, or eliminates to the extent necessary to protect human health and the environment, postclosure escape of dangerous waste, dangerous waste constituents, leachate, contaminated run-off, or dangerous laste decomposition products to the ground, surface water, ground water, or the atmosphere

- Returns the land to the appearance and use of surrounding 1 and areas to the degree possible given the nature of the previous dangerous waste activities. 
In addition, all equipment structures, and other material associated with closure of the ETF also will be decontaminated or removed in accordarice with WAC $173-303-610(2)(a)$.

The ETF is designed for a 30-year operational life with projected closure anticipated for the year 2024. Current regulations and laws will be reviewed periodically and the closure plan modified as necessary. If it is determined that clean closure is not possible or is environmentally impractical, the closure plan will be modified to address required postclosure activities.

Clean closure of the ETF will eliminate the need for postclosure maintenance. To aid in the determination of any soil and groundwater contamination from ETF operations, verification soil sampling will be conducted at the end of closure operations to confirm that no soil contamination exists.

11.1.1.2 Removal or Decontamination Standard [I-1a(2)]. Clean closure of the ETF will consist of the removal and disposal of dangerous waste and the decontamination and/or removal and disposal of contaminated equipment. The ETF was designed to incorporate removable components to facilitate closure by allowing removal, if necessary, of equipment contaminated with dangerous waste. All structures determined to be contaminated will be scoured by sandblasting, steam cleaning, or other appropriate technologies required to effectively clean the surfaces. The leachate, rinsate, or residues from decontamination also will be collected as a potential dangerous waste. A sampling and analysis program will be developed to verify that no contaminant proven to be above health-based standards remains in any structures or soils around the ETF as specified in WAC 173-303-610(2).

The decontamination and/or removal and disposal of all structures and equipment are addressed in Section 11.1.4.

\subsubsection{Partial Closure Activities [I-1b]}

No partial closure activity is anticipated for the ETF.

\subsubsection{Maximum Maste Inventory [I-1c]}

Based on current design specifications, the maximum waste inventory at the ETF at any one time should be approximately 2.08 million gallons (7.87 million liters). This represents an upper-limit volume based on: (1) a summation of the total volumes for the surge tank at the beginning of the waste stream at 100,000 gallons $(380,0001$ iters); (2) the surmation of the volume of the waste in the waste stream within the ETF at 25,000 gallons (95,000 liters); (3) the summation of the three verification tanks at $1,950,000$ gallons $(7,382,000$ liters), and (4) the volume of containers in the filled container storage area at 60,000 gallons $(227,000$ liters). This includes the volumes in tanks containing process chemicals, which could potentially become dangerous waste if not completely used in the process before closure of the ETF. 
DOE/RL-93-03, Rev. 0

$08 / 31 / 93$

1
11.1.4 Inventory Removal, Disposal, or Decontamination of Equipment, Structures, and Soils [I-1d]

Closure of the ETF will consist of removal of all waste and decontamination and disposal of all structures and equipment. The ETF will be closed in a manner that protects human health and the environment, and that minimizes or eliminates the escape of waste constituents to the ground, to surface waters, or to the atmosphere.

The ETF closure plan will provide for the following:

- Uncontaminated equipment disposition

- Contaminated equipment disposition

- Transport pipe disposition between the LERF basins and the ETF

- Soil sampling and decontamination activities.

The following paragraphs discuss removal of the waste from the ETF and decontamination or disposal of contaminated equipment and structures.

11.1.4.1 Inventory Removal. All of the waste inventory at the ETF will be processed before closure. Any residue remaining in piping and equipment will be removed in accordance with Section 11.1.4.4.

11.1.4.2 Uncontaminated Equipment. The ETF will contain some uncontaminated structures including components such as the offices and conference rooms, empty container storage area, and the mechanical room. Uncontaminated structures will be left either for future use or disassembled, dismantied, and removed for disposal.

11.1.4.3 Contaminated Equipment and Structures. The contaminated components of the ETF will contain structures such as the surge tank, processing equipment, decontamination shop, laboratories, hot maintenance shop, and verification tanks. If contaminated with either dangerous or mixed waste constituents, equipment and structures will be decontaminated and/or disassembled, if necessary, packaged, and disposed of in accordance with existing land-disposal restrictions (WAC 173-303-140).

11.1.4.4 Decontamination of Equipment. Initial final closure activities will entail decontamination of all piping and equipment that have contacted dangerous and mixed waste. Decontamination methods will be those methods suitable for removing both dangerous and mixed waste contaminants. The piping, pumps, containment structures, etc., first will be flushed with water. Other decontamination methods, such as applying paint removers, sandblasting, and aquablasting, could be used, depending on the success of the water flush. The flush water will be collected, sampled, and analyzed to determine the effectiveness of the decontamination and disposed of appropriately. Procedures for cleaning and decontaminating equipment contained in the Guide for Decontaminating Buildings, Structures, and Equipment of Superfund Sites (EPA 1985), or other similar procedures, will be used as guidance.

11.1.4.5 Soil sampling. The only possibie sources of soil contamination will be from an accidental spill or a leak from a pipeline, from containment 
structures, and from the loading dock area for the filled container storage area. Aboveground pipelines and tanks will be inspected daily and leaks or spills will be detected with monitoring instruments. Operational practices will require cleanup as soon as possible, given the nature of the spill or leak.

A soil sampling program designed to detect the presence of contaminants will be conducted at the end of cleanup operations. The soil sampling program might use a hollow stem auger to drill to the sample depth followed by a spiti-spoon sampler dropped through the hollow tube to collect samples. If contamination is detected, the sampling effort will be extended to determine the extent of contamination, and the contaminated soils will be removed and disposed of appropriately. As a minimum, soil samples will be collected in areas with documented or potential soil contamination, such as near underground pipelines, storage tanks, or contaminated b' 'Idings.

11.1.4.6 Closure of Containers [I-1d(1)]. Containers will be used to contain dangerous waste in the event of a spil1, unexpected release, or equipment failure. Containers will be used to accumulate nonradioactive dangerous waste and/or mixed waste. Any containers used to contain dangerous and/or mixed waste at the ETF will be disposed of in the appropriate manner. Containers of dangerous and/or mixed waste will not be left in the ETF after closure.

11.1.4.7 Closure of Tanks [I-1d(2)]. Clean closure will consist of the removal and disposal of all dangerous waste and the decontamination and/or removal and disposal of contaminated equipment, including tanks. The ETF will be designed to incorporate removable components. This design will facilitate closure by allowing complete removal of equipment contaminated with dangerous and mixed waste.

\subsubsection{Closure of Waste Piles [I-1d(3)]. Operation of the ETF does not} involve the storage of dangerous waste in piles. Therefore, the requirements of WAC 173-303-660 are not applicable to the ETF.

11.1.4.9 Closure of Surface Impoundments [I-1d(4)]. Operation of the ETF does not involve the placement of dangerous waste in surface impoundments. Therefore, the requirements of WAC 173-303-650 are not applicable.

11.1.4.10 Closure of Incinerators [I-1d(5)]. Operation of the ETF does not involve the incineration of dangerous waste. Therefore, the requirements of WAC 173-303-670 are not applicable to the ETF.

11.1.4.11 Closure of Land Treatment Facilities [I-1d(6)]. Operation of the ETF does not involve the 1 and treatment of waste. Therefore, the requirements of WAC 173-303-655 are not applicable to the ETF. 
DOE/RL-93-03, Rev. 0

$08 / 31 / 93$

8

\subsubsection{Closure of Disposal Units [I-le through I-1e(8)]}

The ETF does not contain any waste piles, landfills, or surface impoundments. In addition, the waste or contaminated materials will not remain at the ETF closure site. Therefore, this section is not applicable to the ETF.

\subsubsection{Schedule for Closure [I-1f]}

Operation is scheduled to begin in 1994 with the ETF designed for a 30-year operational life. Based on these assumptions, the expected year of closure is approximately 2024. The actual year of closure will be controlled by the time required for all waste being processed and could vary based on future use of the unit, unforseen factors, and operational requirements.

The projected closure schedule for the ETF will be examined periodically and will be provided in a future permit modification.

\subsubsection{Extension of Closure Time Frame [I-1g]}

Until a detailed closure schedule is developed for the ETF, it will not be possible to determine whether more than 180 days will be required for closure. Unforseen factors and operational requirements could impact the closure schedule and could necessitate an extension beyond the 180-day period. If final closure of the ETF cannot be completed within the 180-day period allowed by regulations, a request for extension will be made.

\subsubsection{Amendments to Closure Plan}

Should changes be required to the approved closure $p l a n$, an amended $p l a n$ will be prepared and submitted to Ecology for approval in accordance with 40 CFR 264.112(c) and WAC 173-303-610(3)(a).

\subsubsection{Certification of Closure and Survey Plat}

Within 60 days of final closure of the ETF, the DOE-RL will submit a certification of closure to the proper regulatory agency(s) in accordance with 40 CFR 264.115 and WAC $173-303-610(6)$. This certification will be signed by both the DOE-RL and by an independent professional engineer, and will state that the ETF has been closed in accordance with the approved closure plan. The certification will be submitted by registered mail or an equivalent delivery service. Documentation supporting the closure certification will be retained and will be furnished to Ecology upon request to the proper regulatory agency $(s)$. This documentation will be maintained by the DOE-RL contact (or the successor) identified in Section 11.9. 
11.1.9.1 Closure Certification. The DOE-RL and the independent registered engineer will certify that closure is complete with a document similar to Figure 11-1.

11.1.9.2 Survey Plat. The ETF is planned to be clean closed. Because dangerous waste will not be left in place foliowing the operational period, the requirement for producing a survey plat is not applicable to the ETF.

\subsubsection{Notice to Local Land Authority}

The ETF is planned to be clean closed. Because dangerous waste will not be left in place following the operationai period, the requirement for a notification to the local land authority is not applicable to the ETF.

\subsection{POSTCLOSURE PLAN [I-2]}

The ETF is planned to be clean closed. Because dangerous waste will not be left in place following the operational period, the requirement for postclosure activities is not applicable to the ETF.

\subsection{NOTICE IN DEED [I-3]}

The ETF is planned to be clean closed. Because dangerous waste will not be left in place following the operational period, the requirement for a notice in deed is not applicable to the ETF.

\subsection{CLOSURE COST ESTIMATE [I-4]}

Federal facilities are not required to comply with WAC 173-303-620 as is stated in the regulations. However, the DOE-RL has agreed to provide projections of anticipated costs for closure of final status TSD units (i.e., those units that have been incorporated into the Hanford Facility Permit) annually in is separate report (Chapter 12.0). Submittal of this report will take place on October 30 of each year, starting with the year after the issuance of the initial Hanford Facility Permit.

\subsection{FINANCIAL ASSURANCE MECHANISM FOR CLOSURE [1-5]}

In accordance with 40 CFR 264.140(c) and WAC 173-303-620(1)(c), this section is not required for federal facilities. The Hanford Facility is a federally owned facility for which the federal government is the operator, and this section therefore, is not applicable to the ETF. 


\subsection{POSTCLOSURE COST ESTIMATE [I-6]}

Federal facilities are not required to comply with WAC 173-303-620 as is stated in the regulations. However, the DOE-RL has agreed to provide projections of anticipated costs for postclosure for final status TSD units (i.e., those units which have been incorporated into the Hanford Facility Permit) annually in a separate report (Chapter 12.0). Submittal of this report will take place on October 30 of each year, starting with the year after the issuance of the initial Hanford Facility Permit.

\subsection{FINANCIAL ASSURANCE MECHANISM FOR POSTCLOSURE CARE [I-7]}

In accordance with 40 CFR 264.140(c) and WAC 173-303-620(1)(c), this section is not required for federal facilities. The Hanford Facility is a federally owned facility for which the federal government is the operator, and this section is, therefore, not applicable to the ETF.

\subsection{LIAR ?LITY REQUIREMENTS [ I-8]}

In ascordance with 40 CFR 264.140(c) and WAC 173-303-620(1)(c), this section is not required for federal facilities. The Hanford Facility is a federally owned facility for which the federal government is the operator, and this section therefore, is not applicable to the ETF.

\subsection{CLOSURE CONTACTS} ETF.

The following office (or its successor) is the official contact for the

Office of Environmental Assurance, Permits, and Policy

U.S. Department of Energy, Richland Operations Office P.0. Box 550

Richland, Washington 99352 (509) 376-5441 
D0E/RL-93-03, Rev. 0 $08 / 31 / 93$

This page intentionally left blank. 


\section{CLOSURE CERTIFICATION}

FOR

\section{Hanford Facility \\ U.S. Department of Energy, Richland Operations Office}

We, the undersigned, hereby certify that all closure activities were performed in accordance with the specifications in the approved closure plan.

Owner/Operator Signature DOE-RL Representative (Typed Name)

\section{P.E.*} State Signature Independent Registered Professional Engineer of signature)

Figure 11-1. Typical Closure Certification Document. 
CONTENTS

12.0 REPORTING AND RECORDKEEPING . . . . . . . . . . . 12-1

12.1 NOTIFICATION OF DANGEROUS WASTE ACTIVITIES . . . . . 12-1

12.2 TREATMENT, STORAGE, AND/OR DISPOSAL REQUIREMENTS ..... 12-1 12.2.1 Reports . . . . . . . . . . . . . . . . 12-1

12.2.1.1 Waste Manifest Reports ......... 12-1

12.2.1.2 Annual Dangerous Waste Reports ..... 12-2

12.2.1.3 Biennial Hazardous Waste Reports . . . 12-2

12.2.1.4 Groundwater Monitoring Reports ..... 12-2

12.2.1.5 Contingency Plan Incident Notifications . 12-2

12.2.1.6 Closure Reports .......... . 12-4

12.2.1.7 Postclosure Reports ........ 12-4

12.2.2 Recordkesping Requirements .......... 12-4

12.2.2.1 Permit Application Plans ..... . 12-4

12.2.2.2 Operating Records ........ 12-4

12.2.2.3 Miscellaneous Support Records . . . 12-6

12.3 IMMEDIATE REPORTING . . . . . . . . . . . . 12-7

TABLE

27

28

29 12-1. Treatment, Storage, and/or Disposal Reports and Records . . . T12-1

30 
DOE/RL-93-03, Rev. 0

$08 / 31 / 93$

1
2
3
4
5

This page intentionally left blank. 
DOE/RL-93-03, Rev. 0

$08 / 31 / 93$

\subsection{REPORTING AND RECORDKEEPING}

This chapter summarizes the ETF reporting and recordkeeping requirements. Required reports and records can be located through the RCRA Compliance Support organization by calling (509) 372-2804. Reports and records applicable to the Hanford Facility are summarized in Table 12-1.

\subsection{NOTIFICATION OF DANGEROUS WASTE ACTIVITIES}

Regulations require that facilities involved in the generation or transportation of dangerous waste or the owner or operator of a TSD facility have a current EPA/State identification number. The Hanford Facility is a single RCRA facility operating under EPA/State Identification Number WA7890008967. The ETF operates under this same EPA/State identification number.

\subsection{TREATMENT, STORAGE, AND/OR DISPOSAL REQUIREMENTS}

The TSD reports, the operating record and miscellaneous support records contents, and plans submitted with this permit application and maintained at the Hanford Facility are described in this section. The records and reports described in this section are available by contacting RCRA Compliance Support.

\subsubsection{Reports}

This section discusses the reporting requirements of WAC 173-303 and several parts of Title 40 , Code of Federal Regulations relating to aspects of dangerous waste. The following are included in the reporting requirements:

- Waste manifest reports

- Annual dangerous waste reports

- Biennial dangerous waste reports

- Groundwater monitoring notifications

- Contingency plan incident reports

- Closure reports

- Postclosure reports.

Additional details of these reports are provided in the following sections. Copies of these reports are accessible by contacting RCRA Compliance Support.

12.2.1.1 Waste Manifest Reports. The Hanford Facility has methods in place for tracking offsite waste shipments using waste manifest. The waste manifest is the source of two possible reports, the manifest discrepancy report filed in accordance with WAC 173-303-370(4), and the unmanifested waste report filed in accordance with WAC 173-303-390(1). Methods of dealing with manifesting 
DOE/RL-93-03, Rev. 0

$08 / 31 / 93$

discrepancies are described in Chapter 2.0, Section 2.8. Records documenting both onsite and offsite waste shipments are retained and are accessible by contacting RCRA Compliance Support.

12.2.1.2 Annual Dangerous Waste Reports. The state of Washington, pursuant to WAC 173-303-390, requires an annual overall report for each facility that holds an active EPA/State identification number. The report is due to Ecology by March 1 of each year. The report contents for the ETF will include the following:

- The EPA/State identification number

- Name and address of the Hanford Facility

- Calendar year covered by the report

- Sources of the waste treated and disposed of at the ETF

- Description and quantity of the waste received at the ETF

- TSD methods

- Certification statement signed by an authorized representative.

The report form and instructions in the "Waste Management Facility Annual Dangerous Waste Report-Form 5" are used for this report.

12.2.1.3 Biennial Hazardous Waste Reports. The EPA requires, pursuant to 40 CFR 264.75, that an overall report describing each dangerous waste facility activity be submitted on March 1 of each even-numbered year. Ecology has been extended administrative responsibilities for biennial reporting as required by 40 CFR 264.75. A specific biennial report is not prepared and submitted, because reporting requirements are satisfied by submittal of the annual report to Ecology.

12.2.1.4 Groundwater Monitoring Reports. The ETF is not operated as a dangerous waste surface impoundment, waste pile, land treatment unit, or a 1 andfill as defined by WAC 173-303-645(1)(a). Therefore, no groundwater monitoring or reporting is required for the ETF.

12.2.1.5 Contingency Plan Incident Notifications. The building emergency director or coordinator, ETF line management, and the contractor's environmental protection organization are responsible for making the appropriate notifications (Chapter 7.0). Notifications of all emergency situations requiring contingency plan implementation will be made as required by 40 CFR 264.56 and WAC 173-303-360.

If the ETF stops operations in response to a fire, an explosion, or a release that could present a hazard to human health and the environment, the building emergency director or coordinator notifies the DOE-RL, via TSD unit line management, that the unit is operational and the emergency cleanup is complete.

The DOE-RL is responsible for three types of notifications: the incident assessment report, a 15-day report, and the TSD unit restart notification. Details of these notifications are provided in the following sections. 
12.2.1.5.1 Incident Assessment Report. The Occurrence Notification Center (509-376-2900) immediately will notify affected county emergency management, Ecology, and the individual designated as the on-scene coordinator for the southeastern Washington area of the National Response Center (800-424-8802) if a fire, an explosion, or a release at the ETF could threaten human health and the environment.

The report will contain the following information:

- Name and telephone number of reporter

- Name and address of the TSD unit

- Time and type of incident

- Name and quantity of material(s) involved to the extent known

- Extent of injuries if any

- Possibie hazards to human health and the environment outside the Hanford Facility.

12.2.1.5.2 15-Day Report. The DOE-RL will provide a written report to Ecology within 15 days of any incident that requires implementation of the contingency plan. The report will include the following:

- Name, address, and telephone number of the owner or operator

- Name, address, and telephone number of the TSD unit

- Date, time, and type of incident

- Name and quantity of material(s) involved

- Extent of injuries if any

- Assessment of actual or potential hazards to human health or the environment where this is applicable

- Estimated quantity and disposition of recovered material that resulted from the incident

- Cause of incident

- Description of corrective action taken to prevent recurrence of the incident.

12.2.1.5.3 Treatment, Storage, and/or Disposal Unit Restart Notification. If the ETF stops operations in response to a fire, an explosion, or a release that could present a hazard to human health and the environment, the DOE-RL will notify Ecology and the appropriate local 
authorities before operations are resumed in the affected area(s). The notification will indicate that cleanup procedures are complete and that emergency equipment is clean and fit for its intended use.

12.2.1.6 Closure Reports. Reports regarding the closure of the ETF will be made in accordance with the requirements of 40 CFR 264.115 and .116, and WAC 173-303-610(6) and (9). These reports include notification of beginning of closure and certification of closure.

12.2.1.6.1 Notification of Closure. Ecology will be notified in writing at least 45 days before the date on which closure of the ETF is expected to begin.

12.2.1.6.2 Certification of closure. Within 60 days of completion of closure, a certification signed by the DOE-RL and an independent registered professional engineer will be submitted to the regulatory authority. The certification will be sent by registered mail or an equivalent delivery service. The certification will state that the ETF was closed in accordance with the approved closure plan. Documentation supporting the independent registered engineer's certification will be supplied upon request from the regulatory authority.

12.2.1.6.3 Survey Plat. The ETF is not a disposa? unit. This determination eliminates the requirement for producing a survey plat.

12.2.1.7 Postclosure Reports. Postclosure reports required by 40 CFR 264.119 and .120, and WAC 173-303-610(9), (10), and (11) will not be required because the ETF is not a disposal unit.

\subsubsection{Recordkeeping Requirements}

Records retained by the ETF include:

- Permit application plans

- Operating records

- Miscellaneous support records.

These records are described in. the following sections. These records can be located by contacting RCRA Compliance Support.

12.2.2.1 Permit Application Plans. A current copy of the plans contained in this permit application that are incorporated into the Hanford Facility Permit will be maintained in the operating record.

12.2.2.2 Operating Records. Operating records maintained at the ETF can be located by contacting RCRA Compliance Support. These records include the following:

- Description and the quantity of each dangerous waste received and the method(s) and date(s) of treatment at the ETF in accordance with 40 CFR 264 Appendix I and WAC 173-303-380 
- Location of each dangerous waste stored within the ETF and the quantity at each location

- Waste analyses results

- Inspection records

- Waste minimization certification

- Land disposal restriction records

- Groundwater monitoring records

- Contingency plan incident reports.

12.2.2.2.1 Waste Description and Quantity. A description and the quantity of each dangerous waste handled by the ETF unit are maintained. Waste manifests and onsite waste tracking records, describing the types and quantities of waste, are maintained as part of the operating record.

12.2.2.2.2 Waste Location. The locatior of each dangerous or mixed waste and the quantity stored within the ETF are documented and maintained. Transfers are documented on onsite waste tracking records and provided to other Hanford Facility TSD units receiving the waste. Copies of these onsite waste tracking records are maintained and can be lcisated by contacting RCRA Compliance Support.

12.2.2.2.3 Waste Analysis. Waste analysis and designation records for the ETF are generated and maintained, as appropriate, for the following:

- Waste resulting from a spill or leak that cannot be identified

- Waste generated at the ETF during decontamination or maintenance activities if required.

As required, results of these analyses are provided to other TSD units subsequently receiving the waste for further treatment, storage, and/or disposal.

12.2.2.2.4 Inspection Records. Records of ETF inspections are inaintained for a period of at least 5 years from the inspection date. These records can be located by contacting RCRA Compliance Support. The records include the following:

- The date and time of inspection

- The inspector's printed name and handwritten signature

- Notations of observations

- The date and nature of any repairs or other remedial actions. 
12.2.2.2.5 Waste Minimization Certification. Annually a certification by the DOE-RL that the Hanford Facility is in compliance with waste minimization requirements is entered into the operating record as required by 40 CFR 264.73(b)(9).

12.2.2.2.6 Land Disposal Restrictions Records. Records related to treatment and disposal of waste subject to land disposal prohibitions are maintained by the Hanford Facility as required by 40 CFR 264.73(b)(10) and (12). Possible records include:

- Waste placed in land disposal units under an extension to the effective date of any land disposal restriction granted pursuant to 40 CFR 268.5

- Waste placed in land disposal units under a petition granted pursuant to 40 CFR 268.6

- The applicable notice and certification required by 40 CFR 268.7 (a) or 40 CFR 268.7(b)

- The demonstration and certification required by 40 CFR 268.8 , if applicable, for waste subject to land usposal prohibitions or restriction.

An onsite waste tracking system is in place to document the transfer of waste subject to 1 and disposal restrictions. Land disposal restriction documentation can be located by contacting RCRA Compliance Support.

12.2.2.2.7 Groundwater Monitoring Records. Groundwater monitoring records are not applicable as the ETF is not operated as a surface impoundment, waste pile, land treatment unit, or a landfill as defined in WAC $173-303-645(1)(a)$.

12.2.2.2.8 Contingency Plan Incident Records. Records documenting the details of any incidents requiring the implementation of the contingency plan (Chapter 7.0) are maintained in the ETF operating record as required by 40 CFR 264.73 and WAC 173-303-380. The contingericy plan incident records can be located by contacting RCRA Compliance Support. In addition to these records, occurrence reports are generated to document incidents. The occurrence report describes all incidents, including those that are judged too minor to require the implementation of the contingency plan but are identified as offnormal events, unusual occurrences, or emergencies. These records can be located by contacting RCRA Compliance Support.

12.2.2.3 Miscellaneous Support Records. Miscellaneous support records include the following:

- Training records

- Closure cost estimates

- Certification records. 
42

43

44

45

In addition, a rationale for the inapplicability of liability coverage documentation is provided.

12.2.2.3.1 Training Records. The name of each employee and the waste management position held are maintained by the ETF. Training records document that employees have received the training required for that position. Training records on current employees are kept until closure of the unit. Training records on former employees are kept for 3 years from the date the employee last worked at the ETF. Training records are maintained by the contractors' organizations in accordance with the requirements of the Privacy Act. Presently, the training records of individual employees are available for inspection purposes through the Freedom of Information Act. The DOE-RL is seeking authorization through the U.S. Department of Energy-Headquarters to amend the systems notice under the Privacy Act to allow regulatory agencies 'routine use' access to training records under this act.

12.2.2.3.2 Closure and Postclosure Cost Estimates. In accordance with 40 CFR 264.140(c) and WAC 173-303, these estimates are not required for federal facilities. The Hanford Facility is a federally owned facility for which the federal government is an operator and these estimates are not applicable.

An annual report updating projections of anticipated closure and postclosure costs for final status TSD units (i.e., those units which have been incorporated into the Hanford Facility Permit) will be submitted to Ecology on October 30 of each year, starting with the year after the issuance of the Hanford Facility Permit.

12.2.2.3.3 Certification Records. Reports, data, and information requested or required in direct support of the Hanford Facility Permit will be certified as required in accordance with WAC 173-303-810(12) and (13) or 40 CFR Part 2 and 40 CFR 270.11 for Hazardous and Solid Waste Amendment provisions. Records of certification will be maintained as part of the operating record.

12.2.2.3.4 Liability Coverage Documentation. In accordance with 40 CFR 264.140 (c) and WAC 173-303, this documentation is not required for federal facilities. The Hanford Facility is a federally owned facility for which the federal government is an operator and this documentation is therefore not applicable.

\subsection{IMMEDIRTE REPORTIMG}

The DOE-RL verbally will report to Ecology and the EPA any noncompliance with the Hanford Facility Permit that might endanger human health and the environment. Any such information will be reported to Ecology and EPA within 24 hours after the DOE-RL becomes aware of the circumstances of the noncompliance. The immediate verbal report will contain all the information needed to determine the nature and extent of any potential threat to human health and the environment. 
DOE/RL-93-03, Rev. 0 $08 / 31 / 93$

This page intentionally left blank. 
Table 12-1. Treatment, Storage, and/or Disposal Reports and Records. (sheet 1 of 2)

\begin{tabular}{|c|c|}
\hline Records and/or Reports & Regulation \\
\hline \multicolumn{2}{|l|}{ Notification: } \\
\hline $\begin{array}{l}\text { Notification of dangerous waste } \\
\text { activities }\end{array}$ & WAC 173-303-290 \\
\hline \multicolumn{2}{|l|}{ Permit Application Plans: } \\
\hline Waste analysis plan & WAC 173-303-300 \\
\hline Contingency plan and amendments & WAC $173-303-350$ \\
\hline Training plan & WAC 173-303-330 \\
\hline Closure plan & WAC 173-303-610 \\
\hline Inspection plans & WAC $173-303-320$ \\
\hline \multicolumn{2}{|l|}{ Operating Reports and Records: } \\
\hline Waste description and quantity & $\begin{array}{l}\text { WAC 173-303-380 } \\
40 \text { CFR 264, Appendix I }\end{array}$ \\
\hline Waste location & WAC $173-303-380$ \\
\hline Waste analysis & WAC 173-303-300, -380 \\
\hline Inspection records & WAC 173-303-320, -380 \\
\hline Waste minimization certification & 40 CFR 264.73(b)(9) \\
\hline Land Disposal Restriction Records: & $\begin{array}{l}\text { WAC } 173-303-140 \\
40 \text { CFR } 264.74(\mathrm{~b})(10),(11)\end{array}$ \\
\hline Extension to an effective date & 40 CFR 268.5 \\
\hline Petition for a variance & 40 CFR 268.6 \\
\hline $\begin{array}{l}\text { Notice and certification of treatment } \\
\text { standards }\end{array}$ & 40 CFR 268.7 (a) or $268.7(b)$ \\
\hline $\begin{array}{l}\text { Demonstration and certification for a } \\
\text { temporary extension to the effective } \\
\text { date }\end{array}$ & 40 CFR 268.8 \\
\hline Waste Manifest Reports and Records: & WAC 173-303-370 \\
\hline Onsite waste tracking records & NR \\
\hline Manifests & WAC $173-303-370$ \\
\hline Manifest discrepancy & WAC $173-303-220,-370$ \\
\hline Unmanifested waste & WAC 173-303-390 \\
\hline $\begin{array}{l}\text { Contingency Plan Incident Reports and } \\
\text { Records: }\end{array}$ & $\begin{array}{l}\text { WAC 173-303-360, }-380 \\
40 \text { CFR 264.56, } 274.73\end{array}$ \\
\hline Incident assessment report & WAC 173-303-360 \\
\hline 15-day report & WAC 173-303-360 \\
\hline TSD unit restart notification & WAC 173-303-360 \\
\hline
\end{tabular}


Table 12-1. Treatment, Storage, and/or Disposal Reports and Records. (sheet 2 of 2)

\begin{tabular}{|c|c|}
\hline Records and/or Reports & Regulation \\
\hline Closure Reports and Records: & $\begin{array}{l}\text { WAC } 173-303-610 \\
40 \text { CFR 264.115, .116 }\end{array}$ \\
\hline Certification of closure & WAC 173-303-610 \\
\hline Survey plat & WAC 173-303-610 \\
\hline Notice to local land authorities & WAC 173-303-610 \\
\hline Hiscellaneous Support Reports and Records: & \\
\hline Annual dangerous waste report & WAC $173-303-060,-070,-390$ \\
\hline Training documentation & WAC $173-303-330$ \\
\hline
\end{tabular}


2

3

\section{CONTENTS}

13.0 OTHER RELEVANT LAWS $[\mathrm{J}] \ldots$. . . . . . . . . . . . . . . . . . . 13.1 ATOMIC ENERGY ACT OF $1954 \ldots$. . . . . . . . . . . . . . . . 13.2 CLEAN AIR ACT OF $1977 \ldots \ldots$. . . . . . . . . . . . . . . 13.3 CLEAN WATER ACT OF $1977 \ldots \ldots$................... 13.4 WASHINGTON STATE WATER POLLUTION CONTROL ACT . . . . . 13-2 13.5 SAFE DRINKING WATER ACT OF $1974 \ldots \ldots$. . . . . . . . . . . 13.6 ENDANGERED SPECIES ACT OF $1973 \ldots \ldots$. . . . . . . . . . 13.7 FISH AND WILDLIFE COORDINATION ACT OF $1934 \ldots$. . . . . 13-3 13.8 NATIONAL HISTORIC PRESERVATION ACT OF $1966 \ldots \ldots$. . . . . 13-3 13.9 WILD AND SCENIC RIVERS ACT OF $1968 \ldots \ldots$. . . . . . . . 13-3

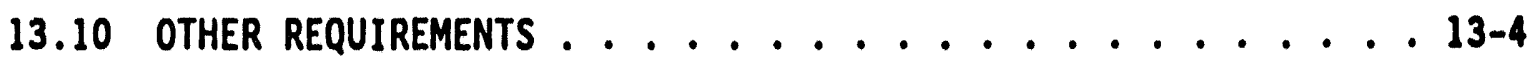


DOE/RL-93-03, Rev. 0

$08 / 31 / 93$

1
2
3
4
5

This page intentionally left blank. 


\subsection{OTHER RELEVANT LANS [J]}

This chapter provides a summary of the regulatory review performed to assist Ecology in determining that the ETF will meet its obligations with resper:t to other federal or state laws. The major environmental laws evaluated include the following, all as amended:

- Atomic Energy Act of 1954

- Clean Air Act of 1977

- Clean Water Act of 1977

- Washington State Water Pollution Control Act (RCW90-48)

- Safe Drinking Water Act of 1974

- Endangered Species. Act of 1973

- Fish and Wildi ife Coordination Act of 1934

- National Historic Preservation Act of 1966

- Wild and Scenic Rivers Act of 1968.

Full reference citations for each of these acts are included in Chapter 15.0.

\subsection{ATONIC ENERGY ACT OF 1954}

The Atomic Energy Act provides that the U.S. Atomic Energy Ccmmission (succeeded by the U.S. Department of Energy for conducting nuclear defense and research and development activities at the Hanford Site) is authorized to develop and implement regulations to govern activities related to the dcsign, location, and operation of U.S. Department of Energy sites, to protect health, and to minimize danger to life or property. The radioactive component of mixed waste is interpreted by the U.S. Department of Energy to be regulated under the Atomic Energy Act; the nonradioactive dangerous component of mixed waste is interpreted to be regulated under the RCRA and WAC 173-303.

The U.S. Department of Energy has issued several orders to govern the activities of its sites and to manage the health protection aspects of mixed waste. These orders provide for a consistent approach to managing waste that results from U.S. Department of Energy activities. The orders set radiation exposure limits and concentration guidelines to minimize exposure to radiation and detall the standards and procedures for managing mixed waste. The ETF operations are carried out in accordance with these orders.

\subsection{CLEAN AIR ACT OF 1977}

The Clean Air Act establishes national ambient air quality standards and sets standards for abating air polilution and preventing further deterioration of air quality. Air standards are implemented and enforced primarily by state 
and local authorities. The ETF will comply with the applicable federal, state, and local requirements to control and abate air pollution, including the following:

- National Emission Standards for Hazardous Air Pollutants (40 CFR 61) and National Emission Standards for Radionuclide Emissions from U.S. Department of Energy Facilities (40 CFR 61, Subpart H); an approval to construct application was submitted to the EPA.

- Air pollution control regulations (WAC 173-400 through 495) issued under the authority of the Washington Clean Air Act of 1967; a Notice for Approval to Construct a New Source for Toxic Air Pollutants was received by Ecology February 12, 1993.

- Radiation Protection-Air Emissions (WAC 246-247), which promulgates the policies set forth in Chapter 70.98 of the Revised Code of Washington, Nuclear Energy and Radiation, issued under the authority of the Washington Clean Air Act; a Radiation Protection-Air Emissions notice of construction was approved by the Washington Department of Health.

- Benton-Franklin-Walla Walla Counties Air Pollution Control Authority general regulation $80-7$ (1980).

\subsection{CLEAN MATER ACT OF 1977}

Operation of the ETF does not result in the discharge of effluent to a surface water requiring a National Pollutant Discharge El imination System permit; therefore, no permits or reviews pursuant to the Clean Water Act are applicable.

\subsection{WASHINGTON STATE MATER POLLUTION CONTROL ACT}

The preferred method to discharge treated effluent from ETF is to a virgin soll column near the 200 West Area. A permit application for a State Waste Discharge Permit, authorized by the Washington State Water Pollution Control Act, 90.48 RCW and WAC 173-216, will be submitted according to the Consent Order No. DE $91 \mathrm{NM}-177$ between the DOE-RL and Ecology.

\subsection{SAFE DRINKING MATER ACT OF 1974}

The ETF does not treat water for drinking from the tap, nor does the ETF discharge water near any surface or subsurface areas that surround drinking water wells. 


\subsection{ENDANGERED SPECIES ACT OF 1973}

The ETF is located in the 200 East Area of the Hanford Facility; Chapter 2.0 provides site location information. The 200 East Area has been developed extensively during past construction activities and during nuclear fuel and chemical reprocessing activities. The site for the ETF cannot be considered an undisturbed area or a major habitat for native plant and animal species. Also, this area is a very small fraction of the Hanford Facility and, hence, would not play a significant role in the ecology of the Hanford Facility. No listed or proposed endangered or threatened species or their habitats are expected to be affected by ETF activities or those activities associated with sites used as material 'borrow areas' for future construction of surface covers.

\subsection{FISH AND WILDLIFE COORDINATION ACT OF 1934}

Activities associated with the ETF do not involve the impoundment, diversion, or other control or modification of any body of water. Therefore, no permits or reviews pursuant to this statute are applicable.

\subsection{NATIONAL HISTOR C PRESERVATION ACT OF 1966}

The construction and pipe route areas were reviewed for cultural resources by the Hanford Cultural Resources Laboratory. The Hanford Cultural Resources Laboratory has declared the building and tank site clear of cultural properties, but has identified two areas of concern with the proposed pipe route to the 200 West Area point of discharge. One concern is the historic White Bluffs Road, which is eligible for the National Register of Historic Places, and the other is an anomalous rock cairn designated HT-39-030. The Hanford Cultural Resources Laboratory cleared the ETF for construction providing specific measures were followed during construction to mitigate or avoid damage to both of these areas.

The ETF was reviewed for the presence of archaeological resources in accordance with regulations issued pursuant to, or other requirements of, the American Antiquities Preservation Act of 1906; the American Indian Religious Freedom Act of 1978; the Historic Sites, Buildings and Antiquities Act of 1935; the Archaeological and Historic Preservation Act of 1960; and the Archaeological Resources Protection Act of 1979.

\subsection{WILD AND SCENIC RIVERS ACT OF 1968}

The ETF will not affect any rivers presently designated under the Wild and Scenic Rivers Act. 


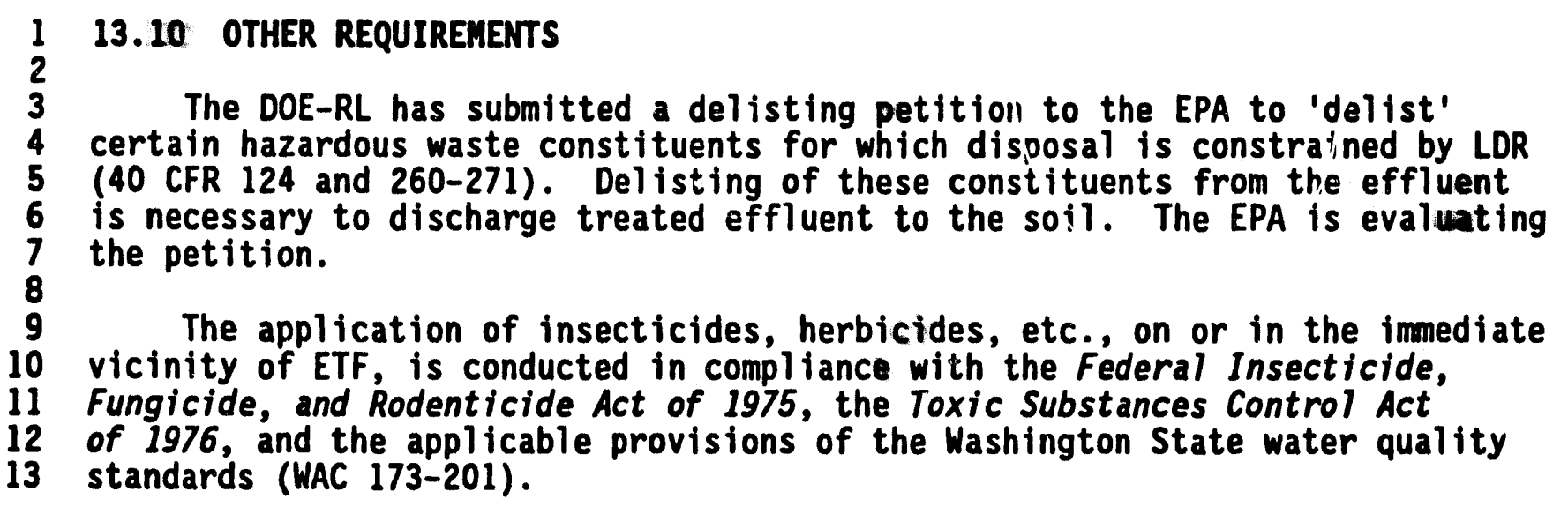


DOE/RL-93-03, Rev. 0
$08 / 31 / 93$

\section{CONTENTS}

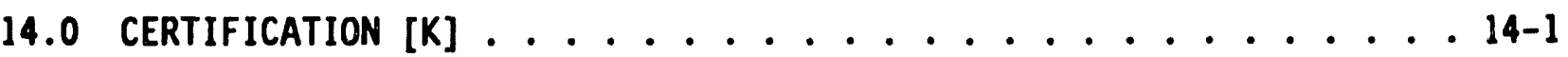


DOE/RL-93-03, Rev. 0

$08 / 31 / 93$

This page intentionally left blank. 


\subsection{CERTIFICATION [K]}

The following certification, required by WAC 173-303-810(13), for all applications and reports submitted to Ecology is hereby included:

I certify under penalty of 1 aw that this document and all attachments were prepared under my direction or supervision in accordance with a system designed to assure that qualified personnel properly gather and evaluate the information submitted. Based on my inquiry of the person or persons who manage the system, or those persons directly responsible for gathering the information, the information submitted is, to the best of my knowledge and belief, true, accurate, and complete. I am aware that there are significant penalties for submitting false information, including the possibility of fine and imprisonment for knowing violations.

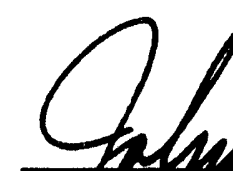

ower joperator

John D. Wagoner.

Magager

s. Department of Energy,

Richland Operations Office

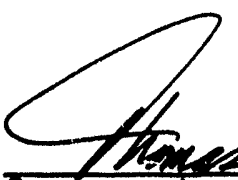

Co-operator

Thomas M. Anderson, President

Westinghouse Hanford Company
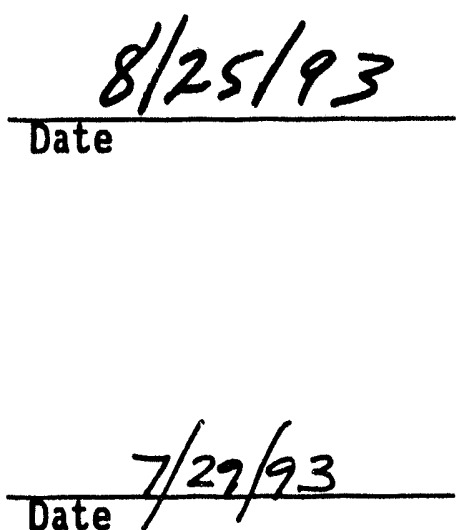
DOE/RL-93-03, Rev. 0

$08 / 31 / 93$

This page intentionally left blank. 
DOE/RL-93-03, Rev. 0 $08 / 31 / 93$

\section{CONTENTS}

15.0 Rl:FERENCES . . . . . . . . . . . . . 15-1

15.1 DOCUMENTS . . . . . . . . . . . . . . . . . . . . .

15.2 CODE OF FEDERAL REgULATIONS AND FEDERAL REGISTER . . . . 15-4

15.3 FEDERAL AND STATE ACTS . . . . . . . . . . . 15-5

15.4 REVISED CODE OF WASHINGTON AND WASHINGTON

ADMINISTRATIVE CODE ...................... 15-6

15.5 U.S. DEPARTMENT OF ENERGY ORDER . . . . . . . . . 15-6 
DOE/RL-93-03, Rev. 0 $08 / 31 / 93$

This page intentionally left blank. 
DOE/RL-93-03, Rev. 0

$08 / 31 / 93$

\subsection{REFERENCES}

\subsection{DOCUMENTS}

AASHTO, 1983, Standard Specification for Highway Bridges, AASHTO-HS-20-44, American Association of State Highway and Transportation Officials, Washington, D.C.

ACI, 1989, Specifications for Structural Concrete for Buildings, AC1-301-89, American Concrete Institute, Detroit, Michigan.

ANSI, 1992, Pia Flanges and Flanged Fitting, ANSI-B16.5, addenda to 1988 publish date, American National Standards Institute, New York, New York.

ANSI/ASME, 1986, Quality Assurance Progran Requirements for Nuclear Facilities, NQA-1-1989, American National Standards Institute/American Society of Mechanical Engineers, New York, New York.

API, 1988, Welded Steel Tanks for 017 Storage, API 650, American Petroleum Institute, Washington, D.C.

API, 1990, Design and Construction of Large Welded Low Pressure Storage Tanks, API 620, American Petroleum Institute, Washington, D.C.

ASME, 1989a, Nuclear Power Plant Air-Cleaning Units and Components, ASME N509, with 1992 interpretations, American Society of Mechanical Engineers, New York, New York.

ASME, 1989b, Testing of Nuclear Air Treatment Systems, ASME N510, American Society of Mechanical Engineers, New York, New York.

ASME, 1990, Chemical Plant and Petroleum Refinery Piping, ASME B31.3, American Society of Mechanical Engineers, New York, New York.

ASME, 1992a, Boiler and Pressure Vessel Code, "Pressure Vessels", ASME Section VIII, Division I, American Society of Mechanical Engineers, New York, New York.

ASME, 1992b, Boller and Pressure Vessel Code, "Welding and Brazing Qual ifications", ASME Section IX, American Society of Mechanical Engineers, New York, New York.

ASNT, 1988, Recommended Practice, SNT-TC-1A, American Society for Nondestructive Testing, Columbus, Ohio.

ASTM, 1983, Standard Guide for Establishing a Quality Assurance Program for Analytical Chemical Laboratories Within the Nuclear Industry, ASTM C-1009-83, American Society for Testing and Materials, Philadelphia, Pennsylvania. 
AWS, 1988, Standard for AWS Certification of Welding Inspectors, AWS QC-1-88, American Welding Society, Miami, Florida.

AWS, 1992, Structural Welding Code - Steel, AWS-D1.1, American Welding Society, Miami, Florida.

AWWA, 1984, Thermosetting Fiberglass-Reinforced Plastic Tanks, AWWA-D120, American Water Works Association, Denver, Colorado.

AWWA, 1987, Factory-Coated Bolted Steel Tanks for Water Storage, AWWA-D103, American Water Works Association, Denver, Colorado.

AWWA, 1989, Welded Steel Tanks for Water Storage, AWWA-D100, addenda to 1984 publish date, American Water Works issociation, Denver, Colorado.

Benton-Franklin-Walla Walla Counties Air Pollution Control Authority, 1980, General Regulation 80-7.

COE, 1969, Lower Columbia River Standard Project Flood and Probable Maximum Flood, U.S. Army Corps of Engineers, North Pacific Division, Portland, Oregon.

Dames and Moore, 1992, Report of Geotechnical Investigation/Consulting Services, Effluent Treatment Facility, Job No. 10805-699-016, Seattle, Washington.

DOE, 1987, Final Environmental Impact Statement: Disposal of Hanford Defense High-Level, Transuranic and Tank Wastes, Vol. 1-5, D0E/EIS-0113, U.S. Department of Energy, Washington, D.C.

DOE, 1988, Site Characterization Plan, Consultation Draft, DOE/RW-0164, Vol. 1, U.S. Department of Energy, Washington, D.C.

DOE-RL, 1988a, "Design Load for Structures," Hanford Plant Standards, HPS-SDC-4.1, Revision 11, U.S. Department of Energy-Richland Operations Office, Richland, Washington.

DOE-RL, 1988b, Hanford Facility Dangerous Waste Part A Permit Application, DOE/RL-88-21, as amended, Vols. 1-3, U.S. Department of Energy-Richland Operations Office, Richland, Washington.

DOE/RL-90-39, Double-Shell Tank System Dangerous Waste Pernit Application, Revision O, 1991, U.S. Department of Energy-Richland Operations Office, Richland, Washington.

DOE/RL-90-42, 242-A Evaporator Dangerous Waste Permit Application, Revision 0, 1991, Westinghouse Hanford Company for U.S. Department of Energy-Richland Operations Office, Richland, Washington.

DOE/RL-90-43, Liquid Effiuent Retention Facility Dangerous Waste Permit Application, Revision 0, 1991, U.S. Department of Energy, Richland Operations Office, Richiand, Washington. 
DOE/RL-93-03, ReV. 0

$08 / 31 / 93$

3

4
DOE/RL-91-28, Hanford Facility Dangerous Waste Permit Application, General Information, Revision 1, 1993, U.S. Department of Energy, Richland Operations Office, Richiand, Washington.

DOE/RL-91-39, Waste Water Pilot Plant Research, Development, and Demonstration Permit Application, Revision 1A, 1993, U.S. Department of Energy, Richland Operations Office, Richland, Washington.

DOE/RL-92-72, 200 Area Effluent Treatment Facility Delisting Petition, Revision 1, 1993, U.S. Department of Energy, Richland Operations Office, Richiand, Washington.

Ecology, 1987, State of Washington Part B Permit Application Requirements, Washington State Department of Ecology, Olympia, Washington.

Ecology, EPA, and DOE, 1992, Hanford Federal Facility Agreement and Consent Order, 2 vol., Washington State Department of Ecology, U.S. Environmental Protection Agency, and U.S. Department of Energy, Olympia, Washington.

EPA, 1983, Interim Guidelines and Specifications for Preparing Quality Assurance Project Plans, QAMS/005/80, EPA-600/4-83/004,

U.S. Environmental Protection Agency, Washington, D.C.

EPA, 1986, Test Methods for the Evaluation of Solid Waste: Physical/Chemical Methods, SW-846, as amended, U.S. Environmental Protection Agency, Washington, D.C.

ERDA, 1976, Evaluation of Impact of Potential Flooding Criteria on the Hanford Project, RLO-76-4, U.S. Energy Research and Development AdministrationRichland Operations Office, Richland, Washington.

FEMA, 1980, Flood Insurance Study: Benton County Washington, Federal Emergency Management Agency, Washington, D.C.

ICBO, 1991, "Earthquake Regulations," Uniform Building Code, UBC Section 2312, International Conference of Building Officials, Whittier, California.

Jungfletsch, F.M., 1990, Wastestrean Designation of Liquid Effluent Analytical Data, WHC-EP-0334, Westinghouse Hanford Company, Richiand, Washington.

NFPA, 1989, National Fire Protection Code, National Fire Protection Association, Quincy, Massachusetts.

NFPA, 1991, Installation of Sprinkler Systems, NFPA 13, National Fire Protection Association, Quincy, Massachusetts.

NFPA, 1992, Installation of Private Fire Service Mains and Their Appurtenances, NFPA 24, National Fire Protection Association, Quincy, Massachusetts. 
NFPA, 1993, Standard for the Installation of Standpipe and Hose Systems, NFPA 14, National Fire Protection Association, Quincy, Massachusetts.

NIOSH, 1990, Registry of Toxic Effects of Chenical Substances, National Institute for Occupational Safety and Health, Washington, D.C.

NRC, 1982, Safety Evaluation Report (Related to the Operation of WPPSS Nuclear Project) No. 2, NUREG-0892 Supplement No. 1, U.S. Nuclear Regulatory Commission, Washington, D.C.

Skaggs, R. L. and W. H. Walters, 1981, Flood Risk Analysis of Cold Creek Near the Hanford site, RHO-BWI-C-120, Rockwell Hanford Operations, Richland, Washington.

UCRL, 1987, Design and Evaluation Guidelines for Defartment of Energy Facilities Subjected to Natural Phenomena Hazards, UCRL-15910, Lawrence Livermore National Laboratory, Livermore, California.

WHC, 1988, Hanford Site Solid Waste Acceptance Criteria, WHC-EP-0063-3, West inghouse Hanford Company, Richland, Washington.

WHC, 1990a, 242-A Evaporator Process Condensate Strean-Specific Report, WHC-EP-0342, Addendum 15, Westinghouse Hanford Company, Richland, Washington.

WHC, 1990b, Liquid Effluent Study Final Project Report, WHC-EP-0367, West inghouse Hanford Company, Richland, Washington.

WHC, 1991, Geology and Hydrology of the Hanford Site: A Standardized Text for Use in Westinghouse Hanford Company Documents and Reports, WHC-SD-ER-TI-003, West inghouse Hanford Company.

WHC, 1992, Design Construction Specification, Project $\mathrm{C}-\mathrm{O} 18 \mathrm{H}$, 242A Evaporator/PUREX Plant Process Condensate Treatment Facility, V-CO1 E8HCl-001, Westinghouse Hanford Company, Richland, Washington.

WSDOT, 1991, Specifications for Roadway Excavation and Embankment Construction Requirements, WSDOE M41-10, Section 2-03.3(14)C, Washington State Department of Transportation, Olympia, Washington.

\subsection{CODE OF FEDERAL REGULATIONS AND FEDERAL REGISTER}

29 CFR 1910.120, Hazardous Waste Operations and Emergency Response

29 CFR 1910.1200, Hazard Communication

40 CFR 61, National Emission Standards for Hazardous Air Pollutants

40 CFR 124, Procedures for Decisionmaking

40 CFR 141, Drinking Water Standards 
40 CFR 260, Hazardous Waste Management System - General

40 CFR 261, Identification and Listing of Hazardous Waste

40 CFR 262, Standards Applicable to Generators of Hazardous Waste

40 CFR 263, Standards Applicable to Transporters of Hazardous Waste

40 CFR 264, Standards for Owners and Operators of Hazardous Waste Treatment, Storage, and Disposal Facilities

40 CFR 265, Interin Status Standard for Owners and Operators of Hazardous Waste Treatment, Storage, and Disposal Facilities

40 CFR 268, Land Disposal Restrictions

40 CFR 270, EPA Administered Permit Programs: The Hazardous Waste Permit Program

40 CFR 302, Designation, Reportable Quantities, and Notification

49 CFR 173, Shippers-General Requirements for Shipments and Packagings

52 FR 22520, Findings and Recommendations on Implementing National

Environmental Policy Act, Vol. 52, No. 113, P. 25520, June 12, 1987.

55 FR 11798, Final Rule Change, Vol 55, pp. 11799, March 29, 1990.

\subsection{FEDERAL AND STATE ACTS}

American Antiquities Preservation Act of 1906, 16 USC 432.

American Indian Religious Freedon Act of 1978, 42 USC 1996.

Archaeological and Historic Preservation Act of 1960, 16 USC 469.

Archaeological Resources Protection Act of 1979, 16 USC 470aa.

Atomic Energy Act of 1954, 42 USC 2011 et seq.

Comprehensive Environmental Response, Compensation, and Liabllity Act of 1980, 42 USC 9601 et seq.

Clean Air Act of 1977, 42 USC 7401 et seq.

Clean Water Act of 1977, 33 USC 1251 et seq.

Endangered Species Act of 1973, 16 USC 1531 et seq.

Federal Insecticide, Fungicide, and Rodenticide Act of 1975, 7 USC 136 et seq. 
Fish and Wildiffe Coordination Act of 1934, 16 USC 661 et seq.

Freedom of Information Act of 1966, as amended, 5 USC 552.

Historic Sites, Buildings and Antiquities Act of 1935, 16 USC 461-467.

National Historic Preservation Act of 1966, 16 USC 470 et seq.

Privacy Act of 1974, 5 USC 552a.

Resource Conservation and Recovery Act of 1976, 42 USC 6901 et seq.

Safe Drinking Water Act of 1974, 42 USC $300 \mathrm{f}$ et seq.

State of Washington Hazardous Waste Management Act of 1976, Revised Code of Washington, Chapter 70.105 et seq., 01 ympia, Washington.

Superfund Amendments and Reauthorization Act of 1986, 42 USC 11001 et seq.

Toxic Substances Control Act of 1976, 15 USC 2601 et seq.

Washington Clean Air Act of 1967, RCW 70.94, as amended.

Wild and Scenic Rivers Act of 1968, 16 USC 1271 et seq.

\subsection{REVISED CODE OF WASHINGTON AND WASHINGTON ADMINISTRATIVE CODE}

RCW 70.98.080, Rules and Regulations-Licensing Requirements and ProceduresRegistration of Sources of Ionizing Radiation-Exemptions from Registration or Licensing

RCW 90.48, Washington State Water Pollution Control Act

WAC 173-201, Water Quality Standards for Surface Waters of the State of Washington

WAC 173-216, State Waste Discharge Permit Progran

WAC 173-303, Dangerous Waste Regulations

WAC 173-400 through 495, General Regulations for Air Pollution Sources

WAC 246-247, Radiation Protection-Air Emissions

WAC 296-155, Washington Industrial Safety and Health Act

\subsection{U.S. DEPARTMENT OF ENERGY ORDER}

6430.1A, General Design Criteria 
DOE/RL-93-03, Rev. 0

$08 / 31 / 93$

\section{APPENDICES}

2A LOCATION MAPS

3A WASTE ANALYSIS PLAN

4A ENGINEERING DESIGN REPORT

4B CERTIFICATION OF NEW TANK SYSTEM INTEGRITY

4C SEISMIC ANALYSIS

4D CORROSION ANALYSIS

7 BA BUILDING EMERGENCY PLAN 200 AREA EFFLUENT TREATMENT FACILITY

8A TRAINING COURSE DESCRIPTIONS

19

20 
DOE/RL-93-03, Rev. 0

$08 / 31 / 93$

This page intentionally left blank. 
DOE/RL-93-03, Rev. 0

$08 / 31 / 93$

\section{APPENDIX 2A}

HANFORD SITE MAPS 
D0E/RL-93-03, Rev. 0 $08 / 31 / 93$

This page intentionally left blank. 


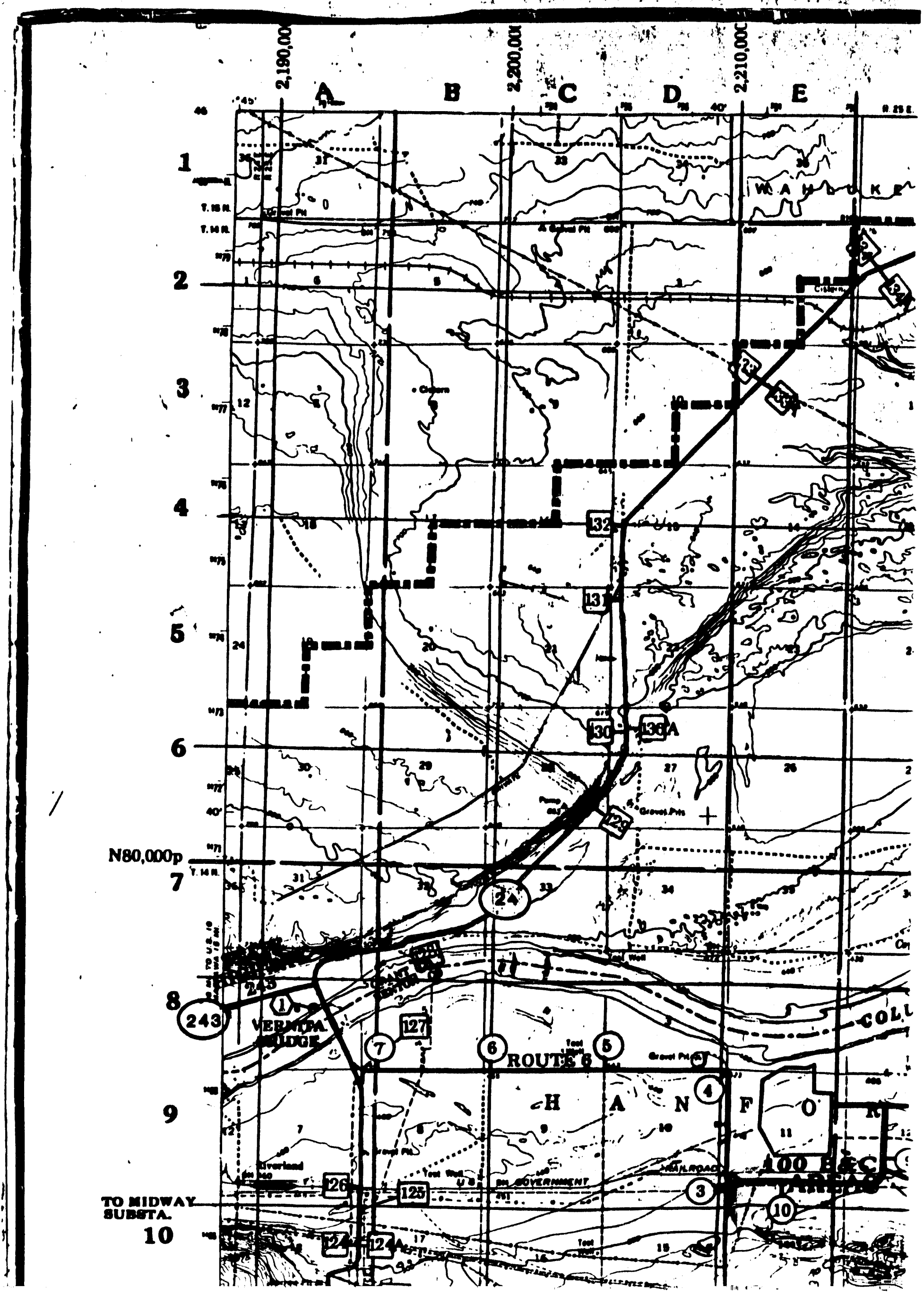





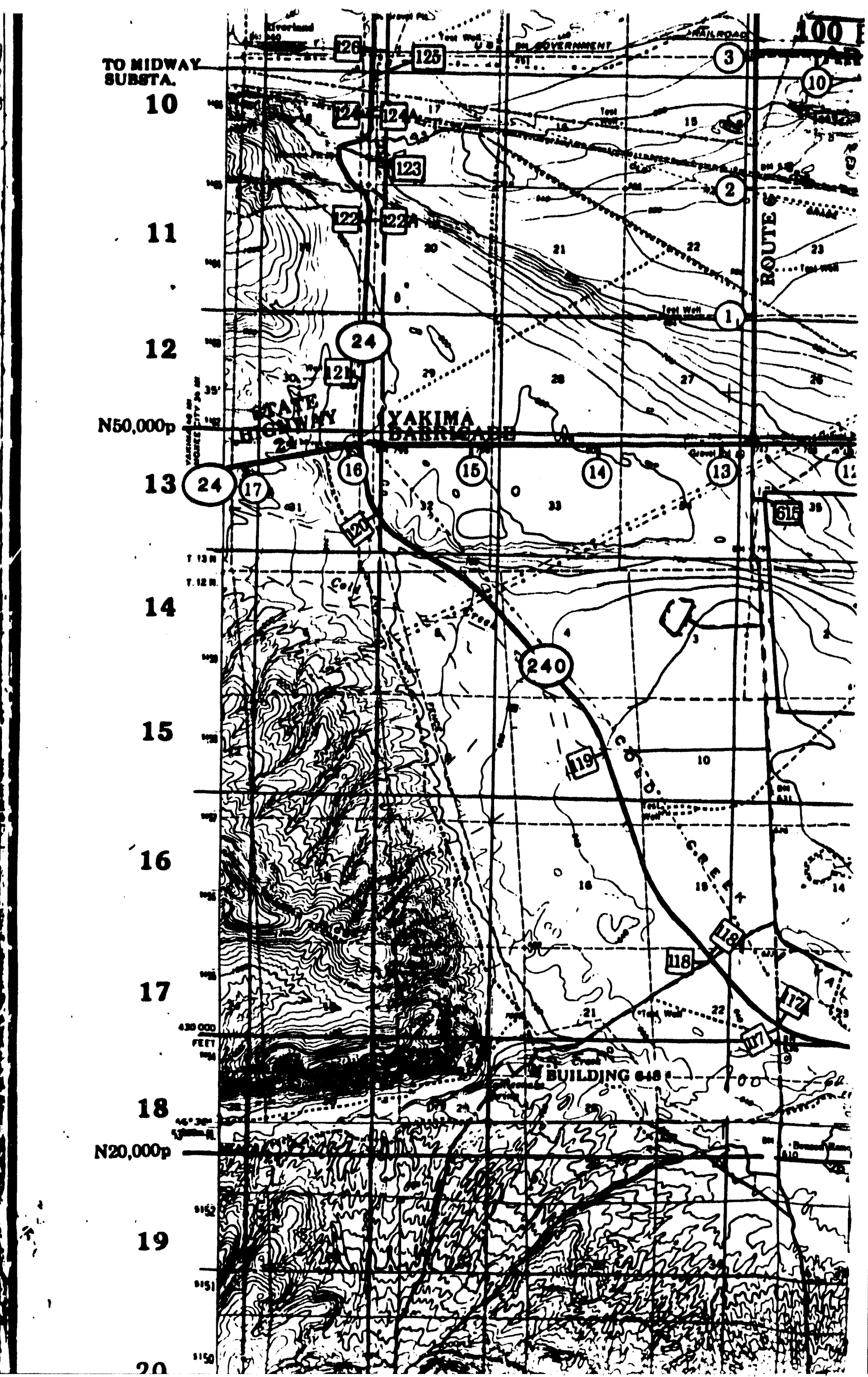




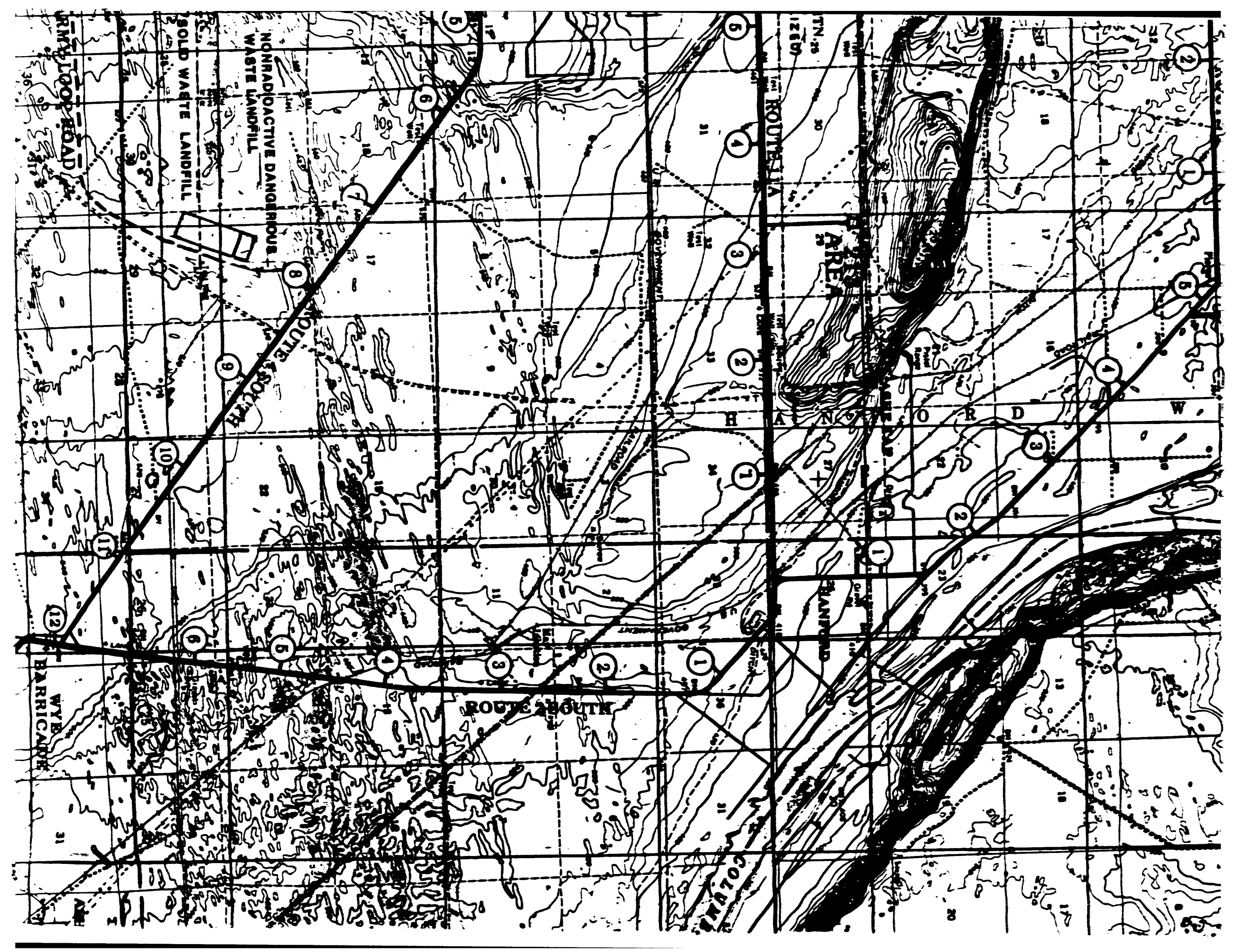




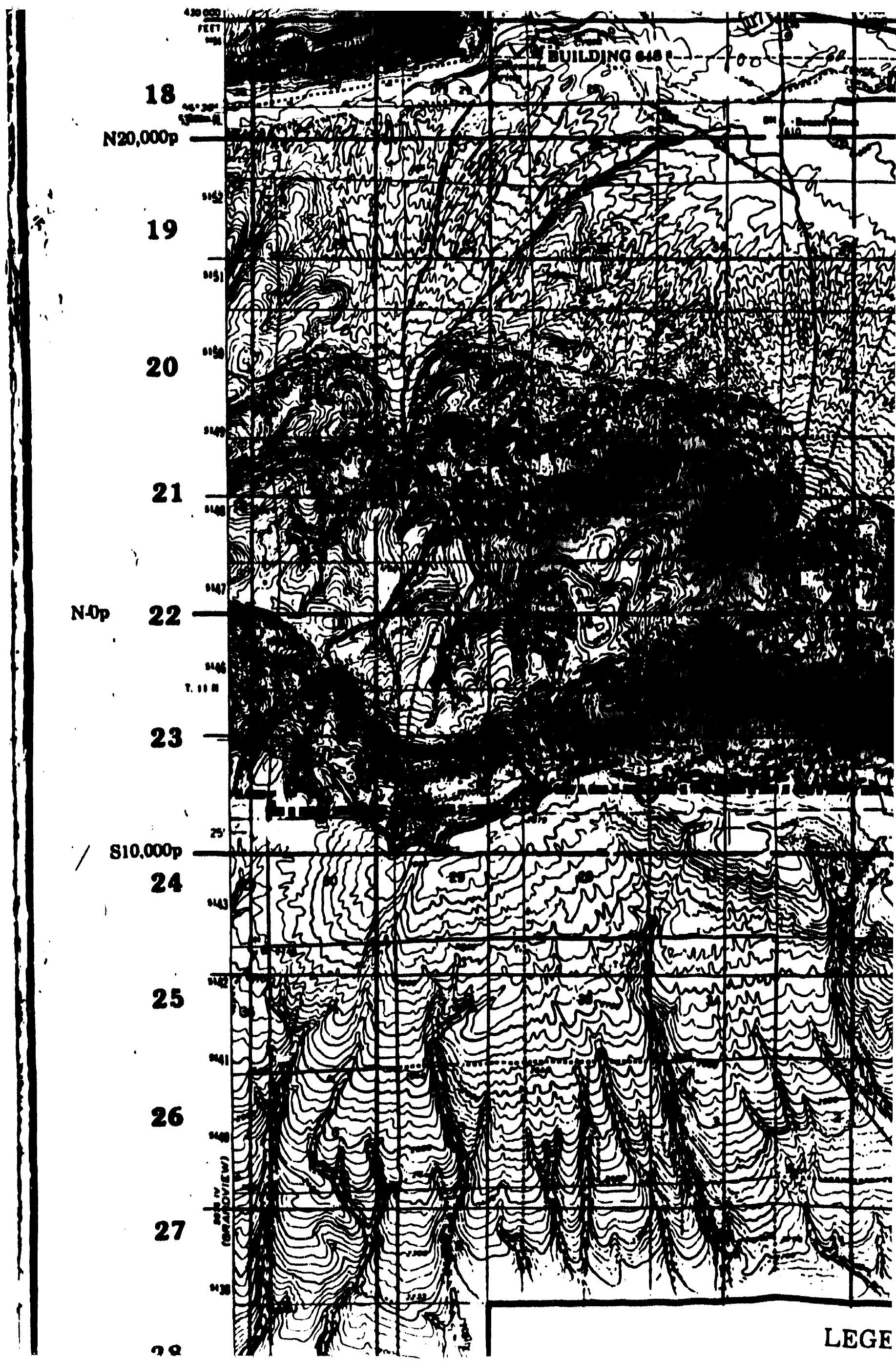




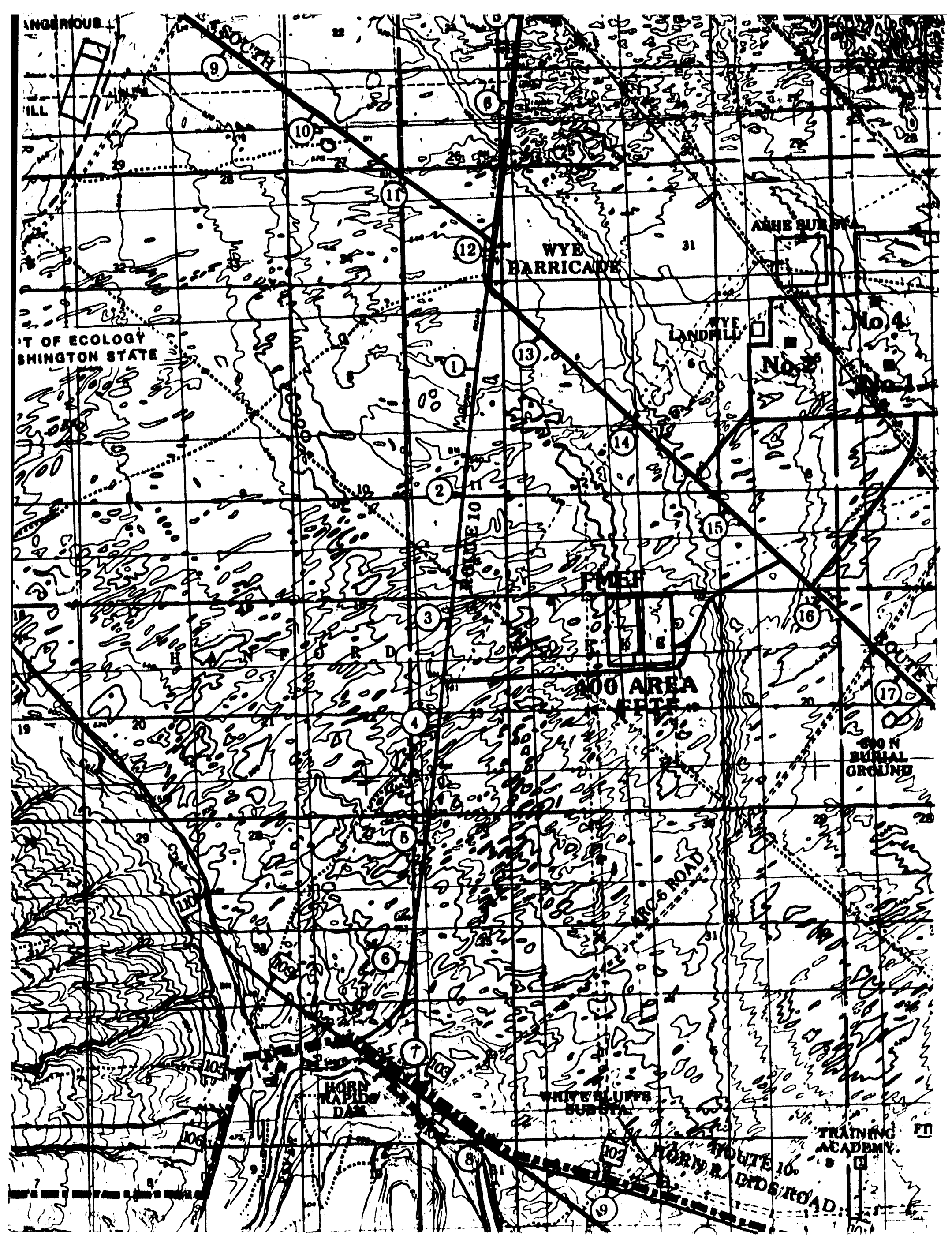




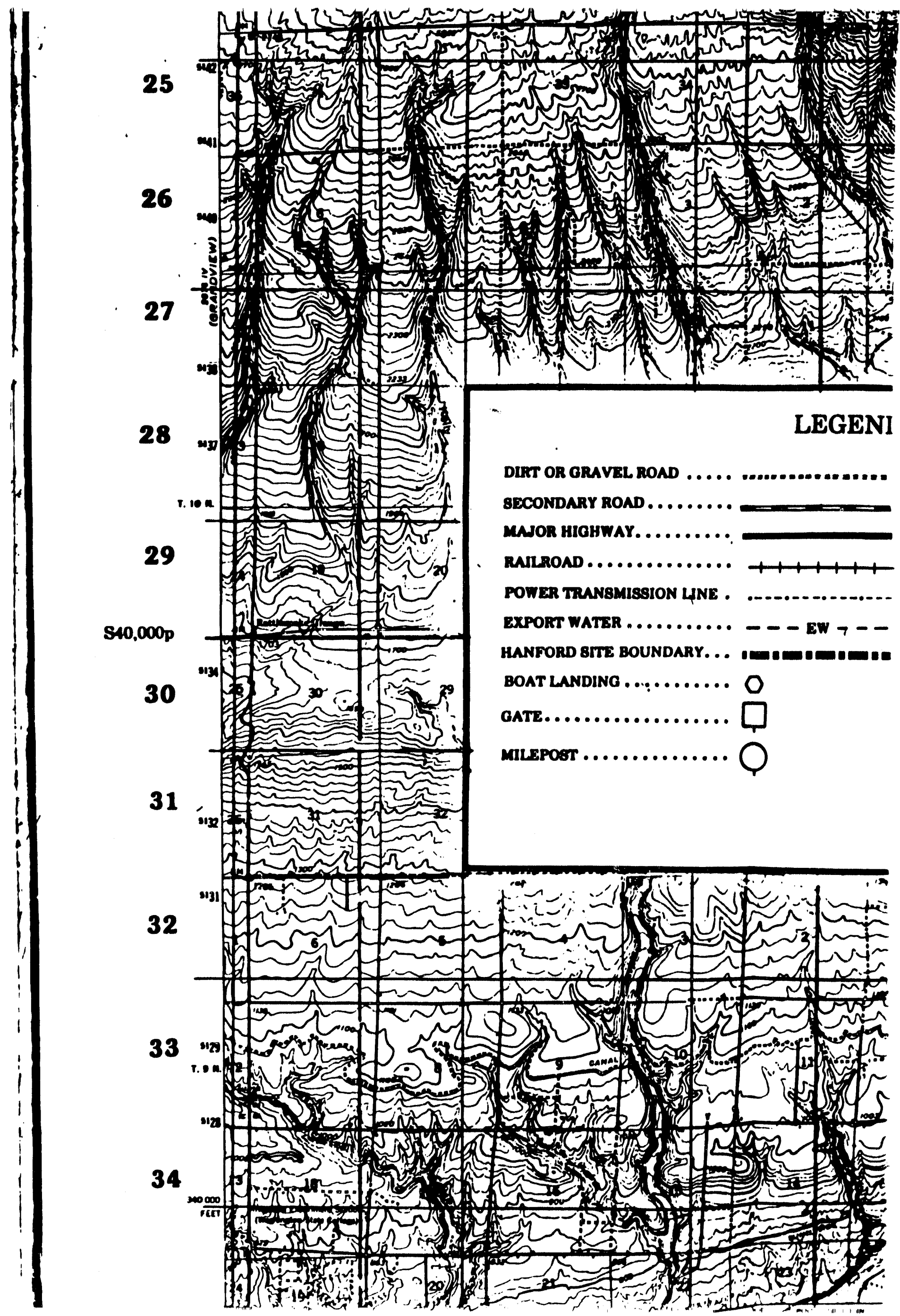




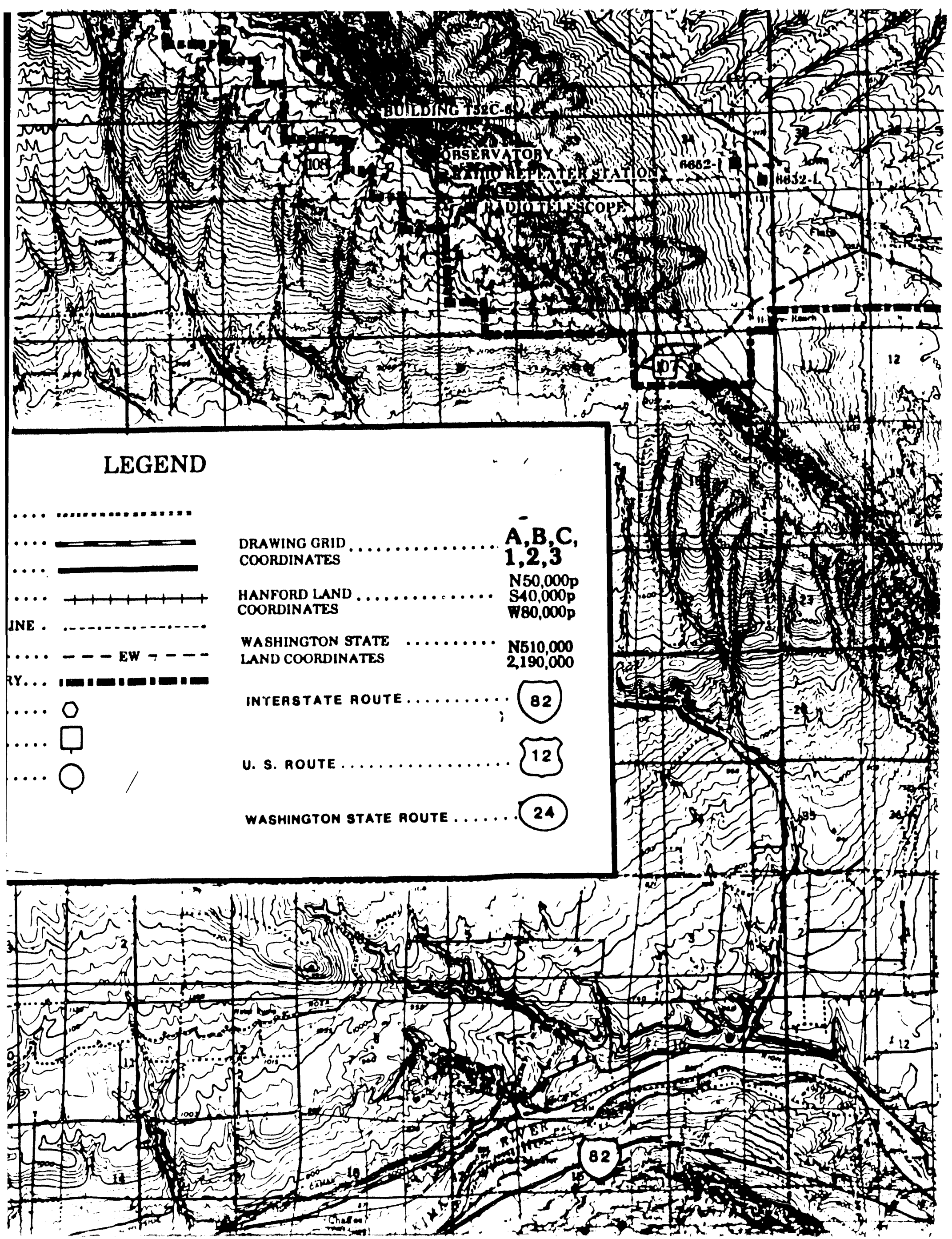




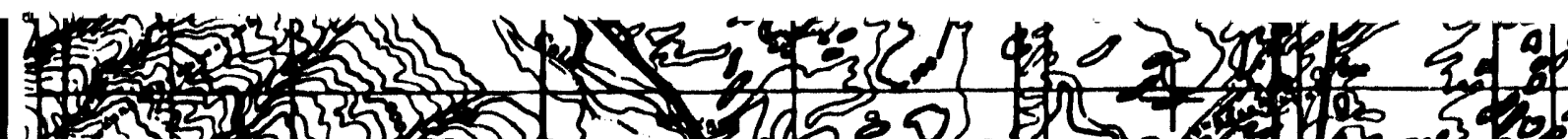

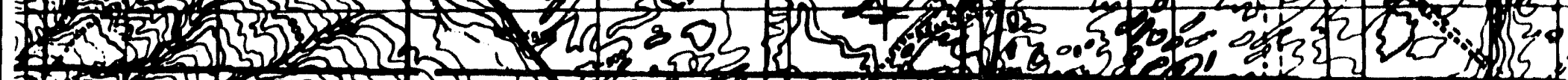

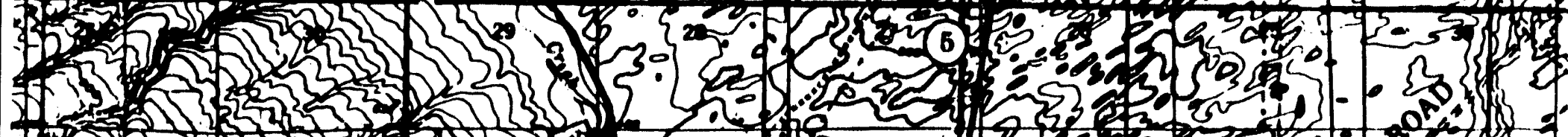

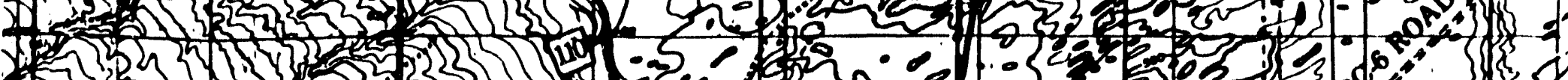

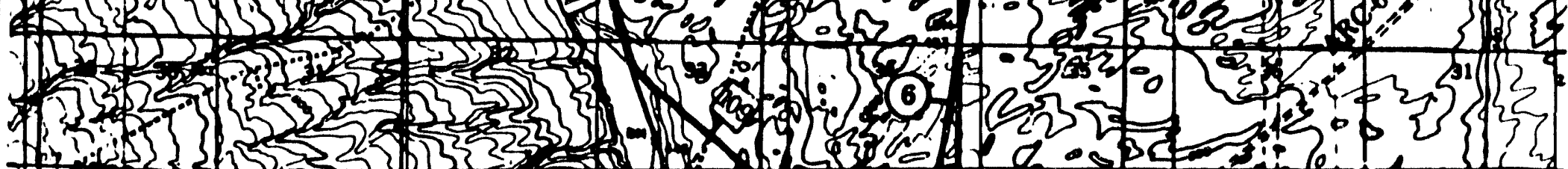

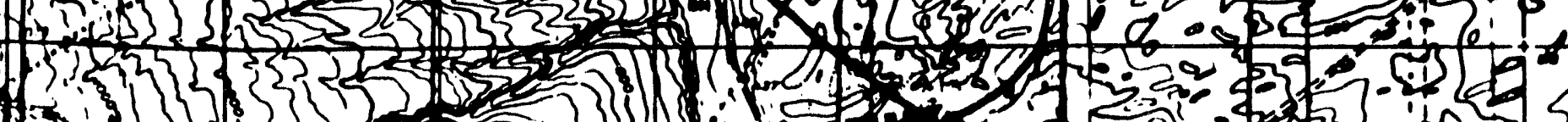
(12)

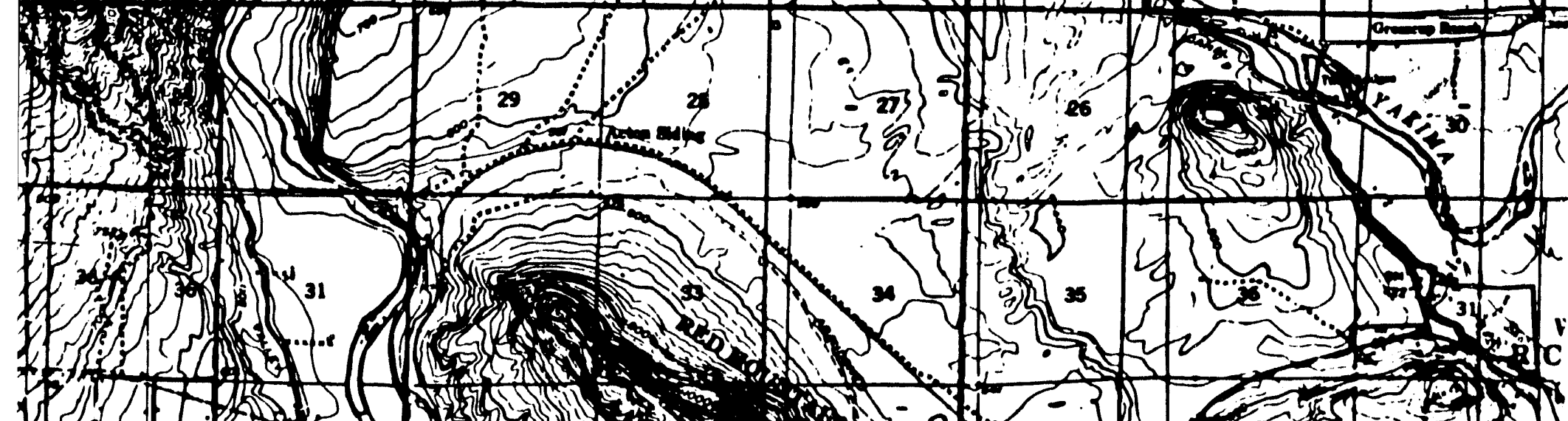

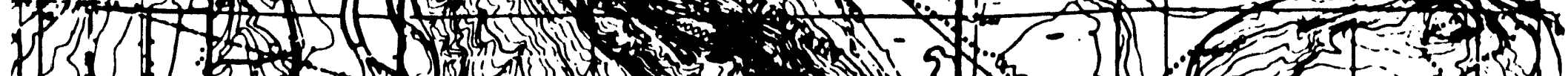

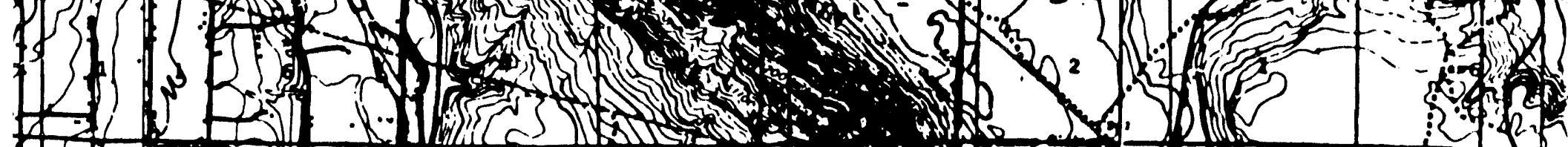
$\left.\frac{12}{2}+12\right\}$

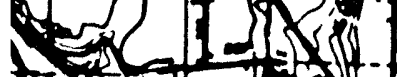

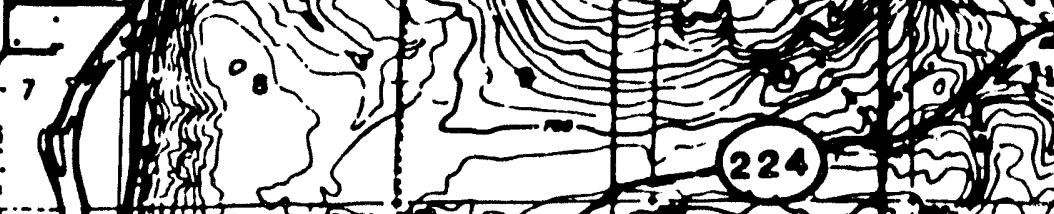


(3)

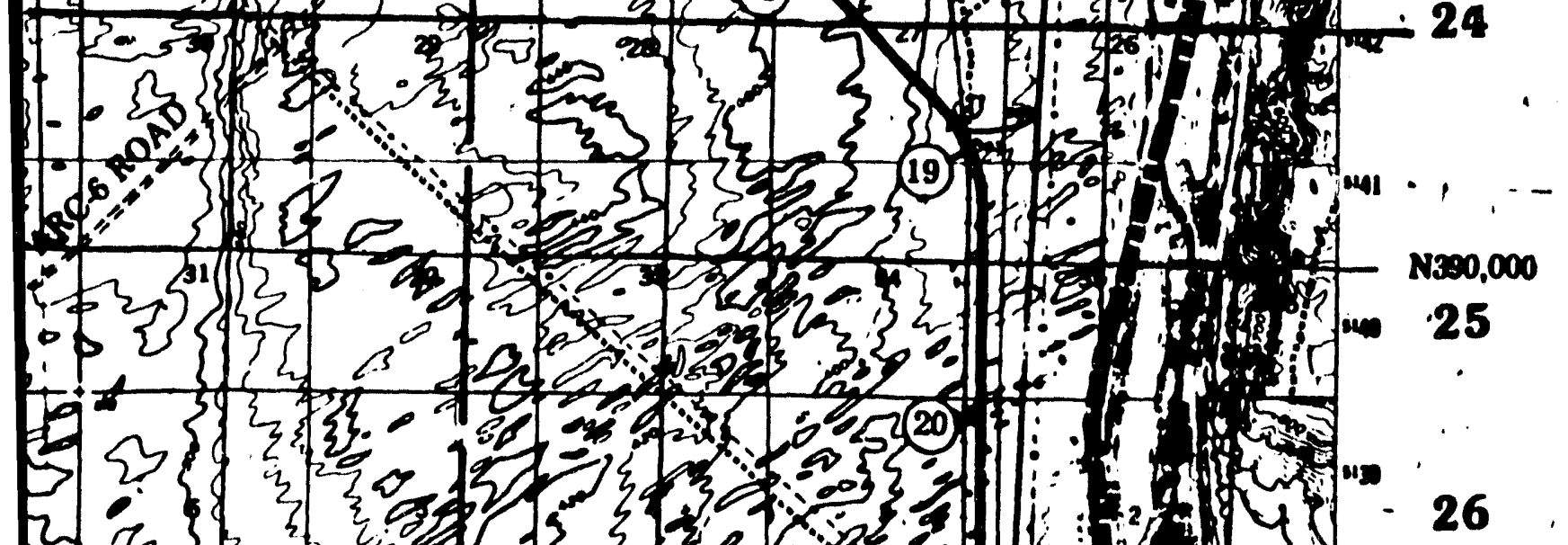

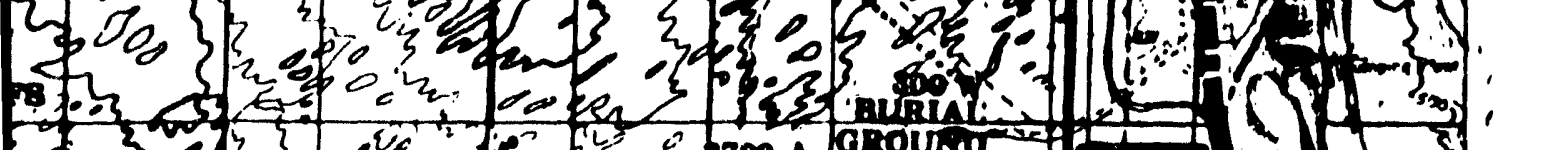

2. a

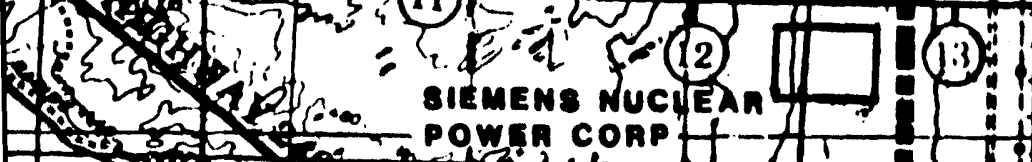
(19) 


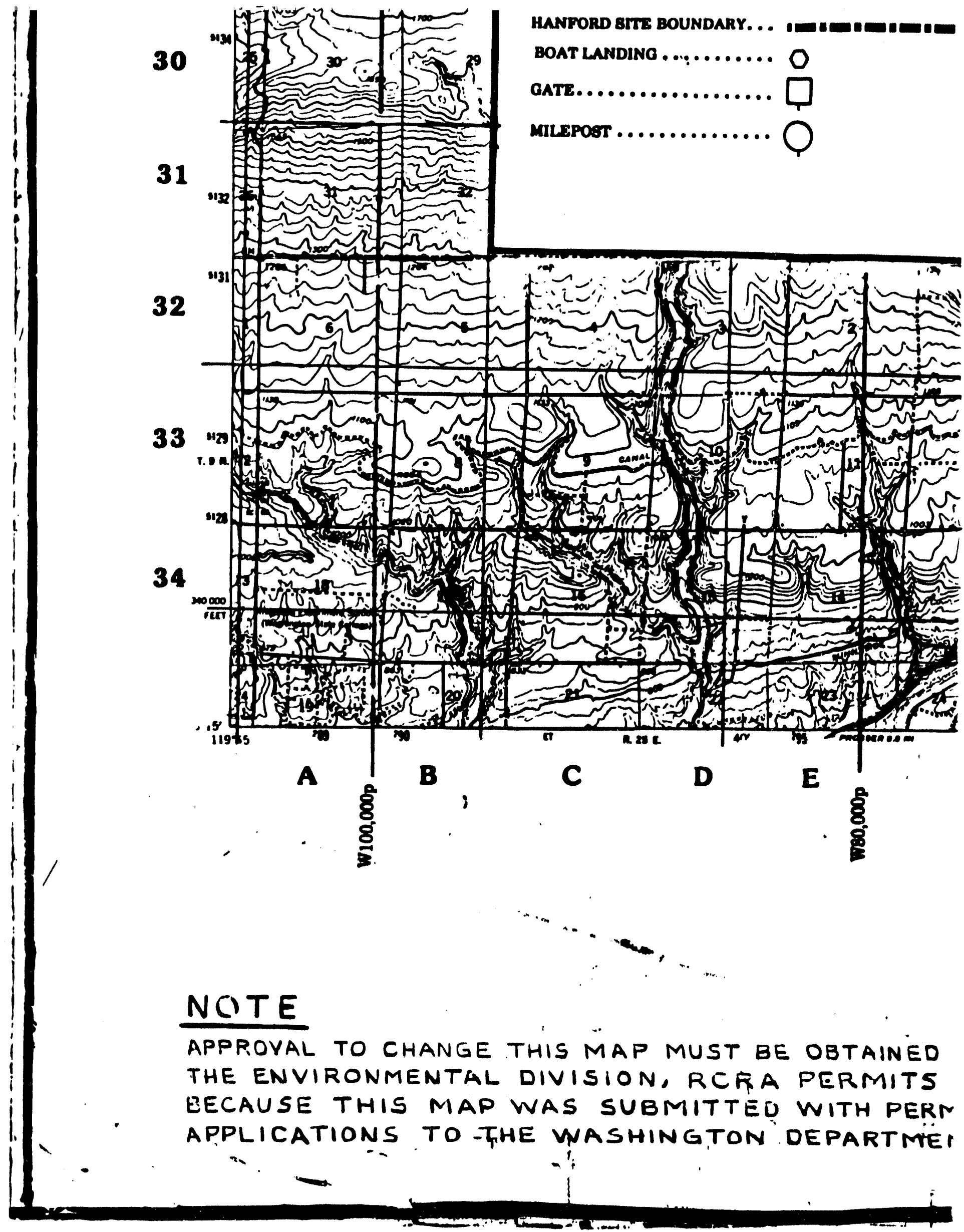


POWER TRANBMLSION LNE .

EXPORT WATER ......... - - - BW ᄀ- -

HANFORD 8TTE BOUNDARY. . . ש

BOAT LANDING .......... O

aATz.............. $\square$

muspost ...........

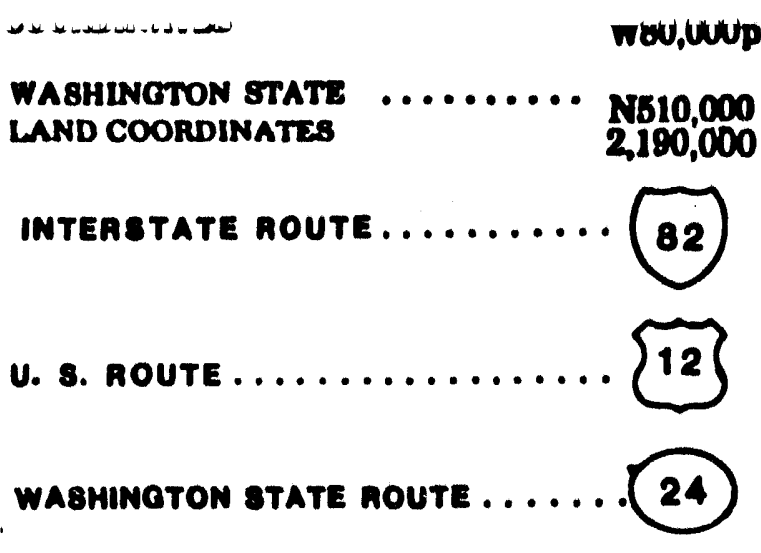

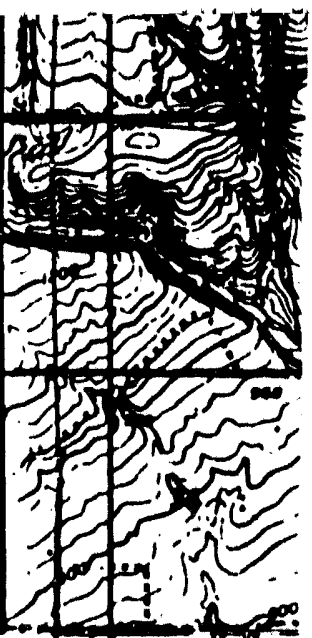

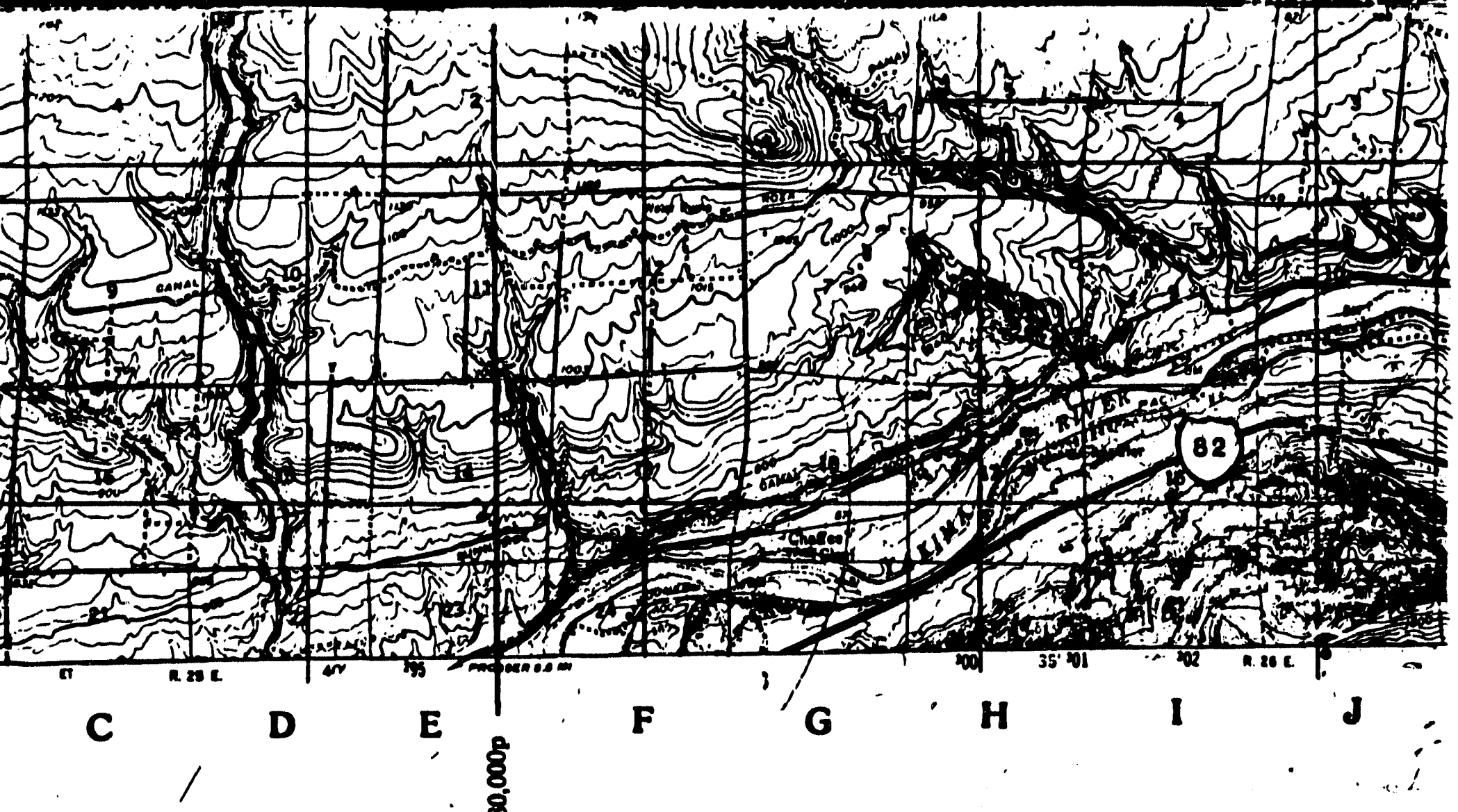

SITE PLAN

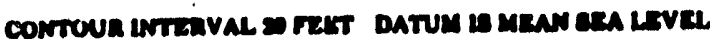

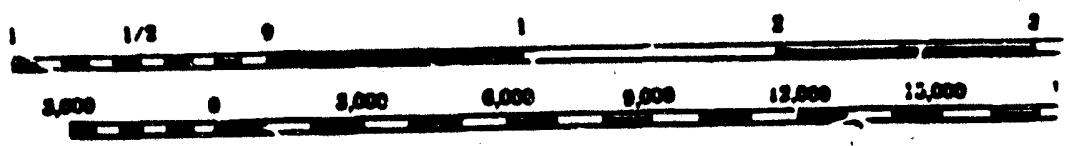

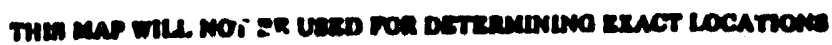

THIS MAP MUST BE OBTAINED FROM

- DIVISION, REFA PERMITS SECTION

- WAS SUBMITTEU WITH PERMIT

FHE WASHINGTON DEPARTMENT OF ECOLOGY. $=$ :

NEXTUSEDON: END ME 


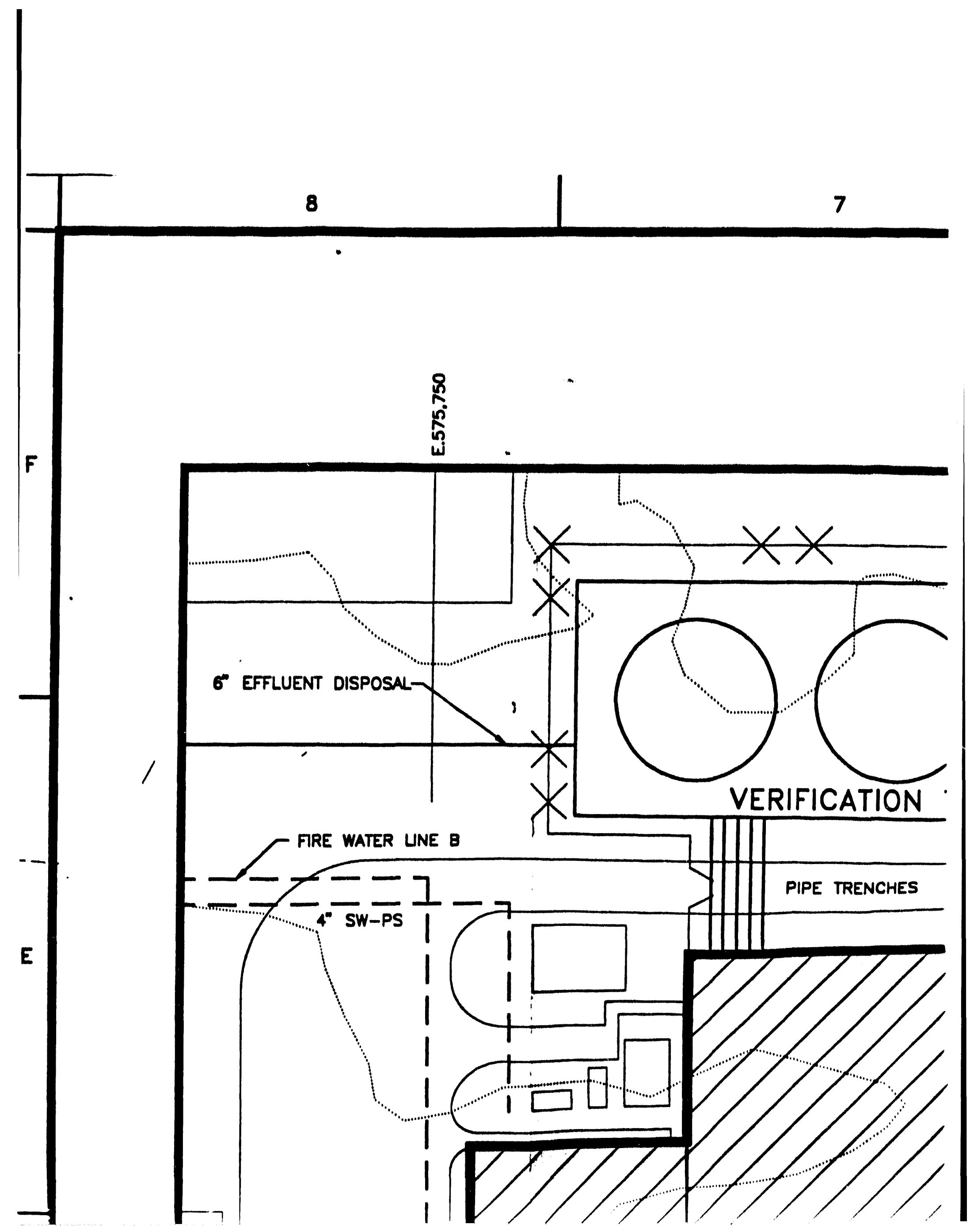




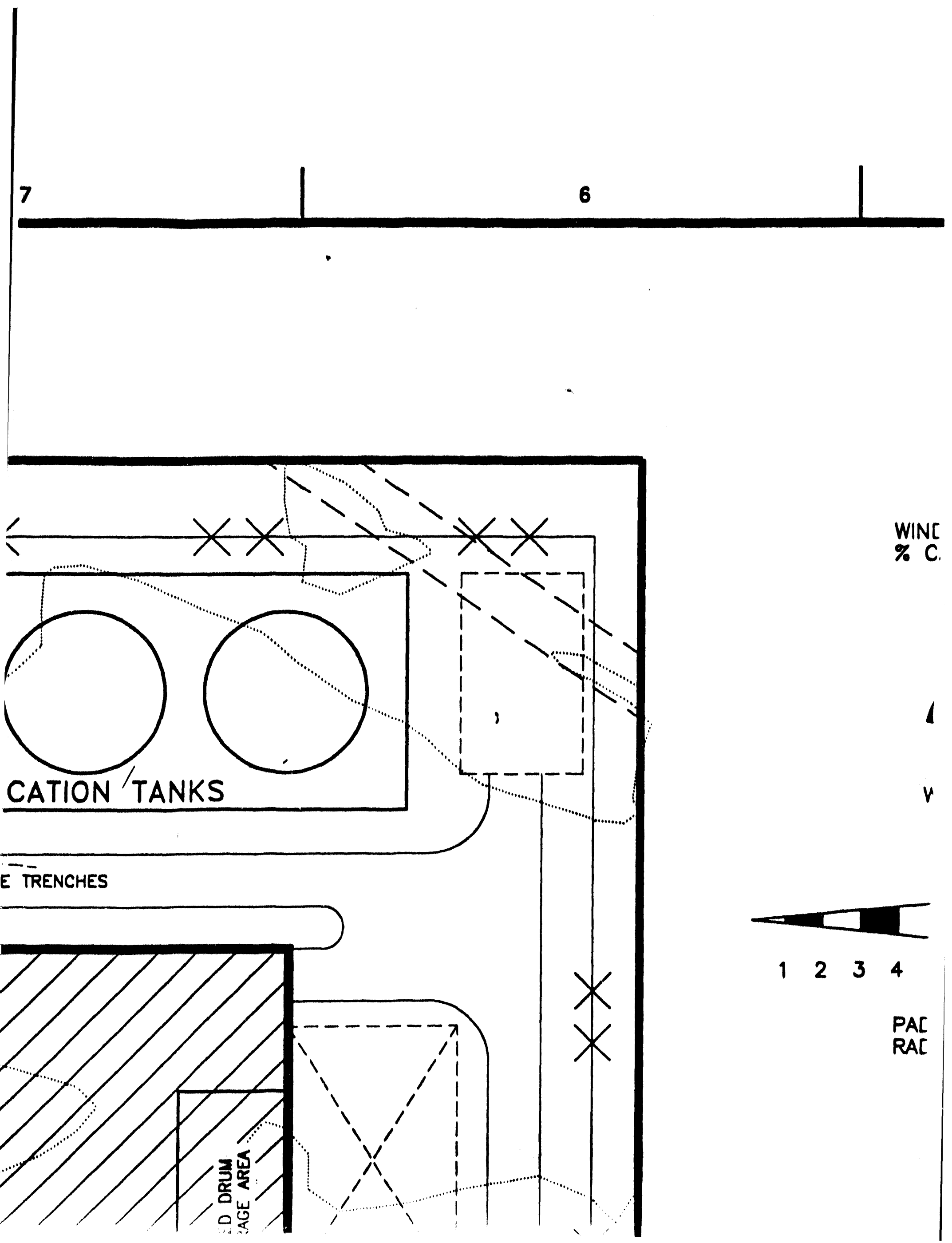


WIND ROSE FDR: 200E AREA

$\%$ CALM WINDS $=.9$

\section{NORTH}

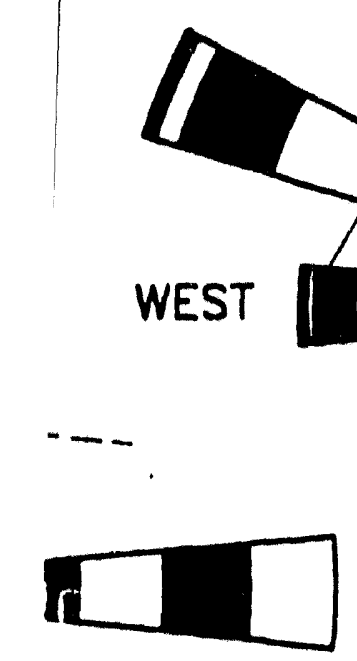

$\begin{array}{llll}4 & 5 & 6 & 7\end{array}$
PERIOD COVERED

$12 / 01 / 85-12 / 31 / 87$

STATION NO. 6

\section{4}

N.137.750

EAST

PADDLES INDICATE DIRECTION WIND IS COMING FROM.

RADIAL GRIDS REPRESENT $5.0 \%$ AND $10.0 \%$ OCCURRENCE.

\begin{tabular}{|c|c|}
\hline WIND CLASS & MILES/HOUR \\
\hline 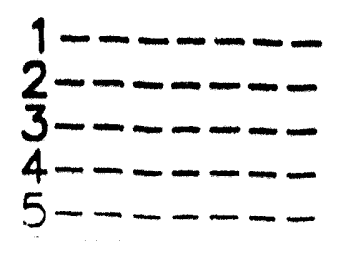 & $\begin{array}{r}1.0=3 . \\
4.0=7 . \\
8.0=12 . \\
13.0=18.0 \\
19.0=74\end{array}$ \\
\hline
\end{tabular}



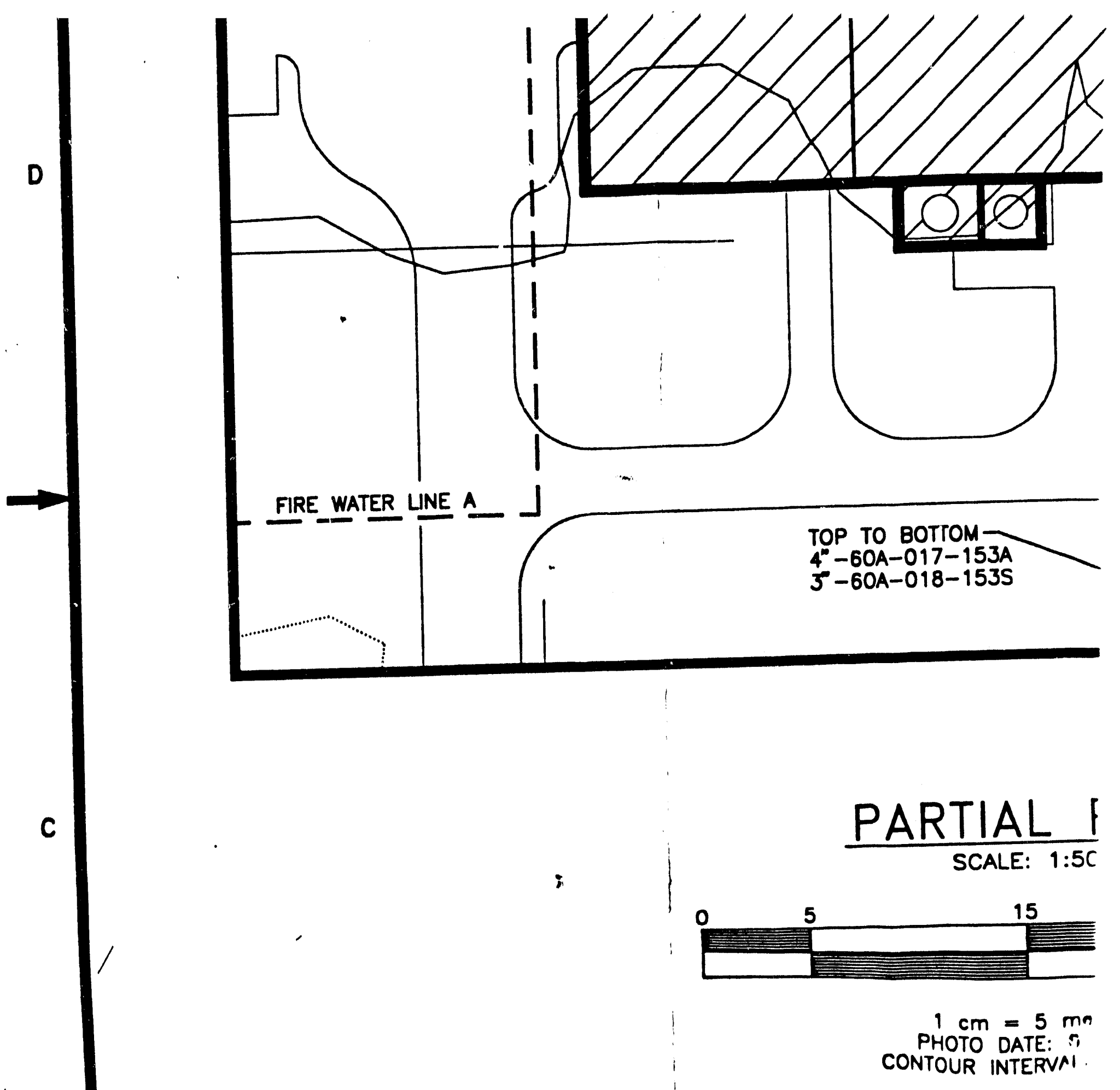

B 

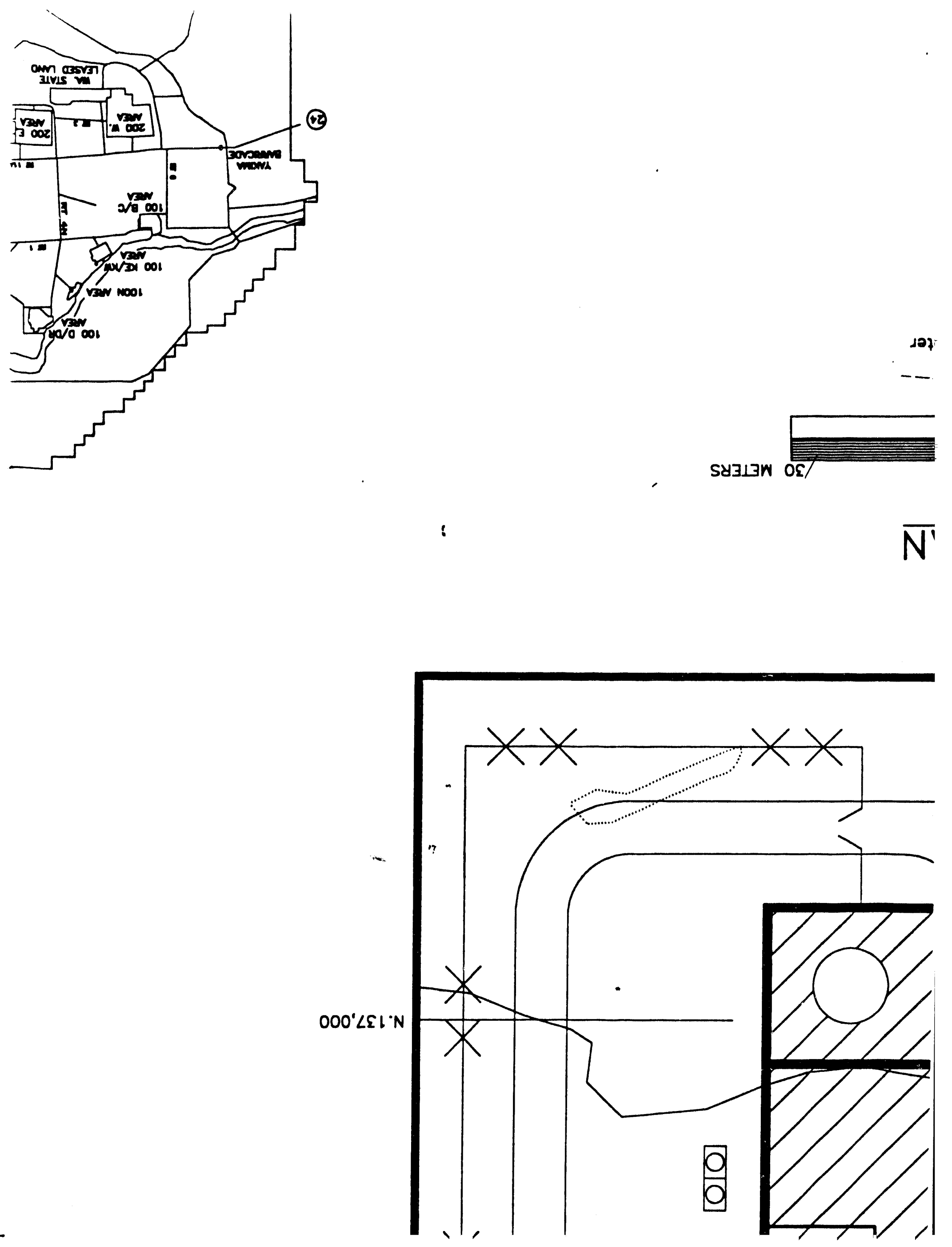


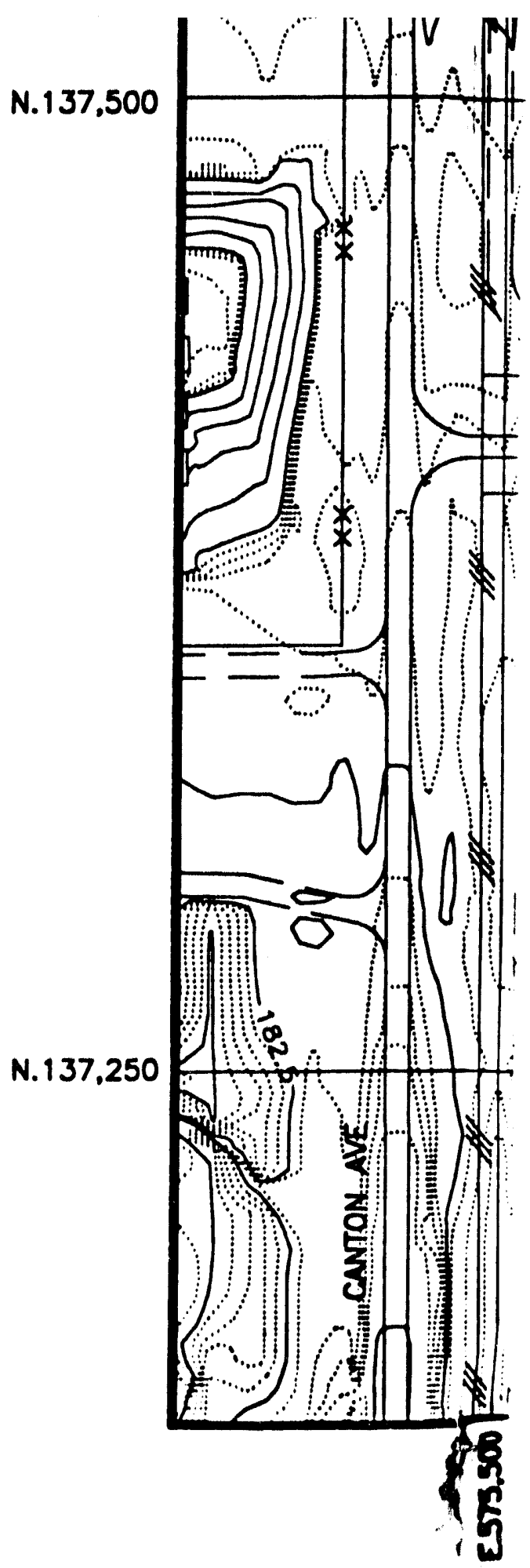




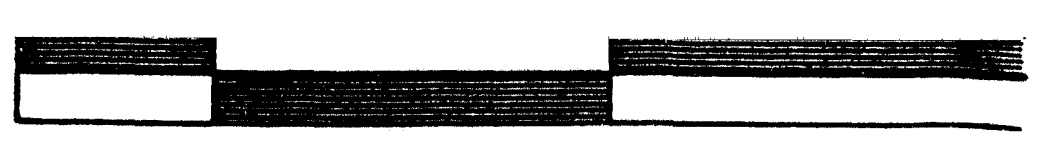

$1 \mathrm{~cm}=5$ meters

PHOTO DATE: $6-24-89$

CONTOUR INTERVAL: 0.5 meter

\section{GENERAL NOTES}

1. THIS MAP IS BASED ON AERIAL PHOTOGRAPHY FLOWN ON 6-24-89. THE TOF BY MERRICK \& COMPANY AND CERTIFIED TO MEET NATIONAL MAP ACCURACY S OFFICIAL COPIES OF THE MERRICK MAPS THAT SHOW THE CERTIFICATE ARE LC ENGINEERING FILES AS DRAWING NUMBERS $\mathrm{H}-2-79476$ SHEET 1 AND $\mathrm{H}-2-7$ THE NAMES OF PHYSICAL FEATURES AND THE TITLE BLOCK OF THE H-13-OC MAPS WERE ADDED BY WESTANGHOUSE HANFORD COMPANY.

2. WASHINGTON COORDINATE SYSTEM: THE OFFICLAL STATE PLANE COORDINATE S REVSED CODE OF WASHINGTON (RCW). THE HANFORD SITE LIES WITHIN THE SOUTH ZONE. THIS GRID COVERS THE ENTIRE SITE AND USES $X$ (EASTINGS)

HORIZONTAL DATUM: NAD-83 LAMBERT PROJECTIONS

VERTICAL DATUM: NATIONAL GEODETIC SURVEY

DATUM AS PROVIDED BY KAISER

ENGINEERS HANFORD.

3. HANFORD PLANT GRID: A LOCAL GRID SYSTEM WITH ITS INITIAL POINT NORCOVERS 200 EAST AND 200 WEST AREA AS WELL AS GENERAL SITE WORK S. GROUNDS. COORDINATES ARE SHOWN AS FEET. IT IS ROTATED FROM NORTR DIFFERENT SCALE THAN LAMBERT.

4. THE PARTIAL PLAN SHOWS THE UNDERGROUND PIPELINES THAT TRANSFER WAE EFFLUENT RETENTION FACILTTY TO THE 200 AREA EFFLUENT TREATMENTT FAC:LPIPELINES TO THE VERIFCATION TANKS. 


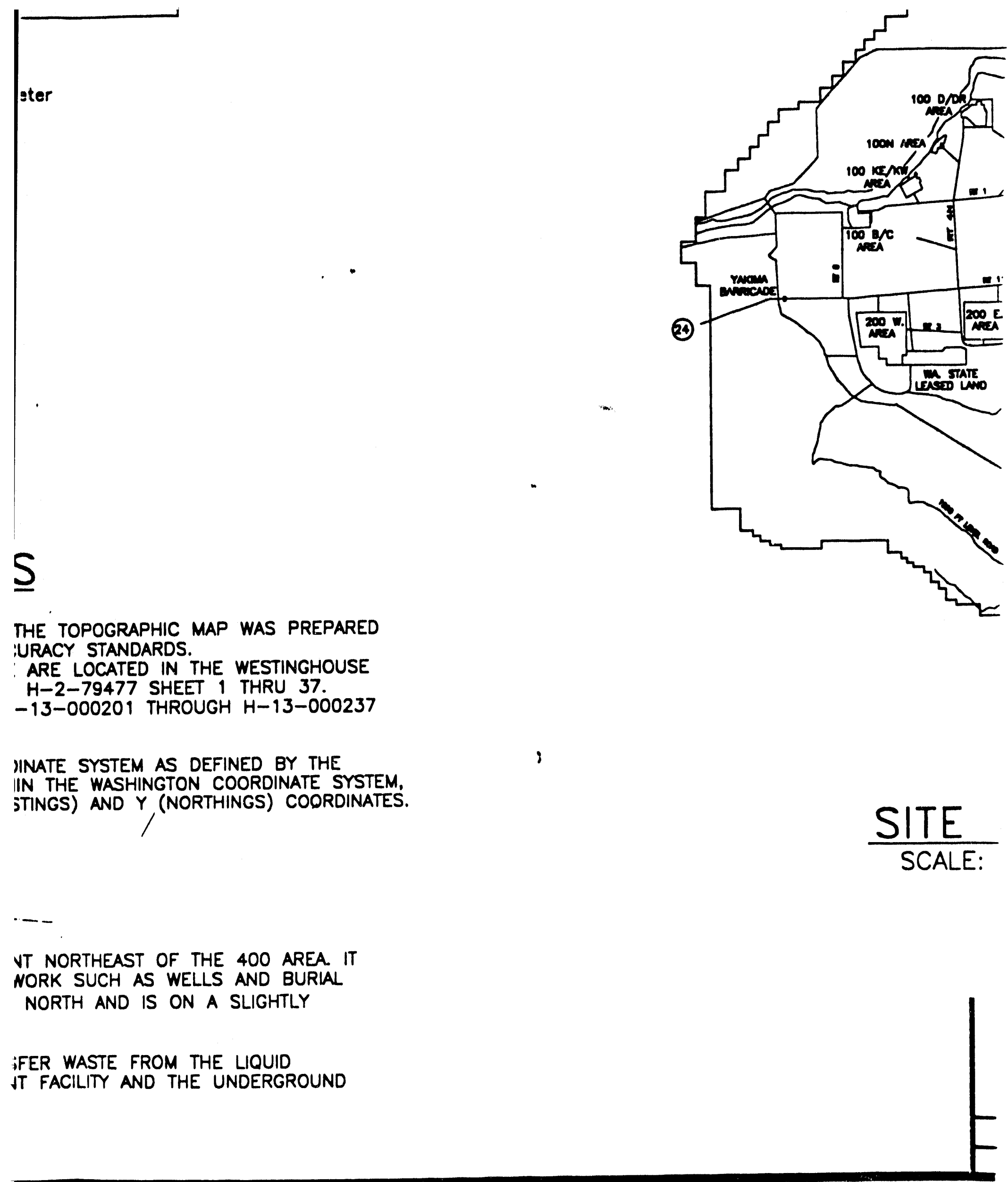




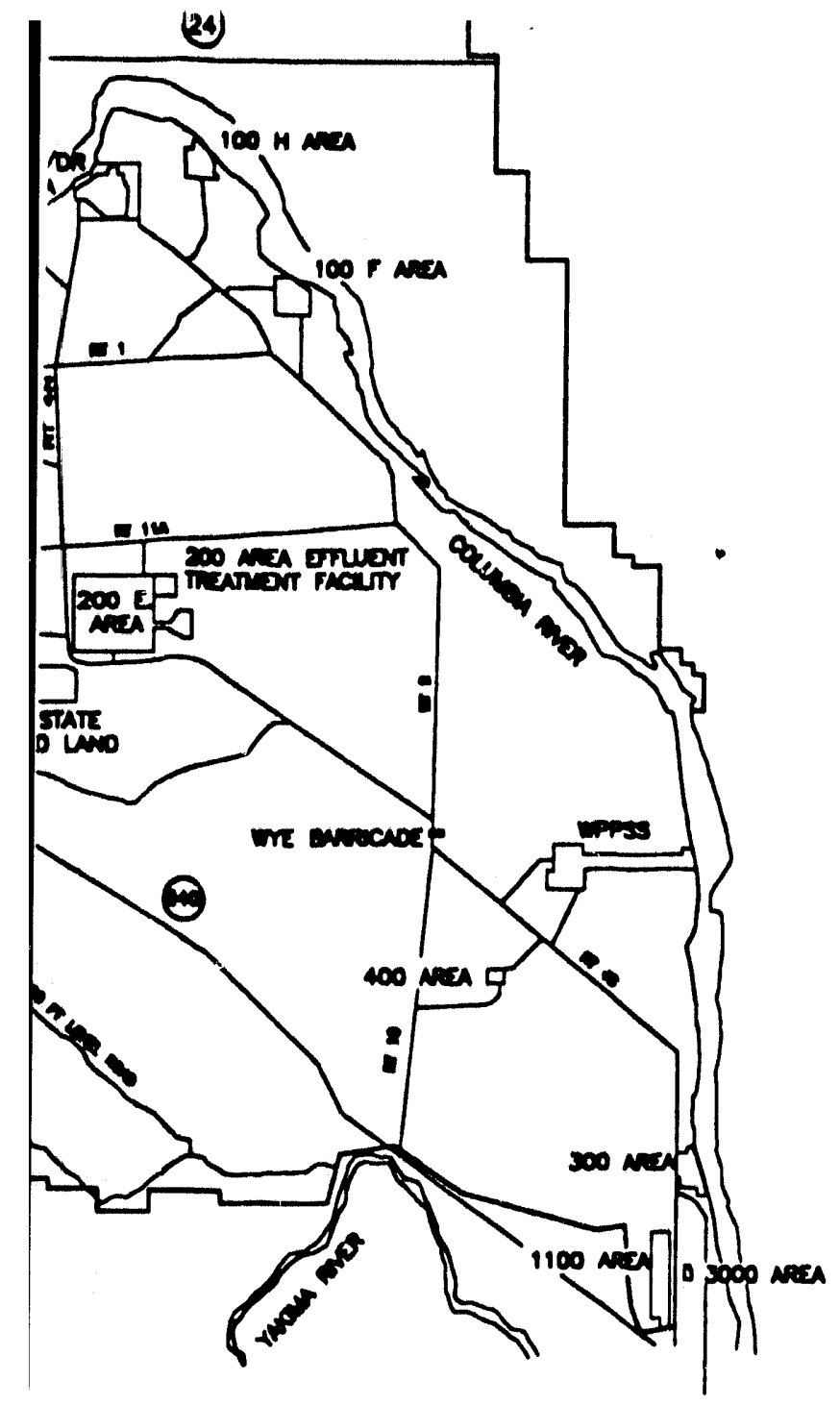

$\therefore$ PLAN

LE: NONE
E.576,250 WASHINGTON STATE CO N.136.000 (METERS)

:1::::::1::

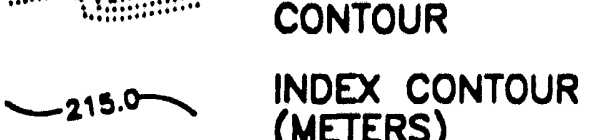

$\longrightarrow$ FENCE

$\longrightarrow *$ POST \& CHAIN FENCE

PERIMETER FENCE

ニニニニ DIRT ROAD
$\mathbb{N}$ BUILDINGS

\section{$=$ PAVED ROAD}

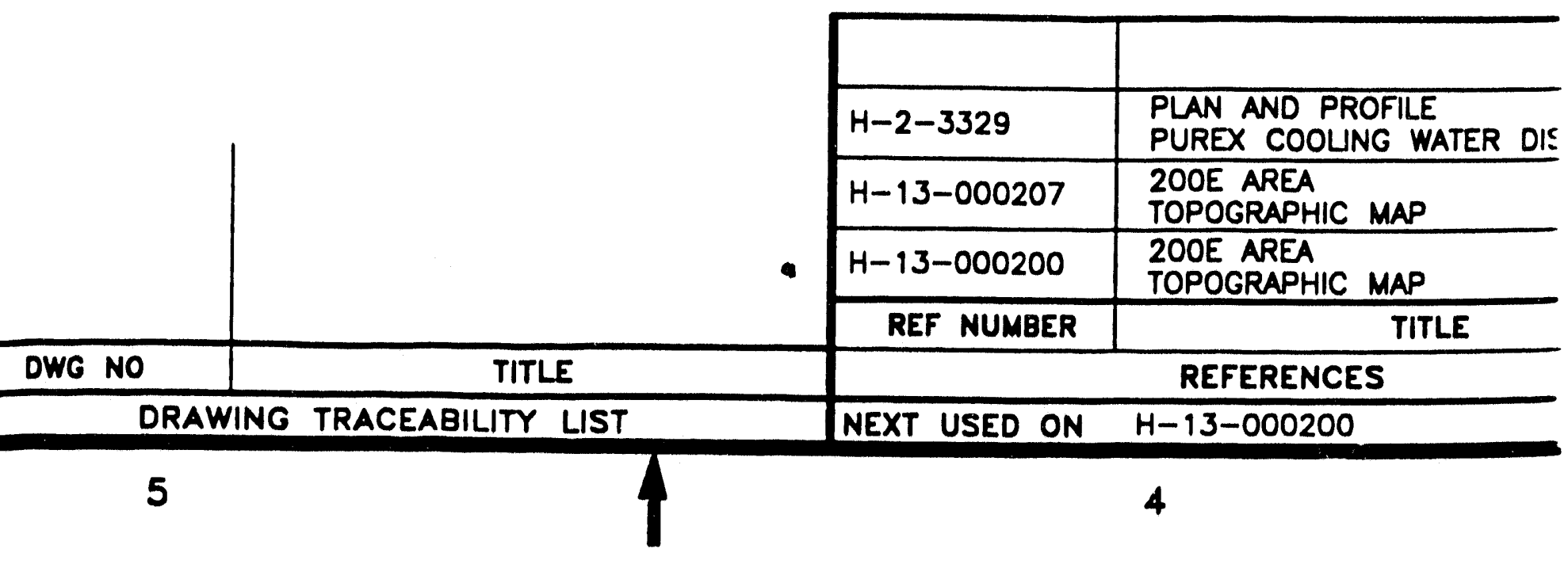




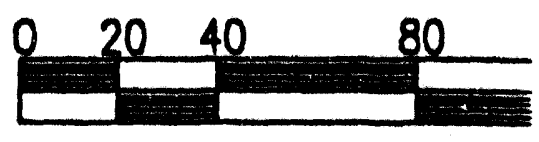

\section{LEGEND.}

HINGTON STATE COORDINATES PERS)

RMEDLATE

TOUR

$X$ CONTOUR

ERS)

:E

- \& CHAN FENCE

UETER FENCE

ROAD

D ROAD

IINGS
216-A-42 CRIB

218-E-10 BURIAL GROUND

242-A BUILING

2-E25-25 WELL

299-E25-25

$0^{S}$ SIGNS

OMH MANHOLE

口 CB CATCH BASIN

0 TREES

+ RALROAD

(24) STATE HIGHWAY

TANKS
$1 \mathrm{~cm}=2 \mathrm{C}$

PHOTO DATE:

CONTOUR INTERV

PROFILE

JOUNG WATER DISPOSAL

A

"HIC MAP

$A$

HIC MAP

TITLE

\section{NCES}

200

-

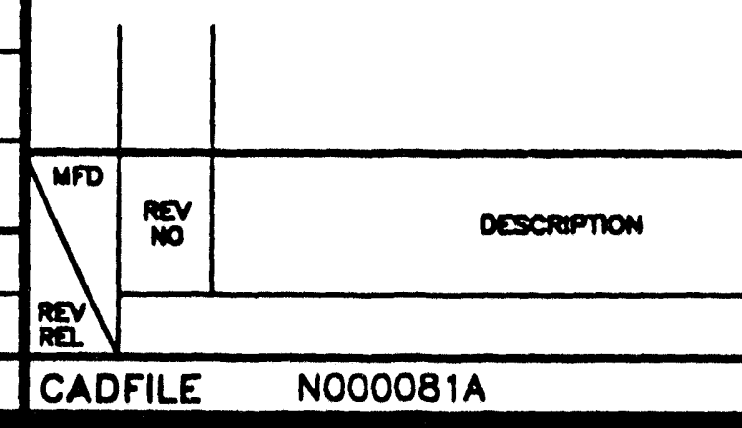

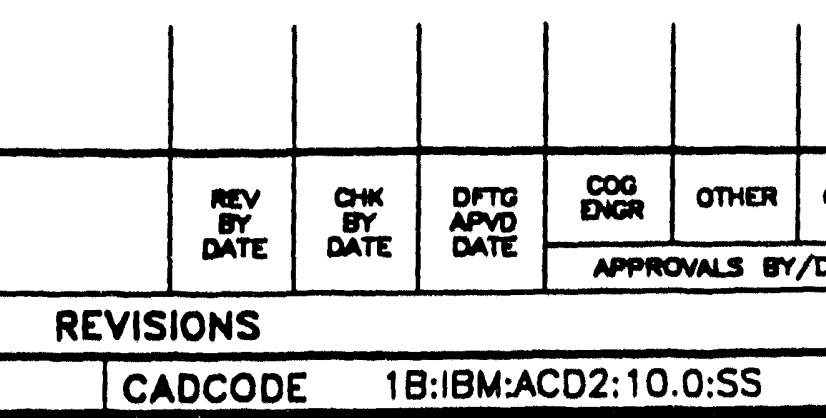


60 METERS

$J$ 
DOE/RL-93-03, Rev. 0

$08 / 31 / 93$

\author{
APPENDIX 3A \\ MASTE AMALYSIS PLAN
}

This plan will be provided in a future permit application revision. 
DOE/RL-93-03, Rev. 0

$08 / 31 / 93$

This page intentionally left blank. 


$$
\text { DOE/RL-93-03, Rev, } 0
$$

08/31/93

\author{
APPENDIX 4A \\ ENGINEERING DESIGN REPORT
}

This report will be provided in a future permit application revision. 
DOE/RL-93-03, Rev. 0

$08 / 31 / 93$

This page intentionally left blank. 
DOE/RL-93-03, Rev. 0

$08 / 31 / 93$

1
2
3
4
5
6
7
8
9

APPENDIX 4B

CERTIFICATION OF NEW TANK SYSTEN INTEGRITY 
DOE/RL-93-03, Rev. 0 $08 / 31 / 93$

This page intentionally left blank. 
DONALD B. MAUSSHARDT, P.E.

\section{PROFESSIONAL ENGINEER}

Mr. Ed Holton, Jr. P.E.

Project Manager

ADTECHS Corporation

2411 Dulles Comer Park, Suite 520

Herndon, VA 22071

\section{REF: K-ETF Project - RCRA Independent Review}

Dear Ed:

Attached is the completed RCRA Information Need Report covering the section 1.7.10.2 of the ETF Contract V-CO18HC1-001, Revision OE. We have noted that all of the design documents diagrams and calculations have already been submitted to Kaiser Engineers Hanford. Hence, we did not include them with this report other than by reference. This report covers only the design of the RCRA related equipment.

There are two issues that we note in our discussion with you and your staff. They are:

(1) Resolution of the LaQue Corrosion Report where there is a difference in the specifications of materials.

(2) The long-lead vendor supplied items are currently undergoing design by your vendors for the package units. We have attempted to address this issue with the Section 2.2 of our report.

The remaining points that were discussed with your staff appear to have been corrected prior to our completion of this review.

Our team is composed of Engineers in the disciplines of Civil, Chemical, Electrical/Mechanical Engineering. As the team leader, I supervised the effort. A completed application for the Washington Professional Engineers License is before the State Board for Registration pending approval. The granting of a formal license should occur shortly. In the interim, according to the State code in Washington, Section RCW 18.43.130, I can fulfill the Registration requirements as specified in the contrat-until the license is formall" granted.

Sincerely yours,

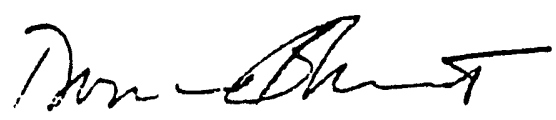

Donald B. Nausshardt. P.E.

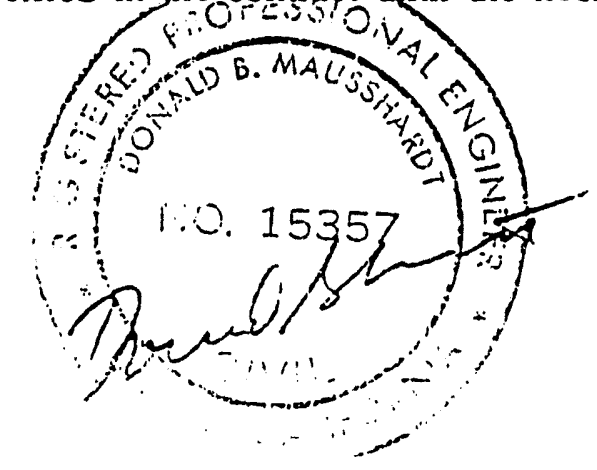


HANFORD EFFLUENT TREATMENT FACILITY(ETF)

PROJECT NUMBER C-018H

INDEPENDENT RCRA INFORMATION NEEDS REPORT

AND CERTIFICATION FOR DESIGN ONLY

prepared by

DONALD B. MAUSSHARDT

PROFESSIONAL ENGINEER

March 22, 1993

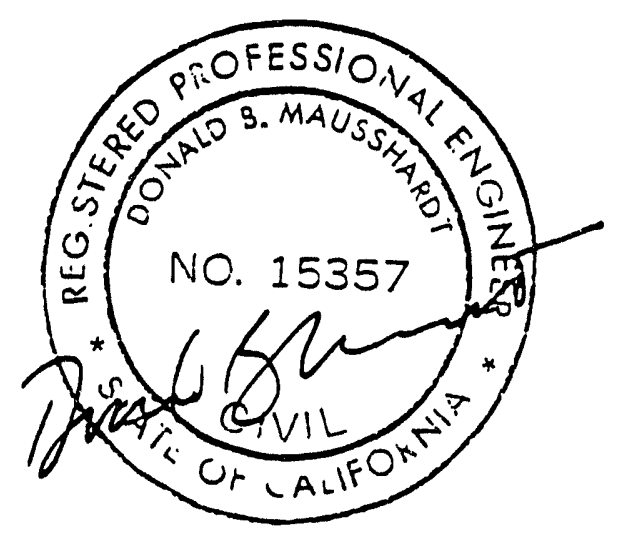




\title{
TABLE OF CONTENTS
}

\author{
1.0 \\ 1.1 \\ 1.2 \\ 1.3 \\ 2.0 \\ 2.1 \\ 2.2 \\ 3.0 \\ 3.1 \\ 3.2 \\ 4.0 \\ INTRODUCTION \\ SYSTEM DESCRIPTION \\ BASIC OPERATING PHILOSOPHY \\ APPROACH EMPLOYED TO CONDUCT THE ASSESSMENT \\ 5.0 \\ 5.1 \\ INFORMATION SHEETS ON VESSELS, TANKS AND \\ PACKAGE UNITS \\ INFORMATION SHEETS ON TANKS AND VESSELS \\ INFORMATION ON VENDOR SUPPLIED UNITS \\ STRUCTURAI INTEGRITY CERTIFICATION \& HAZARD \\ ASSESSMENT \\ REVIEW OF STRUCTURAL INTEGRITY \\ REVIEW OF HAZARD ASSESSMENT \\ SECONDARY CONTAINMENT \\ HANDLING PROCEDURES VERIFICATION \\ DISCREPANCIES CORRECTIVE PROCEDURES \\ 6.0 \\ TANKS AND ANCILLARY TIGHTNESS TESTING \\ 7.0 \\ DESCRIPTION OF LEAK DETECTION SYSTEMS \\ 7.1 \\ LEAK DETECTION-PRIMARY CONTAINMENT \\ LEAK DETECTION-SECONDARY CONTAINMENT \\ 8.0 \\ CERTIFICATION SECTION WAC 173-303-810 13A \\ 9.0 \\ APPENDIX
}




\section{RCRA INFORMATION NEEDS}

\subsection{Introduction}

\subsection{System Description}

The Effluent Treatment Facility (ETF) treats low-activity radioactive water containing small amounts of ammonia, inorganics, organics, and particulates. The waste water to be treated consists of the process condensate (PC) from the 242-A Evaporator, the process distillate discharge (PDD) and the ammonia scrubber distillate (ASD) from the PUREX plant, and waste water in the LERF basin which originates from the 242-A Evaporator PC.

The function of the ETF is to reduce those compounds to less than the level regulated by WHC-CM-7-5, and BAT requirements of the United States Department of Energy (DOE) Order 5400.5 and DOE Order 6430.1A.The ETF includes the following Main equipment, secondary equipment, and Support systems:

Main Treatment Train

Surge Tank

Rough Filter

UV Oxidation System

pH Adjustment Tank

H2O2 Decomposer

Fine Filter

Degasification System

Reverse Osmosis System

Polisher

Effluent pH Adjustment Tank

Verification Tank

Secondary Waste generated during treatment are treated with the following equipment

Secondary Waste Receiving Tank

Evaporator

Concentrate Tank

Thin Film Dryer

Drum Handling system

Resin Dewatering System

Supporting systems to the process units

Chemical Reagent Feed System

Sump Tank

Vessel off-Gas Treatment System

Utilities 
1.2 Basic Operating Philosophy

1.2.1 General

For safe ease of operation, the basic operating philosophy is:

(1) Operation process inputs/outputs will be monitored in the Central Control Room.

(2) Interlocking and sequential control will be provided.

(3) Important process parameters will be controlled and regulated on a continuous basis.

(4) Access to the control system will be classified and controlled for security.

\subsubsection{Locations for Operation control}

The control system will support operation control from three locations: Central Control Room, Local Control Unit(ICU), and Local Control Panel(LCP)

The central control room operation will be conducted via redundant CRT-based operation control system(OCS) consoles. In case of ocss failure, the essential operation of the process will be conducted via LCUs supported by displays. Under normal operation the LCUs can be used to assist the operators.

Operation via the LCPs will be performed during preoperation testing and startup and during annual equipment maintenance.

\subsection{Approach Employed to conduct the Assessment}

This report is organized along the lines of the operating contracts that JGC/ADTECHS hold on the ETF Project. Section 1.7.10.2 RCRA Information Needs is the guiding format for this report. Several of the sections have been responded to separately with the submission of the $100 \%$ design documents by ADTECHS. The design diagrams and design calculations have already been submitted to ICF-Kaiser Hanford.

The approach employed to conduct this assessment was to develop fact sheets on each of 33 tanks and/or vessels. In order to cover those long lead items being purchased as package units, we also prepared a summary sheet of the package items showing the specifications, design criteria and vendor-delivered calculations for each unit. Additionally, to ensure compliance with applicable codes and standards, a review of design codes and standards was performed to assure completeness and application to the unit. The supporting specification used in this review was s-1222-005.

The secondary Containment is covered in a separate section since the operation of the secondary systems encompass more than just individual tanks or vessels. 
Separate sections are also presented for Handling Procedures, Testing Procedures for Tightness, and a Description of the Leak Detection System.

The Professional Engineering certification is enclosed along with the structural certification by a Registered Professional Structural Engineer.

\subsubsection{Reference to codes and standards}

In our review of the applicable codes and standards, the following documents were used as the key for verification with the codes and standards referred to in the ETF contract. The primary document used was s-1136-001, Rev. 13. Document List, and s-1222-005 Applicable Codes and Standards. A check was performed on the procurement packages to ensure that the vendors were using the same codes and standards. A copy of the document list and codes and standards will appear in the appendix. 
2.0 Information Sheets on Tanks, Vessels and Package Units

This section contains an information fact sheet on each of the 33 tanks and/or vessels. The information is presented in summary form and covers those items identified in section 1.7.19.2.1 of the Contract Document V-CO18HC1-001, Rev. OE, Section 01010-53.

Also included for review is a tabular list of those long-lead items currently undergoing design. The information provided represents a status of the development of the vendor supplied package units.

Each tank and/or vessel has been numbered to assisting the review. The fact sheets presented were derived from ADTECHS files and vendor supplied documents all of which are on file at the ADTECHS Herndon Virginia office. 


\subsection{Tanks and Vessels}

\section{Name: $\quad \# 1$ surge Tank}

Equipment Number: 2025E-65A-TK-1

Purpose: Receiving/storing waste liquid, and pH adjustment to 6 for UV Oxidation system

Conditions: (1) Combined flow from four primary sources, viz. PDD, ASD, PC, and LERF

(2) Secondary streams from downstream process, viz. Polisher, evaporator, dryer, etc.

Construction material: Type 304 SS (UNS30400) and electropolished subsequently

Lining Materials: None

Tank Dimensions: $\quad 26^{\prime}$ ID $\times 30^{\prime}-1^{\prime \prime} \mathrm{H}$

Tank capacity: $\quad 100,000$ gallons

Shell thickness: $\quad 3 / 16^{\prime \prime}$

Pressure controls: $\quad$ Pressure Indicator

Foundation construction materials: Concrete ring beam plus concrete slab

Structural support: $\quad$ Saddle 304 sS, support sS

Seams :

Connections: $\quad$ Flanged

Corrosion protection: Type 304 sS is acceptable

Remarks: $\quad$ sloped bottom and installed inside secondary containment 
Name :

Purpose:

Conditions:

Construction Material:

Iining Materials:

Tank Dimensions:

Tank Capacity:

Shell thickness:

Pressure controls:

Foundation construction

structural support:

Seams :

Connections :

Corrosion protection:

Remarks :
\#2 pH Adjustment Tank

Equipment No. 2025E-60C-TK-1

To adjust and maintain the process stream $\mathrm{pH}$ to 4.0

(1) Inlet flow: 170-171 gpm

(2) To provide retention time more than 15 minutes

Type 304 SS and electropolished subsequently

none

10' ID $\times 8^{\prime}-2^{\prime \prime} \mathrm{H}$

2,600 gallons

$1 / 4^{\prime \prime}$

Pressure Indicator

Concrete slab

Saddle support-material 304 SS

\section{Flanged}

Type 304 ss is acceptable

Equipped with an eductor. 


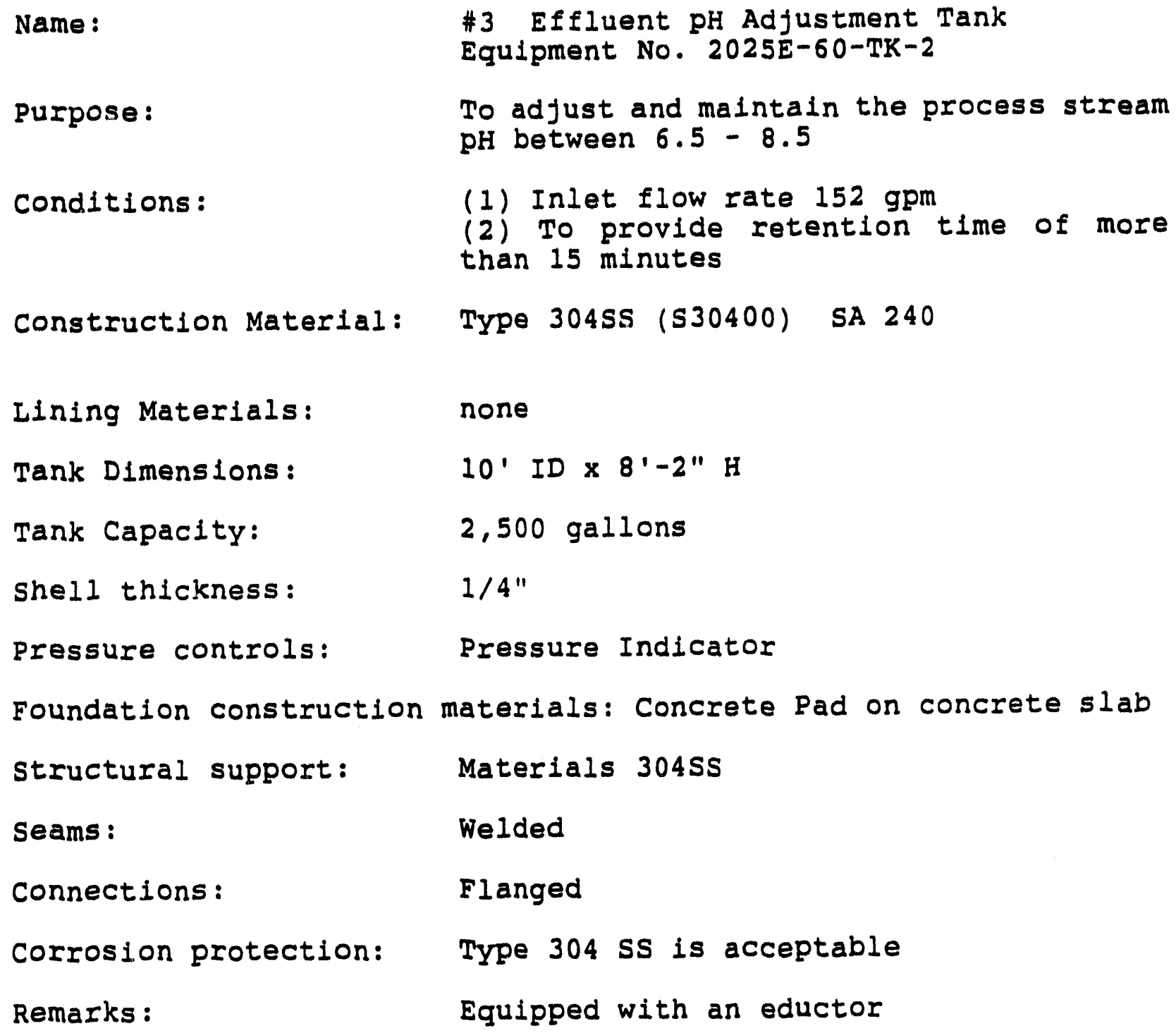


Name :

Purpose:

Conditions:

Construction Material:

Iining Materials:

Tank Dimensions:

Tank Capacity:

Shell thlckness:

Pressure controls:

Foundation construction

Structural support:

Seams :

Connections :

Corrosion protection:

Remarks :
\#4 1st Ro Feed Tank

Equipment No.: 2025E-60F-TK-1

Receiving waste from degasification

(1) Inlet flowrate: 169-171 gpm

(2) Recycle waste: $17 \mathrm{gpm}$

Type 304 sS (S30400) with internal surfaces to be electropolished.

none

10. ID $\times 10^{\prime}-7$ " H

4,000 gallons

$1 / 4 "$

Pressure Indicator

materials: concrete slab

Saddle-material CS, support material 304 SS

Welded

Flanged

Type 304 ss with electropolishing is acceptable

none 
Name :

Purpose:

Conditions :

Construction Material:
\#5 2nd Ro Feed Tank

Equipment No.: $2025 E-60 F-T K-2$

Receiving permeate from lst Ro Stage

Inlet flow rate $163 \mathrm{gpm}$

Type 304 ss $(530400)$ with internal surfaces to be electropolished

none

$10^{\prime} \mathrm{I} \times 5^{\prime} \mathrm{W} \times 5^{\prime} \mathrm{H}$

2,000 gallons

$3 / 16 "$ with Iib stiffeners

Pressure controls: Pressure Indicator

Foundation construction materials: skid on concrete slab

Structural support: $\quad$ Saddle material CS, support material 304 SS

Seams :

Connections :

Corrosion protection:

Remarks :
Welded

Flanged

Type 304 ss with electropolishing is acceptable

none 
Name :

Purpose:

Conditions :

Construction Material
\#6 Verification Tanks

Equipment No. 2025E-60H-TK-1A, 1B, 1C

To receive and hold treated effluent before discharge

(1) Minimum of 72 hours capacity

(2) Inlet flowrate: $152-154 \mathrm{gpm}$

Carbon steel (CS) plus epoxy

Epoxy

Tank Dimensions:

50' ID $\times 37^{\prime}-6^{\prime \prime} \mathrm{H}$ (each)

Tank Capacity:

670,000 gallons (each)

Shell thickness:

$5 / 16^{\prime \prime}$

Pressure controls:

Pressure Indicator

Foundation construction materials: Concrete slab with 4" compacted sand fill base

Structural support:

Seams :

Connections:

Corrosion protection:

Remarks :
Concrete ring beam

Welded

Flanged

LaQue Corrosion Report recommends cathodic protection as a complementary corrosion control technique. As a alternate, select type 316 stainless steel is recommended.

(1) Sloped bottom and installed inside secondary containment outside building (2) Equipped with an electric heater. (3) One system will be undergoing compliance testing, one system will be discharging, and one system ill be filling at any point in time. 
Name :

Purpose:

Conditions :

Construction Material:

Iining Materials:

Tank Dimensions:

Tank Capacity:

shell thickness:

Pressure controls:

Foundation construction materials: Concrete slab

Structural support:

Seams :

Connections :

Corrosion protection:

Remarks :

Welded

Flanged S31603

Mat foundation

Equipped with an eductor
\#7 Concentrate Tanks

Equipment No. 2025E-60J-TK- 1A, 1B

Receiving evaporator concentrate

(1) Evaporator concentrate: $0.41-1.14 \mathrm{gpm}$

(2) Evaporator hold-up: 2,500 gallons

(3) To provide some additional capacity to be able to dilute the waste.

Type 316 sS (S31603) and subsequently electropolished.

None

10' ID $\times 12^{\prime}-6^{\prime \prime} \mathrm{H}$ (each)

5,000 gallons (each)

$1 / 4 "$

Pressure Indicator

LaQue Corrosion Report recommends $\mathrm{Ni}-\mathrm{Cr}-\mathrm{MO}$ Alloy(e.g. N06625, N10276) in lieu of 
Name: $\quad$ \#8 $92 \%$ Sulfuric Acid Storage Tank

Equipment Number: 2025E-65C-TK-1

Purpose :

store 92 Weight Percent Sulfuric Acid

Conditions :

(1) Average flowrate to surge tank: $0.42 \mathrm{gpm}$

(2) Regenerant of polisher: 1,075 gal/batch

( 4 wt o $\mathrm{H} 2 \mathrm{SO} 4$ )

Construction materials: Carbon steel plus Epoxy

Lining Materials: Epoxy

Tank Capacity: $\quad 7,500$ gallon

Tank Dimensions: $\quad 10^{\prime}-4^{\prime \prime}$ ID $\times 16^{\prime-4}$ I $^{\mathrm{H}}$

Shell thickness: $\quad 3 / 8^{\prime \prime}$

Pressure controls:

Foundation construction materials: Concrete slab

Structural support: Saddle-material CS, Support-material CS

Seams : $\quad$ Welded

Connections: $\quad$ Flanged

Corrosion protection: Laque Corrosion Report recommends Type 316 sS (S13603) material in lieu of CS

Remarks :

(1) Install out-door

(2) Equipped with heat trace 
Name :

Purpose:

Conditions :
\#9 $5 \% \mathrm{NaOH}$ Solution Tank

Equipment No. 2025E-65C-TK-4

Dilute the $\mathrm{NaOH}$ from $50 \%$ to $5 \%$

(1) Feed rate to secondary waste tank: 0.003-0.09 gpm

(2) Regenerant for polisher: 862 gal/batch ( 4 w 8 )

Construction Material: FRP

Lining Materials:

None

Tank Dimensions:

$6^{\prime}$ ID $\times 6^{\prime}-10^{\prime \prime} \mathrm{H}$

Tank Capacity:

800 gallons

Shell thickness:

$1 / 4 "$

Pressure controls:

Foundation construction materials: Concrete slab plus skid mounted

Structural support:

Support-material CS

Seams :

Connections:

Flanged

Corrosion protection:

Laque Corrosion Report recommends Type 304 SS in lieu of FRP

Remarks :

Equipped with an eductor 
Name :

Purpose:

Conditions :
\#10 48 H2SO 4 Solution Tank

Equipment No. 2025E-65C-TK-3

Dilute the H2SO4 from $92 \%$ to $4 \%$

Regenerant for polisher (4 wt of H2SO4) 1075 gallons/batch

FRP

None

$5^{\prime}-6^{\prime \prime}$ ID $\times 6^{\prime}-3^{\prime \prime} H$

600 gallons

$1 / 4 "$

Shell thickness:

Pressure controls:

Foundation construction materials: Skid on concrete

Structural support: Support-material CS

Seams :

Connections :

Flanged

Corrosion protection:

FRP is acceptable

Remarks :

Equipped with an eductor 


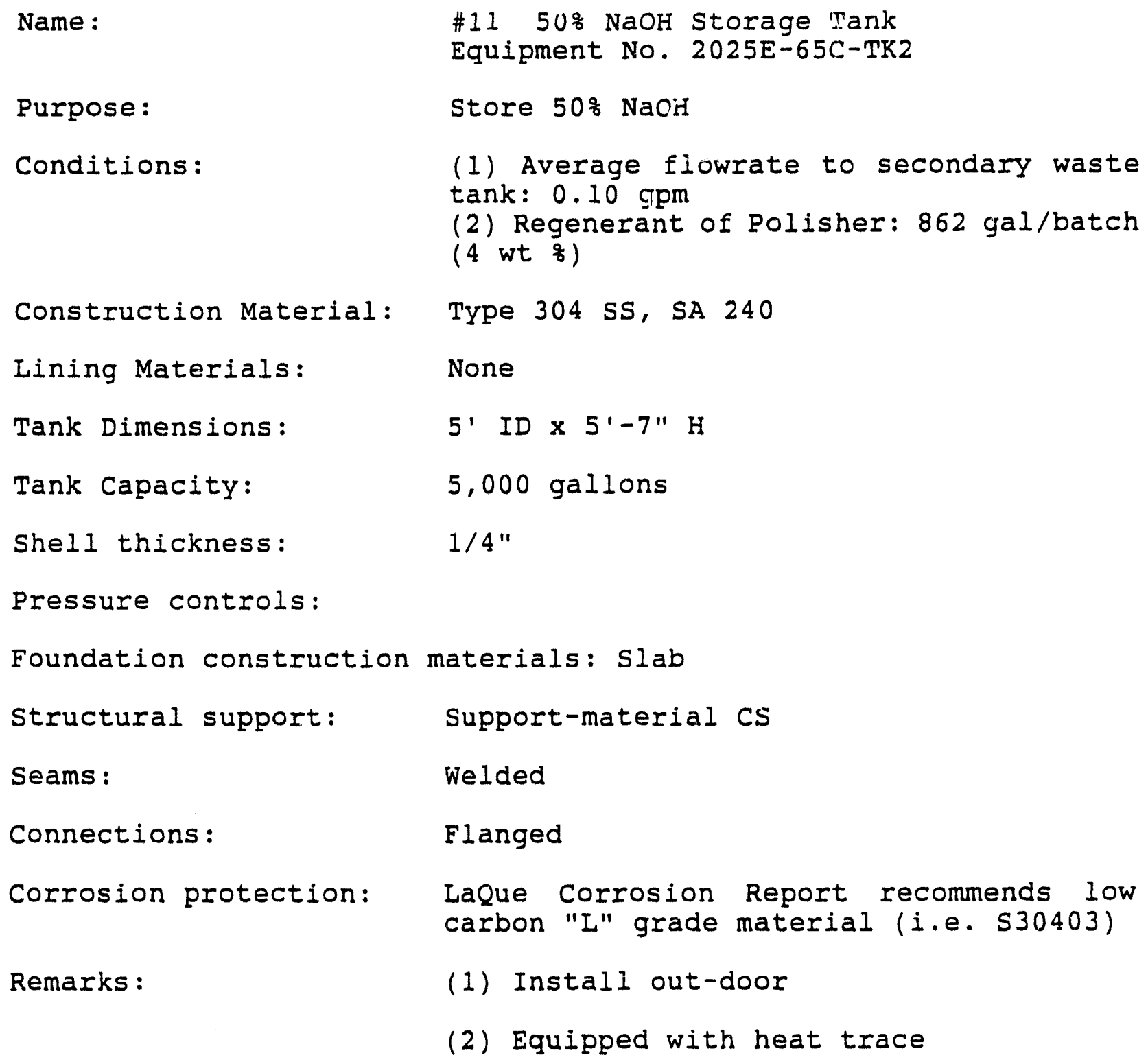


Name :

Purpose :

Conditions :

Lining Materials:

Tank Dimensions:

Tank Capacity:

Shell thickness:

Pressure controls:

Foundation construction materials: Mat foundation concrete

\#12 Secondary Waste-Receiving Tanks

Equipment No. 2025E-65I-TK-1A, 1B

(1) To receive waste from filter backwash, RO condensate, and resin generator.

(2) To adjust pH to around 6 .

(1) Receive polisher regeneration waste, $2540 \mathrm{gal} / \mathrm{regeneration.}$

(2) Filter backwash, 185 gal/backwash continuous inlet flow, Ro concentrate $16.9 \mathrm{gpm}$

Construction Material: Type Ss304 (S30400)

None

14' ID $\times 18^{\prime}-7^{\prime \prime} \mathrm{H}$

15,000 gallons

$1 / 4 "$

Pressure Indicator

Structural support:

Seams :

Connections:

Corrosion protection:

Remarks :
Welded

Flanged

Laque Corrosion Report recommends a $6 \%$ Mo- containing austenitic stainless Steel (e.g. S31254, N08367)

Equipped with a eductor 
Name :

Purpose :

Conditions:

Construction Material: Type 304 SS (S30400)

Lining Materials:

Tank Dimensions:

Tank Capacity:

Shell thickness:

Pressure controls:

Foundation construction

Structural support:

Seams :

Connections :

Corrosion protection:

Remarks :
\#13 Rough Filter

Equipment No. 2025E-60E-FL-1

Rough removal of susperided solids

Fed by stream no. 8 from the surge tank. This stream is characterized by low $\mathrm{Cl}$ $(<2 \mathrm{ppm})$ and moderate TDS levels of 2000 ppm.

None

$\mathrm{N} / \mathrm{A}$

$\mathrm{N} / \mathrm{A}$

$\mathrm{N} / \mathrm{A}$

Pressure Indicator

materials: steel platform tied to concrete slab

Fabricated from angle

Welded

150 1b. R.F. ANSI flanged

Laque Corrosion Report recommended Type 316L Stainless steel

None 
Name :

Purpose:

Conditions:
\#14 UV Oxidizer

Equipment No. 2025E-60D-UV-1A, 1B\&2A, 2B

Decomposition of organic materials into $\mathrm{H} 2 \mathrm{O}$ and $\mathrm{CO} 2$

Feed to the units is the cooled effluent from the rough filter. It is treated with a solution of $508 \mathrm{H} 202$ (stream no. $11, \mathrm{pH} 6$, temperature $100 \mathrm{~F}$ ) yielding a product containing $<200 \mathrm{ppm} \mathrm{H} 2 \mathrm{O}$ and a pH of 4, which is then conveyed to the pi: Adjustment Tank.

Construction Material: Type 316 SS

Lining Materials:

None

Tank Dimensions:

$3^{\prime}$ dia $\times 8^{\prime}$ side $w / F \& D$ Heads

Tank Capacity:

1200 lbs

Shell thickness:

$1 / 4 "$

Pressure controls: N/A

Foundation construction materials: Concrete floor

Structural support: Carbon steel and epoxy painted

Seams: $\quad$ Welded

Connections: $\quad$ Flanged- Threaded

Corrosion protection: Type 316 SS is acceptable

Remarks: none 


\begin{tabular}{|c|c|}
\hline Name: & $\begin{array}{l}\text { \#15 H2O2 Feed Tank } \\
\text { Equipment No. 2025E-60D-TK-1 }\end{array}$ \\
\hline Purpose: & Holds $50 \%$ H2O2 solution \\
\hline Conditions: & Atmospheric \\
\hline Construction Material: & High density polyethylene (PE) \\
\hline Lining Matelials: & None \\
\hline Tark Dimensions: & ? ? ? ? ? ? ? \\
\hline Tank Capacity: & 2,500 gallons \\
\hline Shell thickness: & Molded \\
\hline Pressure controls: & None \\
\hline Foundation construction & $\begin{array}{l}\text { materials: Vendor supplied on skid tied to } \\
\text { concrete floor }\end{array}$ \\
\hline structural support: & skid \\
\hline Seams : & $1 \mathrm{pc}$ \\
\hline Connections : & Quick disconnect \& socket-threads \\
\hline $\begin{array}{l}\text { Corrosion protection: } \\
\text { Remarks: }\end{array}$ & $\begin{array}{l}\text { High Density PE is acceptable } \\
\text { None }\end{array}$ \\
\hline
\end{tabular}


Name :

Purpose:

Conditions:

Construction Material:

Lining Materials:

Tank Dimensions:

Tank Capacity:

Shell thickness:

Pressure controls:

Foundation construction materials: Skid on slab

structural support:

Seams :

Connections :

Corrosion protection:

Remarks :
TBD

\#16 H2O2 Decomposer

Equipment No. 2025E-60D-CO1A, \& CO1B

Decomposition of residual $\mathrm{H} 202$ injected by the UV oxidation system

Feed by stream no.13 from the $\mathrm{pH}$ Adjustment Tank, which is low in halides ( $<2 \mathrm{ppm})$, of moderate TDS $(<3000$ ppm) and a pH of 4 . Discharges is identical to the input except $\mathrm{H} 202$, which is reduced from $<200$ pom to $<5$ ppm.

Carbon steel with epoxy coating

Epoxy coating

$\mathrm{N} / \mathrm{A}$

2500 gallons

TBD

Pressure relief valve

Welded

Flanged

LaQue Corrosion Report recommended 530403 or higher alloy material.

none 
Name :

Purpose:

Conditions :

Construction Material:

Lining Materials:

Tank Dimensions:

Tank Capacity:

Shell thickness:

Pressure controls:
\#17 Fine Filter

Equipment No. 2025E-60B-FL-2

Final removal of suspended solids

Receives process stream no. 14, the effluent of the $\mathrm{H} 2 \mathrm{O} 2$ decomposer. Stream no. 14 has a TDS level ranging from 1650 ppm to $2800 \mathrm{ppm}$, a chloride level of $<2$ ppm and a pH of 4

Type 304 SS (S30400)

None

N/A

$\mathrm{N} / \mathrm{A}$

$3 / 16^{\prime \prime}$

ASME safety relief valve

Foundation construction materials: on steel platform

Structural support: Fabricated from angle

Seams :

Welded

Connections:

150 1b. R.F. ANSI flanged

Corrosion protection:

LaQue Corrosion report recommended using Type 316L SS

Remarks :

none 
Name :

Purpose:

Conditions:
\#18 Degasification Column Inlet Cooler Equipment No. 2025E-60E-E-1

Removal of dissolved carbonate to reduce the load on reverse osmosis system and polisher

Used to cool stream no. 14 from $140 \mathrm{~F}$ to $86 \mathrm{~F}$ after it passes through the fine filter

Construction Material: Type 316 SS (S31600)

Lining Materials: None

Tank Dimensions: N/A

Tank Capacity: N/A

Shell thickness: 1 "

Pressure controls:

Foundation construction materials: Slab

Structural support:

Seams :

Welded

Connections:

Tack welded

Corrosion protection:

LaQue Corrosion Report recommends a $6 \%$ Mo-containing austenitic Stainless steel (e.g. S31254, N08367)

Remarks : 
Name :

Purpose:

Conditions :
\#19 Degasification Column (Induced Draft) Equipment No. 2025E-60E-COl

Removal of dissolved carbonate to reduce the load on the RO and polisher

Receives stream no.15 which is the same as the outlet of the H2O2 decomposer, but cooled to $86 \mathrm{~F}$. Stripping reduces the $\mathrm{H} 2 \mathrm{O} 2$ level to $<5 \mathrm{ppm}$. The $\mathrm{CO}_{2} / \mathrm{CO}^{-}$and TDS are further lowered.

Construction Material: FRP

Lining Materials:

None

Tank Dimensions:

$\mathrm{N} / \mathrm{A}$

Tank Capacity:

N/A

Shell thickness:

Not developed as of this date

Pressure controls:

Foundation construction materials: Skid mounted by vendor

Structural support:

Seams :

Resin and overlap

Connections :

Corrosion protection: Laque Corrosion Report recommended Type $316 L$ SS as preferable.

Remarks :

None 
Name :

Purpose:

Corditions :

Construction Material:

Lining Materials:

Tank Dimensions:

Tank Capacity:

Shell thickness:

Pressure controls:

Foundation construction materials: Skid mounted on concrete floor Structural support:

Seams :

Connections:

Corrosion protection: Epoxy-coated carbon steel is acceptable Remarks : none
\#20 Polisher

Equipment No. 2025E-60G-1X-1X,-1B,-1C

Polishing of the waste water

Receives waste stream no. 17 from the Ro units. The waste stream is very low in TDS(15-32 ppm) with very low chloride present $(<0.02 \mathrm{ppm})$. $\mathrm{pH}$ is 6.0. Stream temperature is <110F. The polisher uses the $48 \mathrm{H} 2 \mathrm{SO} 4$ as a regenerant for cations and $4 \% \mathrm{NaOH}$ as a regenerant for anions.

Carbon Steel with Epoxy coating

Epoxy coating

$\mathrm{N} / \mathrm{A}$

$\mathrm{N} / \mathrm{A}$

$1 / 4^{\prime \prime}$ 
Name :

Purpose:

Conditions :

Construction Material:

Iining Materials:

Tank Dimensions:

Tank Capacity:

Shell thickness:

Pressure controls:
\#21 Feed/Distillate Heat Exchanger Equipment No. 2025E-60I-E-02

Pre-heat the inlet stream no. 30 feed from the secondary waste-receiving tanks to the evaporator and cool the distillate(leading to stream no. 36) from the distillate tank in the evaporator system.

Stream no. 30 has range of $8-17 \mathrm{ppm} \mathrm{Cl}$, $\mathrm{pH}$ of 6 , Temperature of $86 \mathrm{~F}$, and a TDS range of 10,000 to $25,000 \mathrm{ppm}$.

Type 316L SS (31603)

None

$\mathrm{N} / \mathrm{A}$

$\mathrm{N} / \mathrm{A}$

0.049 " wall tubing

$2 "$ schedule 103 shell

PRV-133, PRV-131

Foundation construction materials: skid mounted

Structural support:

Seams :

Connections :

Corrosion protection:

Remarks :
Welded

Flanged

S31603 is azceptable

none 
Name :

Purpose:

Conditions :

Construction Material:

Lining Materials:

Tank Dimensions:

Tank Capacity:

Shell thickness:

Pressure controls:
\#22 Vapor Compressor Inlet Silencer Equipment No. 2025E-60I-C-01A

Reduce pulsations of low pressure steam entering the vapor compressor.

$230 \mathrm{~F}, 15 \mathrm{psia}$

Type 316 I SS $(30400)$

N/A

N/A

N/A

$1 / 4 "$ (still in design by vendor)

PRV-168, PRV-203

Foundation construction materials: Concrete floor

Structural support:

Seams :

Welded

Connections :

Flanged

Corrosion protection:

LaQue Corrosion Report recommended a $6 \%$ Mo-containing austenitic stainless steel (e.g. S31254, N08367)

Remarks :

none 
Name :

Purpose :

Conditions :

Construction Material:

Lining Materials:

Tank Dimensions:

Tank Capacity:

Shell thickness:

Pressure controls:
\#23 Vapor Compressor Outlet Silencer Equipment No. 2025E-60I-C-01B

Reduces the pulsations of low pressure steam

230F, 75 psia

Type 304 sS $(30400)$

None

N/A

N/A

$1 / 4 "$ (Still in design by vendor)

PRV 168, PRV 203

Foundation construction materials: Floor mat on concrete slab

Structural support:

Seams :

Connections:

Corrosion protection:

Remarks :
Welded

Flanged

Laque Corrosion Report recommended a $6 z$ Mo-containing austenitic stainless steel (e.g. S31254, N08367)

none 
Name :

Purpose :

Conditions:

Construction Material:

Lining Materials:

Tank Dimensions:

Tank Capacity:

Shell thickness:

Pressure crntrols:
\#24 Evaporator Heater

Equipment No. 2025E-60I-E-0I

Heats evaporator feed

$230 \mathrm{~F}, 75 \mathrm{psia}$

Alloy 625 (N06625, yubes) and electropolished Type 304 stainless steel (s30400, shell)

N/A

$\mathrm{N} / \mathrm{A}$

$\mathrm{N} / \mathrm{A}$

$3 / 16^{\prime \prime}$

PRV -168

Foundation construction materials: Skid mounted

Structural support:

Seams :

Connections :

Corrosion protection:

Remarks :
Welded

Flanged

Laque Corrosion Report recommends $\mathrm{Ni}-\mathrm{Cr}-$ Mo alloy(N06625 for the shell-side of the heater.

none 
Name :

Purpose:

Conditions:

Construction Material:

Lining Materials:

Tank Dimensions:

Tank Capacity:

shell thickness:

Pressure controls:

Foundation construction materials: Skid mounted

Structural support:

Seams :

Connections :

Corrosion protection:

Remarks :
\#25 Entrainment Separator

Equipment No. 2025E-60I-DE-01

Vapor from the evaporator passes through the entrainment separator before entering the vapor compressor. This unit removes carryover in the vapor(from the evaporator)

$230 \mathrm{~F}, 15 \mathrm{psia}$

Type 316I SS, electropolished internally after fabrication

None

$\mathrm{N} / \mathrm{A}$

$\mathrm{N} / \mathrm{A}$

$3 / 10 "$

PRV - 168 
Name :

Purpose:

Conditions :

Construction Material:

Ining Materials:

Tank Dimensions:

Tank Capacity:

shell thick:.ess:

Pressure controls:

Foundation construction materials: Skid mounted

Structural support:

Seams :

Connections :

Corrosion protection:

Remarks :
\#26 Anti-Foam Tank

Equipment No. 2025E-60I-TK-04

Prevents foaming inside vapor body

Ambient temperature

High density polyethylene(PE)

None

50 gallons

$1 / 8^{\prime \prime}$

Atmospheric

none

Flanged

High density PE is acceptable

none 
Name :

Purpose:

Conditions:
\#27 Thin-Film Dryer

Equipment No. 2025E-60J-D-01

Produces dry powder waste

Primary feed to the dryer is stream no. 33 from the concentrate tanks. This is a $\mathrm{pH} 4$ liquid of high TDS (<400,000 ppm). The dryer is heated by the $370 \mathrm{~F}$ steam from the boiler. Products from the dryer include a distillate and a powaer waste.

\section{Construction Material: Alloy 625 (N06625)}

Lining Materials: None

Tank Dimensions: N/A

Tank Capacity: N/A

Shell thickness: $\quad \mathrm{N} / \mathrm{A}$

Pressure controls: none

Foundation construction materials: skid mounted

Structural support:

Seams :

Welded

Connections:

Welded

Corrosion protection:

Laque Corrosion Report recommends a $\mathrm{Ni}-\mathrm{Cr}-$ Mo alloy, such as N10276(or similar)

Remarks :

None 
Name :

Purpose:

Conditions :

Construction Material:

Iining Materials:

rank Dimensions:

Tank Capacity:

shell thickness:

Pressure controls:

Foundation construction materials: Skid mounted

structural support:

Seams :

Connections :

Corrosion protection:
\#28 Spray Condenser

Equipment No. 2025E-6OJ-DE-01

Condenses water vapor from the thin film dryer.

0.8 GPM, $210 F$

Type 316L SS (S31603).

None

$\mathrm{N} / \mathrm{A}$

N/A

$3 / 16^{\prime \prime}$ (note design not complete) (specified to ASME Code)

Automatic control plug valve
Welded

Welded

LaQue Corrosion Report recommends a $6 \%$ Mo-containing austenitic SS(e.g. S31254, N08367) or a Ni-Cr-Mo alloy (e.g. NO6625, N10276).

Remarks : 

Name: $\quad$ \#29 Sump Tank
Equipment No. 2025E-20B-TK-1, -2
Purpose: Receiving liquid waste from tanks/equipment prior to sending it to the main treatment train.
Conditions: $\quad$ Receiving waste water irregulary

Construction Material: Type ss304 and subsequently electropolished SA240

Iining Materials: None

Tank Dimensions: $\quad 60 " \mathrm{~L} \times 60 " \mathrm{~W} \times 94 " \mathrm{H}$

Tank Capacity: $\quad 800$ gallons

shell thickness:

Pressure controls:

Foundation construction materials: In ground concrete slab and wall

Structural support: Reinforced concrete

Steams : $\quad$ Welded

Connections: $\quad$ Flanged

Corrosion protection: Laque Corrosion Report recommends a $6 \%$ Mo-containing austenitic stainless steel (e.g. S31254, N08367).

Remarks : None 
Name :

Purpose:

Conditions:

Construction Material:

Lining Materials:

Tank Dimensions:

Tank Capacity:
\#30 Distillate Condenser Equipment No. 2025E-60J-CND-1

Cools the spray condenser water which is used to condense dryer water vapor.

250F, atmospheric.

Type $304 \mathrm{sS}$

None

$\mathrm{N} / \mathrm{A}$

$\mathrm{N} / \mathrm{A}$

Shell thickness:

Pressure controls:

Foundation construction materials: skid mounted on concrete slab Structural support:

Seams :

Connections:

Corrosion protection: Type 304 SS is acceptable Remarks : none 
Name :

Purpose:

Conditions:

Construction Material:

Lining Materials:

Tank Dimensions:

Tank Capacity:

Shell thickness:

Pressure controls:

Foundation construction

Structural support:

Seams :

Connections :

Corrosion protection:

Remarks :
\#31 Powder Hopper

Equipment No, 2025E-60J-H-1

Collects radioactive particulate and feeds it into collection drums.

Ambiant conditions

Type $304 \mathrm{SS}$

None

$3 / 16 "$ design not complete Per ASME Code

Stream control valve, auto, plug. 
Name :

\#32 UV Inlet Cooler(Plate Frame Heat Exchanger)

Equipment No. 2025E-60B-E-1

Purpose:

Cools process water entering the UV oxidizer.

Conditions: $\quad 140 \mathrm{~F}, 150 \mathrm{psia}$

Construction Material: Type 316L SS

Lining Materials:

Tank Dimensions: N/A

Tank Capacity: N/A

Shell thickness:

Pressure controls:

Foundation construction materials: On metal frame scaffolding Structural support:

Seams :

Connections :

Corrosion protection:

Remarks :
Welded

Tack welded and pressed

Not covered in Laque Corrosion Report none 


$\begin{array}{ll}\text { Name: } & \begin{array}{l}\# 33 \text { Vent Cooler } \\ \text { Equipment No. 2025E-60J-E-01 }\end{array} \\ \text { Purpose: } & \begin{array}{l}\text { Cools the air coming off the spray } \\ \text { Condenser to remove liquid water. }\end{array} \\ \text { Conditions: } & 250 \mathrm{~F}, \text { atmospheric } \\ \text { Construction Material: } & \begin{array}{l}\text { Carbon steel(H-2-89924) \& Stainless } \\ \text { Steel(H-2-88989) }\end{array} \\ \text { Lining Materials: } & \text { None } \\ \text { Tank Dimensions: } & \text { N/A } \\ \text { Tank Capacity: } & \text { N/A } \\ \text { Shell thickness: } & \text { Am Std SSCF } 05024,0.065 " \text { thick } \\ \text { Pressure controls: } & \text { none }\end{array}$

Foundation construction materials: Skid mounted

Structural support:

Seams :

Welded

Connections :

Welded

Corrosion protection:

CS and SS are acceptable

Remarks :

none 


\subsection{Vendor Supplied Units}

For each of the long-lead vendor supplied units for the ETF facility, the units listed below are the long lead package units that are to be supplied by vendors. Condition were imposed upon the suppliers for material and structural integrity analysis. Secondly the materials specified appear to be compatible to the waste materials to be treated in the operable units..

$$
\begin{aligned}
& \text { List of procured units (package treatment) } \\
& \text { Main System } \\
& \text { Rough Filters } \\
& \text { UV Oxidation \& H2O2 Decomposer } \\
& \text { pH Adjustment Tanks } \\
& \text { Degasification System } \\
& \text { Reverse Osmosis System } \\
& \text { Polishers } \\
& \text { Secondary System } \\
& \text { Evaporator System } \\
& \text { Dryer System } \\
& \text { Drum Handling System } \\
& \text { Resin Dewatering System }
\end{aligned}
$$

Each of the procurement packages were reviewed to verify that the design conditions were included as a part of the procurement. While several of the packaged units have been recently procured, presented in the attached table are the referenced specification used with each package unit. Where the vendors have provided information on the design or calculations we have so noted. It is also noted that much of the equipment is "off the shelf" and has been qualified via other applications in similar environments. The attached table summarizes the review of the package units. 
INFORMATION SHEETS ON PACKAGE UNITS

\begin{tabular}{|c|l|l|l|l|l|l||}
\hline Unit & Vendor Name & $\begin{array}{l}\text { Specification } \\
\text { Reference }\end{array}$ & $\begin{array}{l}\text { Rev } \\
\text { Complete }\end{array}$ & $\begin{array}{l}\text { Vendor } \\
\text { Design }\end{array}$ & $\begin{array}{l}\text { Provided } \\
\text { Drawings }\end{array}$ & $\begin{array}{l}\text { Vendor } \\
\text { Design } \\
\text { Calc. }\end{array}$ \\
\hline ROUGH FILTERS & Pall Power Generation & R-135A-001 & 3 & & V-135A-001-301 & \\
\hline & & S-1131-004 & 0 & & V-135A-001-302 & \\
\hline & & S-1222-003 & 0 & & V-135A-001-303 & \\
\hline & & S-1222-006 & 2 & & V-135A-001-304 & \\
\hline & & S-1222-007 & 1 & & V-135A-001-305 & \\
\hline & & S-135A-001 & 1 & & & \\
\hline & & S-1370-101 & 0 & & & \\
\hline & & S-1380-101 & 2 & & & \\
\hline & & S-1510-003 & 2 & & & \\
\hline & & S-1510-006 & 3 & & & \\
\hline & & S-1510-007 & 2 & & & \\
\hline & & S-SECT 01650 & OD & & & \\
\hline & & S-SECT 01730 & OB & & & \\
\hline & & S-SECT 05120 & OE & & & \\
\hline & & S-SECT 09805 & OE & & & \\
\hline & & S-SECT 13440 & CE & & & \\
\hline & & S-SECT 15491 & OE & & & \\
\hline & & S-SECT 15493 & OE & & & \\
\hline & & & & & & \\
\hline & & & & & &
\end{tabular}


PAGE 2

\begin{tabular}{|l|l|l|l|l|l|l|}
\hline \multicolumn{1}{|c|}{ Unit } & Vendor Name & $\begin{array}{l}\text { Specification } \\
\text { Reference }\end{array}$ & $\begin{array}{l}\text { Rev } \\
\text { Complete }\end{array}$ & $\begin{array}{l}\text { Vendor } \\
\text { Design }\end{array}$ & $\begin{array}{l}\text { Provided } \\
\text { Drawings }\end{array}$ & $\begin{array}{l}\text { Vendor } \\
\text { Design } \\
\text { Calc. }\end{array}$ \\
\hline $\begin{array}{l}\text { UV OXIDATION \& } \\
\text { H202 DECOMPOSER }\end{array}$ & $\begin{array}{l}\text { Peroxidation Systems, } \\
\text { Inc. }\end{array}$ & R-135A-002 & 1 & & V-135A-002-300 & \\
\hline & & S-1131-004 & 0 & & V-135A-002-302 & \\
\hline & & S-1222-003 & 0 & & V-135A-002-307 & \\
\hline & & S-1222-006 & 1 & & V-135A-002-340 & \\
\hline & & S-1222-007 & 1 & & V-135A-002-341 & \\
\hline & & S-135A-002 & 0 & & & \\
\hline & & S-1370-101 & 1 & & & \\
\hline & & S-1380-101 & 1 & & & \\
\hline & & S-1510-003 & 0 & & & \\
\hline & & S-1510-005 & 1 & & & \\
\hline & & S-1510-007 & 1 & & & \\
\hline & & S-SECT 01650 & 1 & & & \\
\hline & & S-SECT 01730 & 1 & & & \\
\hline & & S-SECT 05120 & 1 & & & \\
\hline & & S-SECT 09805 & 1 & & & \\
\hline & & S-SECT 13440 & 1 & & & \\
\hline & & S-SECT 15491 & 1 & & & \\
\hline & & S-SECT 15493 & 1 & & & \\
\hline & & S-SECT 15493 & OE & & & \\
\hline & & & & & & \\
\hline
\end{tabular}


PAGE 3

\begin{tabular}{|c|c|c|c|c|c|c|}
\hline Unit & Vendor Name & $\begin{array}{l}\text { Specification } \\
\text { Reference }\end{array}$ & $\begin{array}{l}\text { Rev. } \\
\text { Completc }\end{array}$ & $\begin{array}{l}\text { Vendor } \\
\text { Design }\end{array}$ & $\begin{array}{l}\text { Provided } \\
\text { Drawings }\end{array}$ & $\begin{array}{l}\text { Vendor } \\
\text { Design } \\
\text { Calc. }\end{array}$ \\
\hline \multirow{14}{*}{$\begin{array}{l}\text { ph } \\
\text { ADJUSTMENTS } \\
\text { TANKS } \\
\end{array}$} & Clawson tank Co. & R-1354-001 & 1 & & V-1354-001-301 & \\
\hline & & R-135A-005 & 3 & & V-1354-001-302 & \\
\hline & & S-1131-004 & 0 & & V-1354-001-303 & \\
\hline & & S-1222-003 & 1 & & V-1354-001-304 & \\
\hline & & S-1222-006 & 2 & & V-1354-001-315 & \\
\hline & & S-1222-007 & 2 & & V-1354-001-316 & \\
\hline & & S-1312-001 & 1 & & V-1354-001-317 & \\
\hline & & S-1351-001 & 0 & & $V-1354-001-318$ & \\
\hline & & S-1354-001 & 0 & & V-1354-001-319 & \\
\hline & & S-1370-101 & 3 & & & \\
\hline & & S-1380-101 & 2 & & & \\
\hline & & S-1510-003 & 2 & & & \\
\hline & & S-1510-006 & 3 & & & \\
\hline & & S-1510-007 & 2 & & & \\
\hline \multirow[t]{4}{*}{$\begin{array}{l}\text { DEGASIFICATION } \\
\text { SYSTEM } \\
\end{array}$} & $\begin{array}{l}\text { McCormack Div. ARI } \\
\text { Technologies, Inc. }\end{array}$ & H-2-88978 & 1 & & & \\
\hline & & R-135A-007 & 1 & & V-1354-007-301 & \\
\hline & & S-1134-004 & 0 & & V-1354-007-302 & \\
\hline & & S-1222-003 & 1 & & V-1354-007-303 & \\
\hline
\end{tabular}


PAGE 4

\begin{tabular}{|c|c|c|c|c|c|c|}
\hline Unit & Vendor Name & $\begin{array}{l}\text { Specification } \\
\text { Reference }\end{array}$ & $\begin{array}{l}\text { Rev } \\
\text { Complete }\end{array}$ & $\begin{array}{l}\text { Vendor } \\
\text { Design }\end{array}$ & $\begin{array}{l}\text { Plovided } \\
\text { Drawings }\end{array}$ & $\begin{array}{l}\text { Vendor } \\
\text { Design } \\
\text { Calc. }\end{array}$ \\
\hline & & S-1222-004 & 1 & & V-1354-007-304 & \\
\hline & & S-1222-004 & 1 & & V-1354-007-305 & \\
\hline & & S-1222-006 & 2 & & V-1354-007-306 & \\
\hline & & \begin{tabular}{|l} 
S-1222-007 \\
\end{tabular} & 1 & & V-1354-007-307 & \\
\hline & & $S-1312-001$ & 1 & & V-1354-007-308 & \\
\hline & & S-135A-007 & 0 & & & \\
\hline & & S-1370-101 & 3 & & & \\
\hline & & S-1380-101 & 2 & & & \\
\hline & & S-1510-003 & 2 & & & \\
\hline & & S- $1510-006$ & 3 & & & \\
\hline & & S-1510-007 & 2 & & & \\
\hline & & S-SECT 13440 & $\mathrm{OE}$ & & & \\
\hline & & S-SECT 16400 & $\mathrm{OB}$ & & & \\
\hline \multirow[t]{5}{*}{$\begin{array}{l}\text { REVERSE } \\
\text { OSMOSIS SYSTEM }\end{array}$} & $\begin{array}{l}\text { Zenon Environmental } \\
\text { Systems }\end{array}$ & R-135A-003 & 1 & & & \\
\hline & & S-1131-004 & & & V-135A-003-301 & \\
\hline & & S-1222-003 & & & V-135A-003-302 & \\
\hline & & S-1222-006 & & & & \\
\hline & & S-1222-007 & & & & \\
\hline
\end{tabular}


PAGE 5

\begin{tabular}{|c|l|l|l|l|l|l|}
\hline Unit & Vendor Name & $\begin{array}{l}\text { Specification } \\
\text { Reference }\end{array}$ & $\begin{array}{l}\text { Rev } \\
\text { Complete }\end{array}$ & $\begin{array}{l}\text { Vendor } \\
\text { Design }\end{array}$ & $\begin{array}{l}\text { Provided } \\
\text { Drawings }\end{array}$ & $\begin{array}{l}\text { Vendor } \\
\text { Design } \\
\text { Calc. }\end{array}$ \\
\hline & & S-135A-003 & 0 & & V-135A-006-303 & \\
\hline & & S-1370-101 & 0 & & V-135A-006-304 & \\
\hline & & S-1380-101 & 1 & & V-135A-006-305 & \\
\hline & & S-1510-003 & 1 & & & \\
\hline & & & & & \\
\hline & & R-135A-006 & 1 & & & \\
\hline & & S-1131-004 & 0 & & & \\
\hline & & S-1222-003 & 0 & & & \\
\hline & & S-1222-006 & 1 & & & \\
\hline & & S-1222-007 & 1 & & & \\
\hline & & S-135A-006 & 0 & & & \\
\hline & & S-1370-101 & 1 & & & \\
\hline & & S-1380-101 & 1 & & & \\
\hline & & S-1510-003 & 0 & & & \\
\hline & & S-1510-006 & 1 & & & \\
\hline & & S-1510-007 & 1 & & & \\
\hline & & S-SECT 01650 & 0 & & & \\
\hline & & S-SECT 01730 & 0 & & & \\
\hline & & S-SECT 05120 & 0 & & & \\
\hline & & S-SECT 09805 & 0 & & & \\
\hline & & & & & & \\
\hline & & & & & &
\end{tabular}


PAGE 6

\begin{tabular}{|l|l|l|l|l|l|l|}
\hline Unit & \multicolumn{1}{|c|}{ Vendor Name } & $\begin{array}{l}\text { Specification } \\
\text { Reference }\end{array}$ & $\begin{array}{l}\text { Rev } \\
\text { Complete }\end{array}$ & $\begin{array}{l}\text { Vendor } \\
\text { Design }\end{array}$ & $\begin{array}{l}\text { Provided } \\
\text { Drawings }\end{array}$ & $\begin{array}{l}\text { Vendor } \\
\text { Design } \\
\text { Calc. }\end{array}$ \\
\hline $\begin{array}{l}\text { EVAPORATOR } \\
\text { SYSTEM }\end{array}$ & $\begin{array}{l}\text { Resources Conservation } \\
\text { Company }\end{array}$ & DCN-1 & 0 & & & \\
\hline & & R-135A-004 & 2 & & V-135A-004-303 & \\
\hline & & R-135A-004 & 2 & & THROUGH & \\
\hline & & S-1131-004 & 0 & & V-135A-005-364 & \\
\hline & & S-1222-003 & 1 & & & \\
\hline & & S-1222-006 & 1 & & & \\
\hline & & S-1222-007 & 1 & & & \\
\hline & & S-135A-004 & 2 & & & \\
\hline & & S-1370-101 & 1 & & & \\
\hline & & S-1380-101 & 1 & & & \\
\hline & & S-1510-006 & 1 & & & \\
\hline & & S-1510-007 & 1 & & & \\
\hline & & S-SECT 01650 & OE & & & \\
\hline & & S-SECT 01730 & 0 & & & \\
\hline & & S-SECT 05120 & OE & & & \\
\hline & & S-SECT 09805 & OE & & & \\
\hline & & S-SECT 13440 & OE & & & \\
\hline & & S-SECT 15491 & OE & & & \\
\hline & & S-SECT 15493 & OE & & & \\
\hline & & & & & & \\
\hline & & & &
\end{tabular}


PAGE 7

\begin{tabular}{|c|l|l|l|l|l|l|}
\hline Unit & \multicolumn{1}{|c|}{ Vendor Name } & $\begin{array}{l}\text { Specification } \\
\text { Reference }\end{array}$ & $\begin{array}{l}\text { Rev } \\
\text { Complete }\end{array}$ & $\begin{array}{l}\text { Vendor } \\
\text { Design }\end{array}$ & $\begin{array}{l}\text { Provided } \\
\text { Drawings }\end{array}$ & $\begin{array}{l}\text { Vendor } \\
\text { Design } \\
\text { Calc }\end{array}$ \\
\hline DRYER SYSTEM & LCI Corporation & S-1131-004 & 0 & & & \\
\hline & & S-1222-003 & 1 & & & \\
\hline & & S-1222-006 & 1 & & & \\
\hline & & S-1222-007 & 1 & & & \\
\hline & & S-135A-005 & 1 & & & \\
\hline & & S-1370-101 & 1 & & & \\
\hline & & S-1380-101 & 1 & & & \\
\hline & & S-1510-003 & 0 & & & \\
\hline & & S-1510-006 & 1 & & & \\
\hline & & S-1510-007 & 1 & & & \\
\hline & & S-SECT. 01650 & OE & & & \\
\hline & & S-SECT. 01730 & O & & & \\
\hline & & S-SECT. 05120 & OE & & & \\
\hline & & S-SECT. 09805 & OE & & & \\
\hline & & S-SECT. 13440 & OE & & & \\
\hline & & S-SECT. 15491 & OE & & & \\
\hline & & S-SECT. 15493 & OE & & & \\
\hline & &
\end{tabular}


PAGE 8

\begin{tabular}{|l|l|l|l|l|l|l|}
\hline Unit & \multicolumn{1}{|c|}{ Vendor Name } & $\begin{array}{l}\text { Specification } \\
\text { Reference }\end{array}$ & $\begin{array}{l}\text { Rev } \\
\text { Complete }\end{array}$ & $\begin{array}{l}\text { Vendor } \\
\text { Design }\end{array}$ & $\begin{array}{l}\text { Provided } \\
\text { Drawings }\end{array}$ & $\begin{array}{l}\text { Vendor } \\
\text { Design } \\
\text { Calc. }\end{array}$ \\
\hline $\begin{array}{l}\text { DRUM HANDLING } \\
\text { SYSTEM }\end{array}$ & Pacific Nuclear Systems & H-2-88989 & 1 & & $135 Z-002-310$ & \\
\hline & & H-2-88990 & 0 & & $135 Z-002-370$ & \\
\hline & & H-2-89006 & 1 & & $135 Z-002-371$ & \\
\hline & & H-2-89008 & 0 & & $135 Z-002-375$ & \\
\hline & & H-2-89009 & 0 & & $135 Z-002-376$ & \\
\hline & & H-2-89128 & 0 & & & \\
\hline & R-135Z-002 & 1 & & & \\
\hline & & S-1131-004 & 0 & & & \\
\hline & & S-1222-003 & 0 & & & \\
\hline & & S-1222-004 & 0 & & & \\
\hline & & S-1222-006 & 1 & & & \\
\hline & & S-1222-007 & 1 & & & \\
\hline & & S-1312-001 & 0 & & & \\
\hline & S-135Z-001 & 1 & & & \\
\hline & & S-135Z-002 & 1 & & & \\
\hline & & S-1370-101 & 2 & & & \\
\hline & & S-1370-102 & 1 & & & \\
\hline & S-1372-001 & 0 & & & \\
\hline & & S-1372-002 & 0 & & & \\
\hline
\end{tabular}


PAGE 9

\begin{tabular}{|c|c|c|c|c|c|c|}
\hline Unit & Vendor Name & $\begin{array}{l}\text { Specification } \\
\text { Reference }\end{array}$ & $\begin{array}{l}\text { Rev } \\
\text { Complete }\end{array}$ & $\begin{array}{l}\text { Vendor } \\
\text { Design }\end{array}$ & $\begin{array}{l}\text { Provided } \\
\text { Drawings }\end{array}$ & $\begin{array}{l}\text { Vendor } \\
\text { Design } \\
\text { Calc. }\end{array}$ \\
\hline & & S-1380-101 & 1 & & & \\
\hline & & S-1510-006 & 2 & & & \\
\hline & & S-1510-007 & 1 & & & \\
\hline & & S-SECT. 13440 & $\mathrm{OE}$ & & & \\
\hline \multirow[t]{13}{*}{ RESIN DEWATERING } & TTI Engineering & S-135A-008 & 0 & & & \\
\hline & & S-1222-006 & 1 & & & \\
\hline & & S-1131-004 & $\mathbf{0}$ & & & \\
\hline & & S-1370-101 & 2 & & & \\
\hline & & S-1380-101 & 1 & & & \\
\hline & & S-1510-006 & 2 & & & \\
\hline & & SECTION 13440 & $\mathrm{OE}$ & & & \\
\hline & & H-2-88990 & 0 & & & \\
\hline & & S-1312-001 & 0 & & & \\
\hline & & & & & & \\
\hline & & & & & & \\
\hline & & & & & & \\
\hline & & & & & & \\
\hline
\end{tabular}


3.0

3.1

Structural Integrity Certificate and Hazard Assessment

Review of Structural Integrity

(To be Provided) 
March 19, 1993

Project No. 212

File No. 6410

Mr. Donald B. Mausshardt, P.E.

7705 Falstaff Road

McLean, VA 22102

Re: 242-A Evaporator/Purex Plant

Process Condensate Treatment Facility

Structural Integrity Analysis - Independent Design Review

Dear Mr. Mausshardt:

In accordance with WAC 173-303-810 13, I, as a Licensed Structural Engineer in the State of Illinois, have reviewed the design calculations and drawings for the tanks, vessels and secondary containment listed below. My review was limited to verification of assumptions, methodology and reasonableness of results. I did not attempt to verify the correctness of mathematical computations.

My review was limited to the following documents:

1. a) Structural Design Calculations.

Document No. C-13G1-001, Revision 0, sheets 1-70, 97-127, 130-131, 136-140.

b) Supplemental Caluculations in Response to Review

Sixteen sheets transmitted by E. Hartsock, Adtechs, on 3-16-93.

Three sheets transmitted by E. Hartsock, Adtechs, on 3-17-93.

Five sheets transmitted by E. Hartsock, Adtechs, on 3-18-93.

2. Drawings.

Drawine No.

H-2-89063

H-2-89064

H-2-89065

H-2-89066

H-2-89067
Revision

1

1

1

1 
March 18, 1993

Page 2

$\begin{array}{ll}\text { H-2-89068, Sheet } 1 \text { of } 2 & 1 \\ \text { H-2-89068, Sheet } 2 \text { of } 2 & 0 \\ \text { H-2-89069 } & 1 \\ \text { H-2-89070 } & 1 \\ \text { H-2-89071 } & 1 \\ \text { H-2-89072 } & 1 \\ \text { H-2-89073 } & 1 \\ \text { H-2-89074 } & 1 \\ \text { H-2-89076 } & 1 \\ \text { H-2-89077 } & 1 \\ \text { H-2-89078 } & 1 \\ \text { H-2-89108 } & 1 \\ \text { H-2-89109 } & 1 \\ \text { H-2-89114 } & 1 \\ \text { H-2-89115 } & 1 \\ \text { H-2-89116 } & 1 \\ \text { H-2-8911, Sheet } 1 \text { of } 2 & 1 \\ \text { H-2-89119, Sheet } 2 \text { of } 2 & 0 \\ \text { H-2-89120, Sheet } 1 \text { of } 2 & 1 \\ \text { H-2-89120, Sheet } 2 \text { of } 2 & 0 \\ \text { H-2-89121, } & 1 \\ \text { H-2-89124, Sheet } 1 \text { of } 2 & 1 \\ \text { H-2-89124, Sheet } 2 \text { of } 2 & 0 \\ \text { H-2-89125, Sheet } 1 \text { of } 2 & 1 \\ \text { H-2-89125, Sheet } 2 \text { of } 2 & 0\end{array}$

The information provided me demonstrates the tanks and vessels have sufficient structural integrity for the materials placed in them. The design is adequate to ensure sufficient structural strength to meet design seismic events for Richland, WA for the vessels, tanks and secondary containment in accordance with the Uniform Building Code.

Very truly yours,

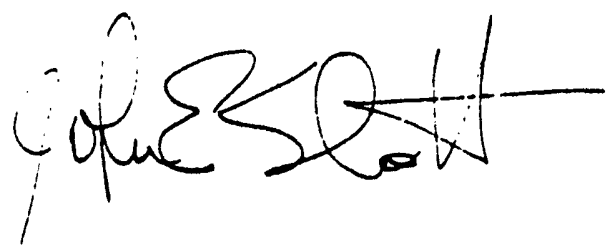

John E. Schmidt, P.E., S.E.

Principal Structural Engineer

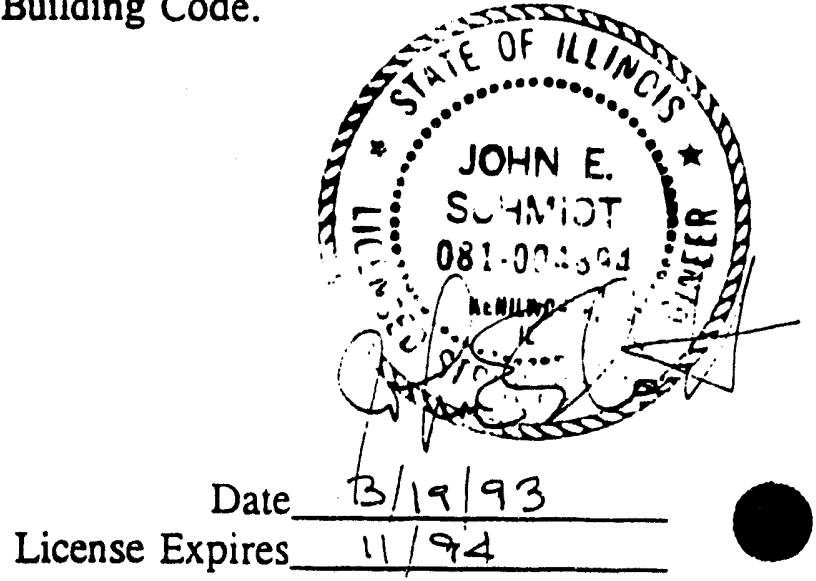




\subsection{Hazards Assessment}

\subsubsection{Introduction}

The Hazards Assessment Document (Specification S-12HO001 ) was reviewed for its completeness and inclusion of major RCRA related issues.

\subsubsection{Hazard Concerns}

The major issues covered in the hazard assessment are summarized below.

(1) The influent waste stream are mixed wastes containing hazardous materials at low concentrations.

(2) The chemical source term consists of tanks containing sulfuric acid, sodium hydroxide, and hydrogen peroxide. Low concentrations of volatile organic compounds(VOCs) are part of the source term and will be converted to hydrogen, oxygen and carbon dioxide by UV oxidation and $\mathrm{H} 2 \mathrm{O} 2$.

(3) The operations area has a separate HVAC system from that of the ETF process area. During normal operations, the ETF ventilation systems are designed to maintain a negative pressure in the Radiologically Controlled Area(RCA) and Non-RCA areas. This will minimize gaseous environmental releases from the ETF into the operations area as a result of door openings. The ETF will utilize charcoal and HEPA filters to minimize the discharge of contaminants.

(4) Liquid releases will be controlled anc sampled prior to authorized discharges. the ETF will use test tanks that will retain processed liquids until liquids are verified to meet discharge limits.

(5) The ETF employs designs that mitigate the severity of accidents or transients through the use of physical barriers such as dams, berms, drip pans enclosures, tents, and other barriers.

(6) The ETF employs instrumentation, monitoring, computer and communication systems to provide automatic shutdown controls, proper monitoring of system operation, interlocks, and communications to safely operate and maintain the facility. 
A summary of the postulated hazard events and their potential consequences is presented in the attached table. The postulated hazard events have a very low probability of occurrence. Even so the analysis of the possible sequences, potential consequences, preventive features and mitigating features were fully addressed and commensurate with the $100 \%$ design documents.

3.2.3 References:

$\begin{array}{ll}\mathrm{V}-\mathrm{CO} 18 \mathrm{HC1}-001 & \text { Design Construction Specification ETF } \\ \mathrm{H}-2-88970 & \text { Process Flow Diagram } \\ \mathrm{H}-2-88970 & \text { Material Balance DB1 } \\ \mathrm{H}-2-88971 & \text { Material Balance DB2 } \\ \mathrm{H}-2-88973 & \text { Material Balance DB3 } \\ \mathrm{S}-1223-001 & \text { System Description }\end{array}$


Table 3-1 RCRA-Related Hazards Identification and Assessmnet

\begin{tabular}{|c|c|c|c|c|}
\hline Event & Possible Sequence & $\begin{array}{l}\text { Potiential } \\
\text { Consequences }\end{array}$ & $\begin{array}{l}\text { Preventive } \\
\text { Features }\end{array}$ & $\begin{array}{l}\text { Mitigating } \\
\text { Features }\end{array}$ \\
\hline Liquid Spill & $\begin{array}{l}\text { Equipment in operation } \\
\text { Pressure boundaries } \\
\text { fail, \& residual liquid } \\
\text { spilis. }\end{array}$ & Personnel exposure & $\begin{array}{l}\text { Bldg confinement } \\
\text { training, use of } \\
\text { berms/dams. }\end{array}$ & $\begin{array}{l}\text { Relatively } \\
\text { low operate } \\
\text { pressure with } \\
\text { execption of } \\
\text { Ro system }\end{array}$ \\
\hline
\end{tabular}

\begin{tabular}{|c|c|c|c|c|}
\hline $\begin{array}{l}\text { Corrosive } \\
\text { Materials } \\
\text { Cause Equip. } \\
\text { Failure }\end{array}$ & $\begin{array}{l}\text { Equip./piping failure } \\
\text { occurs \& containment } \\
\text { is lost }\end{array}$ & Personnel exposure & $\begin{array}{l}\text { Equip. materials } \\
\text { selection, proper } \\
\text { maintenance. }\end{array}$ & $\begin{array}{l}\text { Early } \\
\text { detection by } \\
\text { inspection } \\
\text { and/or } \\
\text { monitors }\end{array}$ \\
\hline $\begin{array}{l}\text { Seismic } \\
\text { Activity }\end{array}$ & $\begin{array}{l}\text { Earthquake occurs \& } \\
\text { support facilities are } \\
\text { disrupted; system } \\
\text { equipment containment }\end{array}$ & $\begin{array}{l}\text { Personnel exposure } \\
\text { Equipment loss }\end{array}$ & $\begin{array}{l}\text { Bldg acts as } \\
\text { confinement. }\end{array}$ & $\begin{array}{l}\text { Low energy } \\
\text { (Pressure \& } \\
\text { Temp) systems }\end{array}$ \\
\hline
\end{tabular}

is lost.

\begin{tabular}{|c|c|c|c|c|}
\hline $\begin{array}{l}\text { Containment } \\
\text { Component Is } \\
\text { Subject To } \\
\text { Stress and/or } \\
\text { Vibration }\end{array}$ & $\begin{array}{l}\text { Stress/vibration causes } \\
\text { fatigue and containment } \\
\text { is lost. }\end{array}$ & Personnel exposure & $\begin{array}{l}\text { Materials selection } \\
\text { Planned maintenance }\end{array}$ & $\begin{array}{l}\text { Early } \\
\text { detection } \\
\text { by inspect } \\
\text { and/or } \\
\text { monitors }\end{array}$ \\
\hline $\begin{array}{l}\text { Misrouting } \\
\text { of Process } \\
\text { Flow }\end{array}$ & $\begin{array}{l}\text { Faulty design allows } \\
\text { misrouting, overflow, } \\
\text { etc. }\end{array}$ & $\begin{array}{l}\text { Personnel exposure } \\
\text { Environmental } \\
\text { release }\end{array}$ & $\begin{array}{l}\text { MCS fail safe; } \\
\text { alarms \& interlocks }\end{array}$ & $\begin{array}{l}\text { Tank level } \\
\text { alarms; } \\
\text { redundancy, } \\
\text { operator } \\
\text { training }\end{array}$ \\
\hline $\begin{array}{l}\text { Faulty } \\
\text { Fabrication/ } \\
\text { Installation }\end{array}$ & $\begin{array}{l}\text { Frabrication/ } \\
\text { iastallation is faulty } \\
\text { and component fails }\end{array}$ & $\begin{array}{l}\text { Personnel exposure; } \\
\text { enviromental } \\
\text { release }\end{array}$ & $\begin{array}{l}\mathrm{QA} \text {; inspection, } \\
\text { planned maintenance }\end{array}$ & $\begin{array}{l}\text { Early } \\
\text { detection } \\
\text { by inspect/ } \\
\text { monitors }\end{array}$ \\
\hline
\end{tabular}


Table 3-1 Continued

\begin{tabular}{|c|c|c|c|c|}
\hline $\begin{array}{l}\text { Chemical } \\
\text { Reaction of } \\
\text { Reagents }\end{array}$ & $\begin{array}{l}\text { NaOH \& H2SO4 can react } \\
\text { violently when mixed }\end{array}$ & $\begin{array}{l}\text { Personnel injury; } \\
\text { Equipment loss }\end{array}$ & $\begin{array}{l}\text { Maintain separation } \\
\text { of chemicals; color } \\
\text { coding; training; } \\
\text { opns procedures. }\end{array}$ & $\begin{array}{l}\text { Metering } \\
\text { and pH } \\
\text { monitors }\end{array}$ \\
\hline $\begin{array}{l}\text { Exposure to } \\
\text { Chemicals } \\
\text { (VOCs) }\end{array}$ & $\begin{array}{l}\text { Loss of ventilation } \\
\text { system }\end{array}$ & Personnel injury & $\begin{array}{l}\text { Design, inspection, } \\
\text { and maintenance }\end{array}$ & $\begin{array}{l}\text { Low conc. } \\
\text { UV oxidizer } \\
\text { converts } \\
\text { WOC to } \mathrm{H} 2,02 \\
\text { and } \mathrm{CO} 2\end{array}$ \\
\hline $\begin{array}{l}\text { Chemical } \\
\text { Vent System } \\
\text { Fails }\end{array}$ & $\begin{array}{l}\text { Room fills with } \\
\text { corrosive vapors }\end{array}$ & $\begin{array}{l}\text { Occupational } \\
\text { injury }\end{array}$ & $\begin{array}{l}\text { Non RCA ventilation } \\
\text { system; redundancy } \\
\text { of vital equipment }\end{array}$ & $\begin{array}{l}\text { Very low } \\
\text { conoentration }\end{array}$ \\
\hline $\begin{array}{l}\text { Chemical } \\
\text { Spills } \\
\text { or Sprays }\end{array}$ & $\begin{array}{l}\text { Personnel come in } \\
\text { contact with chemicals. }\end{array}$ & $\begin{array}{l}\text { Occupational injury } \\
\text { Environ. release }\end{array}$ & $\begin{array}{l}\text { Training; compliance } \\
\text { with operating \& } \\
\text { maintenance } \\
\text { procedures; use of } \\
\text { berms and dams }\end{array}$ & $\begin{array}{l}\text { Spill } \\
\text { prevention } \\
\text { plan; } \\
\text { containment } \\
\text { structure } \\
\text { Shower/eye } \\
\text { wash. }\end{array}$ \\
\hline $\begin{array}{l}\text { Chemically } \\
\text { Induced } \\
\text { Overpressure }\end{array}$ & $\begin{array}{l}\text { Personnel come in } \\
\text { contact with chemicals } \\
\text { and Vocs }\end{array}$ & $\begin{array}{l}\text { Occupational injury. } \\
\text { Environmental release }\end{array}$ & $\begin{array}{l}\text { Building contain; } \\
\text { negative pressure } \\
\text { maintained }\end{array}$ & $\begin{array}{l}\text { Limited } \\
\text { use of } \\
\text { unstable } \\
\text { chemicals } \\
\text { Low conc. }\end{array}$ \\
\hline
\end{tabular}




\subsection{Secondary Containment}

Liquid process wastes containing radioactive or other hazardous materials are collected and monitored near the source of generation before batch transfer through pipe lines and tank transfer to the liquid waste treatment process area takes place. These wastes are collected in storage tanks. The waste storage tanks and transfer ines are designed and constructed so that any leakage is detected and contained before reaching the environment outside the process area.

The secondary containment system consists of the diked and drained concrete floor general process area designed to retain the capacity of the largest single vessel (15,000 gallons). In addition, individual containment areas surround the surge, verification, and external storage tanks.

\subsection{Spill Containment in the Process Area}

The spill containment design is recorded in document number C-13G1001 and references drawing number $\mathrm{H}-2-89077$. The capacity of the largest single vessel, in accordance with the code of Federal Regulations, forms the basis for design. The largest vessels in the process area are the two secondary waste receiving tanks (2025E601-TK-1A \& 1B) each having a capacity of 15,000 gallons or 2005 cubic feet. The containment area consists of the process area of 12,000 cubic feet. The net containment area calculation is based on $80 \%$ of the area being occupied by equipment, and provides for 2400 cubic feet compared to the 2005 cubic feet requirement. This is a very conservative assumption since the clear floor area is closer to $50 \%$ of the gross area. The reinforced concrete floor is finished in accordance with the American concrete Institute specification 301-89. The floor is uniformly sloped to the floor drains at $1 / 8$ inch per foot. Spilis in the process area flow to the drains and are collected in sumps and pumped to the surge tank thereby clearing the process area. All concrete and masonry surfaces in the process area are painted with an epoxy paint in three coats. The primer coat consists of Amercoat 187, the second coat Amercoat 33 and the finish coat is also Amercoat 33. This application protects, facilitates cleaning minor seeps, leaks and spills along with providing a measure of environmental protection. All concrete floor joints are sealed with waterstop $\mathrm{RX}-101$ to prevent leakage from the containment area.

\subsection{Spill Containment - Verification Tanks}

Three verification tanks (2025E-60H-TK-1A, 1B \& 1C), are located apart from and on the north side of the processing facility, each with capacities of 670,000 gallons are surrounded by a secondary containment system. Design criteria for the volume to be contained is based upon containing $110 \%$ of one tank, or 108,383 cubic feet $(737,000$ gallons). The containment area, portrayed by drawing number H-2-8906r, is a 236 by 88 foot rectangle, bounded by an 8 foot reinforced dike. The floor of the containment area is also 
reinforced concrete. The available volume to contain the design volume is 142,032 cubic feet, which subtracts the area occupied by the tanks, leaving a volume well in excess of the minimum design objective. The dike and floor joints are water sealed with waterstop RX-101. There is a scupper drain system and sump pump located in the foundation of the containment area which is manually activated to evacuate natural precipitation. The drain is normally closed. A detection/alarm system is located in the drain sump to signal the accumulation of fluid. The drain must be physically inspected and the contents surveyed by plant personnel before the evacuation pump can be activated to clear nonhazardous and nontoxic fluid from the containment area. Should hazardous or toxic fluid be discovered, plant personnel follow operating procedures dealing with the safe removal of such material.

\subsection{Spill Containment - Surge Tank}

The surge tank (2025E-65A-TK-1) is located outside the facility on a reinforced concrete foundation. The secondary containment area shares part of the southern wall of the main processing plant. The tank has a capacity of 100,000 gallons and stores waste liquid from the 242-A Evaporator/Purex plant waste streams. The tank is surrounded by a 60 foot square containment area defined by a 9.5 foot reinforced concrete dike. The volume available to contain 100,000 gallons, plus 10\%, or 14706 cubic feet is over 28,000 cubic feet, satisfactory volume for containment. The floor, wall and dike joints are sealed with the waterstop $R \times-101$ seal and no drains are incorporated in the base of the containment area. The surge tank containment area is coated with the same epoxy pain referenced in the process area section for the purpose of sealing off contaminated fluid from seeping out of the area and providing a surface that can be cleaned in a safe and environmentally compliant way when dealing with seeps, leaks and spills of a minor nature.

\subsection{Spill Containment - Sulfuric Acid Storage Tank}

The H2SO4 storage tank (2025E-65C-TK-1) is located outside the facility adjacent to the south wall. A portion of the south wall is incorporated in the 20 by 24 foot containment area. The tank sits on a reinforced concrete floor surrounded by a 4 foot reinforced concrete dike. The volume to be contained is 7,500 gallons plus $10 \%$ as a design objective or 1,100 cubic feet. The volume available for containment is 1,920 cubic feet, a satisfactory rolume. The joints in the dike, the union with the facility south wall and the floor joints are water sealed with waterstop $\mathrm{RX}-101$. The wall dike and floor are coated with epoxy paint to seal and provide environmental safeguards when remediating seeps, leaks or minor spills. No drains are incorporated in the secondary containment area.

\subsection{Spill Containment - Sodium Hydroxide Storage Tank}

The $\mathrm{NaOH}$ storare tank (2025E-65C-TK-2) is adjacent to the H2SO4 storage tank, also the south wall. The tank capacity is 5,000 gallons with the design objective $110 \%$ of this quantity or 736 
cubic feet. The containment area is a 20 by 16 foot rectangle. The tank sits on a reinforced concrete floor and is bounded by a 4 foot reinforced concrete dike for an available volume of 1,280 cubic feet which will satisfactorily contain the design objective. The joints throughout the dike, wall and floor are water sealed with Waterstop RX-101. The concrete containment area is painted with Amercoat epoxy. The primer coat uses Amercoat 187 , the second coat uses Amercoat 33, and the finish coat also is applied with Amercoat 33 for the purposes relating to seeps, leaks and minor spills. No drain is incorporated in this secondary containment area. 


\subsection{Handling Procedures Verification}

An examination of the ADTECHS Inspection and Test Plan S-1510-005 revealed that a broad inspection and certification program is planned to require the suppliers and on-site personnel to inspect the tanks and ancillary equipment during manufacturing, shipping and recelpt at the site. specific sections of ADTECHS plan are noted and referenced below:

\begin{tabular}{|c|c|c|}
\hline Weld Breaks & $S-1510-005$ & $\begin{array}{l}\text { Inspection Instruction } \\
\text { II-001, Revision } 1 .\end{array}$ \\
\hline Punctures & $S-1510-006$ & $\begin{array}{l}\text { Note no speciflc } \\
\text { reference however the } \\
\text { item is inspected } \\
\text { visually. }\end{array}$ \\
\hline $\begin{array}{l}\text { Scrapes of } \\
\text { Protective } \\
\text { Coatings }\end{array}$ & $S-1510-005$ & $\begin{array}{l}\text { Inspection instruction } \\
\text { II-003, Revision } 1 \text {. } \\
\text { Instruction for visual } \\
\text { Inspection of painting. }\end{array}$ \\
\hline Cracks & $s-1510-005$ & $\begin{array}{l}\text { Inspection instruction } \\
\text { I I-008, II-009 } \\
\text { Instruction for visual } \\
\text { inspection of Welds. }\end{array}$ \\
\hline Corrosion & $s-1510-006$ & $\begin{array}{l}\text { Inspection instructions } \\
\text { and specification for } \\
\text { inspection requirements } \\
\text { for Package systems. }\end{array}$ \\
\hline & $s-1510-005$ & Inspection and Test Plan. \\
\hline Structural Damage & $\begin{array}{l}S-1510-005 \\
S-1510-007\end{array}$ & $\begin{array}{l}\text { Inspection and test plan. } \\
\text { specification for Non- } \\
\text { Conformance control. }\end{array}$ \\
\hline
\end{tabular}

\subsection{Discrepancies}

ADTECHS has addressed this issue under the specification for Nonconformance control. The reference document is specification S1510-007 which addresses the procedures for Identification, Control, and Resolution of Nonconformance Items. Additionally, the documentation and follow up to closure of the issue are presented in the specification. 


\subsection{Testing Procedures for Tightness}

A review of the $100 \%$ documents in support of assuring that the equipment including tanks and vessels conform to tightness and demonstrate that they are leak tight are covered in specification s-1510-005, Inspection and Test Plan. ADTECH's has developed procedures and specifications that requires the performance of hydrostatic, and pressure testing of all equipment both at the point of manufacturing and at the site when installed. Additionally, this testing will include performance tests to assure system operability and tightness.

For package systems, supplied by vendors, the specification S-1510006 will apply. This inspection requires that the vendor, witnessed by the Engineer(ADTECHS) to perform a Hydrostatic Test, a Mechanical test(Running) and a Performance test to assure meeting the specification. All of this will be performed at the vendors location prior to shipment to the fleld site. specific inspection hold points and scope of inspections are found in Attachment $A$ of s- 1510.005 .

For on site installation, the procedures for Inspection and Testing apply and require again the verification of tightness. This procedure will also apply to all ancillary equipment. Specification S-1510-005, Section II 007, Revision 1 addresses the onsite inspection and test program. 


\subsection{DESCRIPTION OF LEAK DETECTION SYSTEMS}

\subsection{Leak Detection-Primary Containment}

The primary leak detection system must be able to detect the fallure of the primary tank/vessel contalnment structure. This will be accomplished by a combination of the on-line Monitor and Control System(MCS), operator visual observation, periodic maintenance to prescribed procedures and appropriate training on the responses to alarm conditions.

The operating state of major equipment 1 tems such as pumps, blowers, tanks, etc. will be monitored through operator control stations(OCS's) of the MCS. Operating process parameters such as pressure, temperature, flowrate, level in the tank/vessel, etc can be monitored through ocss.

An alarm system will be installed to annunciate the upset of the system to the operator. The operator will be required to take some action when an alarm is annunciated. In the central control room an alarm in the plant will be displayed on the CRT display. Also, in the central control room, important alarms will be individually displayed on the separately installed alarm display window. Every alarm will be displayed on the OCS. Also, the event printer of the MCS will print out the occurrence and nonoccurrence of alarms. Process data, such as liquid level, will be stored in the MCS historical file. Interlocks will be provided to prevent the lowering of the performance of systems, equipment, tank and vesse? damage, and personal accidents, misroutings, etc. due to abnormalities of operating conditions.

Tanks and pumps will normally be monitored and controlled using the OCSs in the control room. In the case of ocs failure, the tanks and pumps can be controlled using the LCU display in the process area. Some system components will be duplicated in consideration of risk versus reliability. For example, the MCS I/O card servicing the sump tank level will be redundant to retain maintainability.

Table 7.1 below identifies the tanks and vessels that will be monitored/controlled by the MCS. Associated with the tanks and vessels are field devices to be utillzed, device applications, and the function to be performed. 
Table 7.1 Leak Detection, Primary Containment via MCs and Moniotrs Tank Name Device Category Applications Function

\begin{tabular}{|c|c|c|c|c|}
\hline Surge & Level & switch & Molsture detection & Alarm \\
\hline $\mathrm{NaOH}$ storage & Level & switeh & Molsture detection & Alarm \\
\hline $\begin{array}{l}92 \% \mathrm{H} 2 \mathrm{SO} \\
\text { Storage }\end{array}$ & Level & switch & Molsture detection & Alarm \\
\hline $\begin{array}{l}\text { H2O2 Feed } \\
\text { System }\end{array}$ & Level & switch & Molsture detection & Alarm \\
\hline $\begin{array}{l}\text { Sump Tank } 2 \\
\text { Secondary Cont. }\end{array}$ & Level & switch & Molsture detection & Alarm \\
\hline $\begin{array}{l}\text { Sump Tank } 1 \\
\text { Secondary Cont. }\end{array}$ & Level & switch & Molsture detection & Alarm \\
\hline 48 solution & Level & switch & Molsture detection & Alarm \\
\hline $\begin{array}{l}\text { Second-waste } \\
\text { Recelving TK A }\end{array}$ & Level & transmitter & $\begin{array}{l}\text { Level indicatorl } \\
\text { control }\end{array}$ & $\begin{array}{l}\text { Alarm/ } \\
\text { pump start }\end{array}$ \\
\hline $\begin{array}{l}\text { Second-waste } \\
\text { Recelving TK B }\end{array}$ & Level & transmitter & $\begin{array}{l}\text { Level indicator/ } \\
\text { control }\end{array}$ & $\begin{array}{l}\text { Alarm/ } \\
\text { pump start }\end{array}$ \\
\hline Concentrate A & Level & transmitter & $\begin{array}{l}\text { Level indicator/ } \\
\text { control }\end{array}$ & $\begin{array}{l}\text { Alarm/ } \\
\text { pump start }\end{array}$ \\
\hline Concentrate B & Level & transmitter & $\begin{array}{l}\text { Level indicatorl } \\
\text { control }\end{array}$ & $\begin{array}{l}\text { Alarm/ } \\
\text { pump start }\end{array}$ \\
\hline$\underset{A}{\text { Verification }}$ & Level & switch & High level switch & Alarm \\
\hline Verification & Level & Switch & High level switch & Alarm \\
\hline Verification & Level & Switch & High level switch & Alarm \\
\hline
\end{tabular}




\subsection{Leak Detection-Secondary Containment}

The secondary systems outside the bullding have monitors located in their respective sumps of the secondary containment unit to monitor for moisture. Like wise the secondary units located inside the bullding for the tank noted (6OD-TK1) has a molsture monitor to warn of a possible accumulation in the sump in secondary containment. On the floor of the main operations building at each sump in the floor there is a molsture monitor to advise of molsture accumulation. These features coupled with the level warning indicators associated with the tanks and vessels will alarm if a sudden loss occurs. 


\section{CERTIFICATION}

I certify under penalty of law that this document and all attachments were prepared under my direction or supervision in accordance with a system designed to assure that qualified Personnel properly gather and evaluate the information submitted. Based upon my inquiry of the person or persons who design the systems, or those persons directly responsible for gathering the information, the information submitted is, to the best of my knowledge and belief, true, and complete. I am aware that there are significant penalties for submitting false information, including the possibility of fine and imprisonment for knowing violations.

I also certify that I have a completed application before the Washington State Board of Engineering Examiners. Notification of a completed application was received dated February 5 , 1993. According to the state code RCW-18.43.130, I am signing this report as a professional Engineer.

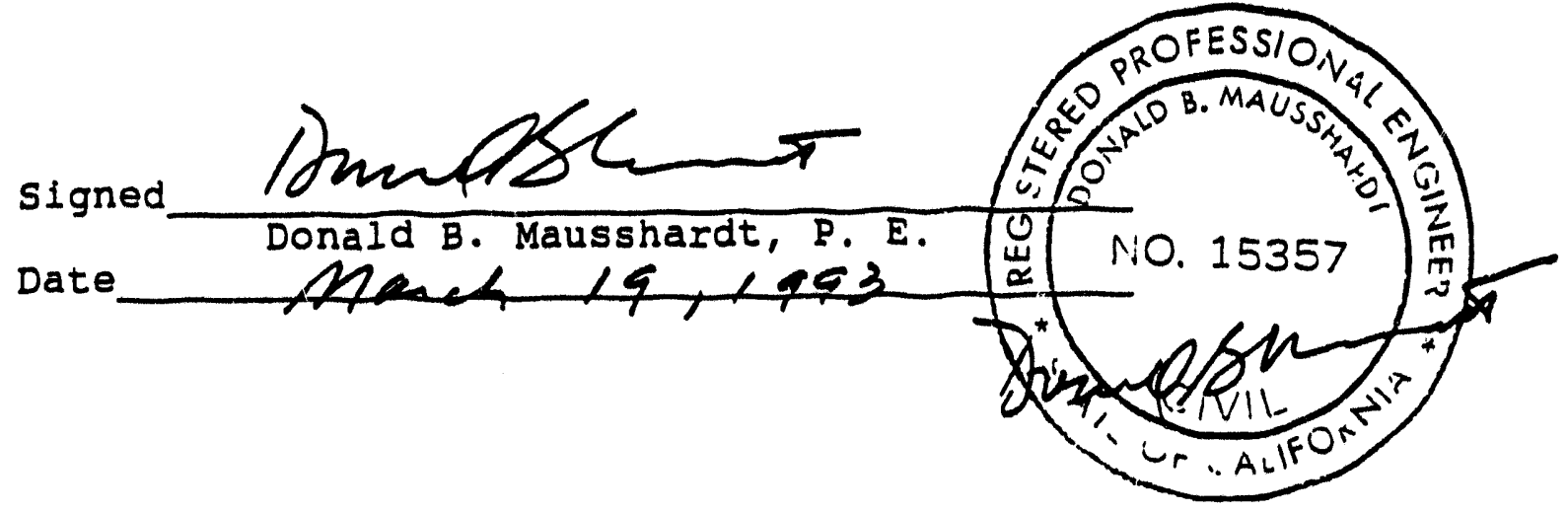




\section{Appendix}

* Interoffice memorandum \# 554 (attached)

* Document List, Doc. No. S-1136-001, Rev 13, 37 pages (cover sheet attached)

* Applicable Codes and Standards, S-1222-005, 22 pages (cover sheet attached) 


\section{INTEROFEICE MEMORANDUM \#554}

PROJECT K-ETE

DATE: $\quad$ March 11,1993

TO: Ed Holton

FROM: Ed Hartsock Clft

SUBJECT: Status of Anchorage Design of Vendor-Furnished Equipment

CC: $\quad$ D. Mausshardt

Ed:

In response to our conversations yesterday and today regarding the content of the structural anchorage calculations for vendor equipment, following is a brief summary of the current status.

1) In order to design their foundations, the verification. tanks and the surge tank have been analyzed for their gross stability under seismic loading. No vendor fabrication drawings are as yet available to check anchor bolt loads. It is understood that such an analysis will be required upon complete submittal of vendor documents.

2) Vendor documentation on equipment anchorage has been submitted for both the ICI dryer and the RCC evaporator. Our foundations will be designed to accommodate these vendor-calculated loads. These foundations are currently on hold on the Issue for construction drawings. I have reviewed these calculations and am willing to endorse them as an independent reviewer.

3) The secondary waste receiving tanks are the largest single components inside the ETF. For foundation design, gross stability was examined. Fowever, as with other tanks, complete vendor information is not available for anchorage design.

4) The seismic design for typical "small" pieces of equipment, the plate and frame heat exchangers, has been submitted by the vendor. As in item $\# 2$ above, I am willing to endorse these submittals as an independent reviewer.

If we make our sibmittal to the regulators making the above information know: and indicating that a process is in place to complete the designs once complete verdor information is available, I think the intent of the permit has been met. 


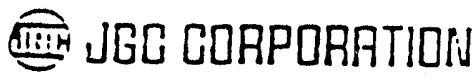

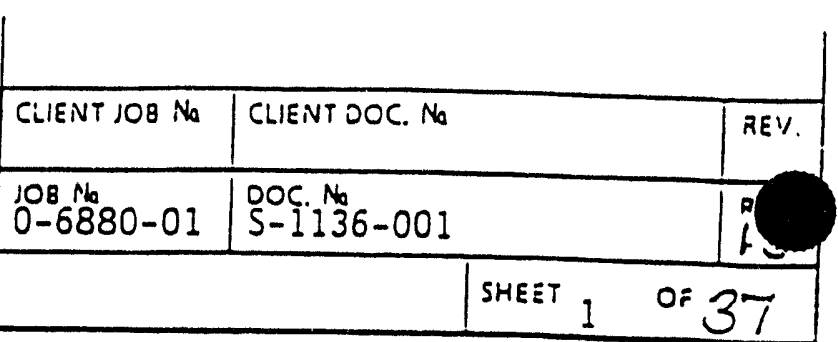

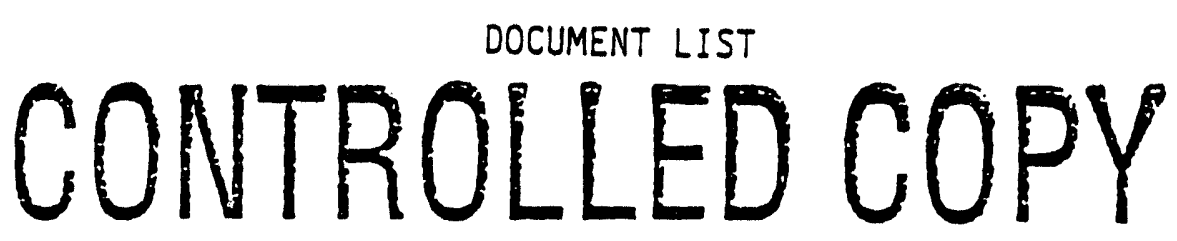

PROJECT $\mathrm{C}-\mathrm{O} 18 \mathrm{H}$

242-A EVAPORATOR/PUREX PLANT

PROCESS CONDENSATE TREATMENT PLANT

\begin{tabular}{|c|c|c|c|c|c|}
\hline & DATE & PAGE & DESTRIFTIONA & PRSPי'D & $\begin{array}{l}A P^{\circ} D \\
\end{array}$ \\
\hline$\Delta 2 \overrightarrow{2}$ & $1-20-93$ & A.11 & 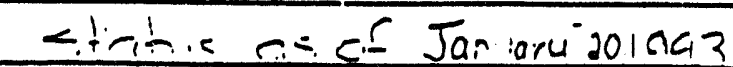 & res & 3.7415 \\
\hline$\sqrt{3, !}$ & $2-22 \cdot 93$ & A11 & Stotuis as of Fehruariaz bo & $x / 12$ & Atatid \\
\hline$(8) !$ & $9-25-92$ & $\mathrm{Ali}^{-}$ & 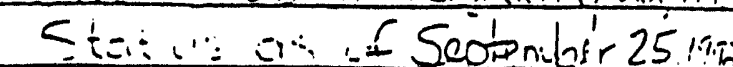 & No & 6.7.11215 \\
\hline (q) & $(n-2 i)-9=$ & 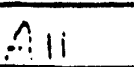 & 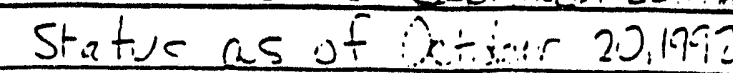 & hes & $1=\div \perp i \pi \pi_{n}$ \\
\hline (10) & $11-20-92$ & Fil & 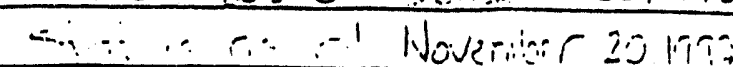 & $1 / 1$ & Ey thalt \\
\hline & & & & & \\
\hline
\end{tabular}




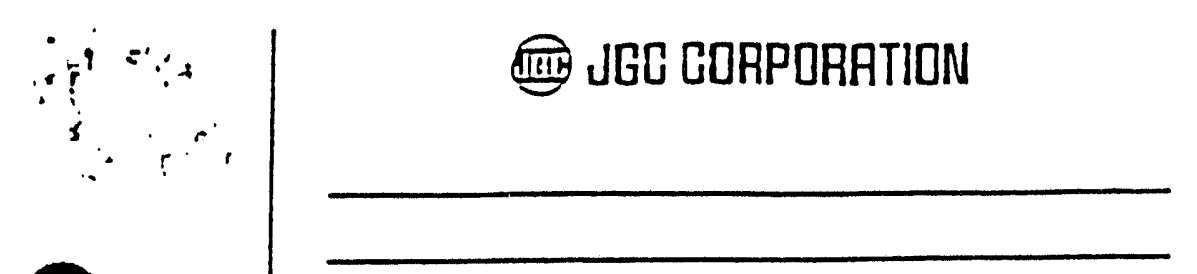

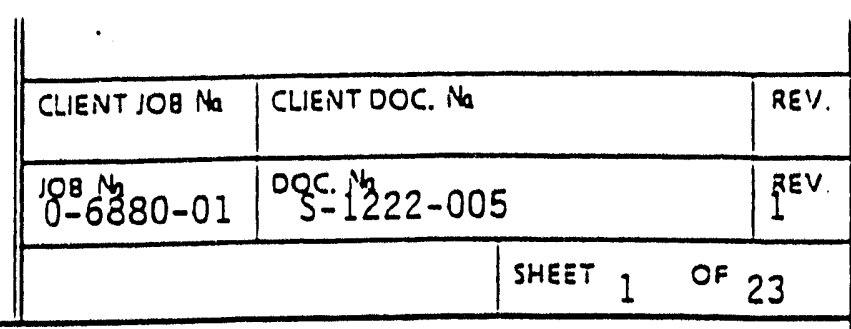

\section{CONTROLLED COPY CENTRAL FILE}

APPLICABLE

CODES \& STANDARDS

PROJECT C-018H

242-A EVAPORATOR/PUREX PLANT

PROCESS CONDENSATE TREATMENT FACILITY

\begin{tabular}{|c|c|c|c|c|c|}
\hline$R E \%$ & oATÉ & PAGE & DESCRIPTION & PREP'D & $\triangle P Q D$ \\
\hline (0) & $12-19-91$ & All & Issue for approval & ht & $\approx$ \\
\hline (1) & $3-3-92$ & Marked & Incorocrate KEH Comments & $2 x y$ & 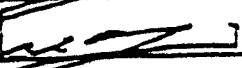 \\
\hline$\Delta$ & & & & & \\
\hline$\Delta$ & & & & & \\
\hline$\Delta$ & & & & & \\
\hline\langle\rangle $\mid$ & & & & & \\
\hline
\end{tabular}




\section{APPENDIX 4C \\ SEISMIC ATHALYSIS}

This report will be provided in a future permit application revision. 
DOE/RL-93-03, Rev. 0

$08 / 31 / 93$

This page intentionally left blank. 
DOE/RL-93-03, Rev. 0

$08 / 31 / 93$

1
2
3
4
5
6
7
8
9

\section{APPENDIX 40}

CORROSION ANALYSIS

This report will be provided in a future permit application revision. 
DOE/RL-93-03, ReV. 0 $08 / 31 / 93$

This page intentionally left blank. 
DOE/RL-93-03, Rev. 0

$08 / 31 / 93$

1

2

3

APPENDIX 7A

BUILDING EMERGENCY PLAN--200 AREA EFFLUENT TREATMENT FACILITY 
DOE/RL-93-03, Rev. 0

$08 / 31 / 93$

This page intentionally left blank. 
DOE/RL-93-03, Rev. 0

$08 / 31 / 93$

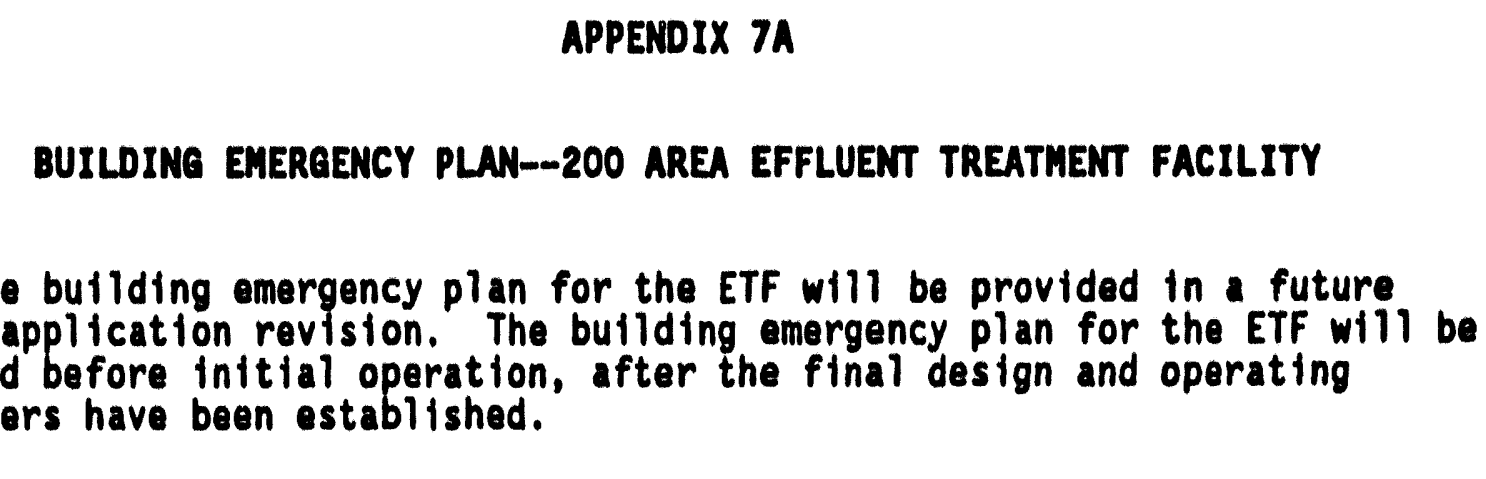

APP 7A-1

930820.1350 


\section{DOE/RL-93-03, Rev. 0}

$08 / 31 / 93$

This page intentionally left blank. 
D0E/RL-93-03, Rev. 0

$08 / 31 / 93$

\section{APPENDIX 8A}

TRAINING COURSE DESCRIPTIONS 
APPENDIX 8A

CONTENTS

8A.1 HAZARDOUS WASTE OPERATIONS TRAINING COURSES . . . . . . . APP 8A-1

8 A.2 UNIT-SPECIFIC COURSES . . . . . . . . . . . . . APP 8A-3

8 A.3 JOB-SPECIFIC COURSES . . . . . . . . . . . . . APP 8A-6 


\begin{tabular}{|c|c|}
\hline & \\
\hline Title & Hazardous Communication and Waste Orientation \\
\hline Description & $\begin{array}{l}\text { Course usually is part of the new employee orientation } \\
\text { and provides an overview of federal hazard communications } \\
\text { programs and hazardous waste disposal requirements. }\end{array}$ \\
\hline Target audience & All employees \\
\hline Delivery & Classroom \\
\hline Evaluation & Not applicable \\
\hline Length & 1 hour \\
\hline Frequency & Not applicable \\
\hline Title & Generator Hazards Safety Training \\
\hline Description & $\begin{array}{l}\text { Course is designed to introduce workers to the } \\
\text { 'right-to-know' laws governing chemical safety in the } \\
\text { work place. The course provides the hazardous } \\
\text { material/waste worker with the basic fundamentals for } \\
\text { safe use and disposal of hazardous material. Course } \\
\text { defines hazardous material, reviews labeling } \\
\text { requirements, and introduces material safety data sheets } \\
\text { and key terms used in chemical safety. The course also } \\
\text { introduces methods for waste minimization and reviews the } \\
\text { cycle of a chemical from the manufacturer to processing } \\
\text { and storage as a hazardous waste. }\end{array}$ \\
\hline Target audience & $\begin{array}{l}\text { General worker, general supervisor/manager, and general } \\
\text { nonradiological shipper }\end{array}$ \\
\hline Delivery & Classroom \\
\hline Evaluation & Written examination \\
\hline Length & 4 hours \\
\hline Frequency & 2 years \\
\hline
\end{tabular}




\begin{tabular}{|c|c|}
\hline Title & $\begin{array}{l}\text { Facility Emergency and Hazard Information Checklist } \\
\text { Training }\end{array}$ \\
\hline Description & $\begin{array}{l}\text { Course consists of a review of specific hazards } \\
\text { associated with the TSD unit and employee's job. The } \\
\text { training is completed by the supervisor or manager using } \\
\text { a checklist. The supervisor or manager reviews job- } \\
\text { specific information concerning hazards in the employee's } \\
\text { work area. The checkl ist act as a guide to ensure } \\
\text { consistent coverage of necessary topics. }\end{array}$ \\
\hline Target audience & $\begin{array}{l}\text { General worker, general supervisor/manager, and general } \\
\text { nonradiological shipper }\end{array}$ \\
\hline Delivery & One-on-one or as a group with supervisor or manager \\
\hline Evaluation & Training checklist documentation \\
\hline Length & Average $=4$ to 6 hours \\
\hline Frequency & 1 year \\
\hline Title & Hazardous Waste Shipment Certification \\
\hline Description & $\begin{array}{l}\text { Course takes an in-depth look at federal, state, and } \\
\text { management requirements for nonradioactive hazardous } \\
\text { waste management. Participants are given specific } \\
\text { instruction by subject matter experts in each area } \\
\text { covered. Each participant receives the federal, state, } \\
\text { and management documents governing the management of } \\
\text { hazardous waste. Course focuses on use of the material } \\
\text { provided while the instructor is available to facilitate } \\
\text { and answer questions. Successful completion prepares the } \\
\text { participant to complete and sign the EPA's hazardous } \\
\text { waste manifests. }\end{array}$ \\
\hline Target audience & General nonradiological shipper \\
\hline Delivery & Classroom \\
\hline Evaluation & Open-book written examination \\
\hline Length & 24 hours \\
\hline Frequency & 1 year \\
\hline
\end{tabular}

15 


\begin{tabular}{|c|c|}
\hline \multicolumn{2}{|c|}{$8 A .2$ UNIT-SPECIFIC COURSES } \\
\hline Title & Hanford General Employee Training \\
\hline Description & $\begin{array}{l}\text { Course covers DOE orders and applicable policies } \\
\text { pertaining to employer and employee rights and } \\
\text { responsibilities, general radiation training, hazardous } \\
\text { communications, and hazardous waste, fire prevention, } \\
\text { personal protective equipment, safety requirements } \\
\text { (including TSD unit orientations), accident reporting, } \\
\text { and avenues for addressing safety concerns. }\end{array}$ \\
\hline Target audience & All employees \\
\hline Delivery & Computer-based training with interactive video \\
\hline Evaluation & Computer generated questions \\
\hline Length & Average $=2$ to 6 hours \\
\hline Frequency & 12 months \\
\hline Title & New Employee Safety Training \\
\hline Description & $\begin{array}{l}\text { Course covers DOE orders and applicable policies } \\
\text { pertaining to employer and employee rights and } \\
\text { responsibilities, general radiation training, hazardous } \\
\text { waste, fire prevention, personal protective equipment, } \\
\text { safety requirements, accident reporting, and avenues for } \\
\text { addressing safety concerns. }\end{array}$ \\
\hline Target audience & All new employees \\
\hline Delivery & Classroom \\
\hline Evaluation & Not applicable \\
\hline Length & 3 hours \\
\hline Frequency & Not applicable \\
\hline
\end{tabular}




\begin{tabular}{|c|c|}
\hline Title & Butlding Emergency Director Training \\
\hline Description & $\begin{array}{l}\text { Course provides an overview of the responsibilities of } \\
\text { the building emergency director, identifies the building } \\
\text { emergency organizations, reviews building emergency plan, } \\
\text { and discusses drill and exercise requirements. }\end{array}$ \\
\hline Target audience & $\begin{array}{l}\text { Primary and alternate building emergency directors and } \\
\text { members of a building emergency organization }\end{array}$ \\
\hline Delivery & Classroom \\
\hline Evaluation & Written test \\
\hline Length & 2 hours \\
\hline Frequency & 1 year \\
\hline Title & Building Emergency Plan Checklist (Appendix 7A) \\
\hline Description & $\begin{array}{l}\text { Course provides the information managers are required to } \\
\text { discuss with employees. The checklist is contained in } \\
\text { the building emergency plan. The building emergency plan } \\
\text { covers designated TSD units. }\end{array}$ \\
\hline Target audience & Al1 TSD unit employees, including subcontractor personnel \\
\hline Delivery & Classroom \\
\hline Evaluation & Not applicable \\
\hline Length & Average $=2$ hours \\
\hline Frequency & 1 year \\
\hline
\end{tabular}




\begin{tabular}{|c|c|}
\hline Title & Treatment, Storage, and/or Disposal Unit Orientation \\
\hline Description & $\begin{array}{l}\text { Course consists of classroom presentation. Topics are } \\
\text { presented according to DOE, federal, and state } \\
\text { requirements that include entry and exit requirements; } \\
\text { location of organizational charts and administrative and } \\
\text { operating procedures; the person in charge of } \\
\text { communications; potential hazards (radiological and } \\
\text { nonradiological); restricted areas; potential } \\
\text { emergencies, alarms, communications, responses and } \\
\text { staging areas; locations and use of personal protective } \\
\text { and emergency equipment; identification of TSD units; } \\
\text { overview of the process; and training requirements. }\end{array}$ \\
\hline Target audience & All personnel assigned to or performing work in TSD units \\
\hline Delivery & Classroom \\
\hline Evaluation & Not applicable \\
\hline Length & 1 hour \\
\hline Frequency & $\begin{array}{l}\text { Initial; } 1 \text { year; } 2 \text { years as determined by TSD unit } \\
\text { management }\end{array}$ \\
\hline
\end{tabular}




\begin{tabular}{|c|c|}
\hline \multicolumn{2}{|c|}{8 A.3 JOB-SPECIFIC COURSES } \\
\hline Title & $\begin{array}{l}\text { Treatment, Storage, and/or Disposal Unit-Specific } \\
\text { Training }\end{array}$ \\
\hline Description & $\begin{array}{l}\text { Course is designed to establish a general understanding } \\
\text { and comprehension of TSD unit operations. }\end{array}$ \\
\hline Target audience & Nuclear operators and nuclear process operators \\
\hline Delivery & Self-study and on-the-job training \\
\hline Evaluation & Written test and on-the-job training checklist \\
\hline Length & Average $=80$ hours \\
\hline Frequency & $\begin{array}{l}1 \text { year for nuclear operator level and } 2 \text { years for nuclear } \\
\text { process operator level }\end{array}$ \\
\hline Title & $\begin{array}{l}\text { Treatment, Storage, and/or Disposal Unit Nuclear Operator } \\
\text { Certifications }\end{array}$ \\
\hline Description & $\begin{array}{l}\text { Courses are designed to prepare and certify TSD unit } \\
\text { nuclear operators and nuclear process operators for } \\
\text { TSD unit operations. The TSD unit supervisors and } \\
\text { managers complete designated courses when determined by } \\
\text { management. Courses are designed, developed, } \\
\text { implemented, and documented based on job and training } \\
\text { analysis. }\end{array}$ \\
\hline Target audience & $\begin{array}{l}\text { Nuclear operators, nuclear process operators, and } \\
\text { TSD unit operations supervisors and managers when } \\
\text { required by TSD unit management }\end{array}$ \\
\hline Delivery & Classroom, self-study, and on-the--job training \\
\hline Evaluation & Written test and on-the-job training checklist \\
\hline Length & Average $=200$ hours \\
\hline Frequency & 2 years \\
\hline
\end{tabular}




\begin{tabular}{|c|c|c|}
\hline 1 & Title & $\begin{array}{l}\text { Treatment, Storage, and/or Disposal Unit Nuclear Operator } \\
\text { Emergency Procedures and Abnormal Conditions Training }\end{array}$ \\
\hline 2 & Description & $\begin{array}{l}\text { Course consists of a review of offnormal and emergency } \\
\text { conditions that could occur in the TSD unit (associated } \\
\text { alarms and communications) and proper responses. }\end{array}$ \\
\hline 3 & Target audience & Nuclear operators and nuclear process operators \\
\hline 4 & Delivery & Self-study and on-the-job training \\
\hline 5 & Evaluation & Written test \\
\hline 6 & Length & Average $=20$ hours \\
\hline 7 & Frequency & 1 year \\
\hline 8 & Title & $\begin{array}{l}\text { Treatment, Storage, and/or Disposal Unit Operations } \\
\text { Supervisors and Managers Certification }\end{array}$ \\
\hline 9 & Description & $\begin{array}{l}\text { Course includes the following topics (topics could vary } \\
\text { for each TSD unit): } \\
\text { - Administrative information } \\
\text { - Technical information } \\
\text { - Hazardous material waste requirements } \\
\text { - Safety analysis reports } \\
\text { - Operational safety requirements } \\
\text { - Handling dangerous waste } \\
\text { - Radiation work procedures } \\
\text { - Occurrence reporting } \\
\text { - Jobs conducted in the area of assigned responsibility } \\
\text { - Processes and services } \\
\text { - Equipment. }\end{array}$ \\
\hline 10 & Target audience & Operations supervisors and managers \\
\hline 11 & Delivery & Self-study and on-the-job training \\
\hline 12 & Evaluation & Written test and on-the-job training checklist \\
\hline 13 & Length & Average $=40$ to 80 hours \\
\hline 14 & Frequency & 2 years \\
\hline
\end{tabular}




\begin{tabular}{|c|c|}
\hline Title & $\begin{array}{l}\text { Treatment, Storage, and/or Disposal Unit Operations } \\
\text { Supervisors and Managers Emergency Procedures and } \\
\text { Abnormal Conditions Training }\end{array}$ \\
\hline Description & $\begin{array}{l}\text { Course is designed to be a review of offnormal and } \\
\text { emergency conditions that could occur in the TSD unit } \\
\text { (associated alarms and communications) and proper } \\
\text { responses in the following areas: } \\
\text { - General } \\
\text { - Unit } \\
\text { - Processes and services } \\
\text { - Equipment. }\end{array}$ \\
\hline Target audience & Operations supervisors and managers \\
\hline Delivery & Self-study and on-the-job training \\
\hline Evaluation & Written test \\
\hline Length & Average $=20$ hours \\
\hline Frequency & 1 year \\
\hline Title & $\begin{array}{l}\text { Phase I Process Engineering Certification (Site-Generic } \\
\text { Training) }\end{array}$ \\
\hline Description & $\begin{array}{l}\text { Phase I training covers general information concerning } \\
\text { TSD unit processing operations. The following topics are } \\
\text { covered: } \\
\text { - Radiological controls } \\
\text { - Accident prevention standards } \\
\text { - Management policies } \\
\text { - Environmental protection } \\
\text { - Packaging and shipping hazardous material and } \\
\text { radioactive waste } \\
\text { - Engineering procedures (configuration control, } \\
\text { document control, and design media control) } \\
\text { - Selected quality assurance procedures. }\end{array}$ \\
\hline Target audience & Process engineers \\
\hline Delivery & Classroom and self-study \\
\hline Evaluation & Written test \\
\hline Length & Average $=20$ hours \\
\hline Frequency & Not applicable \\
\hline
\end{tabular}




\begin{tabular}{|c|c|}
\hline Title & $\begin{array}{l}\text { Phase II Process Engineering Certification } \\
\text { (Unit-Specific Training) }\end{array}$ \\
\hline Description & $\begin{array}{l}\text { Phase II training covers generic information for a } \\
\text { specific TSD unit. The following topics are covered: } \\
\text { - Unit processes } \\
\text { - Unit utilities. }\end{array}$ \\
\hline Target audience & Process engineers \\
\hline Delivery & Self-study \\
\hline Evaluation & Written test and oral walkthrough \\
\hline Length & Average $=40$ hours \\
\hline Frequency & 2 years \\
\hline Title & $\begin{array}{l}\text { Phase III Process Engineering Certification } \\
\text { (Process-Specific Training) }\end{array}$ \\
\hline Descripticn & $\begin{array}{l}\text { Phase III training covers detailed information on } \\
\text { 'specialized' areas within a given TSD unit; in this } \\
\text { case, the information is determined based on job and } \\
\text { training analysis. Topics covered include details of the } \\
\text { following: } \\
\text { - Process flowsheet } \\
\text { - Operating specifications } \\
\text { - Process equipment } \\
\text { - Operating procedures. }\end{array}$ \\
\hline Target audience & Process engineers \\
\hline Delivery & Self-study \\
\hline Evaluation & Written test or oral walkthrough \\
\hline Length & Average $=40$ hours \\
\hline Frequency & 2 years \\
\hline
\end{tabular}




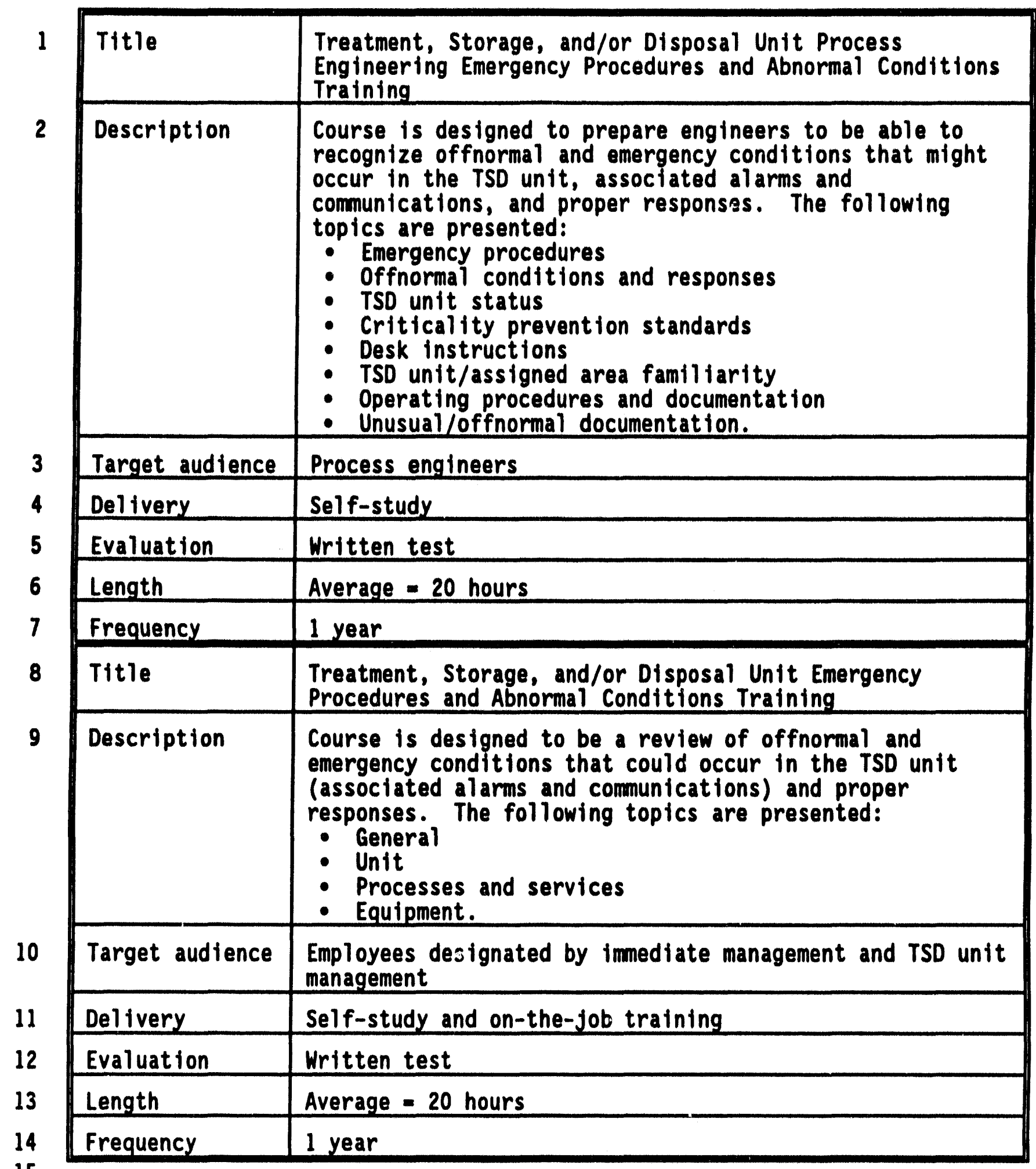




\section{DISTRIBUTION}

Number of coples

\section{OEFSITE}

2

U.S. Environmental Protection Agency 12006 th Avenue

MS: HW124

Seatt 18, Washington 98101

D. L. Duncan (2)

5

Washington State Department of Ecology 99 South Sound Center

PV-11

01ymp 1a, Washington 98504-8711

T. M. Michelena (5)

1 Washinaton State Department of Ecolooy 7601 W. Clearwater Avenue

Suite 102

Kennewick, Washington 99336

D. C. Nylander

2

Science Apolications International

Corporation

7601 W. Clearwater Avenue

Kennewick, Washington 99336

M. Hoxie (2)

ONSITE

4

U.S. Department of Eneray. Richland Operations Office

D. C. Bryson

EAO-OSS File

R3-80

Reading Room

A5-15

R3-80

Pacific Northwest Laboratory

Hanford Technical Library

$k 1-11$

U.S. Environmental Protection Agency

D. R. Sherwood

B5-01 


\section{DISTRIBUTION (cont)}

Number of Coptes

ONSITE

29

Westinghouse Hanford Comoany

R. E. Birney

H6-24

R. C. Bowman

R3-46

B. G. Erlandson

H6-20

J. L. Fields

D. L. Flyckt

H6-24

R. D. Gustavson

R3-45

D. E. Kelly

G. H. Landeen

D. W. Lindsey

P. J. Mackey

J. L. MeCallum

F. N. McDonald

J. J. Noble

M. W. Peres (2)

S. M. Price

RI-51

R3-46

H6-24

R3-45

B3-15

H4-16

R3-45

L4-94

N1-73

C. M. Smith

H6-23

H6-30

T. B. Veneziano

L4-96

R. D. Warriner

$\mathrm{N} 1-73$

B. F. Weaver

J. D. Will tams

$\mathrm{N} 1-73$

B. D. Willitamson

RI-48

R. B. Wurz

B3-15

EDC

EPIC (2)

Information Release Administration (3)

$\mathrm{N} 1-73$

H6-07

H4-17 

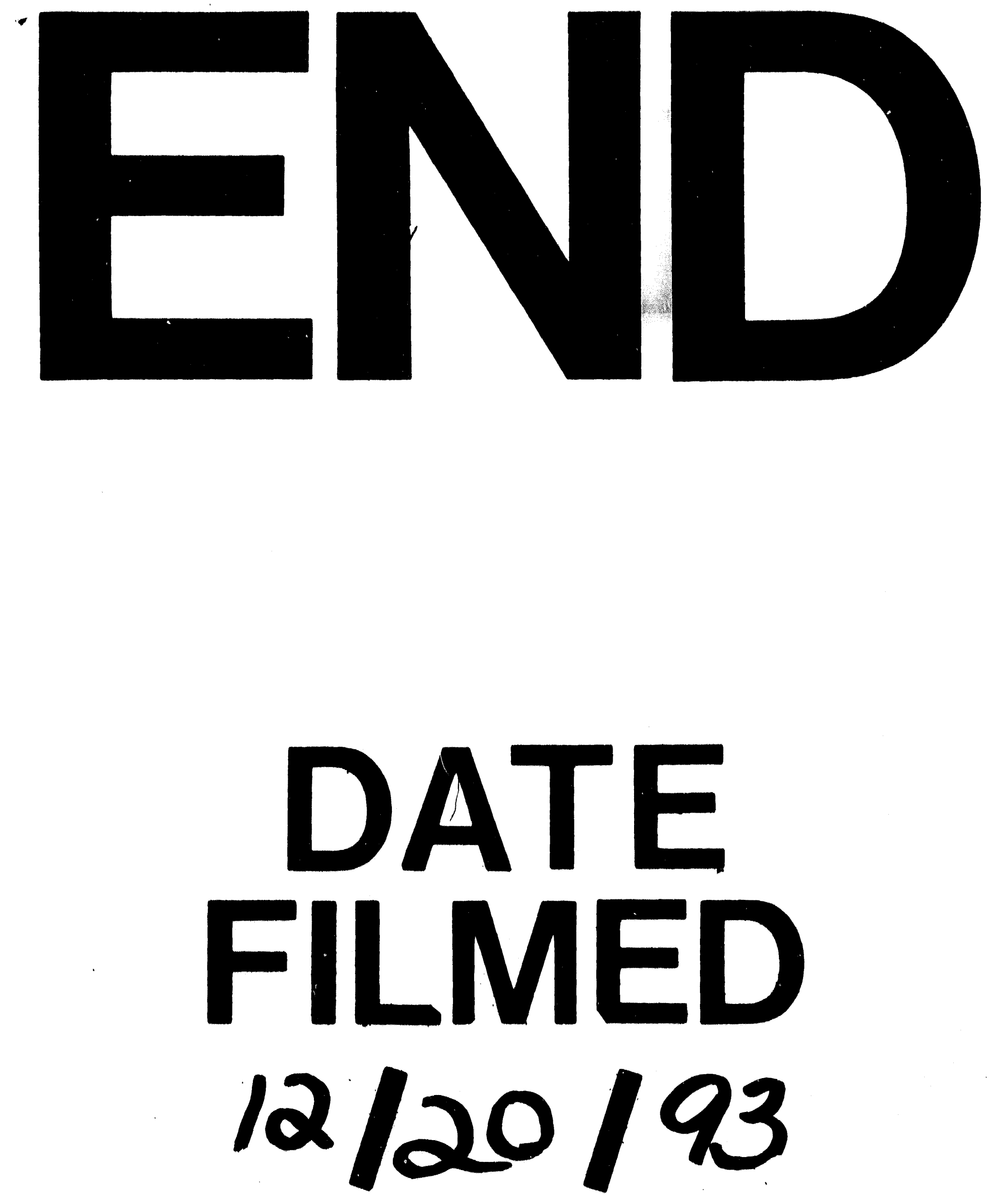
-

-

○ 